\title{
WestVirginiaUniversity
}

THE RESEARCH REPOSITORY @ WVU

Graduate Theses, Dissertations, and Problem Reports

2007

\section{Effect of fiber architecture on properties of pultruded composites}

Vimala Shekar

West Virginia University

Follow this and additional works at: https://researchrepository.wvu.edu/etd

\section{Recommended Citation}

Shekar, Vimala, "Effect of fiber architecture on properties of pultruded composites" (2007). Graduate Theses, Dissertations, and Problem Reports. 1811.

https://researchrepository.wvu.edu/etd/1811

This Thesis is protected by copyright and/or related rights. It has been brought to you by the The Research Repository @ WVU with permission from the rights-holder(s). You are free to use this Thesis in any way that is permitted by the copyright and related rights legislation that applies to your use. For other uses you must obtain permission from the rights-holder(s) directly, unless additional rights are indicated by a Creative Commons license in the record and/ or on the work itself. This Thesis has been accepted for inclusion in WVU Graduate Theses, Dissertations, and Problem Reports collection by an authorized administrator of The Research Repository @ WVU. For more information, please contact researchrepository@mail.wvu.edu. 


\title{
EFFECT OF FIBER ARCHITECTURE ON PROPERTIES OF PULTRUDED COMPOSITES
}

\author{
VIMALA SHEKAR \\ Thesis submitted to the \\ College of Engineering and Mineral Resources at \\ West Virginia University in \\ partial fulfillment of the requirements \\ for the degree of
}

\author{
Master of Science \\ in \\ Mechanical Engineering
}

Jacky C. Prucz, Ph.D., Chair

Hota V. S. GangaRao, Ph.D., Co-chair

Nithi T. Sivaneri, Ph.D.,

Department of Mechanical and Aerospace Engineering

Morgantown, West Virginia

2007

Keywords: Pultrusion, GFRP, Polyurethane, Vinylester, tension, bending, failure modes, strain energy density. 


\title{
ABSTRACT \\ EFFECT OF FIBER ARCHITECTURE ON PROPERTIES OF PULTRUDED COMPOSITES
}

\author{
by
}

\author{
Vimala Shekar
}

\begin{abstract}
The orientation of reinforcements in a composite system has major influence on both the elastic and inelastic properties, including failure modes. Manufacturing a polymer composite structural member can be simplified by using certain types of fiber/fabric architecture. The structural performance of a finished composite part does vary with the manufacturing process and constituent materials including fiber and resin type, fiber architecture and Fiber Volume Fraction (FVF).

In this research, the structural behavior of pultruded composite plates having different fiber architecture (uni-, bi-, tri and quadri-) manufactured by the pultrusion process is investigated. Further the mechanical properties of pultruded composites are compared with performance of composites made from compression mold. The strain energy density values of composites manufactured through compression molding and pultrusion are compared with each other so as to create a database to predict the strength and stiffness of composites. In addition, the response of pultruded composites with two different resin systems namely polyurethane and vinyl ester having same fiber architecture are evaluated.
\end{abstract}

Bi-linear stress-strain response under tension was observed for all composites except for tridirectional composites, which showed tri-linear stress-strain response up to the maximum stress. Under bending, the stress-strain response for uni- and quadri-directional reinforcements are trilinear, while that for bi- and tri-directional reinforcements, the stress-strain curve has four linear slopes. It is observed that under tension, change in first slope took place at $29 \% \sim 40 \%$ for composites with various fiber architectures (uni-, bi-, tri and quari-directional). In bending, it was observed that for composites with uni directional fabrics, the change of first slope takes place at about $50 \%$ of maximum stress, in case of bi-directional the change of first slope is at $22 \%$, and for all other fabrics i.e, tri- and quadri-directional fabrics, the change of first slope is at about $31 \%$ $34 \%$.

The maximum tensile stress and strain in pultruded composites were mostly driven by the fiber orientation, while the maximum bending stress and strain were controlled by interface bonding of resin, fiber architecture and the process type. The ratio of bending strength to tensile strength in pultruded composites varies anywhere from 1.09 to 2.62. For a given fiber architecture, the tensile stress for compression molded plates is always higher than pultruded plates while the bending stress in pultruded composite plates is always higher than the values from compression molded plates. These anomalies are attributed to types of failure modes. With regards to resin system in pultruded composites, vinyl ester resin had more ductility and toughness compared to polyurethane resin, which is contrary to research finding of some researchers. It is likely that the vinyl ester resin is toughened or urethane modified.

The strain energy density of pultruded composites under tension is found to be the lowest value in quadri-directional fabrics compared to other fiber/fabric architecture because of the presence of off-axis plies. The off-axis plies reduce the capability of straining without failure due to stress concentration which in turn reduces the strain energy density. In bending, the strain energy density which is normalized with reference to FVF in the bending direction is within $20 \%$ difference regardless of fiber/fabric architecture. 


\section{ACKNOWLEDGEMENT}

First, I would like to express my gratitude to God for providing me an opportunity to do Master's Program. My sincere thanks to Dr. Hota GangaRao for his encouragement and guidance throughout course of this research program. Special thanks to Dr. Jacky Prucz and Dr. Nithi Sivaneri for serving on my committee and being very supportive in completing the research work. Thanks to Mr. David Turner and Mr. Jerry Nestor for preparing my test specimens. My thanks extends to Aneesh Bethi, Deepika Vadlamani, Manab Mehdi, Ayman, Avinash, Ashish and Siddalingesh who all lend their helping hands towards successful completion of this thesis. Last, but not the least, I wish to thank all my family members whose understanding and encouragement were a constant consolation during the long and arduous process of completing this research program. 


\section{TABLE OF CONTENTS}

ABSTRACT

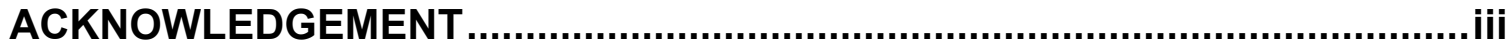

TABLE OF CONTENTS ................................................................................

LIST OF FIGURES

LIST OF TABLES

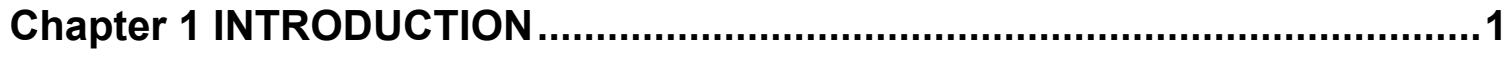

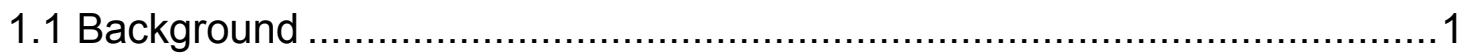

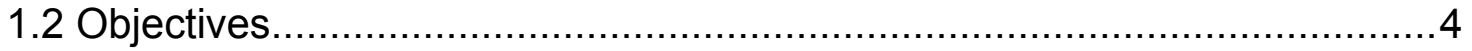

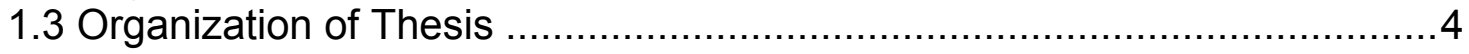

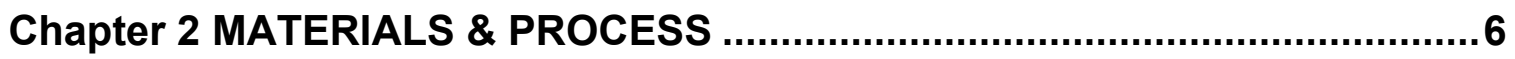

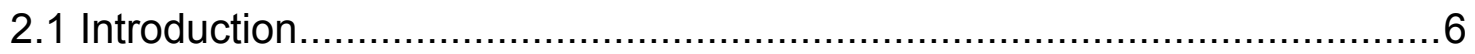

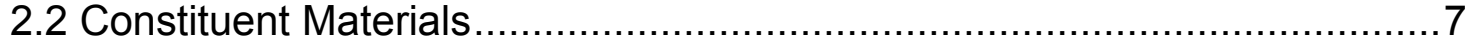

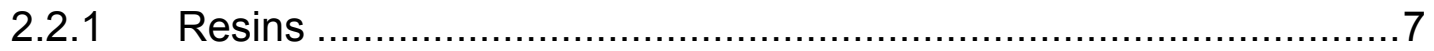

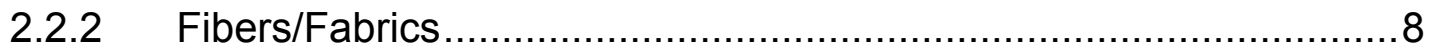

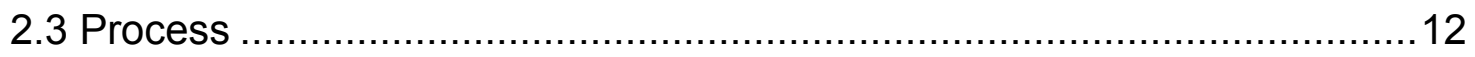

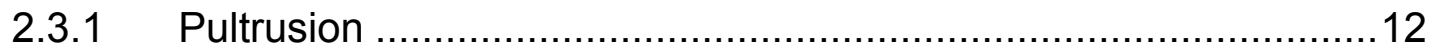

2.3.2 Compression Molding ....................................................13

Chapter 3 LABORATORY TESTING DETAILS .........................................16

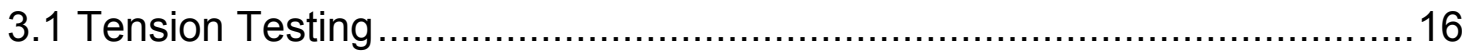

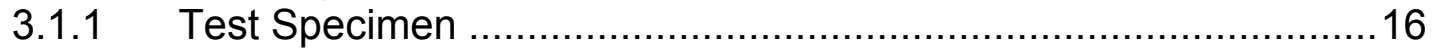

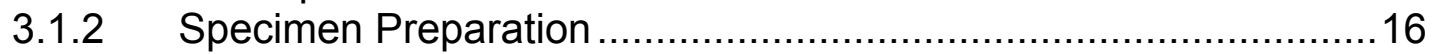

3.1.3 Test Set-up and Test Procedure ..........................................18

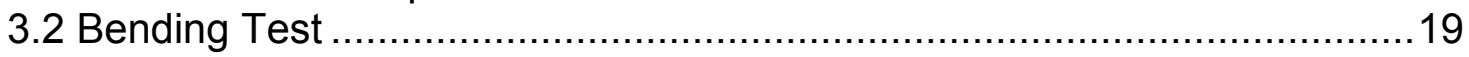

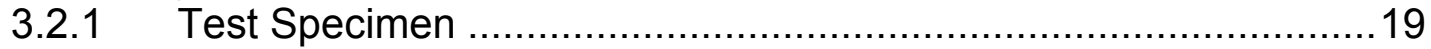

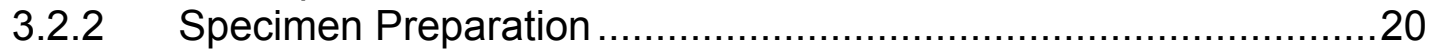

3.2.3 Test Set-Up and Test Procedure ...........................................20

3.3 (Burn out Test) Fiber Volume Fraction Test ........................................21

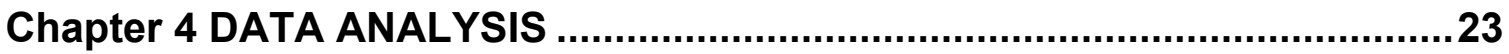

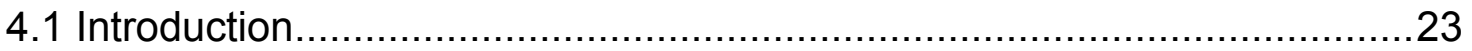

4.2 Determination of FVF from Burn-out Test...........................................23

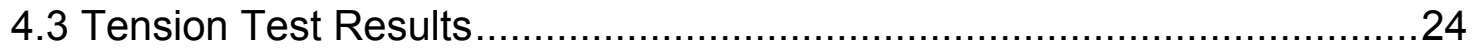

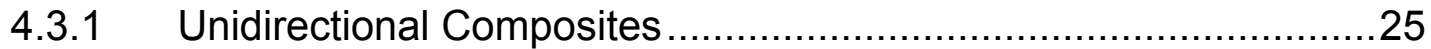

4.3.2 Bi-directional Composites ..................................................28 


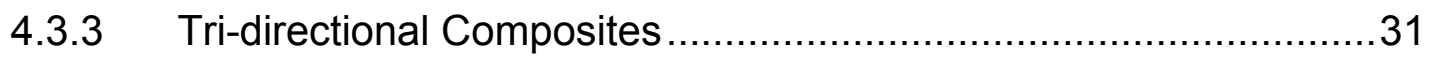

4.3.4 Quadri-directional Composites ...............................................36

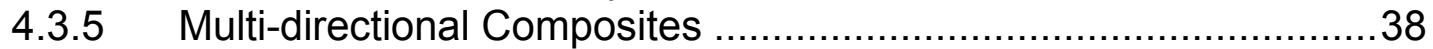

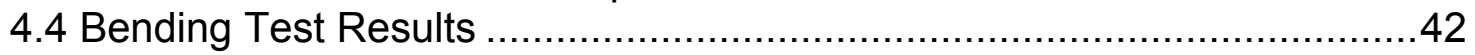

4.4.1 Uni-directional Composites....................................................43

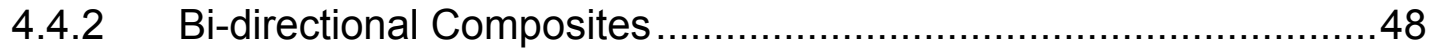

4.4.3 Tri-directional Composites ................................................52

4.4.4 Quadri-directional Composites .............................................58

4.4.5 Multi-directional Composites ................................................62

Chapter 5 DISCUSSION OF EXPERIMENTAL TEST RESULTS ...................69

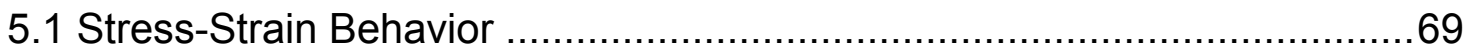

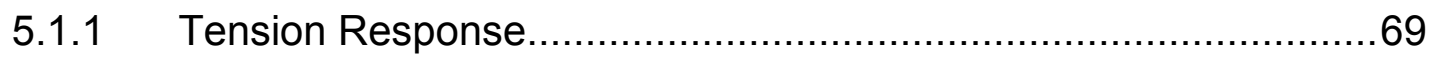

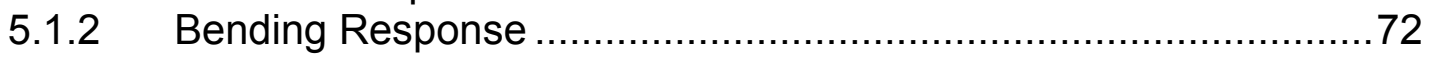

5.2 Effect of Fiber Architecture on Ultimate Strain.....................................76

5.3 Effect of Fiber Architecture on Ultimate Strength ...............................78

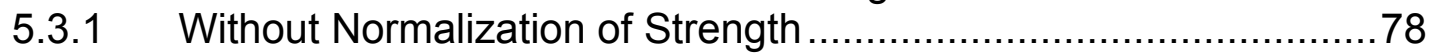

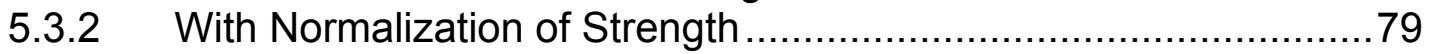

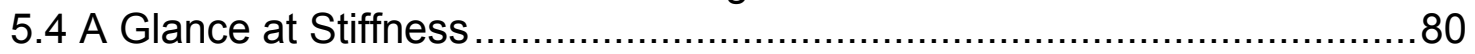

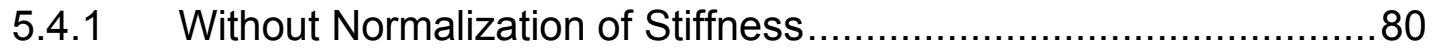

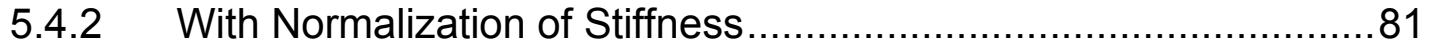

5.5 Effect of Resin Type in Pultruded Composites ..................................... 82

5.5.1 Stress-Strain Behavior- Without Normalization of Stress .............82

5.5.2 Stress-Strain Behavior- With Normalization of Stress ..................8 85

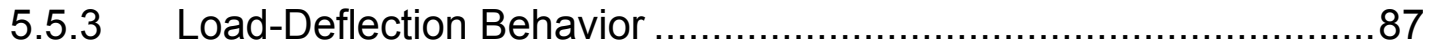

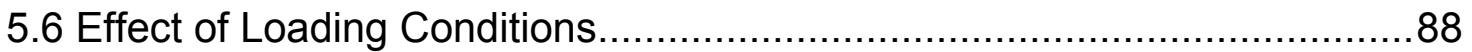

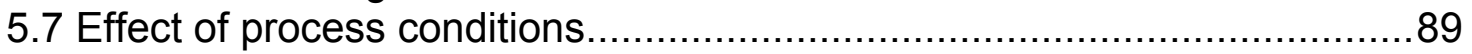

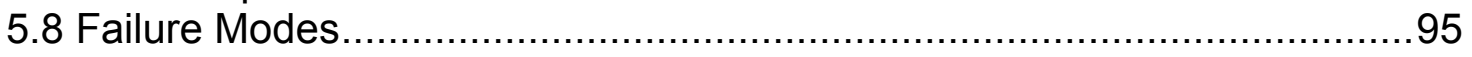

Chapter 6 STRAIN ENERGY DENSITY …..................................................102

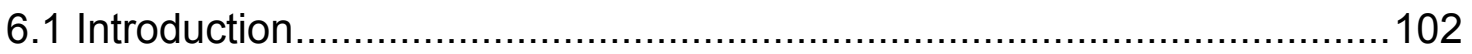

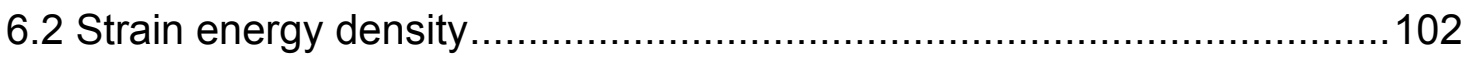

Chapter 7 CONCLUSIONS .......................................................................111

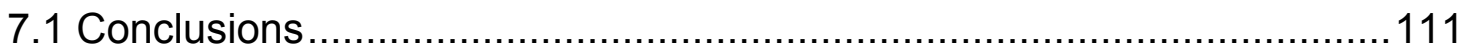

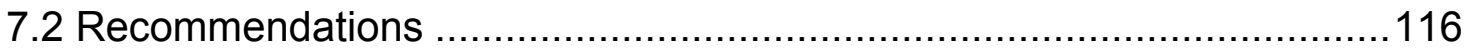

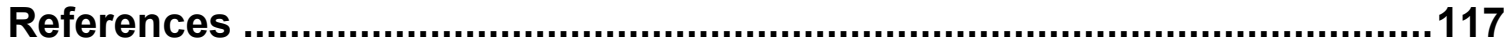




\section{LIST OF FIGURES}

Figure 2.1 Specification Sheet for Vinylester Resin used in Pultruded Samples ..9

Figure 3.1 Strain Gage on Tension Test Specimens ...................................18

Figure 3.22 BALDWIN Universal Testing Machine .....................................18

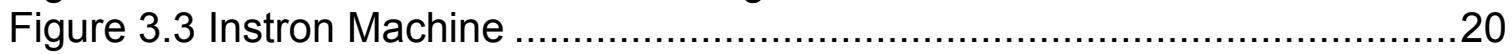

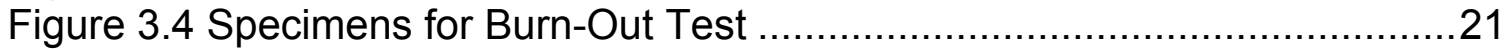

Figure 3.5 Isotemperature Muffle Furnace …….........................................22

Figure 3.6 Checking of each Laminae of a Given Laminate ..........................22

Figure 4.2 Stress-Strain Curve for Unidirectional Composites (Sample 14) .......26

Figure 4.3 Stress-Strain Curve with Bi-linear Slopes for Uni-directional

Composites (Sample 14) .....................................................26

Figure 4.4 Typical Stress-Strain Curve for Bi-directional Composites (Sample

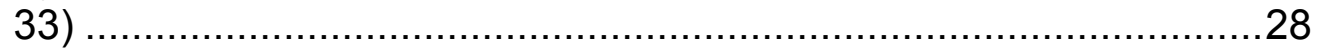

Figure 4.5 Stress-Strain Curve with Bi-linear slopes for Bi-directional

Composites (Sample 33) ....................................................29

Figure 4.6 Typical Stress-Strain Curve for Tri-directional Composites without

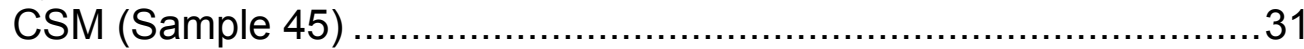

Figure 4.7 Typical Stress-Strain Curve for Tri-directional Composites with

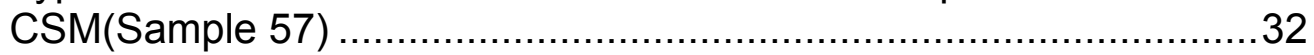

Figure 4.8 Stress-Strain Curve with tri-linear slopes for Tri-directional Composites without CSM (Sample 45) .......................................32

Figure 4.9 Stress-Strain Curve with Tri-linear Slopes for Tri-directional Composites with CSM (Sample 57)....

Figure 4.10 Typical Stress-Strain Curve for Quadri-directional Composites

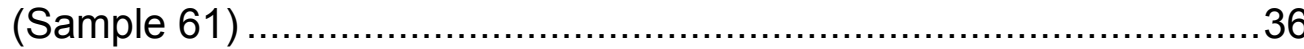

Figure 4.11 Stress-Strain Curve with Bi-linear Slopes for Quadri-directional Composites (Sample 61) .......................................................37

Figure 4.12 Typical Stress-Strain Curve for Multi-directional Composite with Polyurethane System (Sample 75) …….......................................39

Figure 4.13 Typical Stress-Strain Curve for Multi-directional Composite with Vinylester System (Sample 85)...............................................39

Figure 4.14 Stress-Strain curve for Polyurethane System (Sample 75) ..............40

Figure 4.15 Stress-Strain Curve with Bi-linear Slopes for Vinyl ester System

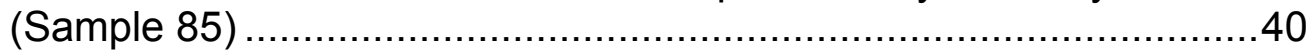

Figure 4.16 Typical Load-Deflection Curve for Unidirectional Composites (Sample 12)

Figure 4.17 Typical Stress-Strain Curve for Unidirectional Composites (Sample

111) 44

Figure 4.18 Load-Deflection Curve with Tri-linear Slopes for Uni-directional Composites (Sample 12)

Figure 4.19 Stress-Strain Curve with Tri-linear Slopes for Uni-directional Composites (Sample 111) 45

Figure 4.20 Typical Load-deflection Curve for Bidirectional Composites (Sample 34) 48 
Figure 4.21 Typical Stress-Strain Curve for Bidirectional Composites (Sample 39)

Figure 4.22 Load-deflection Curve with Linear Slopes (Sample 34) ..................49

Figure 4.23 Stress-Strain Curve with Linear Slopes (Sample 39) .....................50

Figure 4.24 Typical Load-deflection Curve for Tri-directional Composites without

CSM 52

Figure 4.25 Typical Stress-Strain Curve for Tri-directional Composites without CSM

Figure 4.26 Typical Load-deflection Curve with Linear Slopes for Tri-directional without CSM (Sample 46).

Figure 4.27 Typical Stress-Strain Curve with Linear Slopes for Tri-directional Composites without CSM (Sample 413)...

Figure 4.28 Typical Load-deflection Curve for Tri-directional Composites with

CSM (Sample 54)
Figure 4.29 Typical Stress-Strain

(Sample 512)

Strain Curve for Tri-directional Composites with CSM

Figure 4.30 Typical Load-deflection Curve with Linear Slopes for Tri-directional

Composites with CSM (Sample 54). 55

Figure 4.31 Typical Stress-Strain Curve with Linear Slopes for Tri-directional

Composites with CSM (Sample 512) ..............................................
Figure 4.32 Typical Load-deflection Curve for Quadri-directional Composites 55 (Sample 61)

33 Typical Stress-Strain Curve for Quadri-directional Composites

Figure 4.33 Typical Stress-
(Sample 69). 59

Figure 4.34 Typical Load-deflection Curve with Tri-linear Curves for Quadridirectional Composites (Sample 61)

Figure 4.35 Typical Stress-Strain curve with Tri-linear Curves for Quadridirectional Composites (Sample 69).

Figure 4.36 Typical Load-deflection Curve for Multidirectional Composite with Polyurethane resin (Sample 71)

Figure 4.37 Typical Stress-Strain Curve for Multidirectional Composite with Polyurethane Resin (Sample 7H2) .62

Figure 4.38 Load-deflection Curve with Linear Curve for Multidirectional

Composite with Polyurethane Resin (Sample 71)

Figure 4.39 Stress-Strain Curve with Linear Curve for Multidirectional Composite with Polyurethane Resin (Sample 7H2)

Figure 4.40 Typical Load-deflection Curve for Multidirectional Composite with Vinyl ester Resin (Sample 82) 64

Figure 4.41 Typical Stress-Strain Curve for Multidirectional Composite with Vinyl ester Resin (Sample 812)

Figure 4.42 Load-deflection Curve with Tri-linear Curve for Multidirectional Composite with Vinyl ester resin (Sample 82)

Figure 4.43 Stress-Strain Curve with Tri-linear Curve for Multidirectional Composite with Vinyl ester Resin (Sample 812) 66

Figure 5.1 Typical Stress-Strain Curve of Composites with Various Fiber Architecture (tension). 
Figure 5.2 Typical Normalized Stress-Strain Curve of Composites with Various Fiber Architecture (tension)

Figure 5.3 Stress-strain curve of composites with various fiber architecture (bending) 74

Figure 5.4 Typical Normalized Stress-Strain Curve of Composites with Various Fiber Architecture (bending)

Figure 5.5 Typical Load-deflection Curve of Composites with Various Fiber Architecture (bending) 76

Figure 5.6 Stress-Strain Curve of Composites with Different Resin (tension).....83 Figure 5.7 Stress-Strain Curve of Composites with Different Resin (bending)....84

Figure 5.8 Typical Stress-Strain Curve of Composites with Different resin system (tension)

Figure 5.9 Typical Stress-Strain Curve of Composites with Different resin system (bending)

Figure 5.10 Load-deflection Curve of Composites with Different Resin System (bending)

Figure 5.11 Stress-Strain Curve of Composites with Different Process under Tension.

Figure 5.12 Load-deflection Curve of Composites with Different Process under Bending

Figure 5.16 Failure Mode in Quadri-Directional Composites ...........................97

Figure 5.18 Failure Mode in Vinylester Composites......................................98

Figure 5.20 Failure Mode in Bi-directional Composites.....................................99 


\section{LIST OF TABLES}

Table 2.1 Details of Fiber/Fabric Orientation for Pultruded Tension and Bending

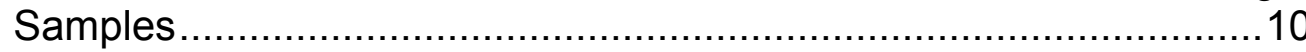

Table 2.2 Details of Fiber/Fabric Orientation for Compression Molded Tension

Samples (Vadlamani, 2007)......................................................11

Table 2.3 Details of Fiber/Fabric Orientation for Compression Molded Bending

Samples (Vadlamani, 2007).....................................................11

Table 3.1 Dimension of Pultruded \& Compression Molded Tension Test

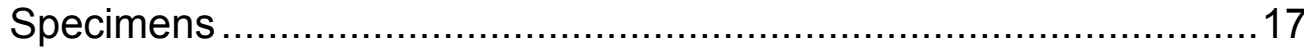

Table 3.2 2 Dimension of Pultruded \& Compression Molded............................ 19

Table 4.1 Structural properties of unidirectional composites ...........................27

Table 4.2 Structural properties of bi-directional composites .............................30

Table 4.3 Structural Properties of Tri-directional Composites ............................35

Table 4.4 Structural Properties of Quadri-directional Composites .....................37

Table 4.5 Structural Properties of Multi-directional Composites .......................41

Table 4.6 Structural Properties of Unidirectional Composites ...........................46

Table 4.7 Structural Properties of Bidirectional Composites ............................51

Table 4.8 Structural Properties of Tri-directional Composites ...........................57

Table 4.9 Structural Properties of Quadri-directional Composites .....................61

Table 4.10 Structural Properties of Multi-directional Composite with

Polyurethane Resin

Table 4.11 Structural Properties of Multi-directional Composite with Vinyl ester

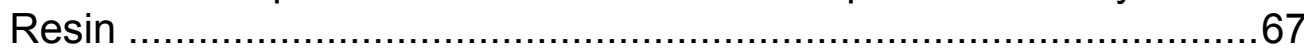

Table 5.1 Ultimate strain of uni, bi, tri and quadri-directional composites ...........77

Table 5.2 Ultimate strength of uni, bi, tri and quadri-directional composites .......79

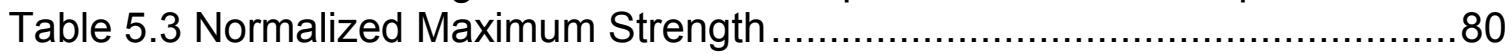

Table 5.4 Stiffness of uni, bi, tri and quadri-directional composites ...................81

Table 5.5 Normalized Tensile and Bending Stiffness.....................................82

Table 5.6 Structural properties of composites with polyurethane and vinyl ester

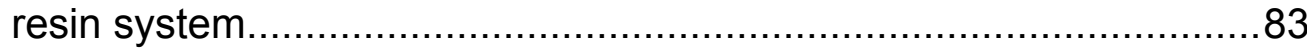

Table 5.7 Normalized Strength and Stiffness for Polyurethane and Vinylester ...86

Table 5.8 Ratio of Bending Strength to Tensile strength..................................8 88

Table 5.9 Details on Physical Properties of Compression Molded vs Pultrusion

Plates.

Table 5.10 Details on Mechanical Properties of Compression Molded Plates ....90

Table 6.1 Tension Test Results for Pultruded Specimens ..............................103

Table 6.2 Bending Test Results for Pultruded Specimens .............................. 104

Table 6.3 Tension Test Results for Compression Molded Specimens ............... 105

Table 6.4 Bending Test Results for Compression Molded Specimens ............. 106

Table 6.5 Comparison of Strain Energy Density for Compression Molding and

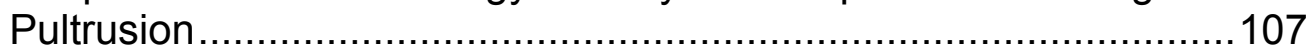

Table 6.6 Normalized Strain Energy Density …..........................................110 


\section{CHAPTER 1}

\section{INTRODUCTION}

\subsection{Background}

Polymer matrix composites are manufactured by combining fibers and matrix wherein fibers are load bearing constituents while matrix binds fibers. The matrix helps dissipate the load to fiber network primarily through in-plane shear, maintains fiber orientation, and protects fibers from environmental hazards.

The orientation of fibers is of great importance to both the elastic and inelastic properties, including failure modes. Manufacturing a polymer composite structural member is simplified by using certain types of fiber/fabric architecture. As a general rule, the fiber architecture of a given member should have mixed combination of rovings, fabrics, and mats. Composites with rovings only (without mats) will develop premature cracking parallel to roving direction under various combination of loads (such as tensile, bending, shear etc), due to low transverse strength and stiffness, which is resin dominated. The fabrics may be bi-, tri- or even quadri-axial in nature. Composites with multi-axial fabrics provide resistance to bending and shear in different directions. With regards to mats, they are not structurally continuous, which makes them less effective than fabrics. The mats are usually incorporated into composite laminates to allow for easy fabrication of composite members. Various fiber forms are shown in Figure 1.1.

Constituents such as fibers, fabrics, mats, nano materials pose a real challenge to manufacturing process both in terms of quality, speed and cost. Therefore, 


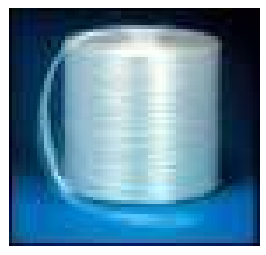

(a) Rovings

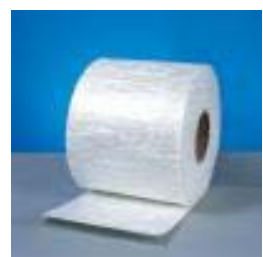

(b) Mat

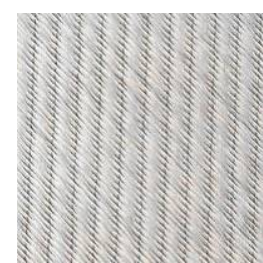

(c) Fabric

Figure 1.1 Fiber Forms

manufacturing of fiber/fabric reinforced composites ranges anywhere from manual to partially automated to fully automated process. Composite parts can be produced with pressures ranging from zero to 2000 psi or more. The process temperatures range from room temperature to well above $200^{\circ} \mathrm{C}$. The manufacturing equipment also varies from simple tooling to sophisticated machines. For thermoset composites, the most common manufacturing processes are hand lay-up, resin transfer molding (RTM), vacuum assisted resin transfer molding (VARTM), filament winding, compression molding, and pultrusion.

The structural performance of a finished composite does vary partially with the manufacturing process variables that include tooling complexity, process and cure, temperature, pressure, reinforcement types, resin wet-out methods including void content, fiber sizing, viscosity of resin etc. Besides manufacturing methods, the other factors that influence the performance of composites are constituent materials and aging. The constituent materials include fiber architecture, resin type, additives such as fillers, UV inhibitors, pigments and others. Aging of a composite is dependent on moisture uptake, and creep, chemical solutions, UV rays etc.

The performances of composites are evaluated based on their mechanical properties and failure modes. Under external and natural loading conditions, failures may be initiated due to fiber breakage, matrix cracking or interfacial bond failure. These damages will first lead to localized failure (such as microcracks, matrix softening, fiber breakage at crossing locations of laminae), leading 
progressively to global failures. The various types of global failure modes in composites are 1) delamination, 2) debonding, 3) fiber buckling, 3) shearing of fibers, 4) longitudinal splitting of fibers, 5) fiber pull out, and 6) others.

Since composites are anisotropic in nature, the failure modes in fabric based composites are very complex; leading to less than accurate prediction of strength and stiffness leading to either over designing or catastrophic failures. Numerous failure theories have been developed by various researchers such as Maximum stress, Maximum strain, Tsai Hill, Tsai Wu, Tresca theory, etc to predict the ultimate strength of composites (Kaddour et.al., 2004). Most of these failure theories do not identify exact failure location. The validity of these theories depends on the convenience of application and degree of correlation of theory with experimental results. Most of the failure theories lack suitable and reliable experimental data, which makes it difficult to select one theory over another. Moreover, most of the current theories are based on stress polynomials (Huang et.al., 2003).

The stress-strain curve under external influences truly represents the characteristic of a material, wherein the manufacturing defects, behavior of constituent materials under various exposure, and behavior of a composite are embedded. The area under stress-strain curve known as the stored strain energy density is the one that gets dissipated at failure. The strain energy density calculated from the area under a stress-strain curve provides a useful estimate of resistance to crack growth and the energy absorbed during fracture (Daniel and Ishai, 2005). The maximum strength of a composite can be predicted once the strain energy density is evaluated.

In this research, the structural behavior of composite plates with different fiber architectures manufactured by pultrusion process are investigated for evaluating strength, stiffness, strain energy density and toughness variability under a wide range of constituent parameters. Further the mechanical properties of pultruded 
composites are compared with compression molded composite with identical fiber architecture. The strain energy density for composites manufactured by compression molding are compared with Pultruded composites so as to create a database to develop strength prediction theories.

\subsection{Objectives}

The primary objective of this research is to test pultruded coupons under tension and bending to evaluate stress, strain and strain energy density. To accomplish the above objective, the following tasks are performed.

1) Developing fiber architecture to manufacture and to pultrude composite plates.

2) Preparing coupon specimens for tension and flexural tests.

3) Conducting tension and flexural tests on composite coupons as per ASTM D 3039 and D 790 respectively to plot stress versus strain.

4) Evaluating stress-strain reponse of pultruded composites for different fiber architecture.

5) Evaluating structural properties of pultruded composite having same fiber architecture with two resin systems namely polyurethane and vinylester.

6) Comparing mechanical properties of pultruded and compression molded specimens (previously tested at CFC-WVU, Vadlamani, 2007) that have identical fiber architecture.

7) Evaluating and comparing the strain energy density of composites made from compression molding and pultrusion process.

\subsection{Organization of Thesis}

Chapter 2 discusses materials and manufacturing (pultrusion) process used in this study. Discussion on the test specimens includes fiber architecture and resin system. 
Chapter 3 describes laboratory testing details including dimension of test specimens, specimen preparation, test set-up and test procedure carried out under tension and bending. Besides, details on finding Fiber Volume Fraction (FVF) are provided.

Chapter 4 provides experimental data analysis for maximum stress, maximum strain and stiffness of uni-, bi-, tri- and quadri- directional fabric based composites.

A comprehensive discussion and summary of test results are given in Chapter 5 . The effect of fiber architecture on structural properties of pultruded composites is presented. In addition, influence of resin system in pultruded composites is discussed. A brief summary on structural properties of compression molded composites versus pultruded composites is provided. The chapter also discusses various types of failure modes that are observed while testing.

Chapter 6 presents the strain energy density approach to determine the strength of a composite, compares the test data of pultruded samples with the data from compression molded samples.

From the details given in Chapters 4, 5, and 6, conclusions and recommendations for future work are drawn in Chapter 7 . 


\section{CHAPTER 2}

\section{MATERIALS \& PROCESS}

\subsection{Introduction}

For optimal utilization of polymer composites, one needs to understand the behavior of constituent materials, especially as a function of manufacturing process. Since a polymer composite constitutes resin and fiber/fabric reinforcement, the mechanical properties including strength, stiffness and failure modes differ depending on:

- Fiber type

- Resin type

- Type of reinforcement construction (unidirectional, mat, fabric - bi, tri or quadri axial, woven, braided etc)

- Reinforcement stacking sequence (balanced, symmetric, etc)

- Fiber Volume Fraction (FVF)

- Process (pultrusion, VARTM, compression molding etc), shape (honeycomb, cellular, sandwich etc)

- Loading (static, dynamic, fatigue etc) and environmental (moisture, freezethaw, conditions etc) conditions.

The FVF in composites depends to an extent on manufacturing process, and the form in which the fibers are incorporated. Since load carrying capacity of fibers are much higher than the resins, higher effective fiber volume fraction will give better mechanical properties. In practice, there are limits to FVF, since the fibers need to be wet with resin. In addition, there are good chances of manufacturing/processing defects (matrix cracks, broken fibers, inadequate cure, improper wet-out, voids) to be already present in the material even before a composite is exposed to external loadings. Typically, with a common hand layup process, a limit for FVF is approximately $30 \%$. With higher quality, more 
sophisticated and precise process, FVF approaching $70 \%$ can be successfully obtained (www.netcomposites.com).

The orientation of fibers/fabrics in a composite is also an important factor. Since fibers have their highest mechanical properties along their lengths, rather than across their widths, composites become highly anisotropic depending on fiber/fabric orientations in longitudinal and transverse directions. Therefore, before producing composite parts, the magnitude and direction of loading that the part, should resist should be known. Depending on loading conditions, one can take advantage of anisotropic nature in composites so that more fiber reinforcement can be provided in the loading direction.

The materials and process conditions used for test specimens are delineated below. In particular, Section 2.2 describes details on constituent materials including resin types, fiber/fabric forms, fiber architecture, density and FVF of the test specimens while section 2.3 discusses the process details of test specimens.

\subsection{Constituent Materials}

\subsubsection{Resins}

The polymers can be broadly classified into two categories that are thermoplastic and thermoset polymers. Thermoplastic polymers always flow, soften upon reheating while thermoset polymers melt during initial stage of manufacturing, but will not melt again upon reheating. Examples of thermoplastic polymers include polyethylene, polypropylene, polystryene, ABS etc. Epoxy, polyester, vinylester, urethane are some of the examples of thermoset polymers.

The test specimens used in this research are made of two types of resins namely vinylester and urethane. Vinylester resins are more flexible; possess higher 
toughness, durable, chemical resistant and low viscosity. Urethane resins are tough, flexible, chemical resistant and fast curing.

Vinylesters were used for both compression molded and pultruded test specimens. For compression molded specimens, vinylester resin was supplied by Ashland Company under the trade name of Hetron 922 L25. In case of pultruded specimens, Interplastic Corporation supplied the resin under the trade name of CoREZYN. The specification data sheet for vinylester resin that was used for pultruded plates is shown in Figure 2.1.

\subsubsection{Fibers/Fabrics}

The fibers/fabrics can be classified into glass, carbon, kevlar, boron, and others. The most commonly used E-glass fibers that have high electrical resistance, mechanical properties and economical. Some of the advantages of glass fibers are: good tensile strength, high strength to weight ratio, little moisture absorption, good thermal and electrical insulation, good fire resistance, and low cost. In this study, E-glass fibers/fabrics are used in various forms as described in section 2.2.2.1 is used. 


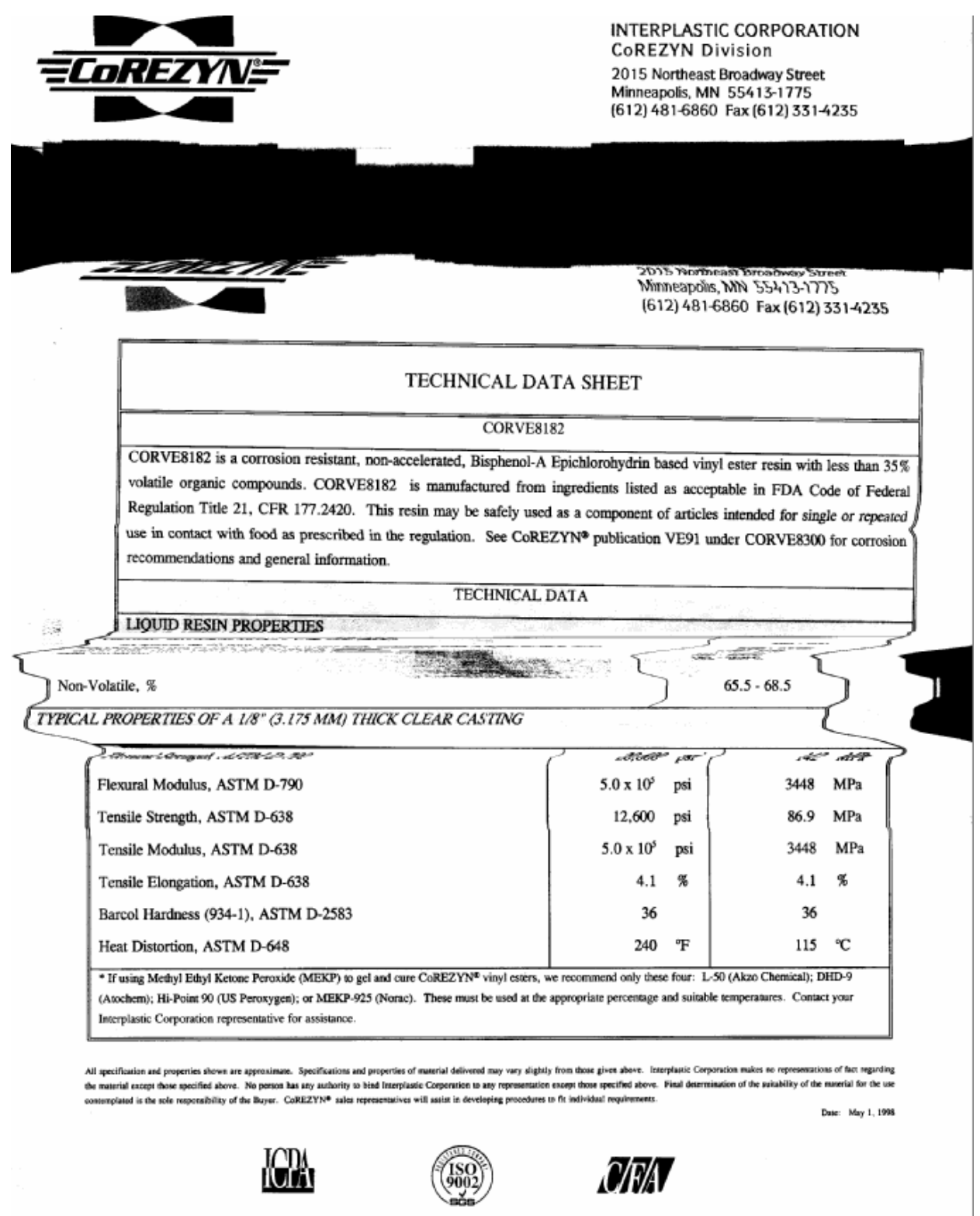

Figure 2.1 Specification Sheet for Vinylester Resin used in Pultruded Samples

\subsubsection{Fiber/Fabric Forms}

Fibers are available in various forms such as rovings, strands, tow and yarns. Depending on construction and orientations, fiber/fabrics are classified into unidirectional (1D), mat, multidirectional (2D) and advanced fabrics (3D). Unidirectional fibers run in one direction ( $0^{0}$ direction) only, which can be used to mainly resist tensile loads in that (fiber) direction. Mats are of two types : 
chopped strand mat and continuous strand mat. They are generally used for smooth finish and ease of manufacturing especially during pultrusion. In case of multidirectional fabrics, multiple layers of continuous rovings are held together by stitching in the plane direction of the fabrics. 2D fabrics are classified into bidirectional (eg., 0/90. $+45 /-45$ etc.), tri-directional (0/45/-45; 90/+45/-45; etc) and quadri-directional fabrics $(0 / 90 /+45 /-45)$. Advanced fabrics include knitted, braided, woven, stitched fabrics etc (Barbero, 1998).

In this study, fiber/fabrics in the form of unidirectional, bi-directional, tridirectional and quadri-directional fabrics with or without CSM, binded with vinylester resin are used during pultrusion. The composite plates with different fiber architecture were supplied by BRP. A similar type of fiber/fabric construction is used for compression-molded samples that were made by CFC-WVU (Vadlamani, 2007). The details for fiber/fabric orientations used for pultrusion and compression molded samples are shown in Table 2.1 through Table 2.3. Evaluation of FVF through burn out test is provided in section 4.1 .

Table 2.1 Details of Fiber/Fabric Orientation for Pultruded Tension and Bending Samples

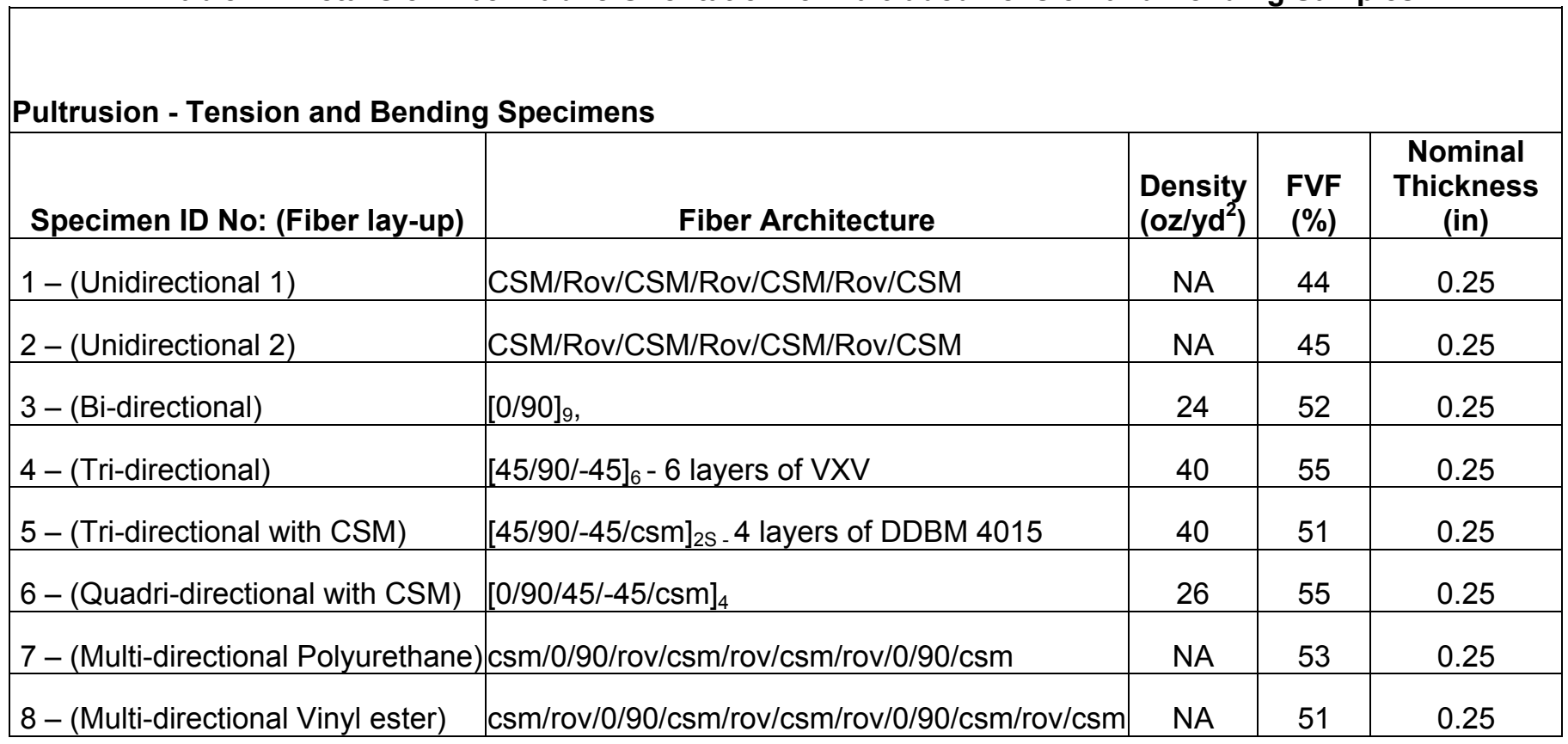


Composite plates with multidirectional fabric shown in Table 2.1 have same fiber/fabric construction (i.e, CSM, Rovings with 0/90 fabric) binded with two different resin system that are polyurethane and vinylester.

Table 2.2 Details of Fiber/Fabric Orientation for Compression Molded Tension Samples (Vadlamani, 2007)

\begin{tabular}{|c|c|c|c|c|}
\hline \multicolumn{5}{|c|}{ Compression Molded - Tension Specimens } \\
\hline Materials ID & Fiber Architecture & $\begin{array}{l}\text { Density } \\
\left(\text { oz/yd }^{2}\right) \\
\end{array}$ & $\begin{array}{l}\text { FVF } \\
(\%)\end{array}$ & $\begin{array}{c}\text { Nominal } \\
\text { Thickness } \\
\text { (in) }\end{array}$ \\
\hline Unidirectional & {$[0]_{19}$} & 12 & 57 & 0.2 \\
\hline Bi-directional & {$[0 / 90]_{9 \mathrm{~s}}$} & 11.84 & 45 & 0.22 \\
\hline Tri-directional with CSM & {$[45 / 90 /-45 / \mathrm{csm}]_{3 s}$} & 53.6 & 59 & 0.21 \\
\hline Quadri-directional with CSM & {$[0 / 90 / 45 /-45 / \mathrm{csm}]_{2 \mathrm{~s}}$} & 61.37 & 55 & 0.23 \\
\hline Quadri-directional without CS & {$[0 / 90 / 45 /-45]_{2 \mathrm{~s}}$} & 47.36 & 44 & 0.17 \\
\hline
\end{tabular}

Table 2.3 Details of Fiber/Fabric Orientation for Compression Molded Bending Samples (Vadlamani, 2007)

\begin{tabular}{|c|c|c|c|c|}
\hline \multicolumn{5}{|c|}{ Compression Molded - Bending Specimens } \\
\hline Materials ID & Fiber Architecture & $\begin{array}{l}\text { Density } \\
\left(\mathrm{oz}^{\prime} \mathrm{yd}^{2}\right)\end{array}$ & $\begin{array}{l}\text { FVF } \\
(\%)\end{array}$ & $\begin{array}{l}\text { Nominal } \\
\text { Thickness } \\
\text { (in) }\end{array}$ \\
\hline Unidirectional & {$[0]_{19}$} & 12 & 65 & 0.2 \\
\hline Bidirectional & {$[0 / 90]_{11 \mathrm{~s}}$} & 11.84 & 37 & 0.28 \\
\hline Tridirectional with CSM & {$[45 / 90 /-45 / \mathrm{csm}]_{2 \mathrm{~s}}$} & 53.6 & 44 & 0.27 \\
\hline Quadridirectional with CSM & {$[0 / 90 / 45 /-45 / \mathrm{csm}]_{2 \mathrm{~s}}$} & 61.37 & 56 & 0.23 \\
\hline Quadridirectional without CSI & $1[0 / 90 / 45 /-45]_{2 \mathrm{~s}}$ & 47.36 & 44 & 0.17 \\
\hline
\end{tabular}


For pultruded samples, specification sheet showing distribution of fiber/fabric at different orientations was provided by Bedford Reinforced Plastics Inc. Typical specification sheet for VXV (tri-directional - 45/90/-45) and DDBM (tri-directional with csm - 45/90/-45/csm) is shown in Figure 2.2. Based on the density of fiber and fiber orientations in a given fabric as indicated on the specification sheet, one can evaluate the effective FVF in the loading direction.

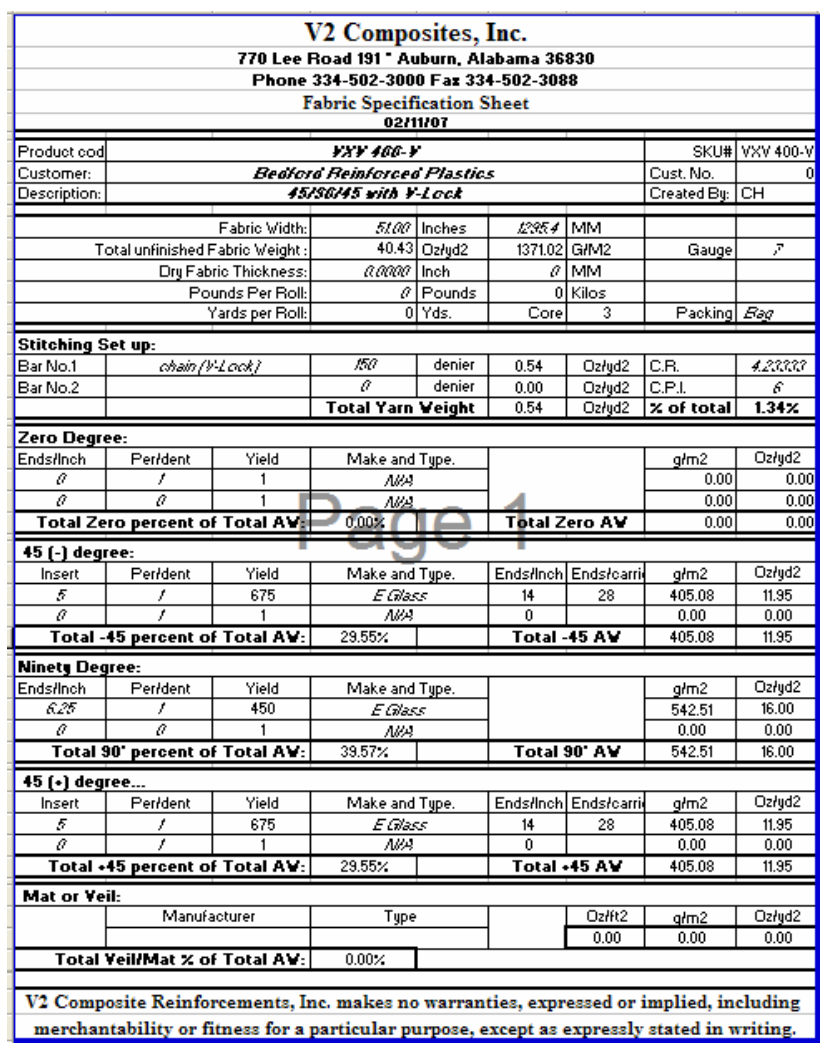

(a) VXV

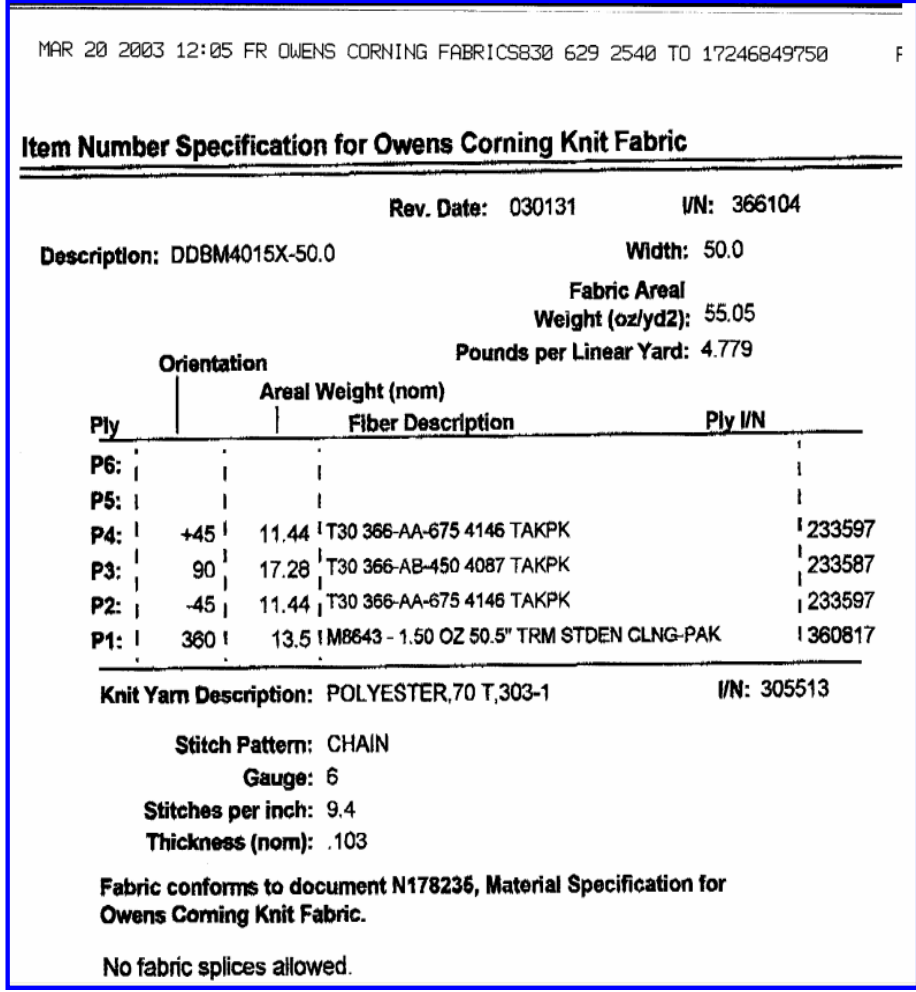

(b) DDBM

Figure 2.2 Specification Sheet for VXV and DDBM Fabric used in Pultruded Samples

\subsection{Process}

\subsubsection{Pultrusion}

Pultrusion is a process where composite parts are manufactured by pulling layers of fibers/fabrics, through resin bath and through a heated die, thus forming the desired cross-sectional shape with no part length limitation. However the size of the finished part is limited in height and width by the size of the die with a current 
maximum part width of 10 feet. Most commonly available fiber forms such as rovings, mat, fabrics embedded with thermoset resin with or without cores (such as wood, foam) can be used during pultrusion. Some of the advantages in pultrusion include minimal kinking of fibers/fabrics, rapid processing, low material scrap rate and good quality control. The disadvantages of the process include excess start-up costs, improper fiber wet-out, fiber breakage, inadequate cure, die jamming, complex die design, etc.

For this research, eight plates of size $8^{\prime} \times 1^{\prime}$ with $1 / 4^{\prime \prime}$ inch thick were pultruded with different fiber architectures (as shown in Table 2.1) by Bedford Reinforced Plastic Inc (BRP). From the past experience, nominal density with required orientation of fiber/fabric for a given plate was given by CFC. Some of the various stages during pultrusion process are shown in Figure 2.3.

\subsubsection{Compression Molding}

Compression molding is done for polymer composite using sheet-molding compound (SMC), bulk-molding compound (BMC), or preform mat. A weighed charge of SMC or BMC, or a preform of glass reinforcement shaped to the mold is placed on a press ranging in size from 300 to 4,000 tons. Resin is added with the preform while SMC and BMC contain all components including fiber, resin, fillers, catalyst etc. The mold temperature is maintained in the range of $350^{\circ} \mathrm{F}$ to $400{ }^{\circ} \mathrm{F}$. Beside temperature, pressure of about 150 to 1,000 psi is applied to cure the parts. The resin then flows through the glass reinforcement and fills mold cavity. While the mold is closed, the composite cures and gets the shape of mold. Some of the advantages of compression molding are short cycle time (1 6 minutes), high quality surface, low tooling cost, minimal voids, minimal wastage. The disadvantages of the process includes intensive labor, hard to produce complex shapes, and unsuitable for mass production in a way as pultrusion process. 


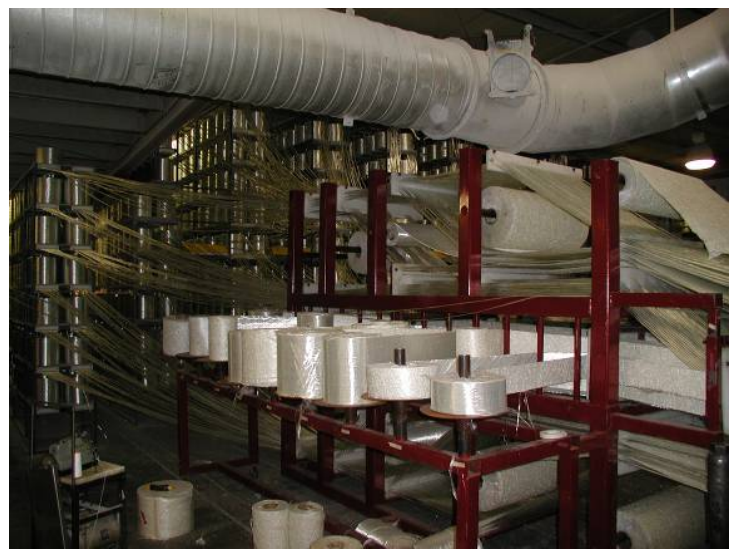

(a) Fiber/Fabric lay-up

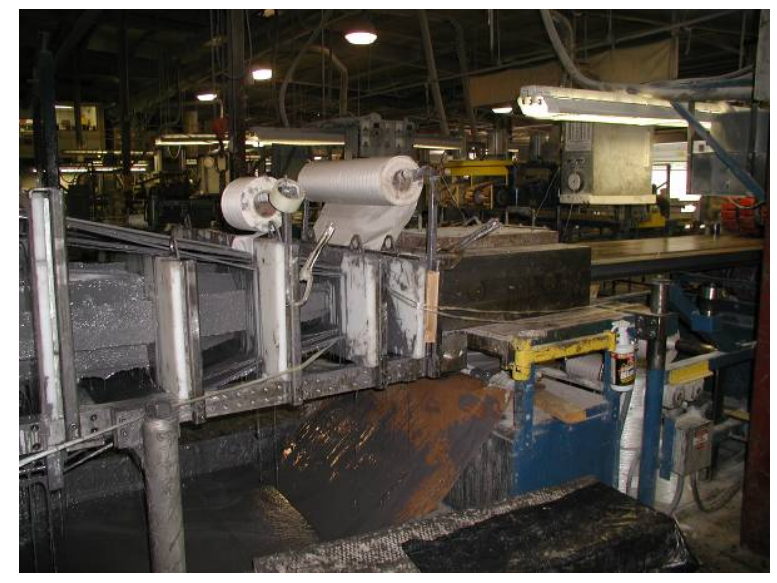

(c) Composite entering die

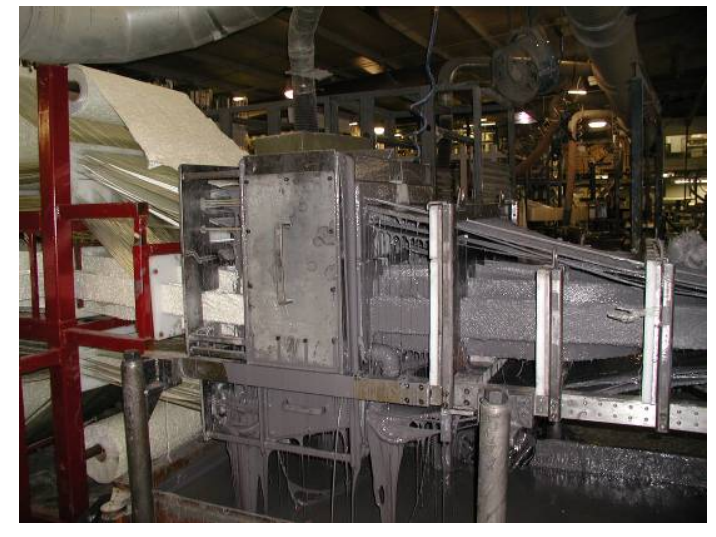

(b) Fiber/Fabric wet-out

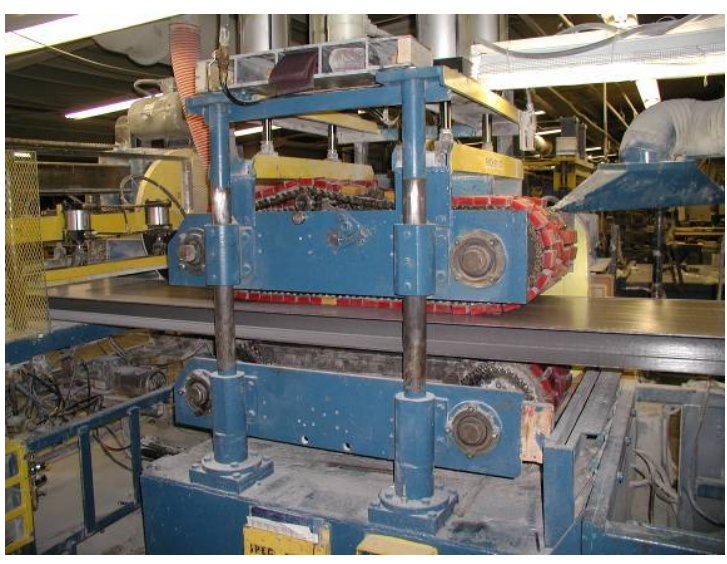

(d) Puller device

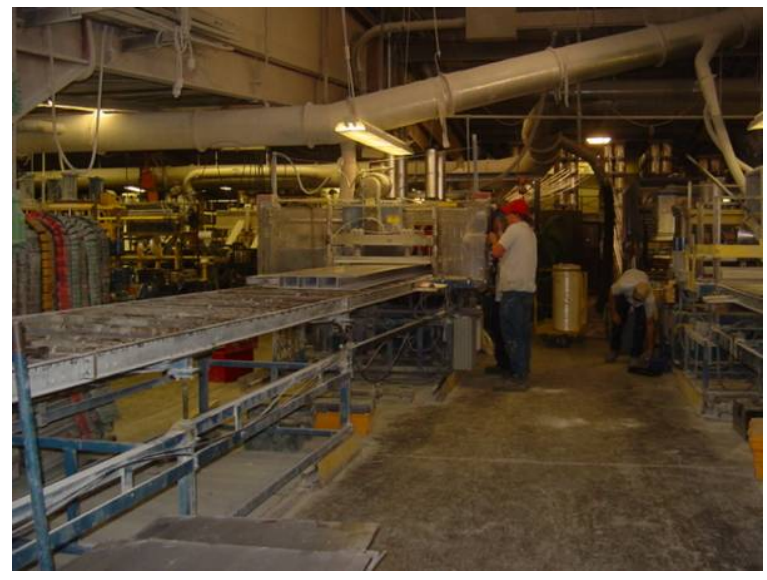

(e) Cut-off saw

Fiaure 2.3 Different Stages durina Pultrusion (Source BRP) 
Compression molded plates of size 17 " $\times 12$ " with approximately $1 / 4$ " thick were made at CFC (Vadlamani, 2007) using E-glass fibers and vinylester resin. The processing was done by hand lay-up in conjunction with compression molding process. For more details on manufacturing of compression molded plates refer to Vadlamani, 2007.

In Chapter 3, laboratory testing details including test specimen preparation, testset up, test procedure etc are discussed. 


\section{CHAPTER 3}

\section{LABORATORY TESTING DETAILS}

The following sections, deal with test procedures for tension (Section 3.1) and bending (Section 3.2) including preparation of test specimens, and test set-up. In addition, procedure for burn out test is provided in Section (3.3).

\subsection{Tension Testing}

Tension and bending tests are performed on pultruded samples at coupon level to evaluate strength, stiffness, and strain energy densities. Tension test was performed as per ASTM D 3039. The test specimens, specimen preparation and test set-up for above mentioned ASTM tests are described in the following sections.

\subsubsection{Test Specimen}

The pultruded samples were delivered from BRP Inc. in the form of $1 / 4$ " thick plates of sizes $4^{\prime} \times 1^{\prime}$. Test specimens were cut from the plates in the longitudinal direction having average dimensions as shown in Table 3.1. Five specimens from each batch were tested under tension to failure. Totally 40 tests were conducted on coupons as per ASTM D 3039. Details of test specimen size for compression molded specimens are also shown in Table 3.1 for quick reference.

\subsubsection{Specimen Preparation}

The total length of each tension test specimens was 18" out of which 5" inches on either ends of specimens were ground to roughen the surface for proper adhesion of grips. FRP tabs (1/4" thick) of 5" x 1" length were cut from 12" x 12" plates that were also ground slightly on the surface where tab is to be bonded. The tabs were bonded to tension coupons using an epoxy based adhesive. The 
adhesive was supplied by Eager Plastics in two parts ie., Part A: EP6151 and Part B: Activator EP 6151. Both the parts were mixed in 1:1 ratio to apply on roughened surface of the coupons and tabs. The glue was applied with pressure (using C-clamps) and cured for 24 hours to ensure proper adhesion of the tabs to the test coupons. Tabs are generally used to avoid crushing of specimens between the grips and thus avoid grip failure. Strain gages were mounted in the longitudinal direction (as shown in Figure 3.1) at the center of each test specimen to evaluate tensile strength and stiffness.

Table 3.1 Dimension of Pultruded \& Compression Molded Tension Test Specimens

\begin{tabular}{|c|c|c|c|}
\hline Specimen Description & \begin{tabular}{|c|} 
Gage length \\
(in)
\end{tabular} & \begin{tabular}{|c|} 
Average \\
Width (in)
\end{tabular} & \begin{tabular}{|c|} 
Average \\
Thickness (in)
\end{tabular} \\
\hline \multicolumn{4}{|l|}{ Pultruded Samples } \\
\hline Unidirectional 1 & 8 & 1.01 & 0.26 \\
\hline Unidirectional 2 & 8 & 1.02 & 0.25 \\
\hline Bi-directional & 8 & 1.01 & 0.25 \\
\hline Tri-directional & 8 & 1.02 & 0.25 \\
\hline Tri-directional with CSM & 8 & 1.01 & 0.25 \\
\hline Quadri-directional with CSM & 8 & 1.01 & 0.25 \\
\hline Multidirectional Polyurethane & 8 & 1.01 & 0.25 \\
\hline Multidirectional Vinyl ester & 8 & 1.01 & 0.25 \\
\hline \multicolumn{4}{|l|}{ Compression Molded Samples } \\
\hline Unidirectional & 5.3 & 1.03 & 0.20 \\
\hline Bi-directional & 6 & 1.01 & 0.22 \\
\hline Tri-directional with CSM & 7.8 & 1.03 & 0.22 \\
\hline Quadri-directional with CSM & 7.4 & 1.02 & 0.23 \\
\hline Quadri-directional without CSM & 6 & 1.01 & 0.17 \\
\hline
\end{tabular}




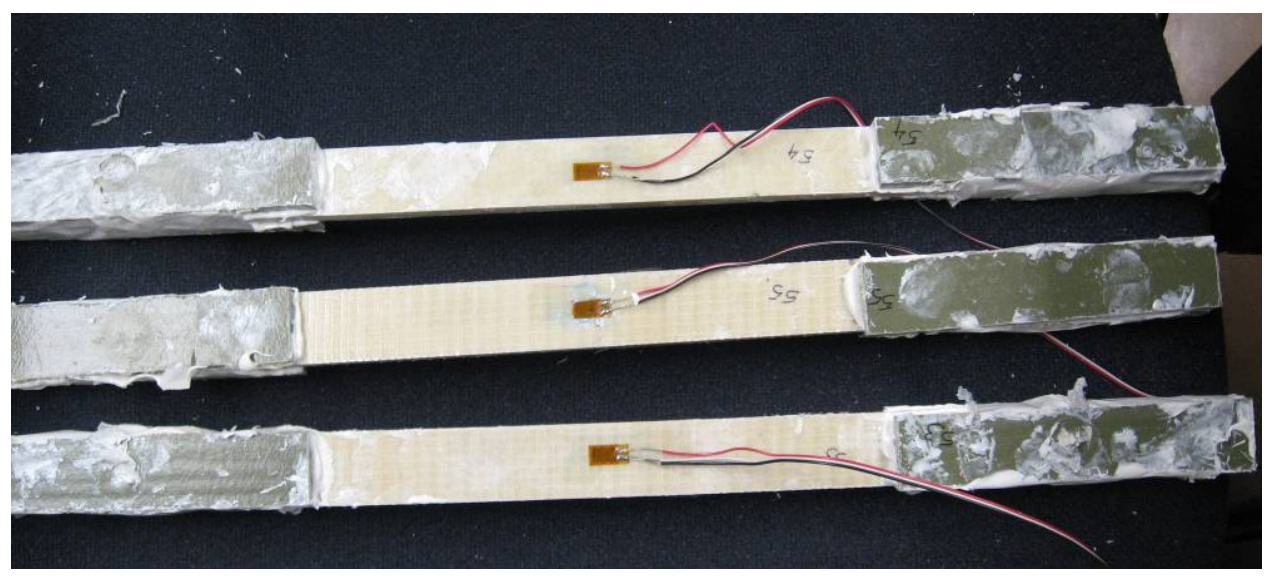

Figure 3.1 Strain Gage on Tension Test Specimens

\subsubsection{Test Set-up and Test Procedure}

The test specimens were tested using a universal testing machine (BALDWIN) as per ASTM D3039 as shown in Figure 3.2. Data acquisition system was used to record load and strain during loading of tension specimens. Specimens were loaded to failure, to evaluate ultimate failure stress of the coupon.

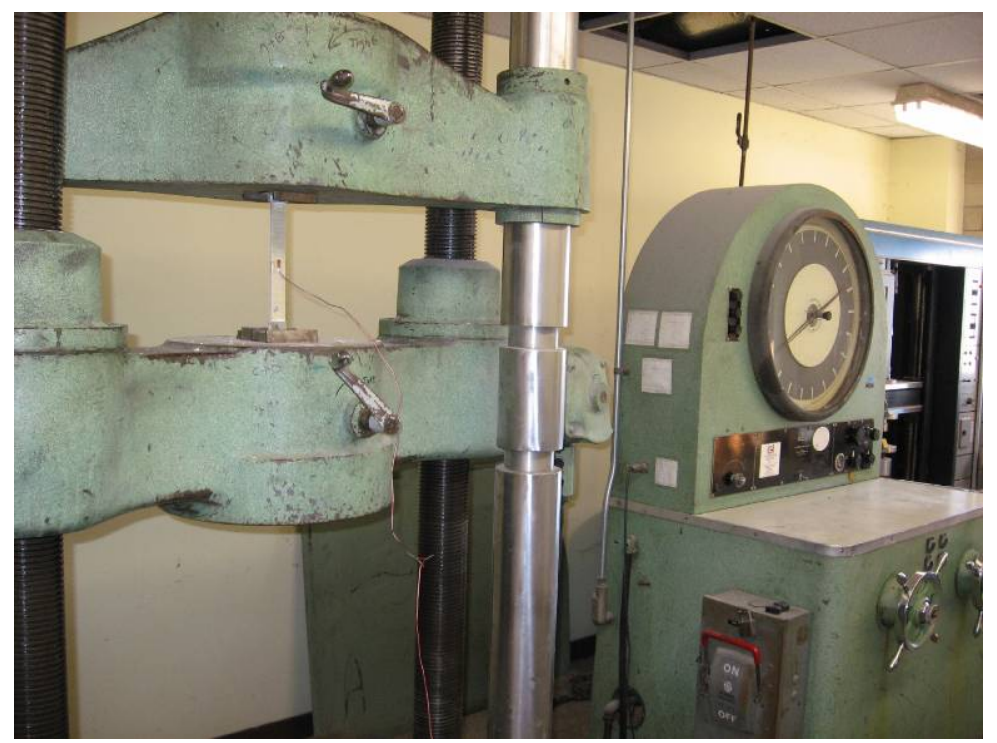

Figure 3.2 2 BALDWIN Universal Testing Machine 


\subsection{Bending Test}

\subsubsection{Test Specimen}

The test specimens were cut as per dimensions recommended by ASTM D790 for a four point bending test. Dimensions of test specimens are shown in Table 3.2. Thirteen specimens from each batch were tested under bending, out of which 5 specimens from each batch were mounted with strain gages to record strains. Thus a total of about 105 tests were conducted under bending as per ASTM D790.

Table 3.2 2 Dimension of Pultruded \& Compression Molded Bending Test Specimens

\begin{tabular}{|c|c|c|c|}
\hline Specimen Description & $\begin{array}{c}\text { Span length } \\
\text { (in) }\end{array}$ & $\begin{array}{c}\text { Average } \\
\text { Width (in) }\end{array}$ & \begin{tabular}{|c} 
Average \\
Thickness (in) \\
\end{tabular} \\
\hline \multicolumn{4}{|l|}{ Pultruded Samples } \\
\hline Unidirectional 1 & 6 & 0.77 & 0.26 \\
\hline Unidirectional 2 & 6 & 0.77 & 0.24 \\
\hline Bi-directional & 6 & 0.78 & 0.25 \\
\hline Tri-directional & 6 & 0.76 & 0.25 \\
\hline Tri-directional with CSM & 6 & 0.78 & 0.24 \\
\hline Quadri-directional with CSM & 6 & 0.76 & 0.24 \\
\hline Multidirectional Polyurethane & 6 & 0.78 & 0.25 \\
\hline Multidirectional Vinyl ester & 6 & 0.76 & 0.25 \\
\hline \multicolumn{4}{|l|}{ Compression Molded Samples } \\
\hline Unidirectional & 6 & 0.77 & 0.20 \\
\hline Bi-directional & 6 & 0.72 & 0.27 \\
\hline Tri-directional with CSM & 6 & 0.74 & 0.28 \\
\hline Quadri-directional with CSM & 6 & 0.77 & 0.22 \\
\hline Quadri-directional without CSM & 6 & 0.75 & 0.17 \\
\hline
\end{tabular}




\subsubsection{Specimen Preparation}

Test specimens for bending were cut in the longitudinal direction of the plates with overall length of 8 ". Once the test specimens were ready, strain gages were installed on the tension face of each bending specimen to evaluate bending strength and stiffness.

\subsubsection{Test Set-Up and Test Procedure}

Bending tests were conducted using an Instron Model 8501. The Instron cross speed was set as per ASTM D790. Four point bending, with simply supported conditions with point loading at $1 / 3$ of the overall test span was performed. Strain was recorded at constant load intervals through a data acquisition system. The specimens were tested to failure and the corresponding failure strains were noted. A typical test set-up is shown in Figure 3.3. The compression molded specimens were also tested in similar manner.

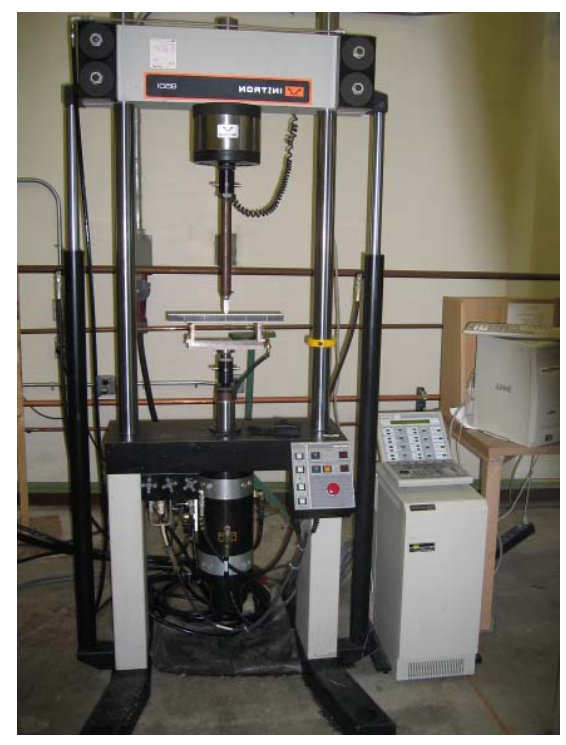

Figure 3.3 Instron Machine 


\section{3 (Burn out Test) Fiber Volume Fraction Test}

Fiber Volume Fraction (FVF) test is performed to determine the fiber volume (or weight) content of composite materials. The tests are performed as per Procedure G of ASTM D 3171. Three specimens of size 1" x1" (Figure 3.4) were cut from each batch of plates. The dimensions of the specimens were first measured to the nearest 0.001 inches and each specimen was placed in a preweighed crucible.

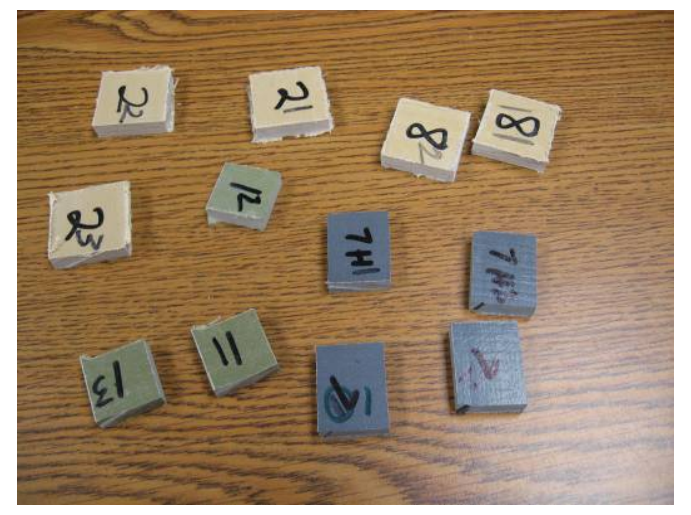

Figure 3.4 Specimens for Burn-Out Test

The crucible (along with specimen) was kept in a preheated furnace (Isotemperature muffle furnace, Model 550-58) at $600{ }^{\circ} \mathrm{C}$ (Figure 3.5) for 3 hours. The specimens were taken out from the furnace and the crucible along with the fibers which was further weighed. 


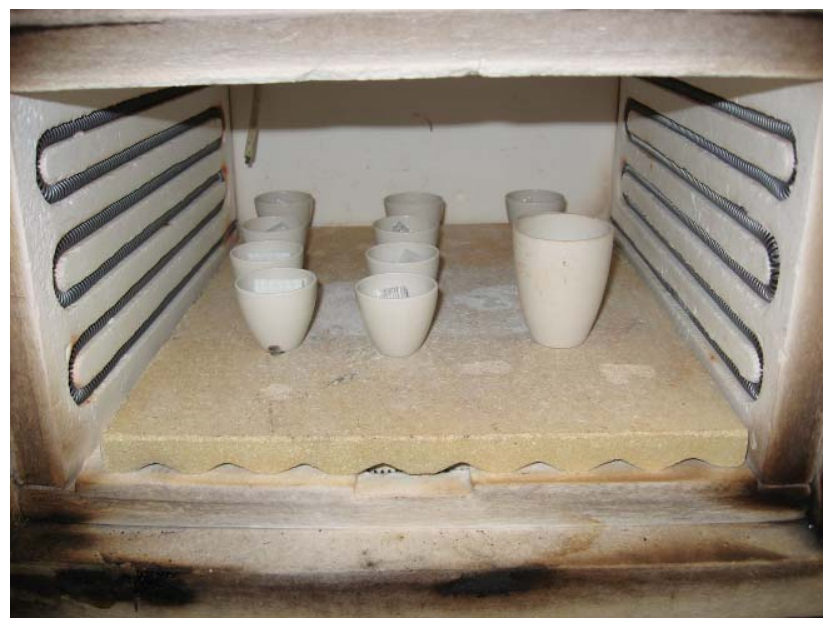

Figure 3.5 Isotemperature Muffle Furnace

The composite that has left out fibers/fabrics in the crucible was thoroughly examined for fiber/fabric lay-up and orientations buy checking each laminae (Figure 3.6) of a given laminate and verified against manufacturer's specifications.

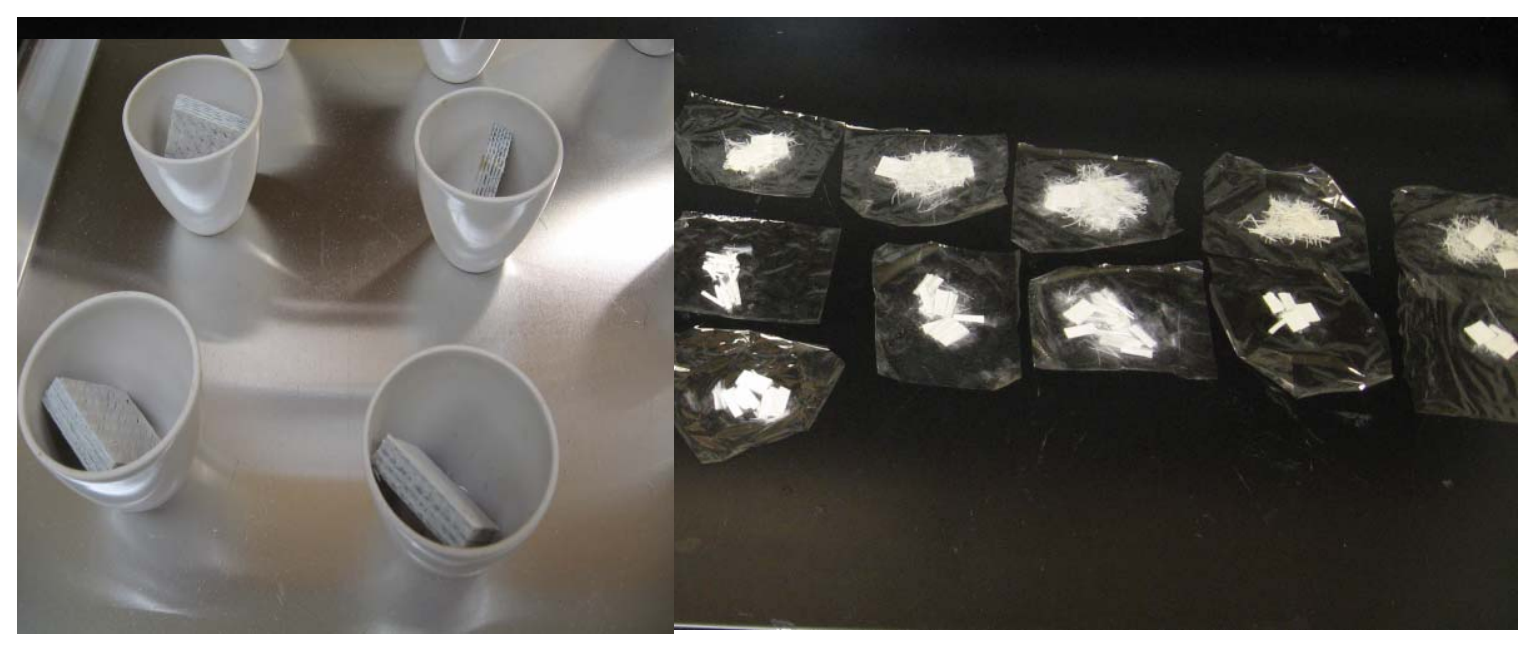

Figure 3.6 Checking of each Laminae of a Given Laminate

The synthesis on laboratory testing data's is provided in Chapter 4. 


\section{CHAPTER 4}

\section{DATA ANALYSIS}

\subsection{Introduction}

As mentioned in earlier Chapters, response of FRP composites including elastic properties is highly dependent on fiber content, orientation, distribution and manufacturing process and type of resin. Test data and procedures to determine Fiber Volume Fraction (FVF), strength and stiffness under tension and bending and regression analysis to fit stress vs strain have been discussed herein.

\subsection{Determination of FVF from Burn-out Test}

Step 1: Measure dimension of the composite sample - Length $(\mathrm{L}$ in $\mathrm{cm})$, Width ( $W$ in $\mathrm{cm}$ ) and Thickness ( $T$ in $\mathrm{cm}$ ).

Step 2: Measure the weight of empty crucible ( $\mathrm{W}_{\mathrm{C}}$ in gms)

Step 3: Measure the weight of crucible + sample ( $\mathrm{W}_{\mathrm{c}+\mathrm{s}}$ in gms) before burn-out

Step 4: Measure weight of fabric (left after resin burn) + crucible $\left(W_{f+c}\right.$ in gms) after burn-out

Step 5: Evaluate $F V F=\frac{W_{f+c}-W_{C}}{\rho L W T} \times 100$

Where, $\rho$ is density of fiber $=2.522 \mathrm{gm} / \mathrm{cc}$.

FVF of composites used in this study are provided in Table 2.1. 


\subsection{Tension Test Results}

Tensile strength is given by

$\sigma=\frac{\mathrm{P}}{\mathrm{A}} \quad$ (psi)

where, $\mathrm{P}=$ Load applied on the test specimen (Ibs)

W $=$ Width of specimen (in)

$T=$ Thickness of specimen (in)

$\mathrm{A}=\mathrm{W} \times \mathrm{T}=$ Cross-sectional area of the specimen $\left(\mathrm{in}^{2}\right)$

Tensile Stiffness:

A typical stress-strain response for fabric based composites under tension load may be bilinear (two slopes) or tri linear (three slopes) as shown in Figure 4.1. In the stress-strain curve, the point where change in slope takes place from the initial slope is identified as bifurcation point (Vadlamani, 2007). Based on the bifurcation points, the tensile stiffness is evaluated. Thus a given stress-strain curve may have two or more bifurcations points according to which the tensile stiffness is identified as follows:

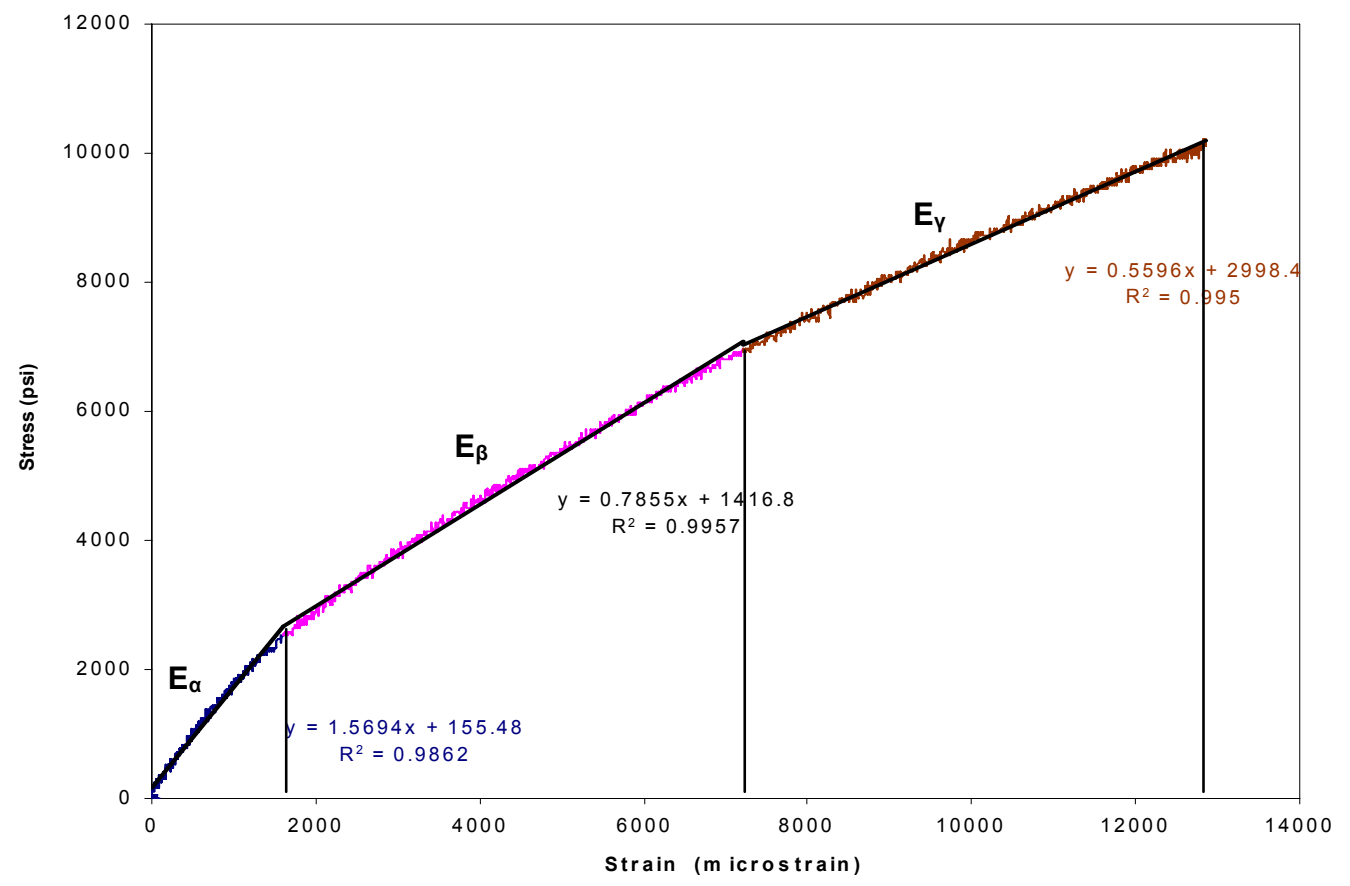

Figure 4.1 Stress-Strain Curve with Tri-linear Slopes 
$E_{\alpha}=$ The first modulus obtained up to first bifurcation point (computed by regression analysis of stress-strain curve up to bifurcation point - Figure 4.1).

$E_{\beta}=$ Second modulus obtained starting from first bifurcation point to second bifurcation point (computed by regression analysis of stress-strain curve from first to second bifurcation points - Figure 4.1).

$E_{Y}=$ Third modulus obtained starting from second bifurcation point to third bifurcation point (computed by regression analysis of stress-strain curve from second to third bifurcation points - Figure 4.1).

Over 40 specimens having cross-sectional area of about 1"x $1 / 4$ " with different fiber architectures were tested in the longitudinal direction. The test specimen ID numbers are shown in Table 2.1. For instance, a sample labeled as 14 in Table 4.1 represents sample number 4 belonging to specimen ID No: 1 , which is a unidirectional plate 1 that is constructed with CSM and Rovings (Refer Table 2.1). Using experimental data, the maximum load, stress, strain and stiffness for different fiber architecture are evaluated and shown in Tables 4.1 through 4.4.

\subsubsection{Unidirectional Composites}

Table 4.1 shows that Sample ID 11 through 25 belong to unidirectional plates having same fiber architecture with nearly identical FVF. However, they are identified under different Specimen ID No: 1 \& 2 (Refer Table 2.1) because they were manufactured at two different time frames. Specimen ID No: 1 plate was not pultruded along with the same batch as rest of other plates (specimen ID no: 2 thru 8 - Refer Table 2.1). A typical stress vs strain curve for unidirectional composite is shown in Figure 4.2. The maximum stress, strain and stiffness are evaluated as mentioned above, and presented in Table 4.1.

It is observed from Figure 4.3, that the stress-strain curve is bilinear and is attributed to the presence of CSM in the unidirectional plates. The second slope is linear up to maximum load. Details of stress, strain and stiffness based on the 
two linear slopes are provided in Table 4.1. The average maximum stress is about $61 \mathrm{ksi}$ and corresponding strain ranged from $17000 \sim 22000$ microstrain.

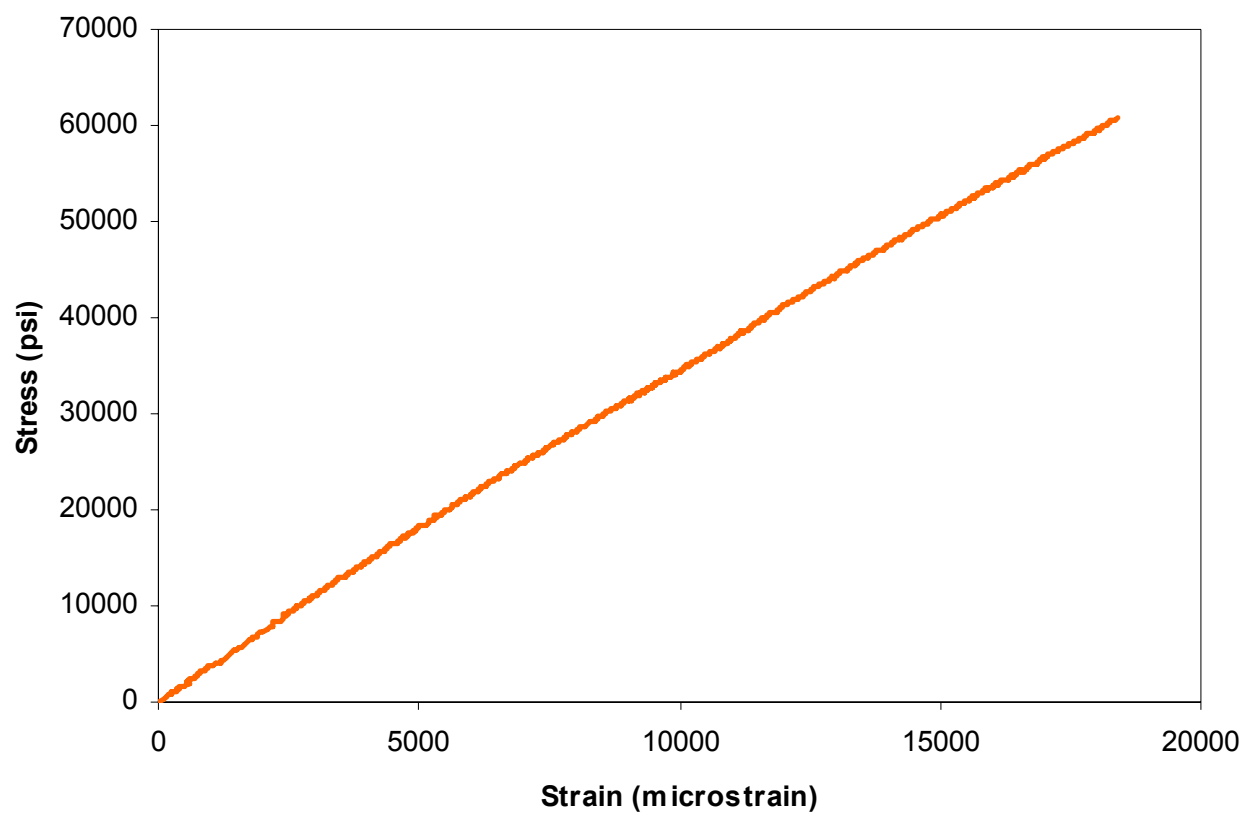

Figure 4.2 Stress-Strain Curve for Unidirectional Composites (Sample 14)

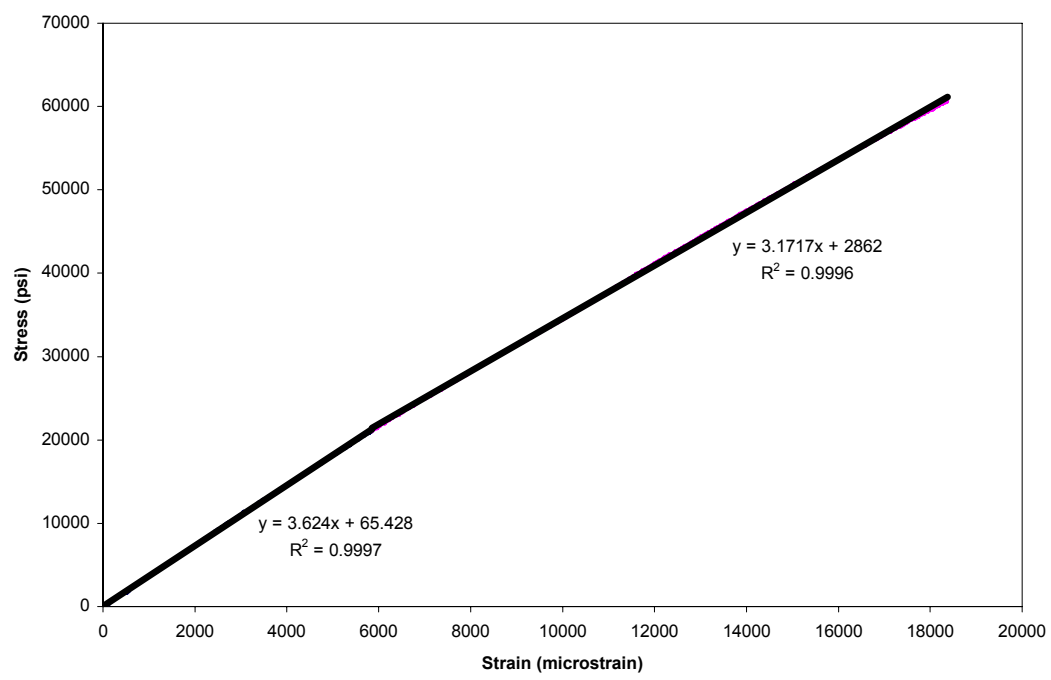

Figure 4.3 Stress-Strain Curve with Bi-linear Slopes for Uni-directional Composites (Sample 14) 
Table 4.1 Structural properties of unidirectional composites

\begin{tabular}{|c|c|c|c|c|c|c|c|c|c|c|c|c|c|}
\hline $\begin{array}{c}\text { Sample } \\
\text { ID }\end{array}$ & Lay-up & $\begin{array}{l}\text { Density } \\
\left(\mathrm{oz} / \mathrm{yd}^{2}\right)\end{array}$ & $\begin{array}{l}\text { FVF } \\
(\%)\end{array}$ & \begin{tabular}{|c|}
$\begin{array}{c}\text { FVF- } \\
\text { X }\end{array}$ \\
$(\%)$ \\
\end{tabular} & $\begin{array}{l}\text { Max } \\
\text { Load } \\
\text { (kips) }\end{array}$ & $\begin{array}{c}\text { Strain at } \\
\text { Max Load } \\
(\mu \varepsilon)\end{array}$ & $\begin{array}{l}\text { Stress at } \\
\text { Max Load } \\
\text { (ksi) }\end{array}$ & $\begin{array}{c}\text { Load at } \\
\text { F.Slope } \\
\text { (kips) }\end{array}$ & $\begin{array}{c}\text { Strain at } \\
\text { F.Slope } \\
(\mu \varepsilon)\end{array}$ & $\begin{array}{l}\text { Stress at } \\
\text { F.Slope } \\
\text { (ksi) }\end{array}$ & $\begin{array}{c}E \alpha \\
\text { (msi) }\end{array}$ & $\begin{array}{c}\mathrm{E} \beta \\
(\mathrm{msi})\end{array}$ & $E \alpha / E \beta$ \\
\hline 11 & Uni & & \multirow[b]{3}{*}{44} & \multirow[b]{3}{*}{34} & 15.60 & 19730.00 & 59.60 & 5.60 & 6300.00 & 21.27 & 3.41 & 2.87 & 1.19 \\
\hline 12 & with CSM & & & & 15.50 & 17107.00 & 57.90 & 5.50 & 5981.00 & 20.70 & 3.48 & 3.26 & 1.07 \\
\hline \multirow[t]{3}{*}{14} & & & & & 15.60 & 18382.00 & 60.70 & 5.85 & 5857.00 & 20.96 & 3.62 & 3.17 & 1.14 \\
\hline & & AVG & & & 15.57 & 18406.33 & 59.40 & 5.65 & 6046.00 & 20.98 & 3.50 & 3.10 & 1.13 \\
\hline & & STDEV & & & 0.06 & 1311.67 & 1.41 & 0.18 & 228.54 & 0.29 & 0.11 & 0.20 & 0.06 \\
\hline 23 & & & \multirow[b]{3}{*}{45} & \multirow[b]{3}{*}{35} & 16.80 & 21877.00 & 64.20 & 5.82 & 6667.00 & 22.21 & 3.38 & 2.74 & 1.23 \\
\hline 24 & & & & & 16.50 & 20665.00 & 64.80 & 5.84 & 6526.00 & 22.90 & 3.52 & 2.97 & 1.19 \\
\hline \multirow[t]{3}{*}{25} & & & & & 15.10 & 21022.00 & 61.70 & 5.17 & 6463.00 & 21.10 & 3.29 & 2.80 & 1.18 \\
\hline & & AVG & & & 16.13 & 21188.00 & 63.57 & 5.61 & 6552.00 & 22.07 & 3.40 & 2.84 & 1.20 \\
\hline & & STDEV & & & 0.91 & 622.82 & 1.64 & 0.38 & 104.46 & 0.91 & 0.12 & 0.12 & 0.03 \\
\hline
\end{tabular}

\section{Points to be noted:}

Unidirectional

Fabric Construction: CSM/Rov/CSM/Rov/CSM/Rov/CSM

FVF: 45\%

Average peak stress (group 1): $59 \mathrm{ksi}$; Average peak stress (group 2): 64 ksi

Average peak strain: (group1): $18406 \mu \varepsilon$; Average peak strain (group2): $21188 \mu \varepsilon$

Average stiffness: (group 1): $3.50 \mathrm{msi}$; Average stiffness (group 2): $3.4 \mathrm{msi}$

Average ratio in change of slope (group 1): 1.13; Average ratio in change of slope (group 2): 1.20

For $\mathrm{E} \alpha, \mathrm{E} \beta$ refer Figure 4.1. 
Summary: It is seen from table that unidirectional composites have bilinear slopes which is attributed to the presence of CSM. The first change of slope is at about $35 \%$ of ultimate stress wherein micro cracking or matrix softening would have occurred. The ratio of change of first and second slope is about 1.2.

\subsubsection{Bi-directional Composites}

Bi-directional composites were made with 9 layers $0^{\circ} / 90^{\circ}$ fabric, wherein each layer weighed $24 \mathrm{oz} / \mathrm{yd}^{2}$. A typical stress strain curve for bi-directional composite is shown in Figure 4.4.

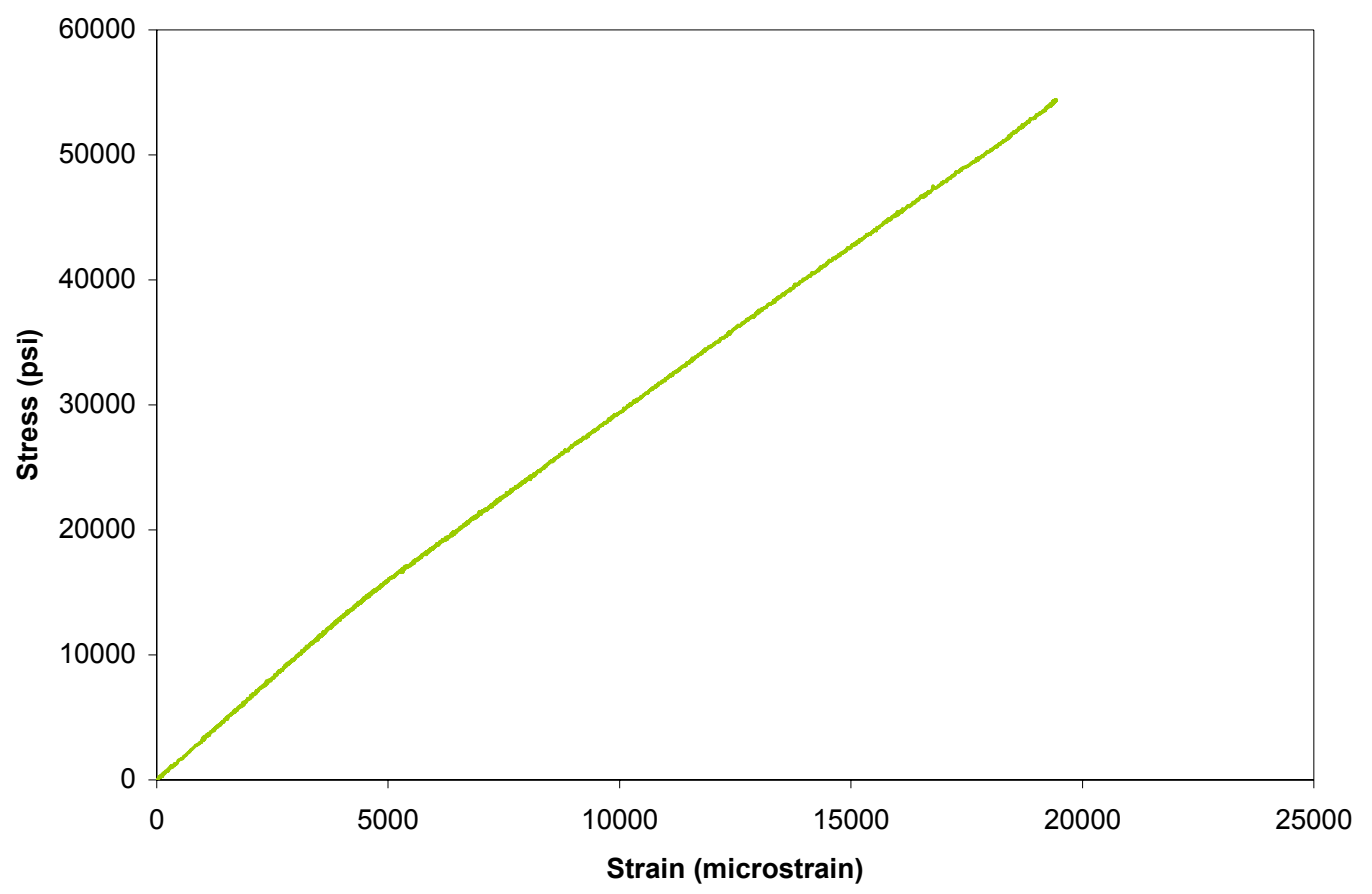

Figure 4.4 Typical Stress-Strain Curve for Bi-directional Composites (Sample 33) 


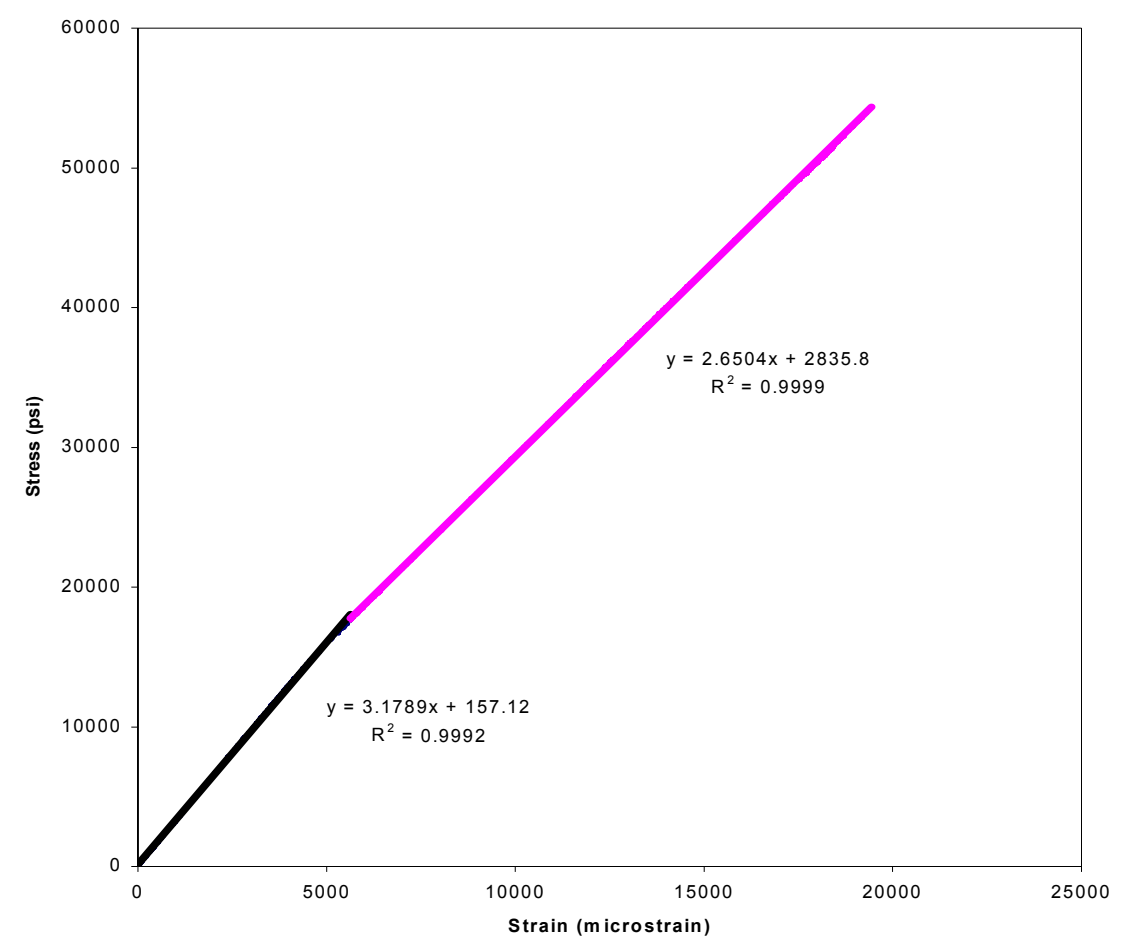

Figure 4.5 Stress-Strain Curve with Bi-linear slopes for Bi-directional Composites (Sample 33)

Figure 4.5, shows that bi-directional composites exhibited bilinear stress-strain responses. The second slope is linear up to maximum load which happens to be the load at failure. The average maximum stress is about $57 \mathrm{ksi}$, corresponding to maximum strain ranged from 19,000 220000 microstrain as shown in Table 4.2.

Summary: It is seen from Table 4.2, that bi-directional composites have bilinear slopes similar to unidirectional composites. The first change of slope took place at about $33 \%$ of the ultimate stress wherein micro cracking or matrix softening especially at crossing points of $0^{\circ}$ and $90^{\circ}$ fibers would have occurred. The ratio of change of first and second slope is 1.24 which is closer to uni-directional composites. 
Table 4.2 Structural properties of bi-directional composites

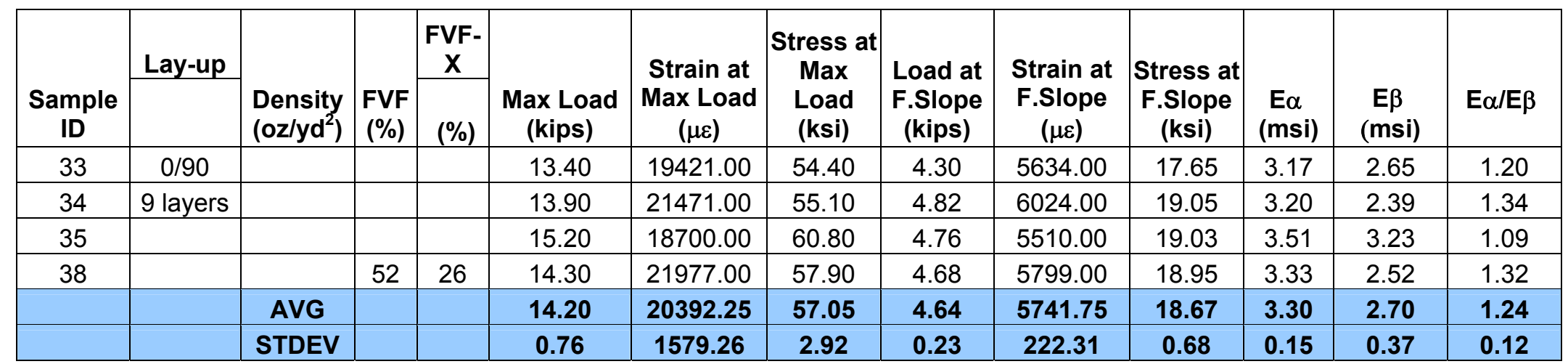

Points to be noted:

Bi-directional

Fabric Construction: 0/90, 0/90, 0/90, 0/90, 0/90, 0/90, 0/90, 0/90, 0/90 (not symmetric)

FVF: $52 \%$

Average peak stress: $57 \mathrm{ksi}$

Average peak strain: $20392 \mu \varepsilon$

Average stiffness: $3.3 \mathrm{msi}$.

Ratio in change of slope: 1.24 


\subsubsection{Tri-directional Composites}

Tri-directional composites were made with $45^{\circ} / 90^{\circ} /-45^{\circ}$ fabric. Bedford Reinforced Plastics Inc. (BRP) supplied two types of tri-directional composites, one without CSM (Specimen ID No; 4) under the trade name of VXV (Figure 2.2) and the other with CSM (Specimen ID No: 5) under trade name of DDBM (Figure 2.2). Tri-directional composites without CSM were constructed with 6 layers of $45^{\circ} / 90^{\circ} /-45^{\circ}$ wherein each layer weighed $40 \mathrm{oz} / \mathrm{yd}^{2}$ and the one with CSM is constructed with 4 layers of $45^{\circ} / 90^{\circ} / 45^{\circ} / \mathrm{CSM}$ weighing $40 \mathrm{oz} / \mathrm{yd} 2$. Typical stress vs strain curve for a tri-directional composite without and with CSM are shown in Figures 4.6 and 4.7 respectively. In both cases, gradual change in slope is observed between zero to maximum stress. It is very distinct from Figure 4.6 that first change of slope is at much earlier point (about $30 \%$ of peak stress) than in Figure 4.7 , which is about $40 \%$ of maximum stress. Such a response is attributed to CSM contributing to higher stiffness than the one without CSM.

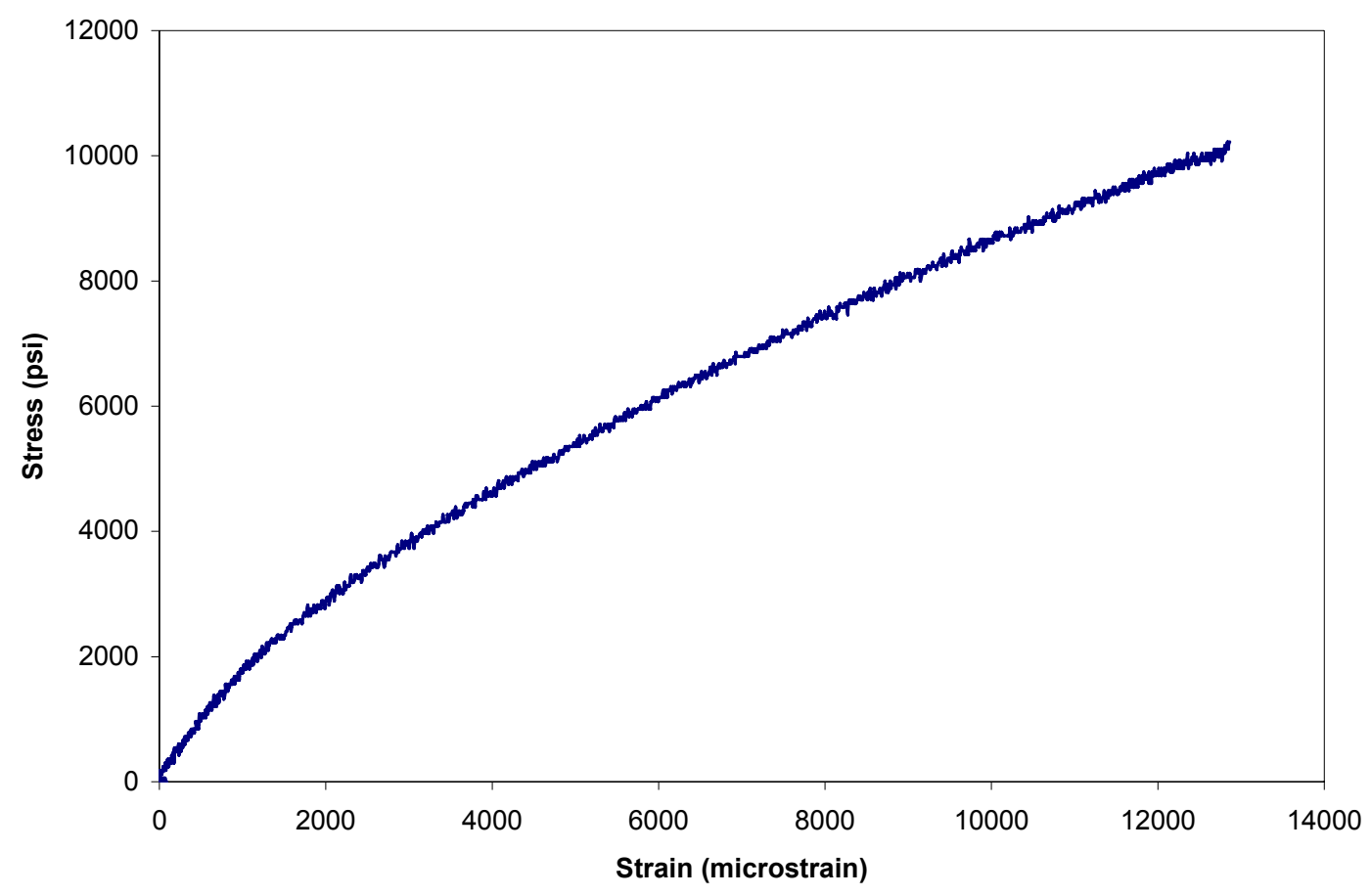

Figure 4.6 Typical Stress-Strain Curve for Tri-directional Composites without CSM (Sample 45) 


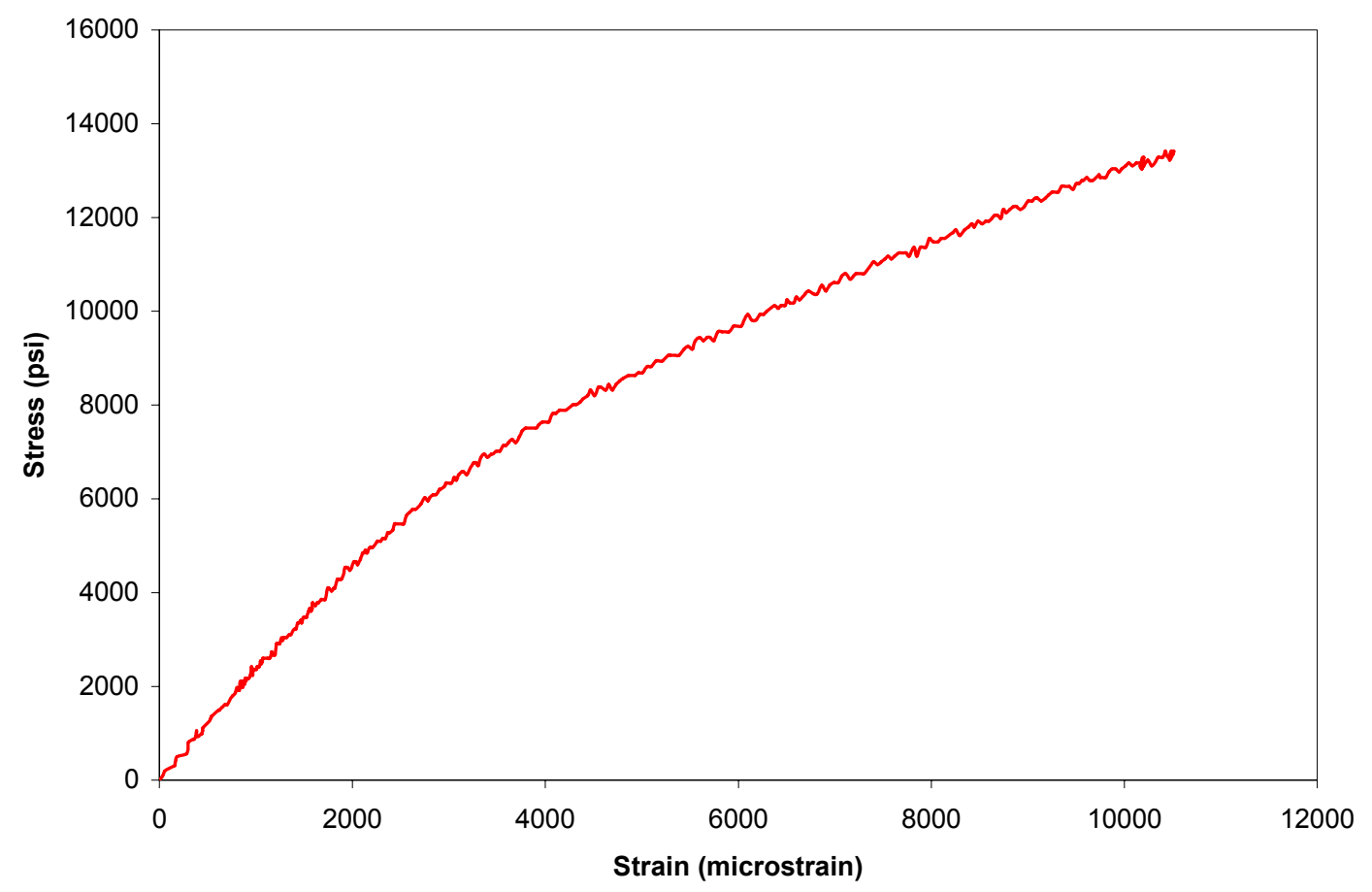

Figure 4.7 Typical Stress-Strain Curve for Tri-directional Composites with CSM(Sample 57)

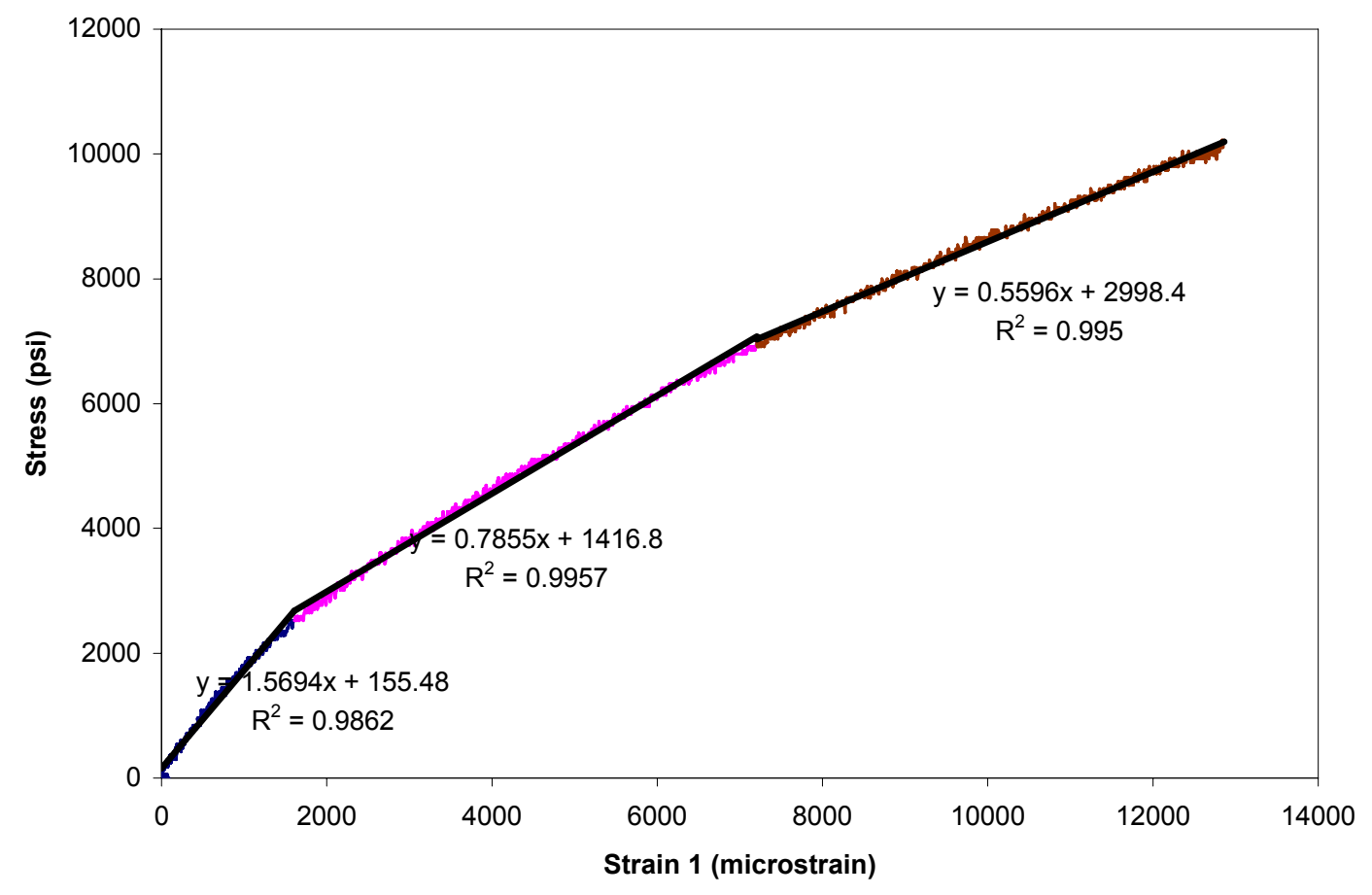

Figure 4.8 Stress-Strain Curve with tri-linear slopes for Tri-directional Composites without CSM (Sample 45) 


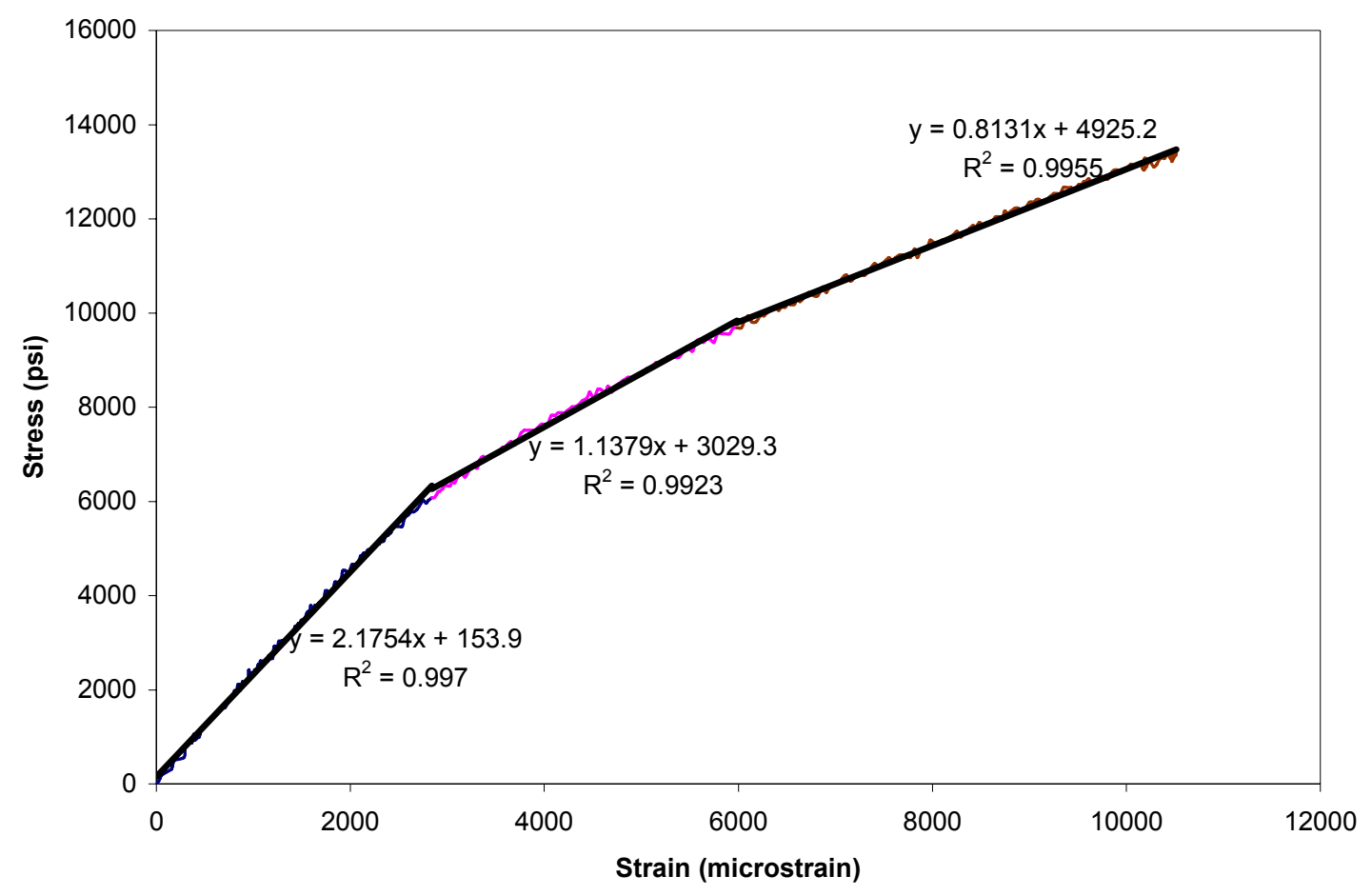

Figure 4.9 Stress-Strain Curve with Tri-linear Slopes for Tri-directional Composites with CSM (Sample 57)

Figure 4.8 and 4.9 are showing that tri-directional composites have tri-linear slopes, regardless of the presence of CSM. In both curves, slopes are linear from the change of slope at second point up to maximum stress. Details of stress, strain, stiffness are provided in Table 4.3. The average maximum stress is about $9.7 \mathrm{ksi}$ and $14 \mathrm{ksi}$ for tri-directional without CSM and with CSM respectively. For both composites, the average strain is about 12000 microstrain.

Summary: Overall, the maximum stress in tri-directional composites is very low compared to uni-/bi-directional composites because of the absence of load carrying $0^{\circ}$ fibers. From Table 4.3 , one can observe that maximum stress is about $45 \%$ higher for composites with CSM than in composites without CSM. This is attributed to the presence of CSM which resists additional loads over the one without CSM. The maximum strain in Tri-directional composites is lower because of high stress concentration due to imbalance of fabric orientation. The first change of slope occurred at about $29 \%$ of maximum stress for tri-directional 
case without CSM and at about $40 \%$ of maximum stress with CSM. This is attributed to the fact that in composites with $\pm 45^{\circ}$ fibers, and without CSM, the micro cracks or matrix softening initiates earlier than presence of CSM. The second change of slope is at about $74 \%$ of maximum stress for composites without CSM and $69 \%$ of maximum stress for composites with CSM which indicates that composites without CSM is more close to failure. In general the change of slopes in stress-strain curve for tri-directional composites indicates the failure initiates with matrix softening, followed by cracking of $90^{\circ}$ plies with eventual shearing of $45^{\circ}$ plies. The ratio of change in the first and second slope for both composites is about 2.0 due to nature of fiber orientation. The ratio of change in second and third slope is about 1.5.

\section{Points to be noted:}

Tri-directional without CSM

Fabric Construction: 0/45/90/-45, 45/90/-45, 45/90/-45, 45/90/-45, 45/90/-45, 45/90/-45 (not symmetric)

FVF: $55 \%$

Average peak stress: $9.7 \mathrm{ksi}$

Average peak strain: $11502 \mu \varepsilon$

Average stiffness: $1.61 \mathrm{msi}$.

Ratio in change of first and second slope: 2.01

Tri-directional with CSM

Fabric Construction: 45/90/-45/csm, 45/90/-45/csm, csm/-45/90/45, csm/-45/90/45 (symmetric) FVF: $51 \%$

Average peak stress: $14.0 \mathrm{ksi}$

Average peak strain: $11486 \mu \varepsilon$

Average stiffness: $2.13 \mathrm{msi}$.

Ratio in change of first and second slope: 1.82 
Table 4.3 Structural Properties of Tri-directional Composites

\begin{tabular}{|c|c|c|c|c|c|c|c|c|c|c|c|c|c|c|c|c|c|c|}
\hline $\begin{array}{c}\text { Sample } \\
\text { ID }\end{array}$ & Lay-up & $\begin{array}{l}\text { Density } \\
\left(\text { oz/yd }^{2}\right)\end{array}$ & $\begin{array}{l}\text { FVF } \\
(\%)\end{array}$ & \begin{tabular}{|c|} 
FVF- \\
$X$ \\
\end{tabular} & $\begin{array}{l}\text { Max } \\
\text { Load } \\
\text { (kips) }\end{array}$ & $\begin{array}{c}\text { Strain at } \\
\text { Max } \\
\text { Load } \\
(\mu \varepsilon)\end{array}$ & $\begin{array}{c}\text { Stress } \\
\text { at } \\
\text { Max } \\
\text { Load } \\
\text { (ksi) }\end{array}$ & \begin{tabular}{|c|} 
Load at \\
F.Slope \\
(kips)
\end{tabular} & $\begin{array}{c}\text { Strain } \\
\text { at } \\
\text { F.Slope } \\
(\mu \varepsilon)\end{array}$ & $\begin{array}{l}\text { Stress } \\
\text { at } \\
\text { F.Slope } \\
\text { (ksi) }\end{array}$ & $\begin{array}{l}\text { Load } \\
\text { at S. } \\
\text { Slope } \\
\text { (kips) }\end{array}$ & $\begin{array}{c}\text { Strain at } \\
\text { S. Slope } \\
(\mu \varepsilon)\end{array}$ & $\begin{array}{c}\text { Stress at } \\
\text { S.Bif } \\
\text { (ksi) }\end{array}$ & $\begin{array}{c}E \alpha \\
\text { (msi) }\end{array}$ & $\begin{array}{c}\mathrm{E} \beta \\
\text { (msi) }\end{array}$ & $\begin{array}{c}E \gamma \\
(m s i)\end{array}$ & $E \alpha / E \beta$ & $E \beta / E \gamma$ \\
\hline 44 & Triaxial & & & & 2.40 & 11641.00 & 9.60 & 0.68 & 1698.00 & 2.70 & 1.80 & 7416.00 & 7.10 & 1.65 & 0.76 & 0.55 & 2.17 & 1.38 \\
\hline 45 & without CSM & & & & 2.60 & 12862.00 & 10.20 & \begin{tabular}{l|l}
0.65 & 1 \\
\end{tabular} & 1608.00 & 2.50 & 1.80 & 7208.00 & 6.90 & 1.57 & 0.79 & 0.56 & 1.99 & 1.41 \\
\hline \multirow[t]{3}{*}{46} & (6 layers) & & 55 & 16 & 2.40 & 10004.00 & 9.40 & \begin{tabular}{l|l}
0.86 & 2 \\
\end{tabular} & 2157.00 & 3.40 & 1.90 & 7074.00 & 7.50 & 1.60 & 0.85 & 0.59 & 1.88 & 1.44 \\
\hline & & AVG & & & 2.47 & 11502.33 & 9.73 & 0.73 & 1821.00 & 2.87 & 1.83 & 7232.67 & 7.17 & 1.61 & 0.80 & 0.57 & 2.01 & 1.41 \\
\hline & & STDEV & & & 0.12 & 1434.04 & 0.42 & 0.11 & \begin{tabular}{|l|}
294.44 \\
\end{tabular} & 0.47 & 0.06 & 172.33 & 0.31 & 0.04 & 0.05 & 0.02 & 0.15 & 0.03 \\
\hline 51 & Triaxial & & & & 3.60 & 11535.00 & 13.90 & \begin{tabular}{l|l}
1.20 & 2 \\
\end{tabular} & 2182.00 & 4.60 & 2.20 & 5485.00 & 8.70 & 2.13 & 1.30 & 0.83 & 1.64 & 1.57 \\
\hline 54 & with CSM & & & & 3.70 & 12977.00 & 14.50 & 1.50 & 3213.00 & 6.10 & 2.30 & 5957.00 & 9.30 & 1.89 & 1.14 & 0.75 & 1.66 & 1.52 \\
\hline 56 & (4 layers) & & & & 3.50 & 11233.00 & 13.70 & 1.60 & 3036.00 & 6.10 & 2.50 & 6332.00 & 9.80 & 2.06 & 1.12 & 0.82 & 1.84 & 1.37 \\
\hline 57 & & & & & 3.30 & 10516.00 & 13.40 & 1.50 & 2842.00 & 6.10 & 2.40 & 5984.00 & 9.70 & 2.17 & 1.14 & 0.81 & 1.90 & 1.41 \\
\hline \multirow[t]{3}{*}{510} & & & 51 & 15 & 3.60 & 11172.00 & 14.90 & 1.40 & 2578.00 & 5.90 & 2.70 & 6567.00 & 11.10 & 2.40 & 1.28 & 0.78 & 1.88 & 1.64 \\
\hline & & AVG & & & \begin{tabular}{|l|}
3.54 \\
\end{tabular} & 11486.60 & 14.08 & \begin{tabular}{l|l}
1.44 & 2 \\
\end{tabular} & 2770.20 & 5.76 & 2.42 & 6065.00 & 9.72 & 2.13 & 1.20 & 0.80 & 1.82 & 1.50 \\
\hline & & STDEV & & & 0.15 & 912.28 & 0.61 & 0.15 & 404.60 & 0.65 & 0.19 & 411.68 & 0.88 & 0.19 & 0.09 & 0.03 & 0.13 & 0.11 \\
\hline
\end{tabular}




\subsubsection{Quadri-directional Composites}

Quadri-directional composites are constructed with 4 layers of $0 \% 190 \% 45 \%$ $45 \%$ CSM fabric, each layer weighing 26 oz/yd ${ }^{2}$. A typical stress vs strain curve for quadri-directional composite is shown in Figure 4.10. It is evident from Figure 4.11 that the curve is almost bi-linear and is very similar to uni-, and bi-directional composites; however, the maximum stress and strain for quadri-directional composites are different from uni-, bi-directional composites. Details of stress, strain and stiffness are provided in Table 4.4. The average maximum stress is about $26 \mathrm{ksi}$ and the maximum strain is 10,000 microstrain.

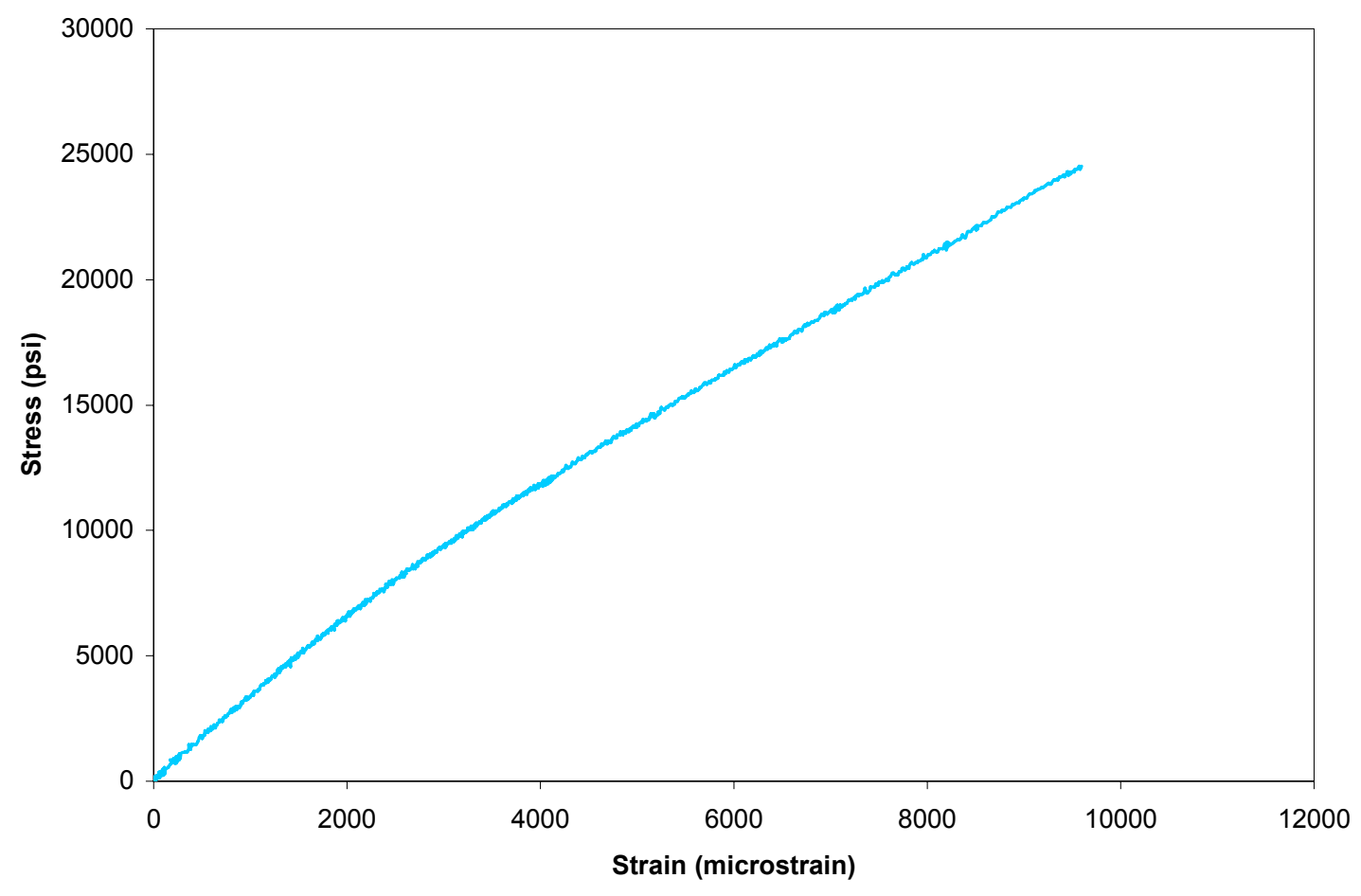

Figure 4.10 Typical Stress-Strain Curve for Quadri-directional Composites (Sample 61) 


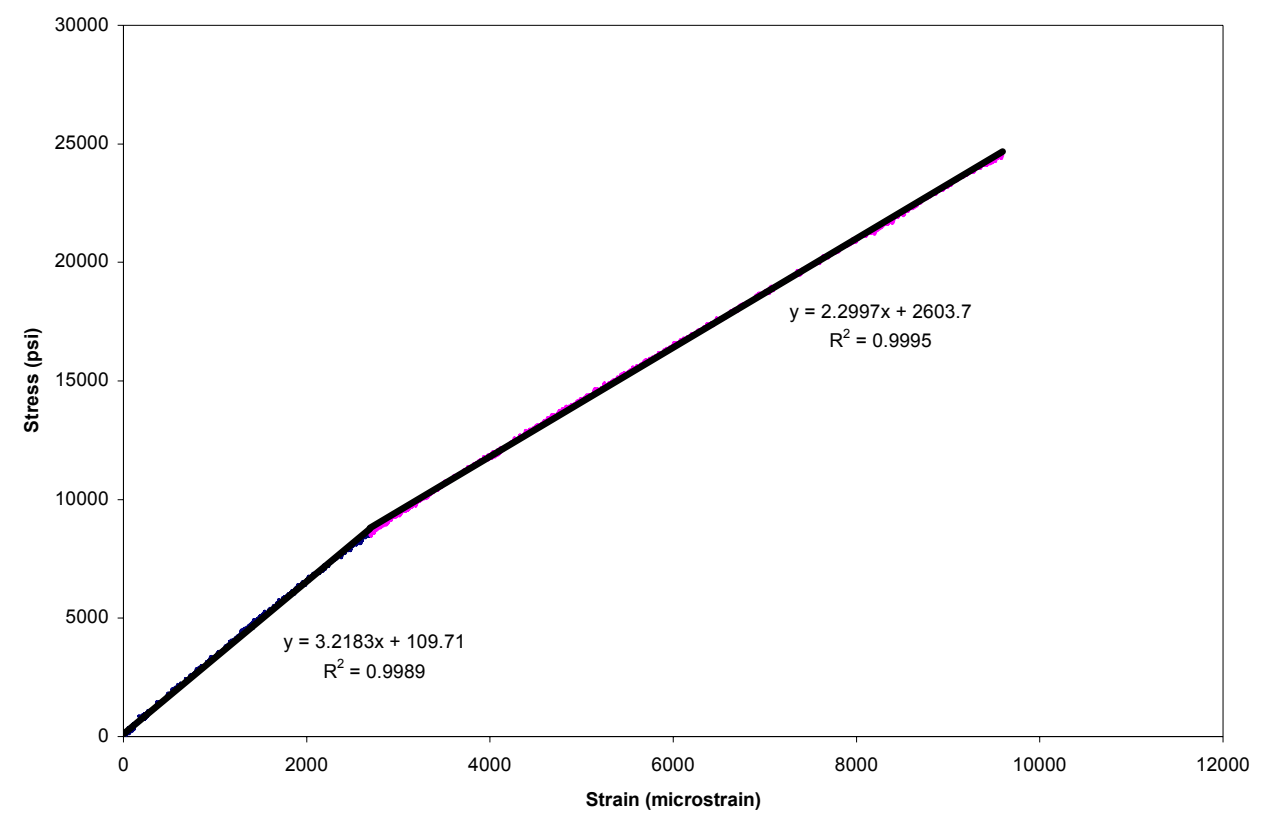

Figure 4.11 Stress-Strain Curve with Bi-linear Slopes for Quadri-directional Composites (Sample 61)

Table 4.4 Structural Properties of Quadri-directional Composites

\begin{tabular}{|c|c|c|c|c|c|c|c|c|c|c|c|c|c|}
\hline \multirow[b]{2}{*}{$\underset{\text { SD }}{\text { Sample }}$} & \multirow[t]{2}{*}{ Lay-up } & \multirow[b]{2}{*}{$\begin{array}{l}\text { Density } \\
\left(\mathrm{oz} / \mathrm{yd}^{2}\right)\end{array}$} & \multirow[b]{2}{*}{$\begin{array}{l}\text { FVF } \\
(\%)\end{array}$} & \multirow{2}{*}{\begin{tabular}{|c|}
$\begin{array}{c}\text { FVF- } \\
X\end{array}$ \\
$(\%)$ \\
\end{tabular}} & \multirow{2}{*}{$\begin{array}{l}\text { Peak } \\
\text { Load } \\
\text { (kips) }\end{array}$} & \multirow{2}{*}{$\begin{array}{c}\text { Strain at } \\
\text { Peak } \\
\text { Load } \\
(\mu \varepsilon)\end{array}$} & \multirow{2}{*}{$\begin{array}{l}\text { Stress } \\
\text { at Peak } \\
\text { Load } \\
\text { (ksi) }\end{array}$} & \multirow{2}{*}{$\begin{array}{c}\text { Load at } \\
\text { F.Slope } \\
\text { (kips) }\end{array}$} & \multirow{2}{*}{$\begin{array}{c}\text { Strain at } \\
\text { F.Slope } \\
(\mu \varepsilon)\end{array}$} & \multirow{2}{*}{$\begin{array}{c}\text { Stress at } \\
\text { F.Slope } \\
\text { (ksi) }\end{array}$} & \multirow[b]{2}{*}{$\begin{array}{l}E \alpha \\
\text { (msi) }\end{array}$} & \multirow[b]{2}{*}{$\begin{array}{c}E \beta \\
\text { (msi) }\end{array}$} & \multirow[b]{2}{*}{$E \alpha / E \beta$} \\
\hline & & & & & & & & & & & & & \\
\hline 61 & Quad & & & & 6.20 & 9595.00 & 24.50 & 2.20 & 2691.00 & 8.50 & 3.22 & 2.29 & 1.41 \\
\hline 62 & $0 / 45 / 90 /-45$ & & & & 6.40 & 9341.00 & 25.90 & 2.40 & 2888.00 & 9.70 & 3.34 & 2.47 & 1.35 \\
\hline 64 & with CSM & 26 & & & 6.90 & 10931.00 & 27.40 & 2.10 & 2684.00 & 8.30 & 3.13 & 2.28 & 1.37 \\
\hline \multirow[t]{3}{*}{65} & & & 55 & 25 & 6.70 & 10436.00 & 26.50 & 2.20 & 3075.00 & 8.80 & 2.92 & 2.50 & 1.17 \\
\hline & & AVG & & & 6.55 & 10075.75 & 26.08 & 2.23 & 2834.50 & 8.83 & 3.15 & 2.39 & 1.32 \\
\hline & & STDEV & & & 0.31 & 737.61 & 1.22 & 0.13 & 186.14 & 0.62 & 0.18 & 0.12 & 0.11 \\
\hline
\end{tabular}

Points to be noted:

Quadri-directional without CSM

Fabric Construction: 0 0/90/45/-45/csm, csm/-45/45/90/0, csm/-45/45/90/0, csm/-45/45/90/0 (not symmetric)

FVF: $55 \%$

Average peak stress: $26.08 \mathrm{ksi}$

Average peak strain: $10075 \mu \varepsilon$

Average stiffness: $3.15 \mathrm{msi}$.

Ratio in change of slope: 1.32 


\subsubsection{Summary}

It is seen from Table 4.4 that quadri-directional composites have bilinear slopes similar to uni-/bi-directional composites. However the maximum stress in uni- and bi- directional composite is about $64 \mathrm{ksi}$ and $57 \mathrm{ksi}$ respectively, but quadridirectional one has only $26 \mathrm{ksi}$. This is because of the stress concentration factor due to criss crossing of fibers which is more in quadri- compared to uni-/bidirectional fabrics. Moreover the the $90^{\circ}$ and $45^{\circ}$ fibers are not effective in taking more loads under tensile loading due to edge effects developed by cutting. Similarly the strain in quadri- directional one is as low as tri-directional composites. The change of slope is at about $34 \%$ of maximum stress wherein micro cracking or matrix softening would have occurred. The ratio of change of first versus second slope is 1.32 .

\subsubsection{Multi-directional Composites}

Multi-directional composites having fabric construction of CSM, rovings and $0^{\circ} / 90^{\circ}$ fabric (Refer Table 2.1) with two different resin systems was supplied by BRP Inc.. The two resin systems are polyurethane and vinylester. A typical stress vs strain curve for multi-directional composite with polyurethane and vinylester are shown in Figure 4.12 and 4.13 respectively. We can observe from Figure 4.14, that stress vs strain behavior of a composite with polyurethane resin is linear until peak stress, while stress strain curve for vinylester resin based composites has a bilinear curve (Figure 4.15). Details of maximum stress, maximum strain, and stiffness are provided in Table 4.5. The maximum stresses for both resin system are about $62 \sim 68 \mathrm{ksi}$. The maximum strain of polyurethane is about $26 \%$ lesser than that of vinylester resin system. With respect to stiffness, composite with polyurethane resin is higher than that of vinylester because of higher fiber volume fraction. 


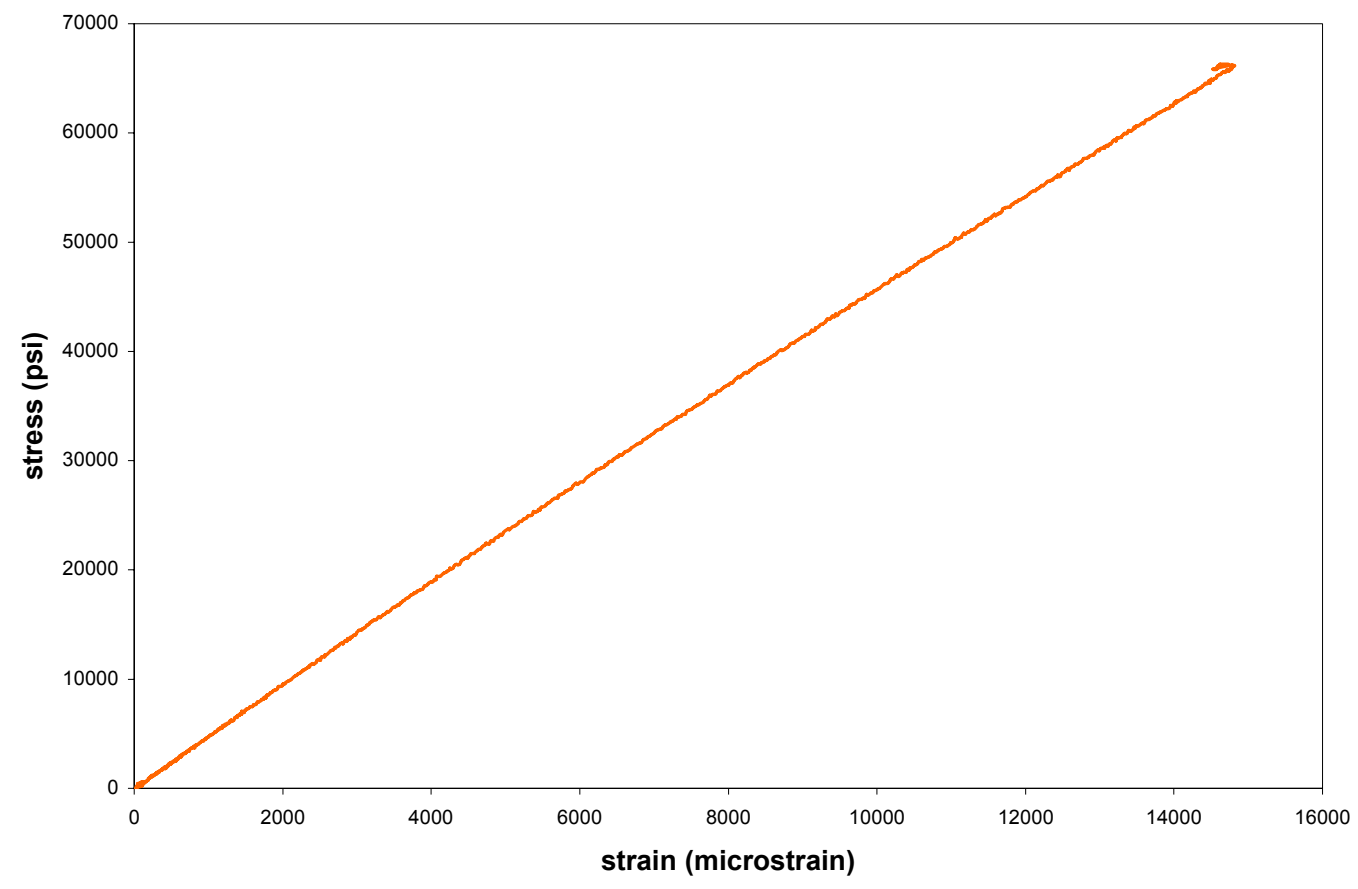

Figure 4.12 Typical Stress-Strain Curve for Multi-directional Composite with Polyurethane System (Sample 75)

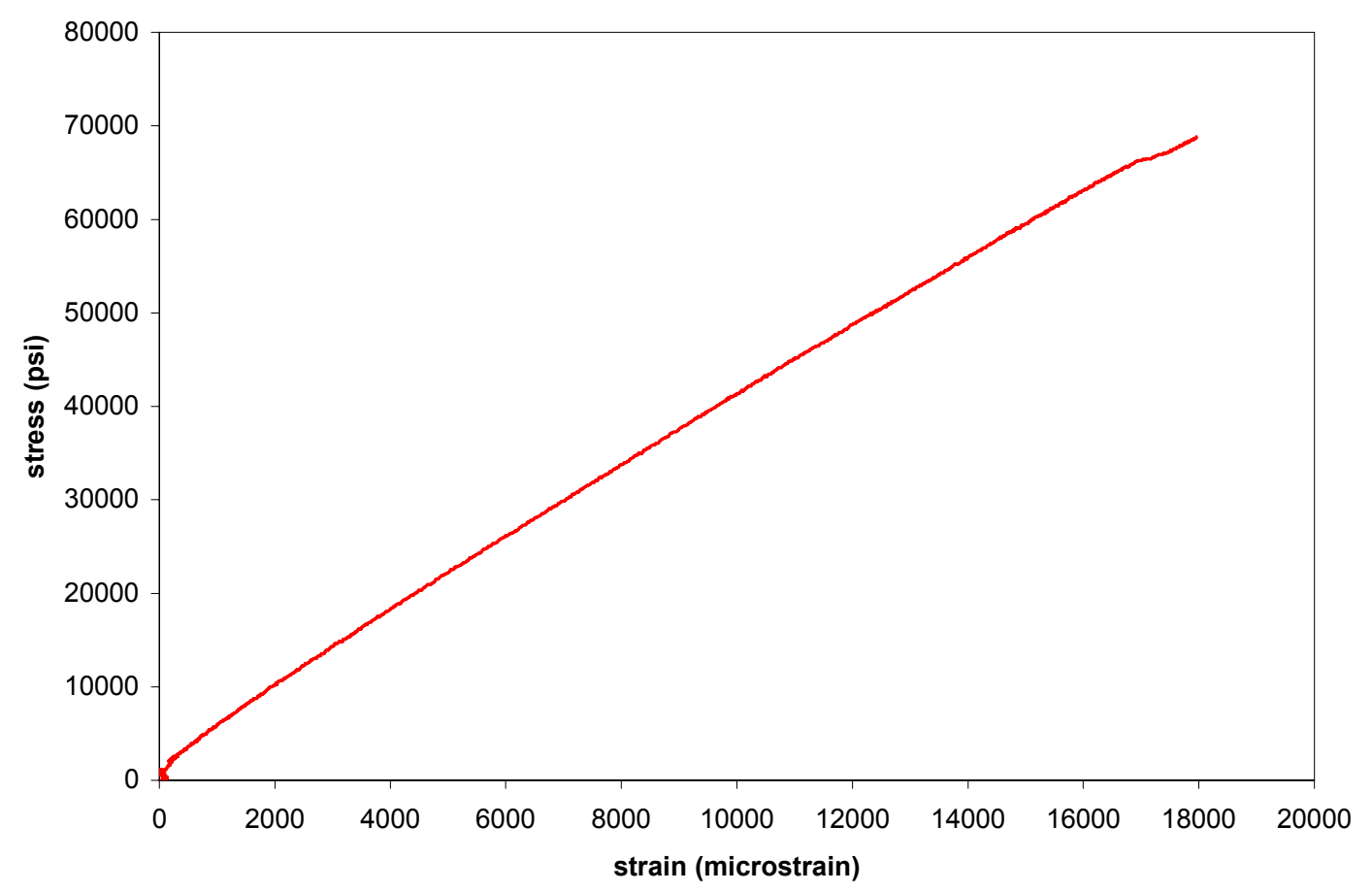

Figure 4.13 Typical Stress-Strain Curve for Multi-directional Composite with Vinylester System (Sample 85) 


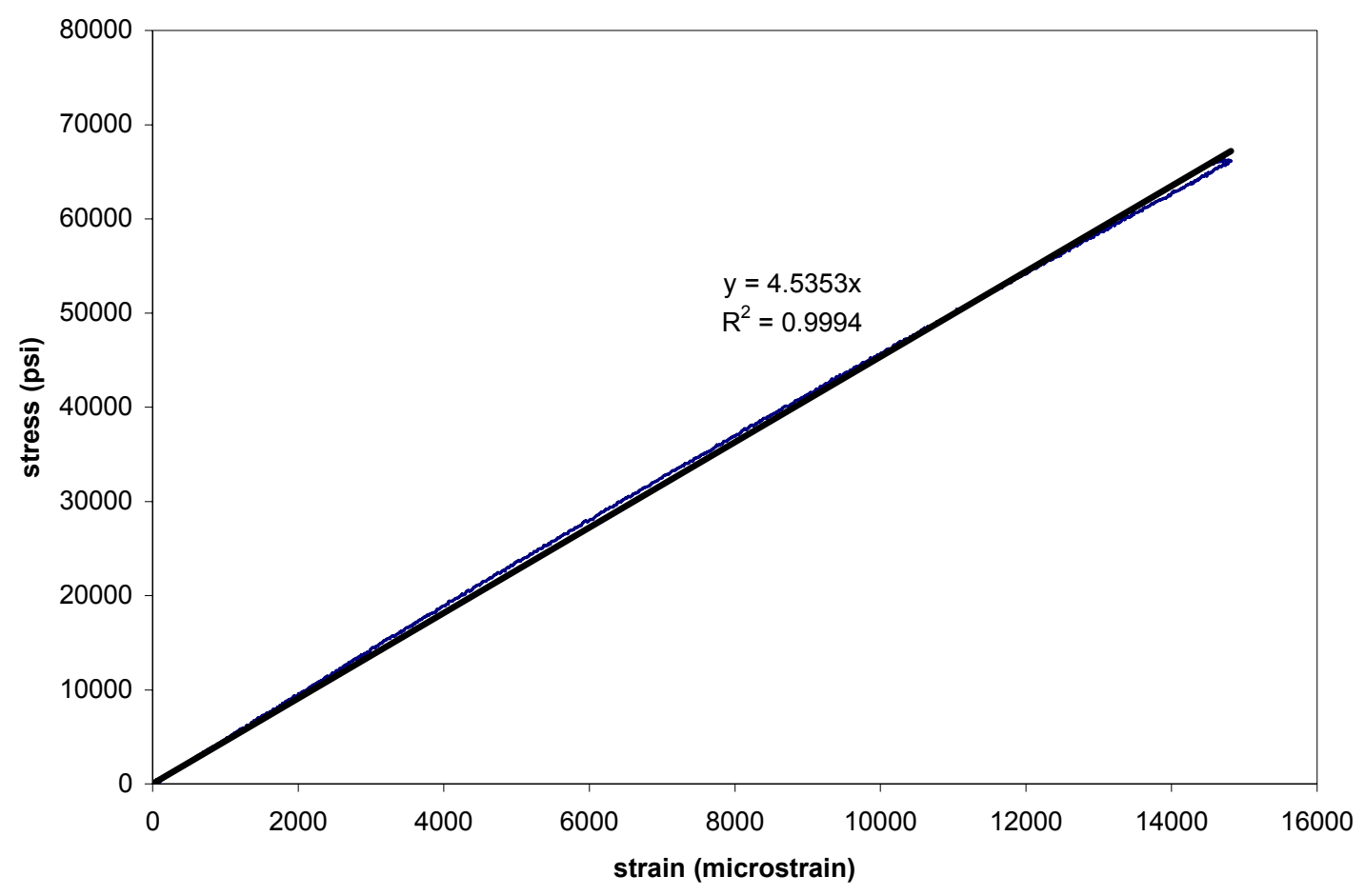

Figure 4.14 Stress-Strain curve for Polyurethane System (Sample 75)

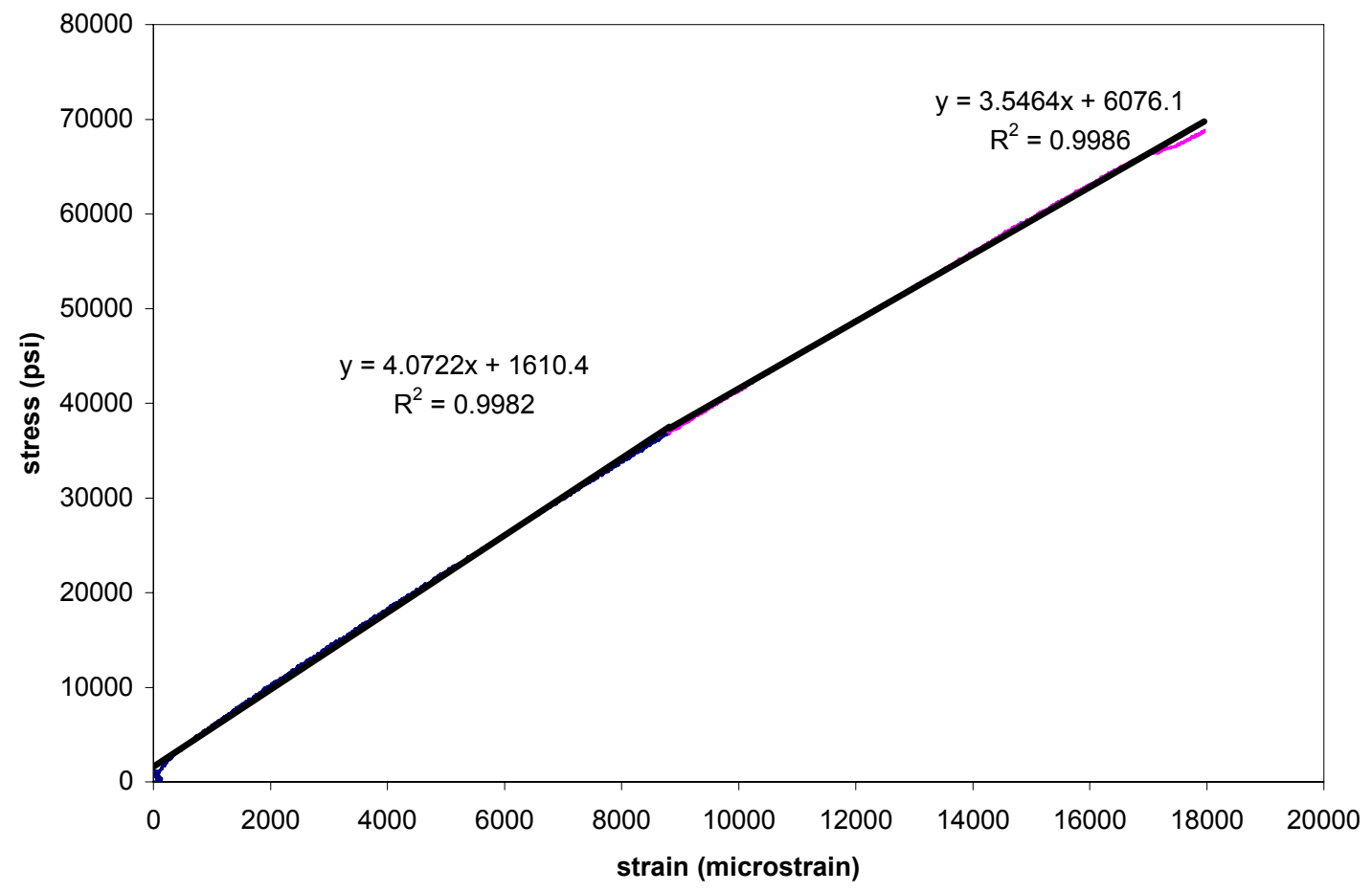

Figure 4.15 Stress-Strain Curve with Bi-linear Slopes for Vinyl ester System (Sample 85) 
Table 4.5 Structural Properties of Multi-directional Composites

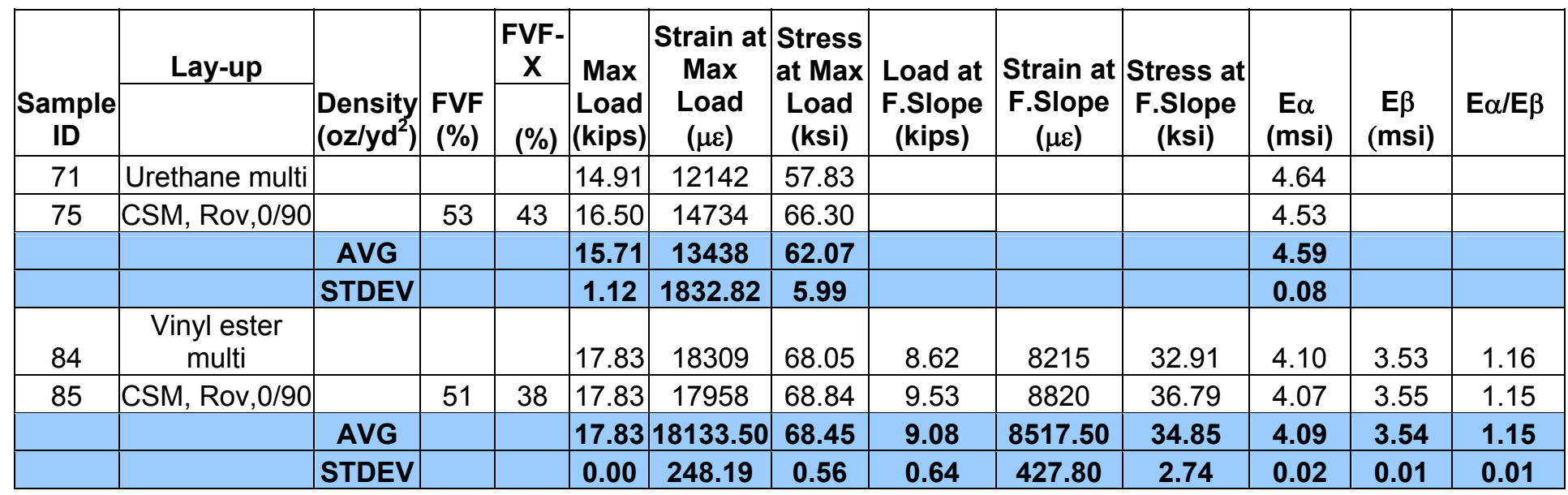

\section{Points to be noted:}

Multi-directional with polyurethane system

Fabric Construction: csm/0/90/rov/csm/rov/csm/rov/0/90/csm

FVF: $53 \%$

Average peak stress: $62.07 \mathrm{ksi}$

Average peak strain: $13438 \mu \varepsilon$

Average stiffness: $4.59 \mathrm{msi}$.

Multi-directional with vinylester system

Fabric Construction: csm/rov/0/90/csm/rov/csm/rov/0/90/csm/rov/csm

FVF: $51 \%$

Average peak stress: $68.45 \mathrm{ksi}$

Average peak strain: $18133 \mu \varepsilon$

Average stiffness: $4.09 \mathrm{msi}$.

\subsubsection{Summary:}

It is seen from Figures 4.14 and 4.15 that multi-directional composites with polyurethane has linear slope up to maximum stress while vinyl ester systems has bilinear slopes. There is no significant different in maximum stress between polyurethane $(62 \mathrm{ksi})$ and vinyl ester system (68 ksi). With regards to strain, the maximum bending strain of polyurethane resin system is about $38 \%$ less than vinylester resin because the vinyl ester resin used herein is called as high 
elongation resin which must be hybrid of epoxy and urethane resins. In vinylester resin system, the change of slope is at about $50 \%$ of maximum stress. The ratio of change of first and second slope is 1.15 .

\subsection{Bending Test Results}

Calculation of bending strength and stiffness is based on four-point bending tests with 3 equal span segments.

Bending modulus (based on stress-strain curve): $E_{x}^{B}=\frac{23 L^{3} m}{108 b d^{3}}$

Bending Modulus (based on load-deflection curve): $\mathrm{E}_{x}^{\mathrm{B}}=\frac{23 \mathrm{PL}^{3}}{108 \mathrm{~b} \delta \mathrm{d}^{3}} \mathrm{psi}$

The flexural strength, is given by $\sigma_{\mathrm{ult}}=\frac{\mathrm{PL}}{\mathrm{bd}^{2}}$, for rectangular section with 3-equal load span segments.

where, $\mathrm{P}$ is the maximum load.

$\mathrm{m}=\mathrm{P} / \delta=$ Slope of Elastic Zone of Load Vs Deflection curve

$L=$ Span Length of the specimen (in)

$\mathrm{L} 1=\mathrm{L} 2=\mathrm{L} / 3=$ Load Span (in)

$\mathrm{b}=$ Width of specimen (in)

$d=$ Thickness of the specimen (in)

Over 100 specimens of different fiber architectures were tested in longitudinal direction under four-point bending test. The fiber-layup, density, FVF and thickness of test specimens are same as those of tension specimens (Table 2.1). From each batch of specimen, about 7 specimens were tested without strain gages and 6 specimens with gages so as to evaluate the structural properties based on load-deflection and stress-strain curves to compare the consistency of the test results. 


\subsubsection{Uni-directional Composites}

Typical load vs deflection and stress-strain curves for unidirectional composites under four-point bending are shown in Figure 4.16 and Figure 4.17 respectively. It is evident from Figure 4.18 and Figure 4.19 that the load-deflection and stressstrain curve are tri-linear. In case of load-deflection curve, the linear slope was taken to find the bending stiffness by converting load to engineering stress. Details of stress, strain and stiffness are tabulated in Table 4.6.

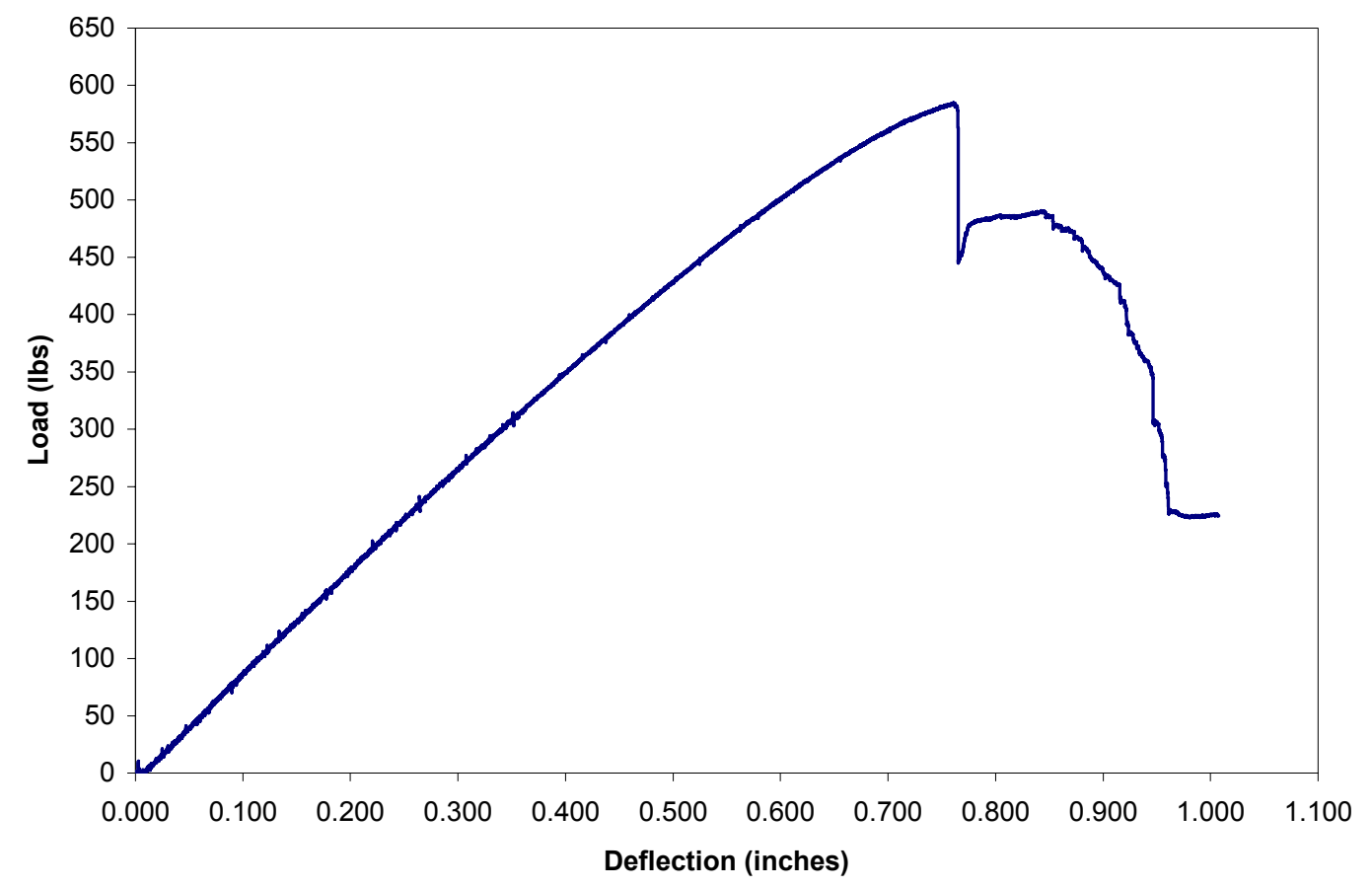

Figure 4.16 Typical Load-Deflection Curve for Unidirectional Composites (Sample 12) 


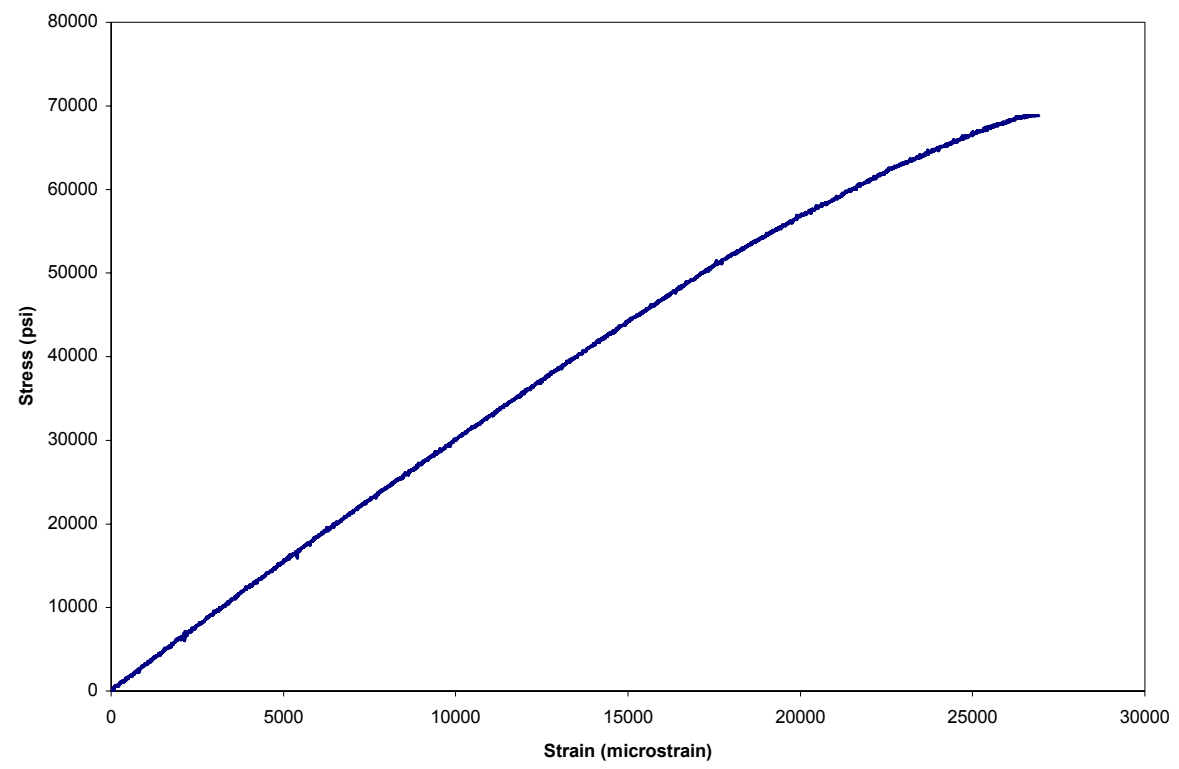

Figure 4.17 Typical Stress-Strain Curve for Unidirectional Composites (Sample 111)

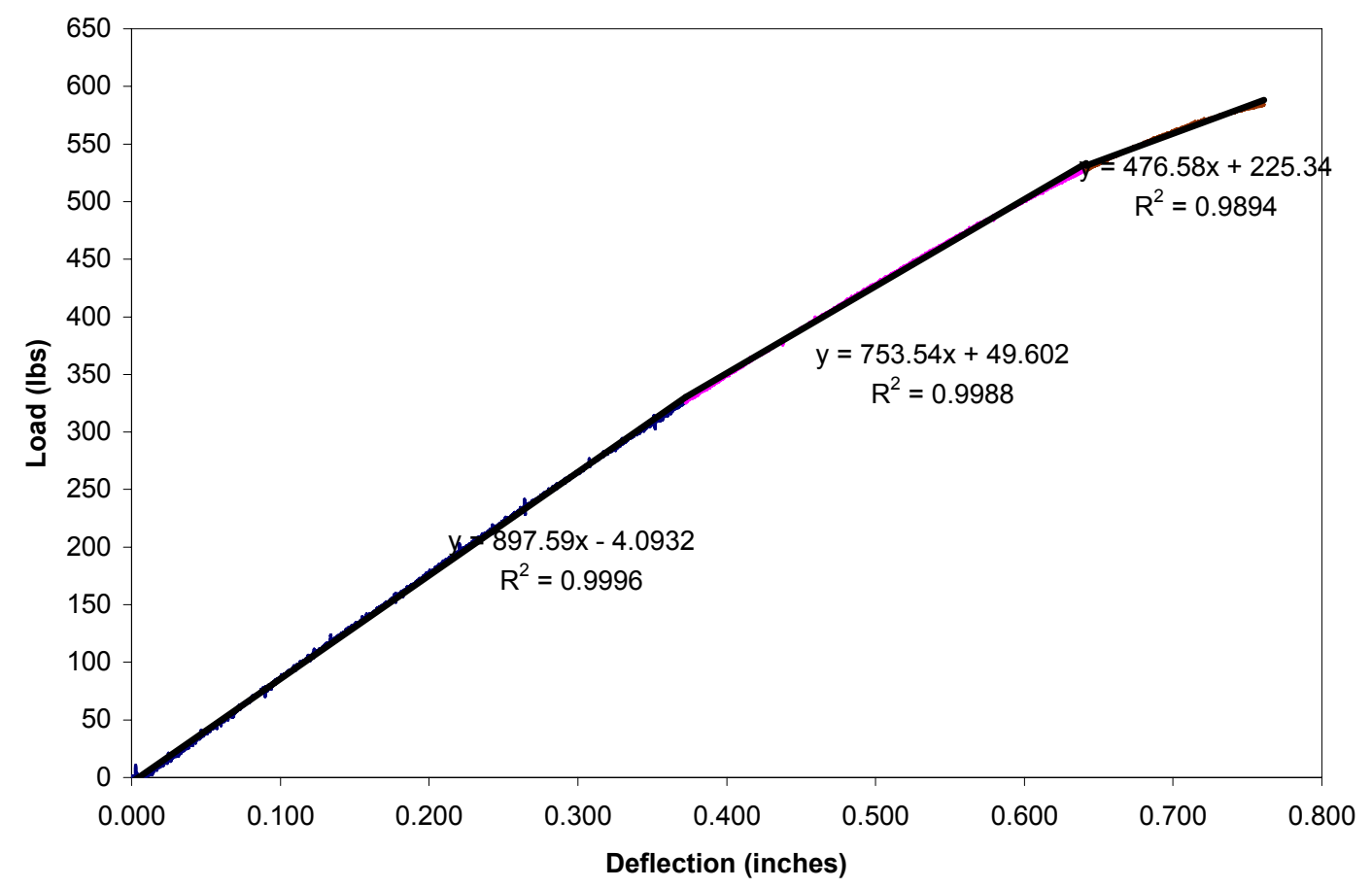

Figure 4.18 Load-Deflection Curve with Tri-linear Slopes for Uni-directional Composites (Sample 12) 


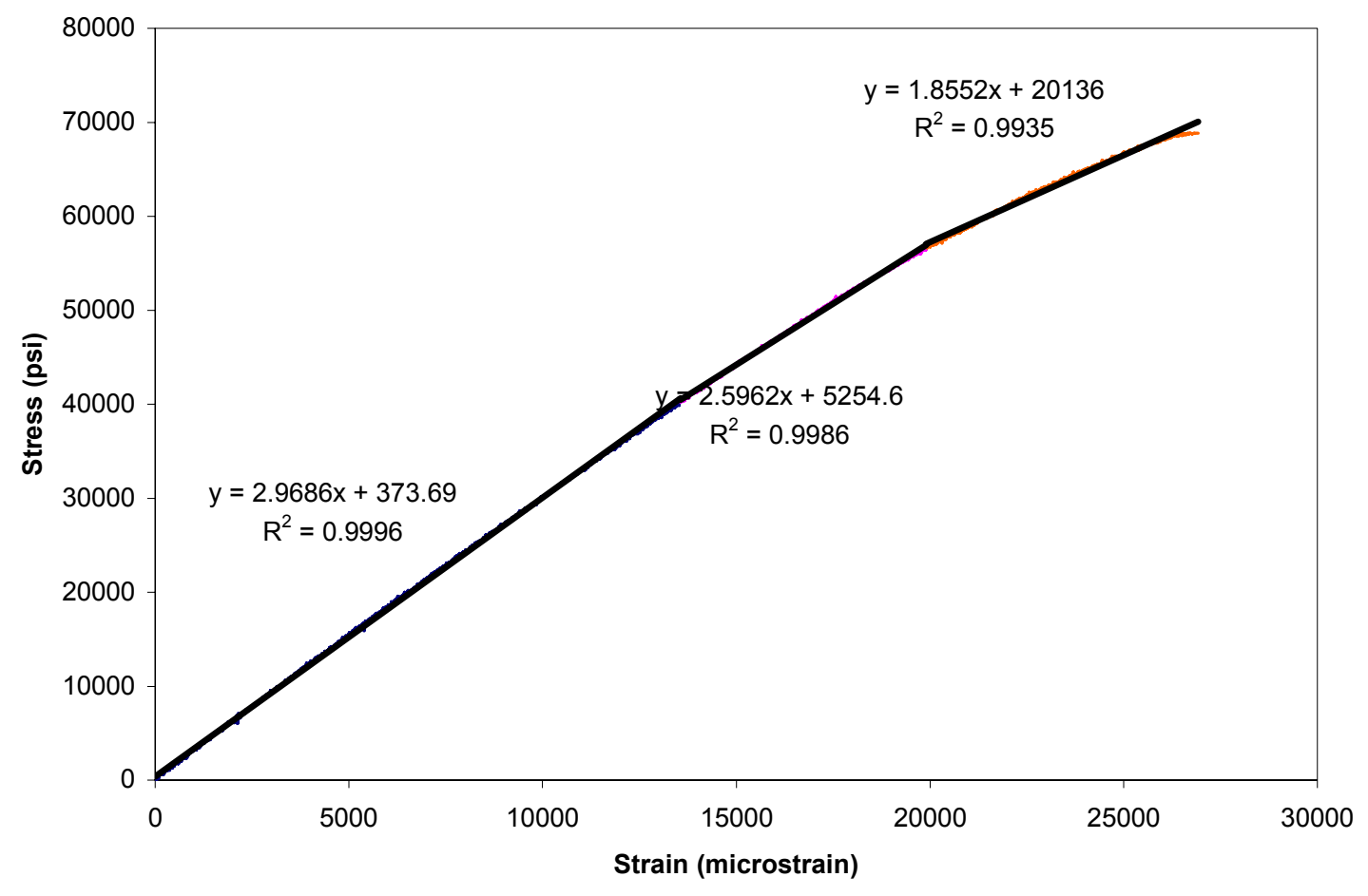

Figure 4.19 Stress-Strain Curve with Tri-linear Slopes for Uni-directional Composites (Sample 111)

From Table 4.6 it is observed that stress, strain and stiffness of the unidirectional composites belonging to Specimen ID No: 1 and 2 (Table 2.1) are same because both groups have same FVF. The maximum average stress is about $70 \mathrm{ksi}$ and the maximum strain is about 25,000 microstrain. 
Table 4.6 Structural Properties of Unidirectional Composites

\begin{tabular}{|c|c|c|c|c|c|c|c|c|c|c|c|c|c|c|c|c|}
\hline Sample ID & $\frac{\text { Lay-up }}{\text { (FA) }}$ & Density & $\begin{array}{l}\text { FVF } \\
(\%)\end{array}$ & \begin{tabular}{|c|} 
FVF-X \\
$\mathbf{( \% )}$
\end{tabular} & $\begin{array}{c}\text { Max } \\
\text { Load } \\
\text { (Ibs) }\end{array}$ & $\begin{array}{c}\text { Strain at } \\
\text { Max Load } \\
(\mu \varepsilon)\end{array}$ & $\begin{array}{c}\text { Stress at } \\
\text { Max Load } \\
\text { (ksi) }\end{array}$ & $\begin{array}{c}\text { Strain at } \\
\text { F.slope } \\
(\mu \varepsilon)\end{array}$ & $\begin{array}{l}\text { Stress at } \\
\text { F.slope } \\
\text { (ksi) }\end{array}$ & $\begin{array}{l}\text { Strain at } \\
\text { S. Bif. }(\mu \varepsilon)\end{array}$ & $\begin{array}{c}\text { Stress at } \\
\text { S.Bif } \\
\text { (ksi) }\end{array}$ & $\begin{array}{c}E \alpha \\
(m s i)\end{array}$ & $\begin{array}{c}E \beta \\
(m s i)\end{array}$ & $\begin{array}{c}\mathrm{E} \gamma \\
(\mathrm{msi})\end{array}$ & $E \alpha / E \beta$ & $\mathrm{E} \beta / \mathrm{E} \gamma$ \\
\hline 11 & Unidirectional & & & & 607 & 26706 & 71.79 & 10660 & 34.07 & 19655 & 58.96 & 3.41 & 2.88 & 1.93 & 1.18 & 1.49 \\
\hline 12 & with CSM & & & & 585 & 25319 & 68.89 & 12384 & 38.35 & 21346 & 62.1 & 3.17 & 2.66 & 1.68 & 1.19 & 1.58 \\
\hline 13 & & & & & 604 & 25413 & 69.57 & 11203 & 35.03 & 19635 & 58.15 & 3.33 & 2.92 & 2.08 & 1.14 & 1.40 \\
\hline 14 & & & & & 617 & 24975 & 70.19 & 13455 & 42.03 & 21888 & 63.96 & 3.32 & 2.72 & 2.02 & 1.22 & 1.34 \\
\hline 15 & & & & & 628 & 27412 & 71.43 & 11197 & 33.12 & 21346 & 59.79 & 3.19 & 2.74 & 1.99 & 1.16 & 1.38 \\
\hline 16 & & & & & 631 & 25641 & 71.78 & 11197 & 35.45 & 20219 & 60.37 & 3.34 & 2.87 & 2.17 & 1.16 & 1.33 \\
\hline 17 & & & & & 590 & 27097 & 65.59 & 11220 & 31 & 21369 & 55.65 & 3.04 & 2.61 & 1.87 & 1.17 & 1.39 \\
\hline 19 & & & & & 587 & 25416 & 68 & 14813 & 41.3 & 21545 & 59.2 & 2.80 & 2.57 & 2.27 & 1.09 & 1.13 \\
\hline 110 & & & & & 612 & 29435 & 70.2 & 14763 & 41.4 & 23542 & 62.5 & 2.79 & 2.42 & 1.42 & 1.15 & 1.70 \\
\hline 111 & & & & & 572 & 26924 & 68.9 & 13566 & 40.2 & 19899 & 56.9 & 2.97 & 2.59 & 1.86 & 1.15 & 1.39 \\
\hline \multirow{2}{*}{112} & & AVE & & & 603.7 & 26566.4 & 70.0 & 12439.8 & 37.3 & 21114.4 & 60.1 & 3.1 & 2.7 & 1.9 & 1.2 & 1.4 \\
\hline & & STD & & & 18.5 & 1368.5 & 2.1 & 1503.6 & 3.8 & 1180.5 & 2.7 & 0.2 & 0.2 & 0.2 & 0.0 & 0.2 \\
\hline 22 & Unidirectional & & & & 516 & 22428 & 61.93 & 10344 & 31.44 & 19425 & 55.72 & 3.53 & 3.01 & 2.29 & 1.17 & 1.31 \\
\hline 23 & with CSM & & & & 566 & 20753 & 73.43 & 9704 & 37.64 & 16235 & 60.36 & 4.15 & 3.62 & 3.04 & 1.15 & 1.19 \\
\hline 25 & & & & & 598 & 23385 & 81.99 & 9832 & 38.8 & 16580 & 63.31 & 3.92 & 3.49 & 2.68 & 1.12 & 1.30 \\
\hline 26 & & & & & 591 & 24948 & 76.62 & 10783 & 36.57 & 17271 & 57.09 & 3.79 & 3.34 & 2.69 & 1.13 & 1.24 \\
\hline 28 & & & & & 491 & 29248 & 65.2 & 11540 & 30.8 & 23627 & 57.3 & 2.67 & 2.22 & 1.51 & 1.20 & 1.47 \\
\hline 29 & & & & & 525 & 28897 & 68.2 & 11120 & 30.6 & 21858 & 55.7 & 2.74 & 2.35 & 1.75 & 1.17 & 1.34 \\
\hline 210 & & & & & 481 & 22449 & 62.3 & 10911 & 32.9 & 20063 & 57.1 & 3.04 & 2.64 & 2.22 & 1.15 & 1.19 \\
\hline \multirow[t]{3}{*}{212} & & & 45 & 35 & 505 & 30264 & 66.1 & 12234 & 31.1 & 24019 & 55.2 & 2.55 & 2.07 & 1.70 & 1.23 & 1.22 \\
\hline & & AVE & & & 534.1 & 25296.5 & 69.5 & 10808.5 & 33.7 & 19884.8 & 57.7 & 3.3 & 2.8 & 2.2 & 1.2 & 1.3 \\
\hline & & STD & & & 45.2 & 3664.7 & 7.2 & 850.6 & 3.4 & 3077.7 & 2.8 & 0.6 & 0.6 & 0.5 & 0.0 & 0.1 \\
\hline
\end{tabular}




\section{Points to be noted:}

$\underline{\text { Unidirectional }}$

Fabric Construction: CSM/Rov/CSM/Rov/CSM/Rov/CSM

FVF: 45\%

Average peak stress (group 1): $70 \mathrm{ksi}$

Average peak stress (group 2): $69 \mathrm{ksi}$

Average peak strain: (group1): $26566 \mu \varepsilon$

Average peak strain (group2): $25296 \mu \varepsilon$

Average stiffness: (group 1): $3.1 \mathrm{msi}$.

Average stiffness (group 2): $3.3 \mathrm{msi}$

Average ratio in change of first slope to second slope (group 1): 1.2 Average ratio in change of first slope to second slope (group 2): 1.2 Average ratio in change of second slope to third slope (group 1): 1.4 Average ratio in change of second slope to first slope (group 2): 1.3

Summary: From Figures 4.18 and 4.19 it is observed that unidirectional composites have tri-linear curve. The first change of slope is at about $50 \%$ of maximum stress (indiacation of micro delam) and second change of slope is at about $80 \%$ (indication of cracking of fibers) of maximum stress. The ratio of change of first and second slope is 1.2 which is close to the response under tension. The ratio of second and third slope is about 1.4. The stiffness is in the range of $3.1-3.3 \mathrm{msi}$. 


\subsubsection{Bi-directional Composites}

Typical load-deflection and stress-strain curves for bi-directional composites under four-point bending are shown in Figures 4.20 and 4.21 respectively. It is evident from Figures 4.22 and 4.23 that the load-deflection and stress-strain curves are not linear up to maximum stress. Details of stress, strain and stiffness are tabulated in Table 4.7. The maximum average stress is about $68 \mathrm{ksi}$ and maximum strain is about 23000 microstrain.

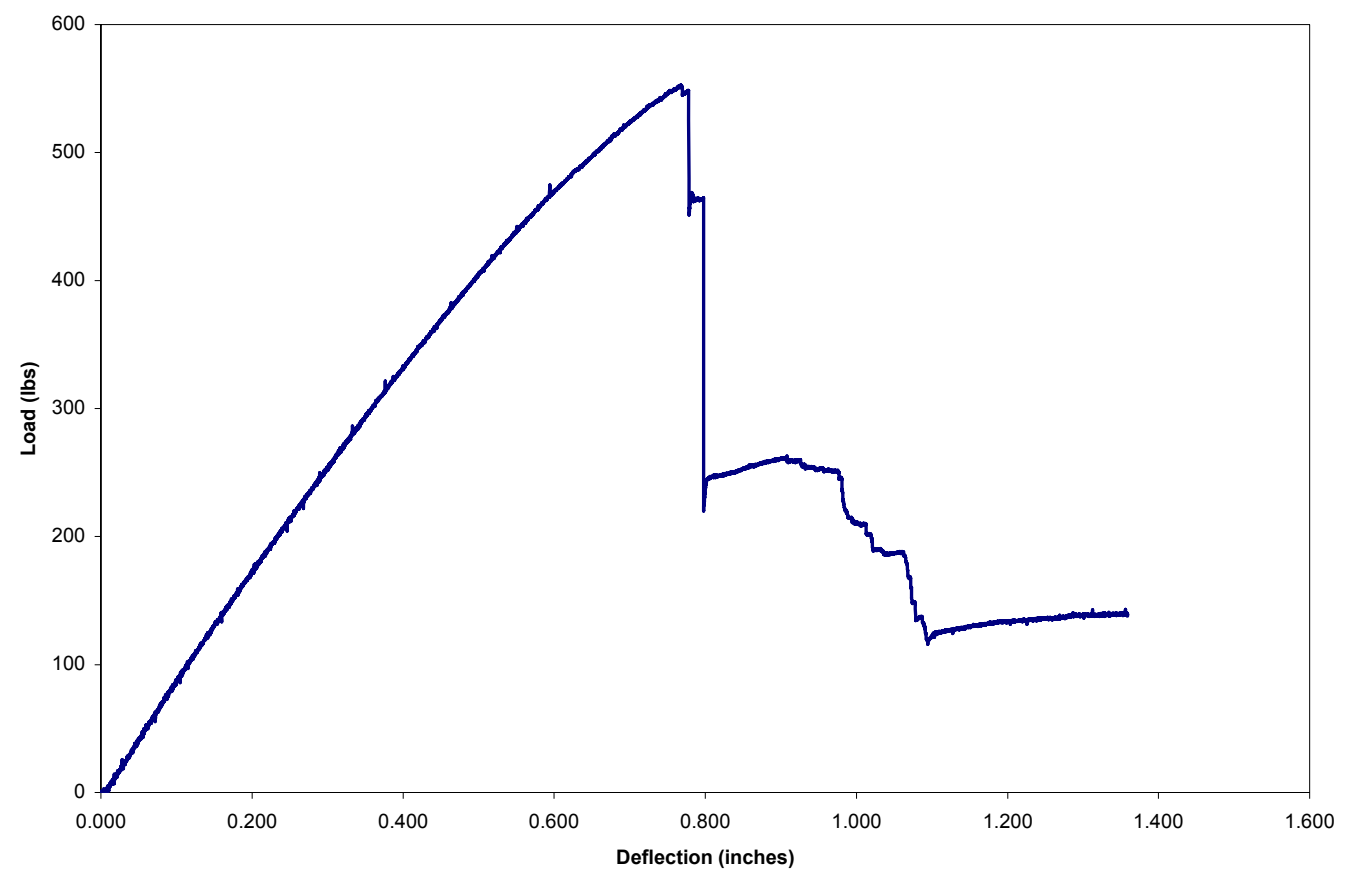

Figure 4.20 Typical Load-deflection Curve for Bidirectional Composites (Sample 34) 


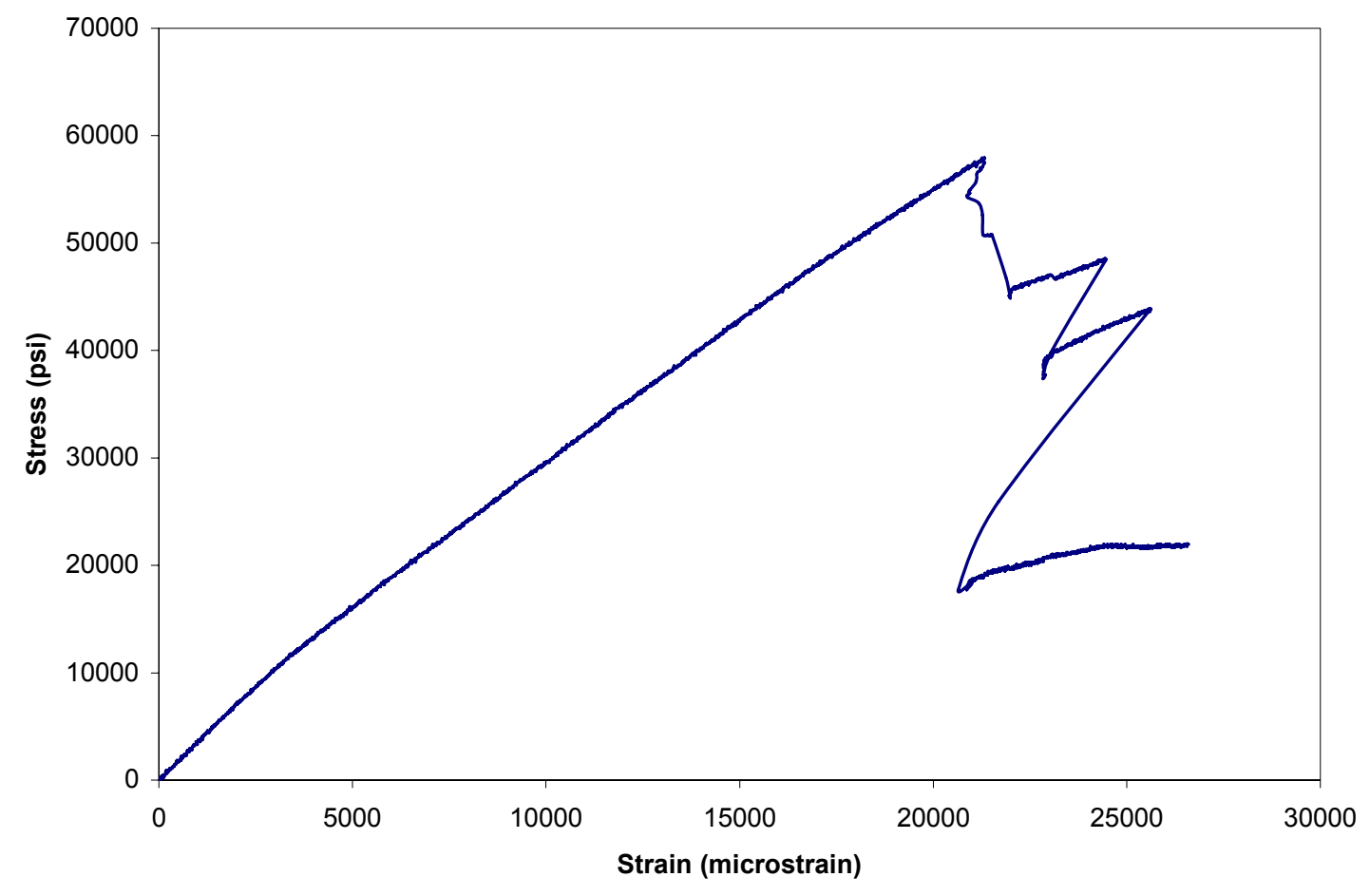

Figure 4.21 Typical Stress-Strain Curve for Bidirectional Composites (Sample 39)

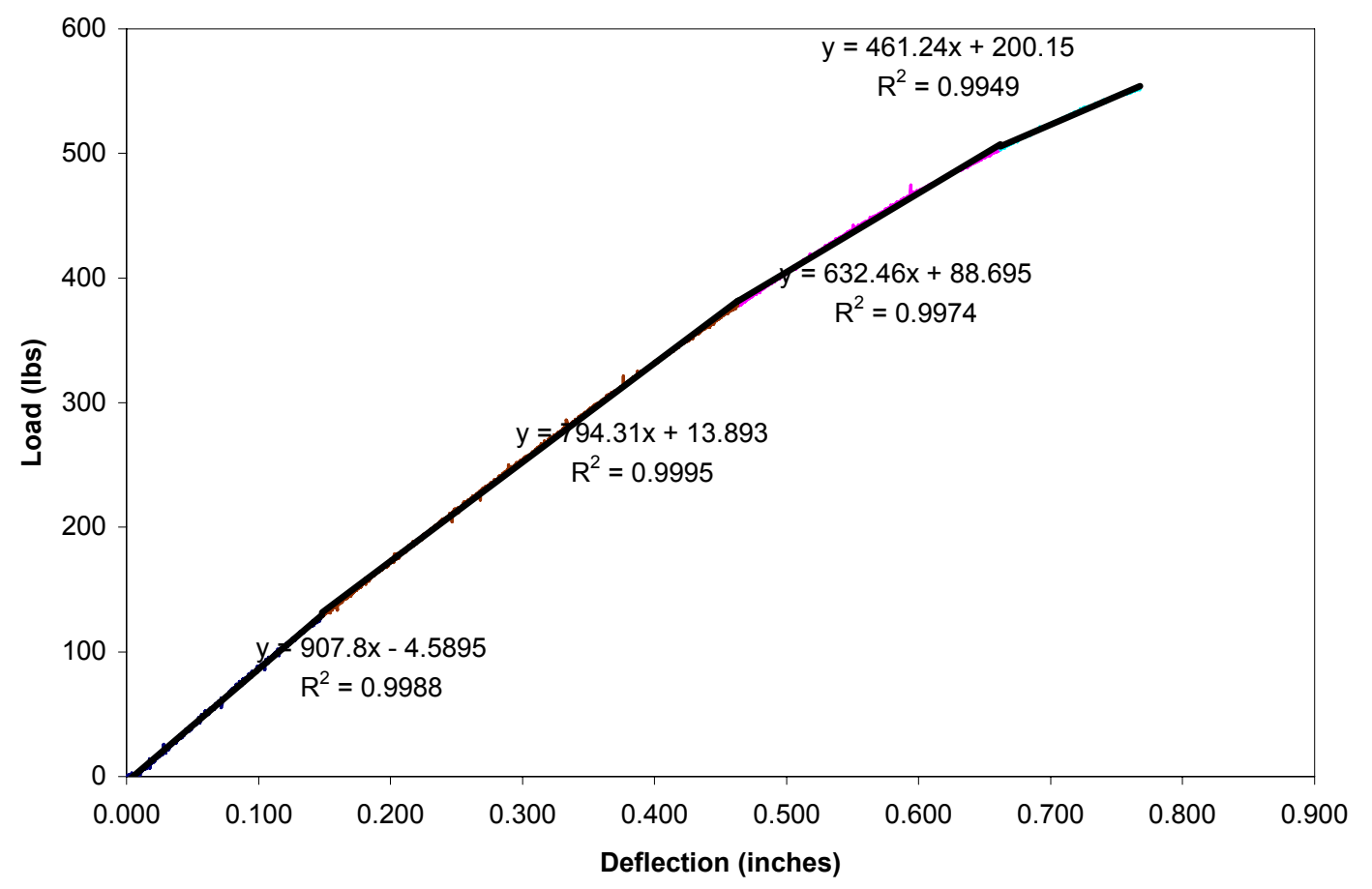

Figure 4.22 Load-deflection Curve with Linear Slopes (Sample 34) 


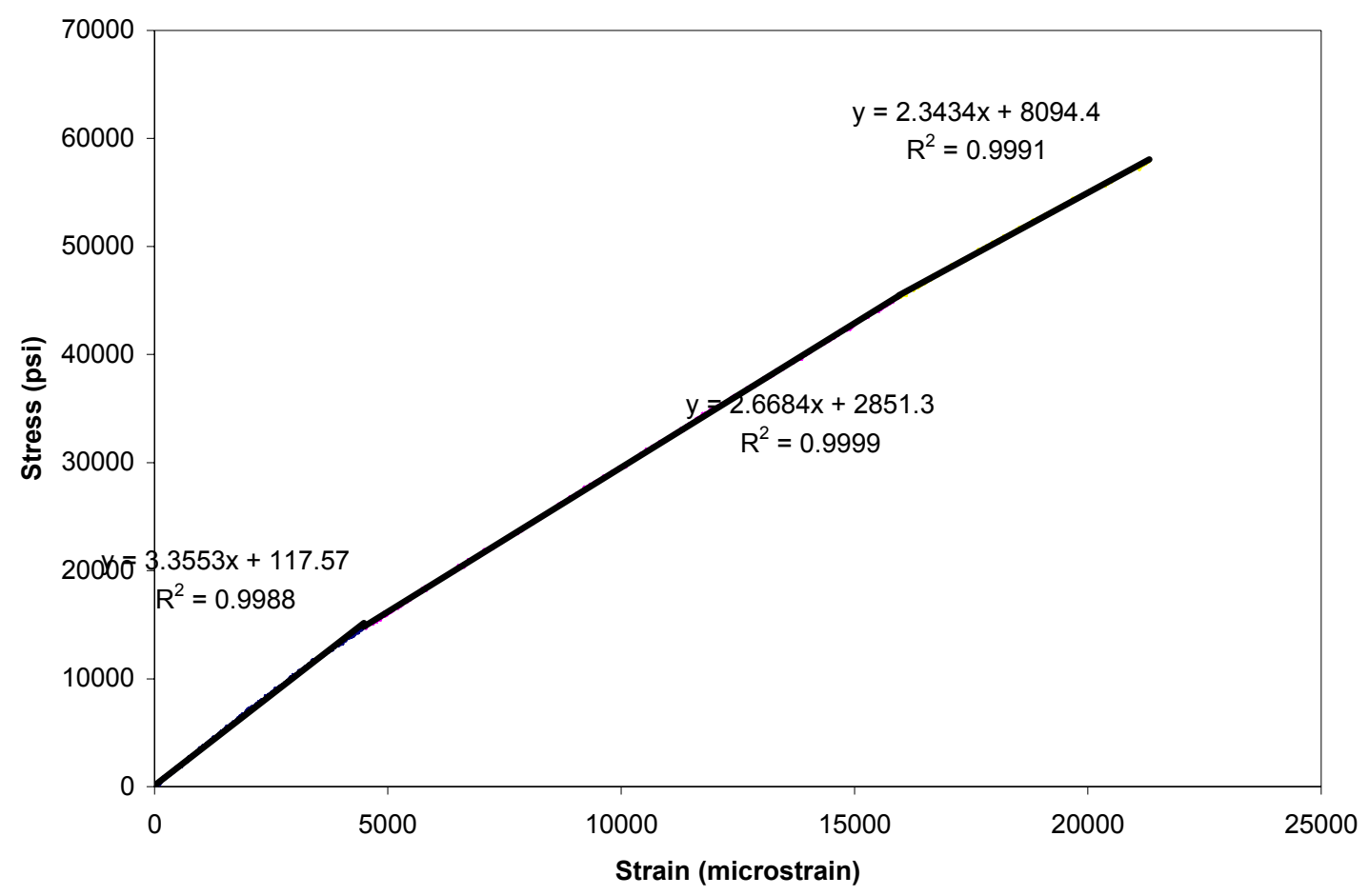

Figure 4.23 Stress-Strain Curve with Linear Slopes (Sample 39)

Summary: It is observed from Table 4.7 that the stress-strain response for bidirectional composites under bending is tri-linear. The change of first, second and third slope is at about $22 \%, 65 \%$ and about $90 \%$ of maximum stress. This indicates that at first change of slope microcracks would have initiated at interface of fiber and resin specifically at crossing points of $0^{\circ}$ and $90^{\circ}$ fibers eventually leading to cracking of $90^{\circ}$ plies at second change of slope and total failure after third change of slope. The ratio of change of first and second slope is close to tension response which is about 1.1. The ratio of second and third change of slope is 1.2 and third to fourth is 1.3 . 
Table 4.7 Structural Properties of Bidirectional Composites

\begin{tabular}{|c|c|c|c|c|c|c|c|c|c|c|c|c|c|c|c|c|c|c|c|c|}
\hline $\begin{array}{c}\text { Sample } \\
\text { I ID }\end{array}$ & \begin{tabular}{|c} 
Lay-up \\
(FA)
\end{tabular} & $\begin{array}{l}\text { Density } \\
\left(\mathrm{oz}^{\prime} \mathrm{yd}^{2}\right)\end{array}$ & $\begin{array}{l}\text { FVF } \\
\text { (\%) }\end{array}$ & $\frac{\text { FVF-X }}{(\%)}$ & $\begin{array}{c}\text { Max } \\
\text { Load } \\
\text { (lbs) }\end{array}$ & $\begin{array}{c}\text { Strain } \\
\text { at Max } \\
\text { Load } \\
(\mu \varepsilon)\end{array}$ & $\begin{array}{c}\text { Stress } \\
\text { at Max } \\
\text { Load } \\
\text { (ksi) }\end{array}$ & $\begin{array}{c}\text { Strain } \\
\text { at } \\
\text { F.slope } \\
(\mu \varepsilon)\end{array}$ & $\begin{array}{c}\text { Stress at } \\
\text { F.slope } \\
\text { (ksi) }\end{array}$ & $\begin{array}{l}\text { Strain at } \\
\text { S. slope } \\
(\mu \varepsilon)\end{array}$ & $\begin{array}{c}\text { Stress } \\
\text { at } \\
\text { S.slope } \\
\text { (ksi) }\end{array}$ & $\begin{array}{c}\text { Strain } \\
\text { at } \mathrm{T} . \\
\text { slope. } \\
(\mu \varepsilon)\end{array}$ & $\begin{array}{l}\text { Stress } \\
\text { at } \\
\text { T.slope } \\
\text { (ksi) }\end{array}$ & $\begin{array}{c}E \alpha \\
\text { (msi) }\end{array}$ & $\begin{array}{c}\mathrm{E} \beta \\
(\mathrm{msi})\end{array}$ & $\begin{array}{c}\mathrm{E} \gamma \\
(\mathrm{msi})\end{array}$ & $\begin{array}{c}E_{\eta} \\
(\mathbf{m s i})\end{array}$ & $\mathrm{E} \alpha / \mathrm{E} \beta$ & $E \beta / E \gamma$ & $\mathrm{E}_{\gamma} / \mathrm{E}_{\eta}$ \\
\hline 32 & \begin{tabular}{|c|}
$\mathrm{Bi}-$ \\
direction \\
al
\end{tabular} & & & & 553 & 22137 & 67.41 & 4285 & 15.01 & 12936 & 43.32 & 19423 & 61.46 & 3.69 & 3.20 & 2.82 & 2.20 & 1.15 & 1.13 & 1.28 \\
\hline 33 & 9 layers & & & & 546 & 21947 & 67.1 & 4016 & 13.7 & 12937 & 43.4 & 18882 & 60.1 & 3.87 & 3.52 & 2.97 & 2.48 & 1.10 & 1.19 & 1.20 \\
\hline 34 & $0 / 90$ & & & & 553 & 25034 & 68.9 & 4826 & 16.1 & 12936 & 41.1 & 21585 & 62.7 & 3.70 & 3.24 & 2.58 & 1.88 & 1.14 & 1.26 & 1.37 \\
\hline 35 & & & & & 556 & 21669 & 74.3 & 3842 & 16 & 12416 & 47.2 & 17622 & 63.9 & 3.98 & 3.45 & 3.04 & 2.47 & 1.15 & 1.14 & 1.23 \\
\hline 36 & & & & & 604 & 25522 & 74.4 & 4152 & 14.8 & 13304 & 44.2 & 20708 & 65.2 & 3.85 & 3.42 & 2.99 & 1.94 & 1.12 & 1.14 & 1.54 \\
\hline 37 & & 24 & 52 & 26 & 547 & 22270 & 68.2 & 4324 & 14.9 & 13401 & 44.9 & 18355 & 59.3 & 3.79 & 3.47 & 2.97 & 2.37 & 1.09 & 1.17 & 1.25 \\
\hline \multirow[t]{3}{*}{39} & & & & & 433 & 21319 & 57.94 & 4486 & 14.7 & 15956 & 45.27 & & & 3.36 & 2.67 & 2.34 & & 1.26 & 1.14 & \\
\hline & & & AVE & & 541.7 & 22842.6 & 68.3 & 4275.9 & 15.0 & 13412.3 & 44.2 & 19429.2 & 62.1 & 3.8 & 3.4 & 2.9 & 2.2 & 1.1 & 1.2 & 1.3 \\
\hline & & & STD & & 52.0 & 1698.4 & 5.5 & 321.5 & 0.8 & 1165.8 & 1.9 & 1483.4 & 2.3 & 0.1 & 0.1 & 0.2 & 0.3 & 0.0 & 0.0 & 0.1 \\
\hline
\end{tabular}

\section{Points to be noted:}

Bi-directional

Fabric Construction: 0/90, 0/90, 0/90, 0/90, 0/90, 0/90, 0/90, 0/90, 0/90 (not symmetric)

FVF: $52 \%$

Average peak stress: $68.3 \mathrm{ksi}$

Average peak strain: $22960 \mu \varepsilon$

Average stiffness: $3.8 \mathrm{msi}$.

Ratio in change of first slope to second slope: 1.1

Ratio in change of second slope to third slope: 1.2 ; Ratio in change of third slope to fourth slope: 1.3 


\subsubsection{Tri-directional Composites}

Typical load-deflection and stress-strain curves for tri-directional composites without CSM are shown in Figures 4.24 and 4.25 respectively. It is evident from Figures 4.26 and 4.27 that the load-deflection and stress-strain curve is not linear up to peak stress. Figures 4.28 and 4.29 represent load-deflection and stressstrain curves for tri-directional composites with CSM. The curve is not linear up to peak stress (Figure 4.30 and Figure 4.31). Details of stress, strain and stiffness for tri-directional composites without and with CSM are tabulated in Table 4.8.

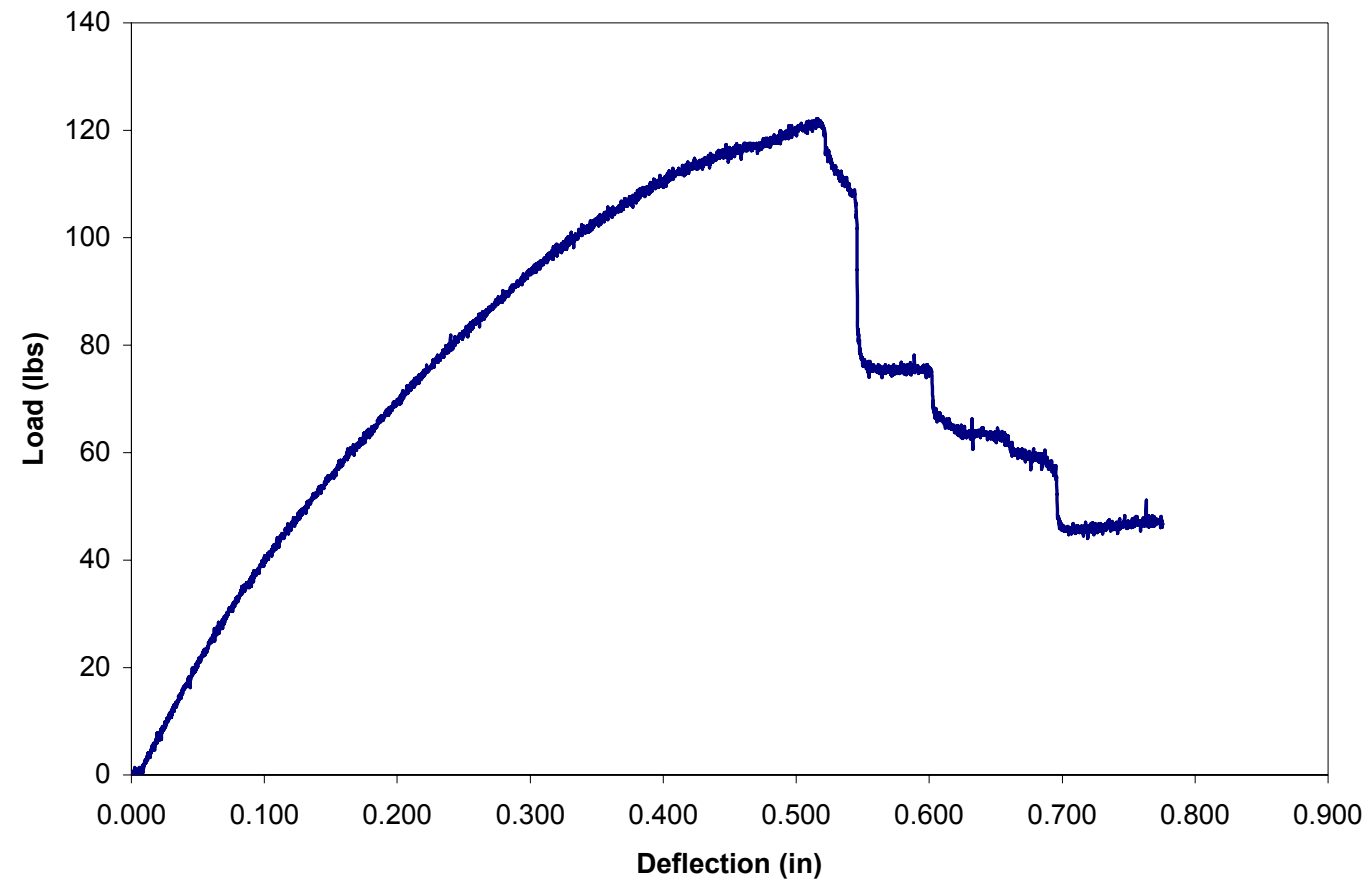

Figure 4.24 Typical Load-deflection Curve for Tri-directional Composites without CSM 


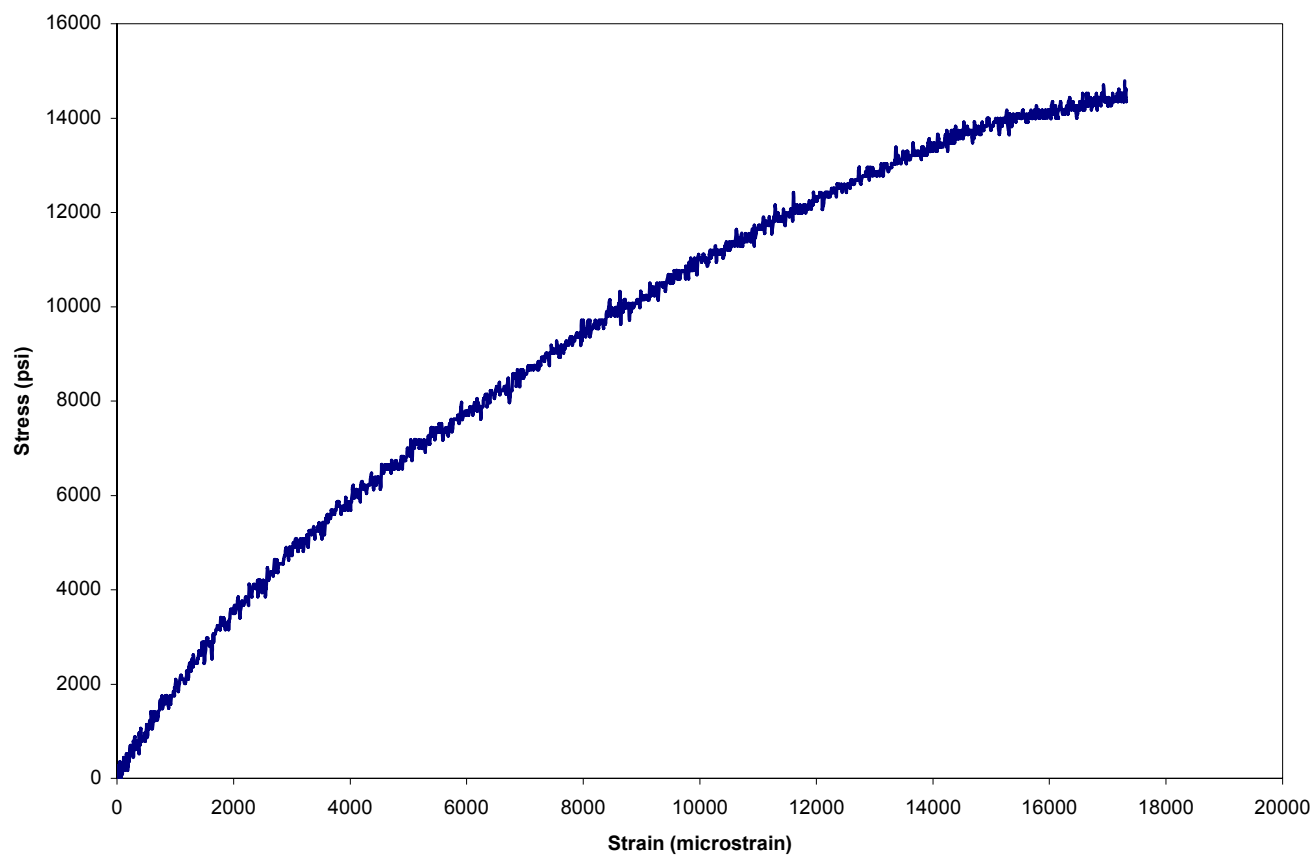

Figure 4.25 Typical Stress-Strain Curve for Tri-directional Composites without CSM

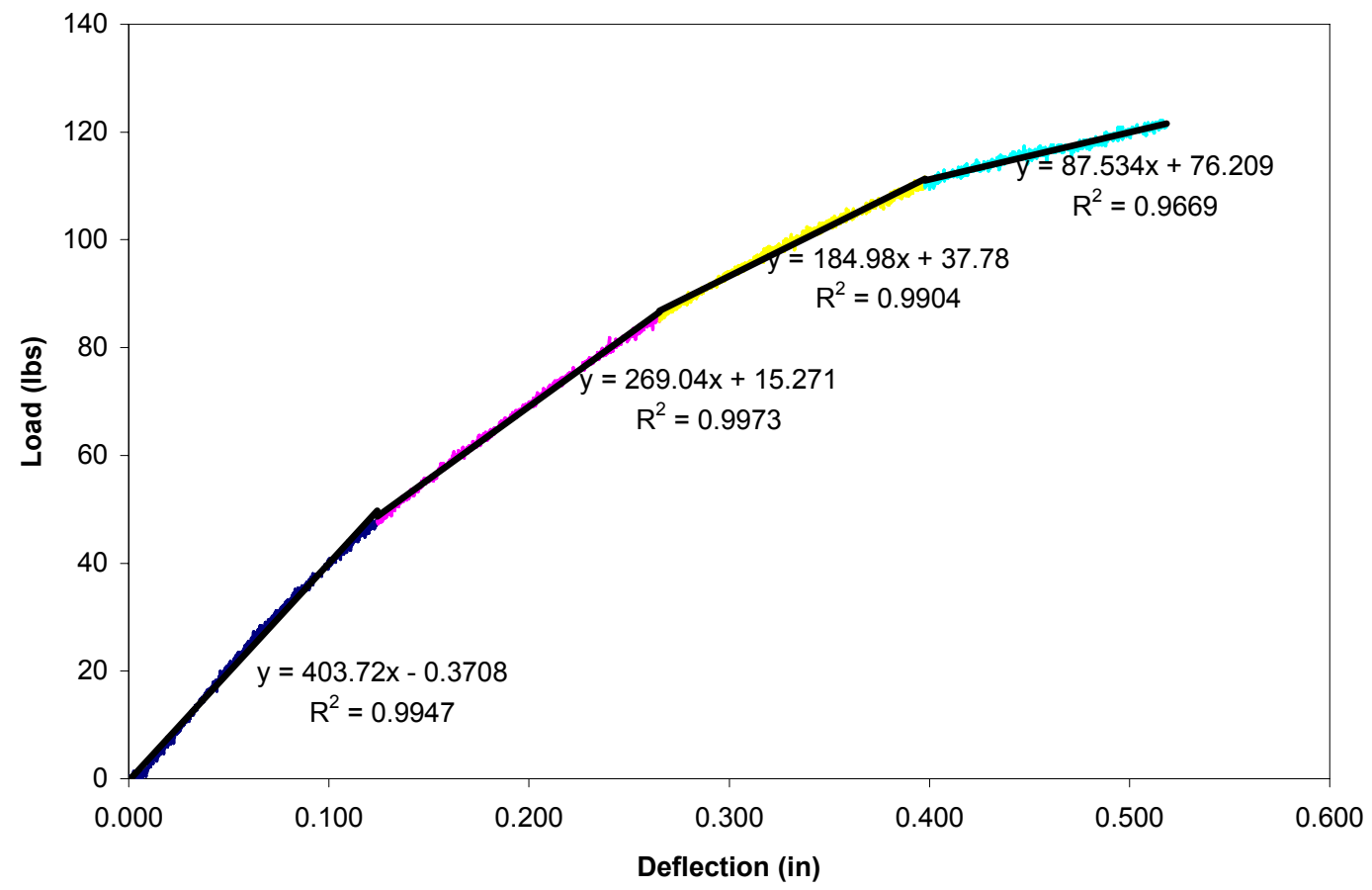

Figure 4.26 Typical Load-deflection Curve with Linear Slopes for Tri-directional without CSM (Sample 46) 


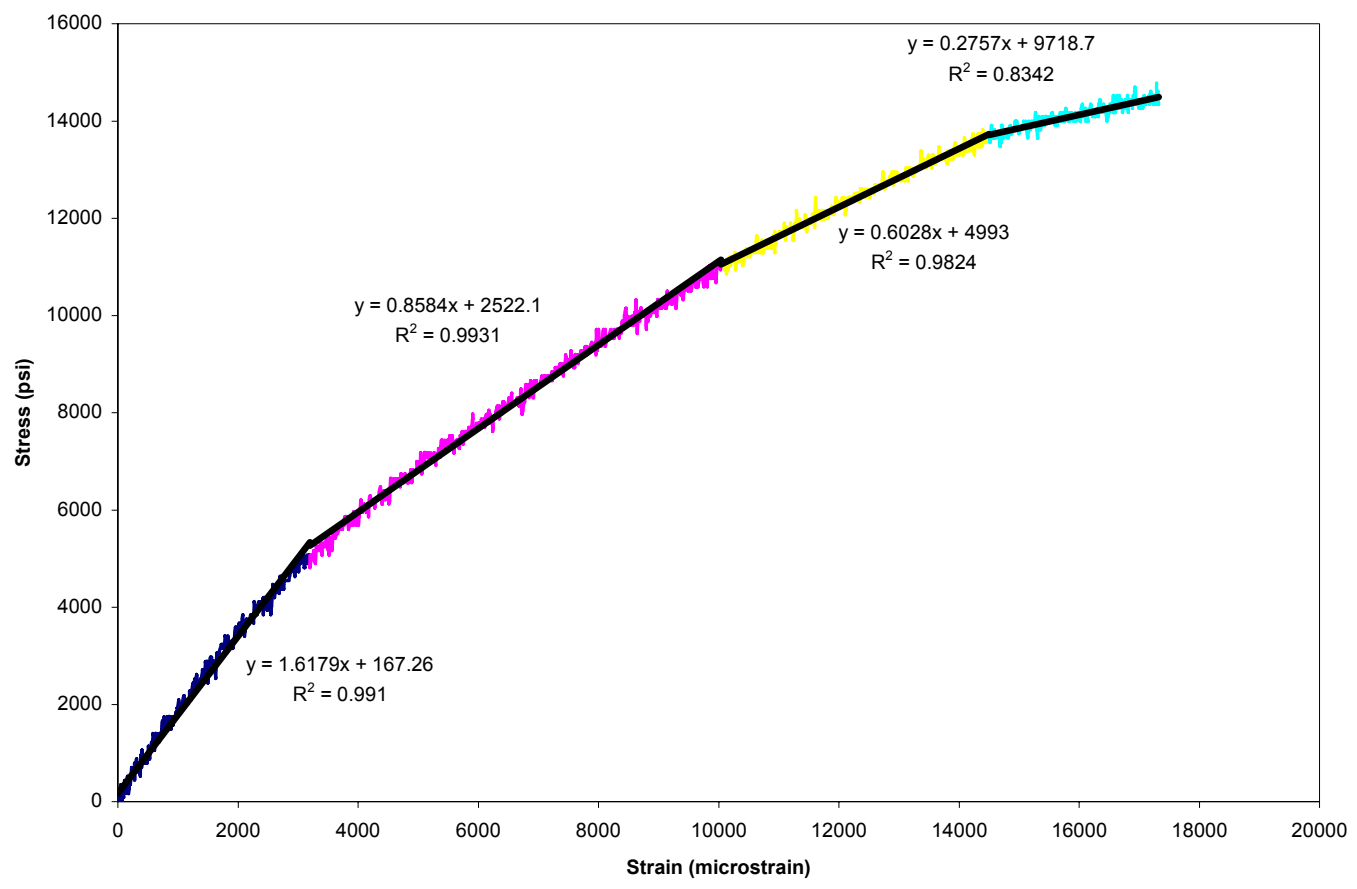

Figure 4.27 Typical Stress-Strain Curve with Linear Slopes for Tri-directional Composites without CSM (Sample 413)

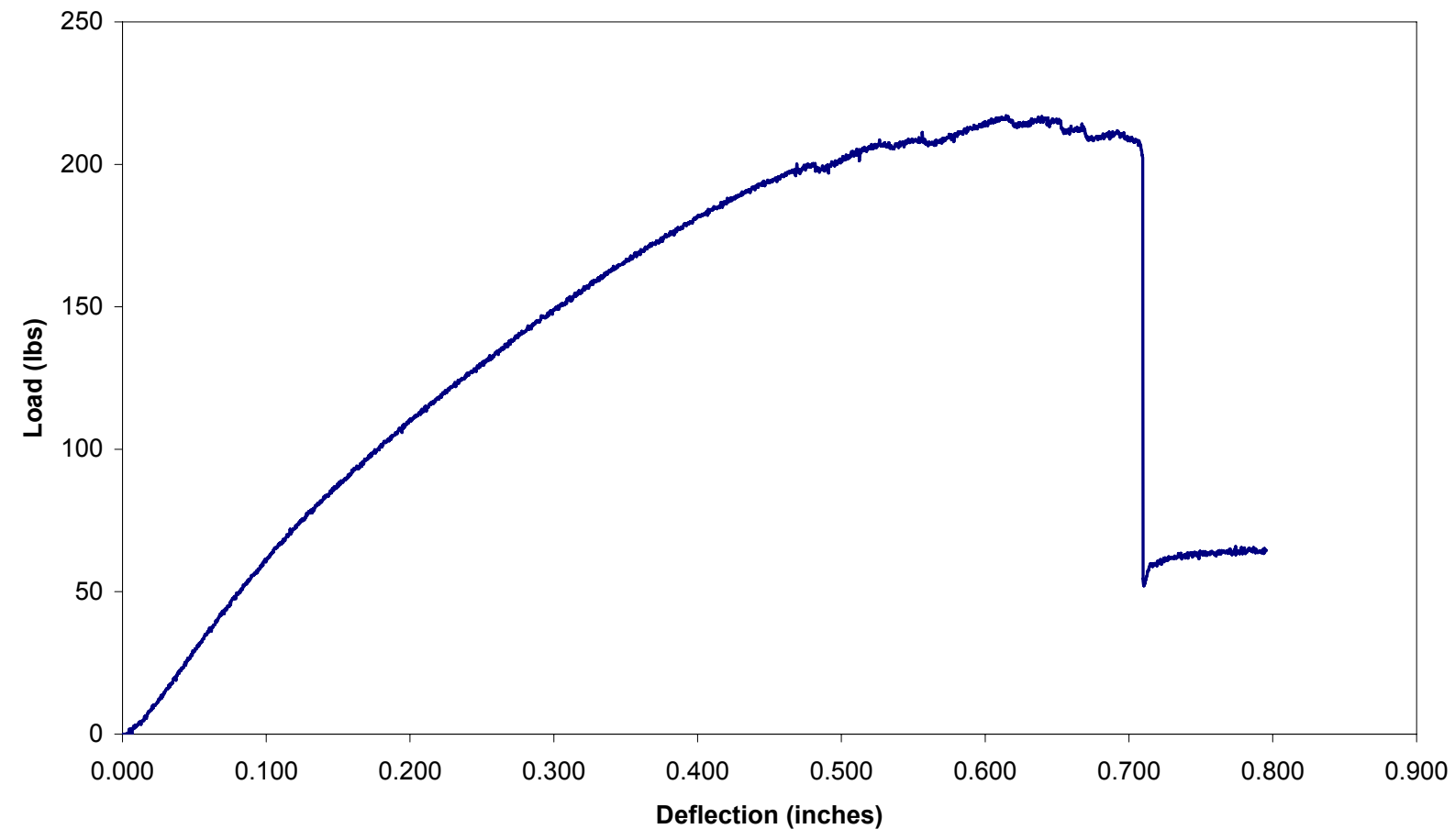

Figure 4.28 Typical Load-deflection Curve for Tri-directional Composites with CSM (Sample 54) 


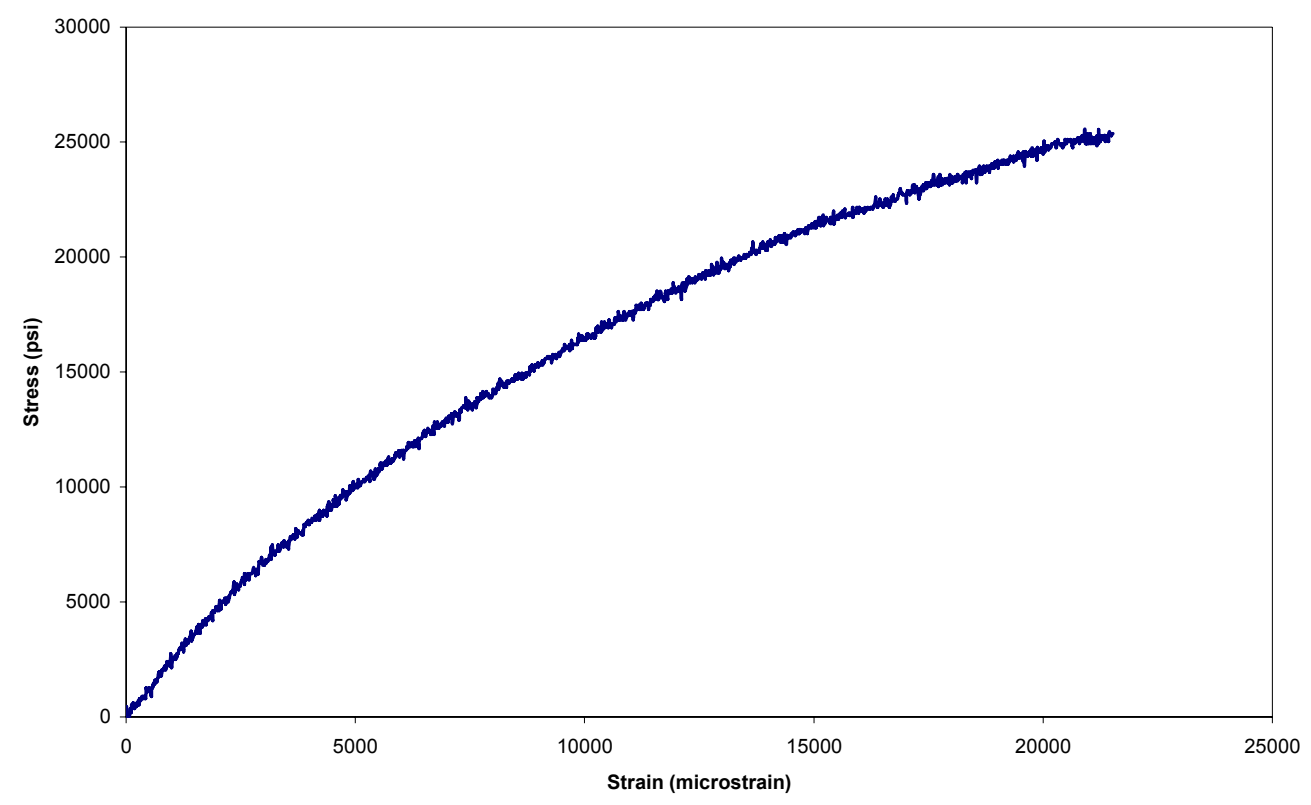

Figure 4.29 Typical Stress-Strain Curve for Tri-directional Composites with CSM (Sample 512)

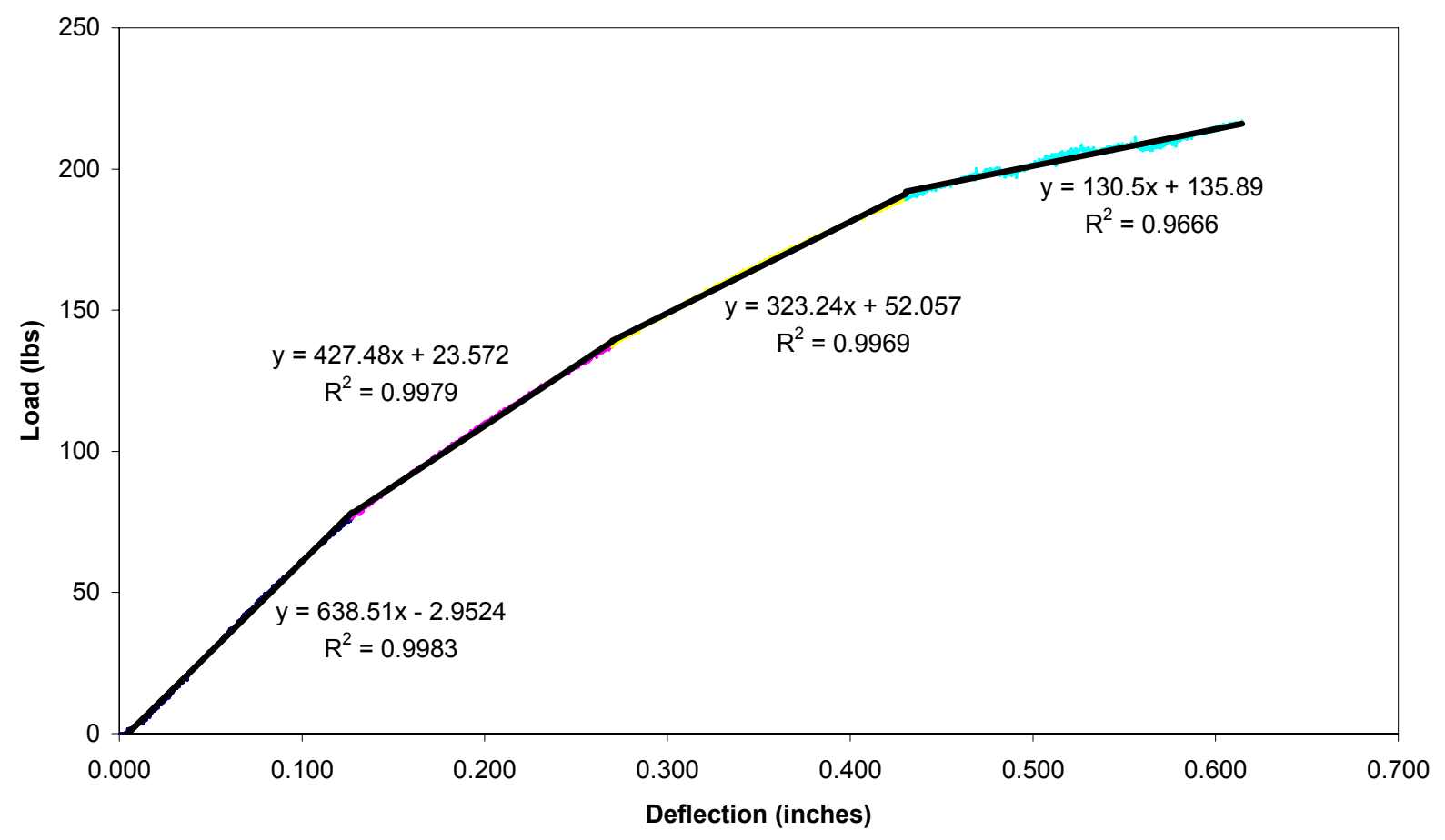

Figure 4.30 Typical Load-deflection Curve with Linear Slopes for Tri-directional Composites with CSM (Sample 54) 


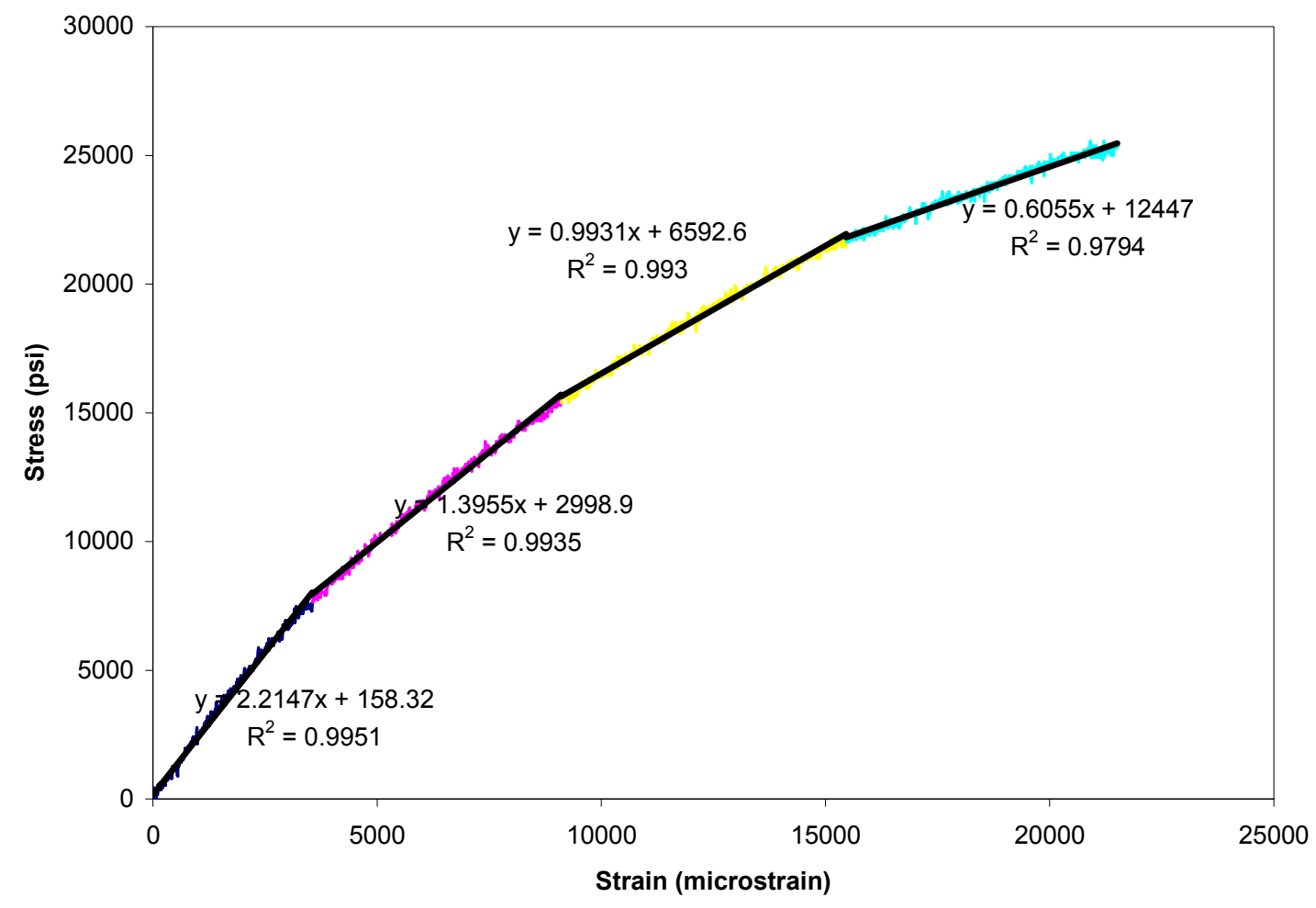

Figure 4.31 Typical Stress-Strain Curve with Linear Slopes for Tri-directional Composites with CSM (Sample 512)

Summary: The average maximum stress for tri-directional composite without CSM is about $14 \mathrm{ksi}$ while that for the same composite with CSM is about $26 \mathrm{ksi}$ (almost twice). This is attributed to the presence of CSM which is capable of taking more loads under bending. However, the average strain for samples with CSM is only about $15 \%$ more than that without CSM. The stress-strain responses for tri-direcional composites have four linear slopes. The change in slopes for first, second and third slopes (with and without CSM) is about $34 \%$, $70 \%$, and $90 \%$ of maximum stress respectively. The ratio of change of first and second slope is 1.6 and 2.4 for tri-directional without and with CSM respectively and ratio of change of second and third slope for both composites is 1.4. 
Table 4.8 Structural Properties of Tri-directional Composites

\begin{tabular}{|c|c|c|c|c|c|c|c|c|c|c|c|c|c|c|c|c|c|c|c|c|}
\hline $\begin{array}{c}\text { Sample } \\
\text { ID }\end{array}$ & $\begin{array}{l}\text { Lay-up } \\
\text { (FA) }\end{array}$ & \begin{tabular}{|c|}
$\begin{array}{c}\text { Densi } \\
\text { ty }\end{array}$ \\
$\left(\begin{array}{c}\text { oz/y } \\
\left.d^{2}\right)\end{array}\right.$ \\
\end{tabular} & \begin{tabular}{|l|} 
FVF \\
$(\%)$ \\
\end{tabular} & \begin{tabular}{|c|}
$\begin{array}{c}\text { FVF- } \\
\text { X }\end{array}$ \\
$(\%)$ \\
\end{tabular} & $\begin{array}{l}\text { Max } \\
\text { Load } \\
\text { (lbs) }\end{array}$ & $\begin{array}{c}\text { Strain } \\
\text { at Max } \\
\text { Load } \\
(\mu \varepsilon)\end{array}$ & $\begin{array}{c}\text { Stress at } \\
\text { Max Load } \\
\text { (ksi) }\end{array}$ & $\begin{array}{c}\begin{array}{c}\text { Strain } \\
\text { at } \\
\text { F.Slope } \\
(\mu \varepsilon)\end{array} \\
\end{array}$ & $\begin{array}{c}\text { Stress } \\
\text { at } \\
\text { F.Slope } \\
\text { (ksi) }\end{array}$ & $\begin{array}{c}\text { Strain } \\
\text { at S. } \\
\text { Slope } \\
(\mu \varepsilon)\end{array}$ & $\begin{array}{c}\text { Stress } \\
\text { at } \\
\text { S.Slope } \\
\text { (ksi) }\end{array}$ & $\begin{array}{c}\text { Strain } \\
\text { at } T . \\
\text { Slope } \\
(\mu \varepsilon)\end{array}$ & $\begin{array}{c}\text { Stress } \\
\text { at } \\
\text { T.Slope } \\
\text { (ksi) }\end{array}$ & $\begin{array}{c}E \alpha \\
(\mathrm{msi})\end{array}$ & $\begin{array}{c}E \beta \\
(\mathrm{msi})\end{array}$ & $\begin{array}{c}\mathrm{E} \gamma \\
\text { (msi) }\end{array}$ & $\begin{array}{c}E_{\eta} \\
(m s i)\end{array}$ & $E \alpha / E \beta$ & $E \beta / E \gamma$ & $\mathrm{E} \gamma / \mathrm{E}_{\eta}$ \\
\hline 42 & Traxial & & & & 100 & 12145 & 13.55 & 2528 & 4.41 & 6170 & 8.86 & 9293 & 11.81 & 1.67 & 1.14 & 0.89 & 0.60 & 1.46 & 1.29 & 1.49 \\
\hline 43 & $45 / 90 /-45$ & & & & 104 & 13936 & 14.22 & 2816 & 4.38 & 6189 & 8.75 & 9822 & 12.29 & 1.65 & 1.23 & 0.94 & 0.45 & 1.34 & 1.31 & 2.10 \\
\hline 44 & without & & & & 114 & 14577 & 14.15 & 2395 & 3.65 & 6450 & 8.49 & 10775 & 12.18 & 1.73 & 1.22 & 0.91 & 0.54 & 1.42 & 1.33 & 1.69 \\
\hline 45 & CSM & & & & 110 & 13909 & 15.57 & 4116 & 6.55 & 8267 & 11.45 & 12029 & 14.22 & 1.63 & 1.14 & 0.74 & 0.42 & 1.43 & 1.53 & 1.78 \\
\hline 46 & (6 layers) & & & & 122 & 16911 & 15.56 & 4051 & 6.13 & 8647 & 10.86 & 12970 & 14.03 & 1.67 & 1.11 & 0.76 & 0.36 & 1.50 & 1.45 & 2.11 \\
\hline 48 & & & & & 115 & 19417 & 15.2 & 3076 & 4.7 & 9918 & 10.5 & 16908 & 14.3 & 1.57 & 0.85 & 0.56 & 0.29 & 1.85 & 1.52 & 1.93 \\
\hline 411 & & & & & 107 & 15544 & 14.1 & 3348 & 4.9 & 12339 & 12.1 & & & 1.54 & 0.78 & 0.54 & & 1.97 & 1.44 & \\
\hline 412 & & 40 & & & 109 & 18888 & 14.5 & 2450 & 4 & 10744 & 11.1 & 16170 & 13.9 & 1.74 & 0.85 & 0.53 & 0.14 & 2.05 & 1.60 & 3.79 \\
\hline \multirow[t]{3}{*}{413} & & & 55 & 16 & 115 & 17287 & 14.8 & 3197 & 5.1 & 10040 & 11 & 14495 & 13.7 & 1.62 & 0.86 & 0.60 & 0.28 & 1.88 & 1.43 & 2.14 \\
\hline & & & AVE & & 110.7 & 15846.0 & 14.6 & 3108.6 & 4.9 & 8751.6 & 10.3 & 12807.8 & 13.3 & 1.6 & 1.0 & 0.7 & 0.4 & 1.7 & 1.4 & 2.1 \\
\hline & & & STD & & 6.6 & 2449.9 & 0.7 & 645.6 & 0.9 & 2197.6 & 1.3 & 2853.5 & 1.0 & 0.1 & 0.2 & 0.2 & 0.1 & 0.3 & 0.1 & 0.7 \\
\hline 51 & Traxial & & & & 202 & 16809 & 27.36 & 3590 & 8.99 & 8274 & 18.05 & 12437 & 24.06 & 2.58 & 1.82 & 1.36 & 0.78 & 1.42 & 1.33 & 1.74 \\
\hline 52 & $45 / 90 /-45$ & & & & 211 & 17798 & 28.2 & 3591 & 9.16 & 8275 & 17.9 & 12437 & 23.71 & 2.53 & 1.76 & 1.35 & 0.81 & 1.44 & 1.30 & 1.67 \\
\hline 53 & with & & & & 192 & 15768 & 25.63 & 3591 & 9.1 & 8274 & 17.62 & 12448 & 22.94 & 2.53 & 1.72 & 1.23 & 0.73 & 1.47 & 1.40 & 1.68 \\
\hline 54 & CSM & & & & 217 & 20036 & 27.06 & 4152 & 9.48 & 8792 & 17.06 & 14040 & 23.57 & 2.57 & 1.72 & 1.30 & 0.52 & 1.49 & 1.32 & 2.48 \\
\hline 55 & (4 layers) & & & & 202 & 20619 & 29.03 & 3591 & 8.98 & 9315 & 19.67 & 15559 & 27.32 & 2.59 & 1.75 & 1.17 & 0.00 & 1.48 & 1.49 & \\
\hline 56 & & & & & 199 & 16173 & 26.54 & 4642 & 10.55 & 10367 & 20.36 & & & 2.41 & 1.63 & 1.02 & 0.00 & 1.47 & 1.60 & \\
\hline 57 & & & & & 206 & 17809 & 27.82 & 4631 & 10.63 & 9836 & 19.95 & 13490 & 24.71 & 2.46 & 1.73 & 1.27 & 0.62 & 1.43 & 1.36 & \\
\hline 58 & & & & & 198 & 21630 & 25.8 & 3095 & 7.2 & 9279 & 16.1 & 16495 & 23.2 & 2.38 & 1.43 & 0.96 & 0.00 & 1.66 & 1.49 & \\
\hline 59 & & & & & 195 & 17268 & 24.8 & 3161 & 7.7 & 9346 & 16.8 & & & 2.49 & 1.47 & 0.94 & & 1.69 & 1.56 & \\
\hline 510 & & & & & 194 & 19112 & 25.2 & 3571 & 8.4 & 9616 & 17.3 & 15195 & 22.5 & 2.39 & 1.43 & 0.96 & & 1.67 & 1.49 & \\
\hline 511 & & & & & 189 & 16639 & 25.1 & 4004 & 9.2 & 10081 & 17.7 & & & 2.37 & 1.36 & 1.14 & & 1.74 & 1.19 & \\
\hline 512 & & 40 & & & 196 & 21652 & 25.5 & 3549 & 7.7 & 9101 & 15.4 & 15458 & 21.6 & 2.21 & 1.39 & 0.99 & 0.00 & 1.59 & 1.40 & \\
\hline \multirow[t]{3}{*}{513} & & & 51 & 15 & 191 & 21109 & 23.9 & 3814 & 8.3 & 11354 & 17.3 & & & 2.19 & 1.20 & 0.67 & 0.00 & 1.83 & 1.79 & \\
\hline & & & AVE & & 199.4 & 18647.8 & 26.3 & 3767.8 & 8.9 & 9377.7 & 17.8 & 14173.2 & 23.7 & 2.4 & 1.6 & 1.1 & 0.3 & 1.6 & 1.4 & 1.9 \\
\hline & & & STD & & 8.2 & 2144.1 & 1.5 & 478.5 & 1.0 & 900.6 & 1.5 & 1561.1 & 1.6 & 0.1 & 0.2 & 0.2 & 0.4 & 0.1 & 0.2 & 0.4 \\
\hline
\end{tabular}




\section{Points to be noted:}

Tri-directional without CSM

Fabric Construction: 45/90/-45, 45/90/-45, 45/90/-45, 45/90/-45, 45/90/-45, 45/90/-45 (not symmetric)

FVF: $55 \%$

Average peak stress: $14.6 \mathrm{ksi}$

Average peak strain: $15846 \mu \varepsilon$

Average stiffness: $1.6 \mathrm{msi}$.

Ratio in change of first slope to second slope: 1.7

Ratio in change of second slope to third slope: 1.4

Tri-directional with CSM

Fabric Construction: 45/90/-45/csm, 45/90/-45/csm, csm/-45/90/45, csm/-45/90/45 (Symmetric)

FVF: $51 \%$

Average peak stress: $26.3 \mathrm{ksi}$

Average peak strain: $18647 \mu \varepsilon$

Average stiffness: $2.4 \mathrm{msi}$.

Ratio in change of first slope to second slope: 1.6

Ratio in change of second slope to third slope: 1.4

\subsubsection{Quadri-directional Composites}

Typical load-deflection and stress-strain curves for quadri-directional composites are shown in Figures 4.32 and 4.33 respectively. It is evident from Figures 4.34 and 4.35 that the load-deflection and stress-strain curve is tri-linear. Details of stress, strain and stiffness are tabulated in Table 4.9. 


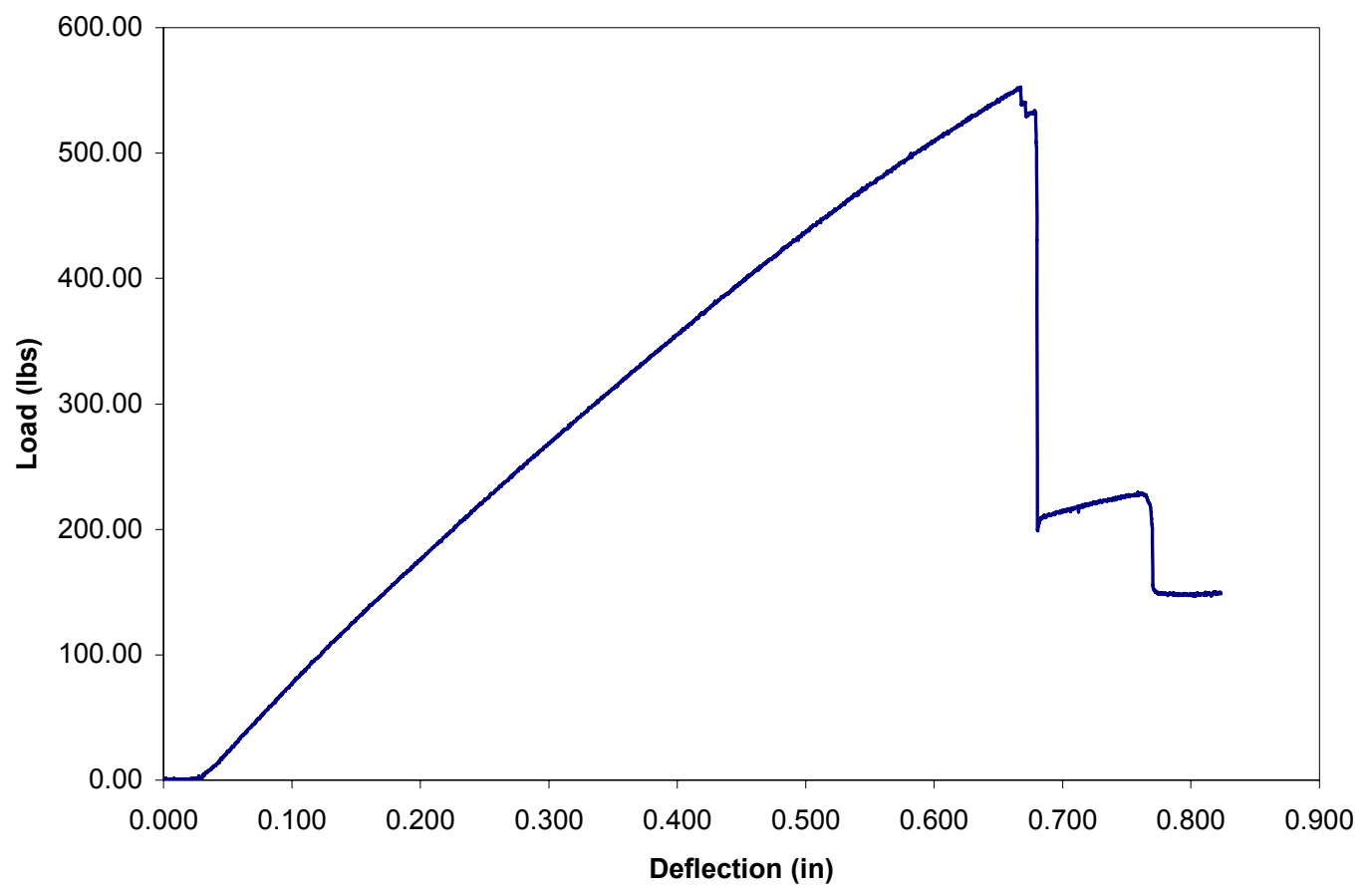

Figure 4.32 Typical Load-deflection Curve for Quadri-directional Composites (Sample 61)

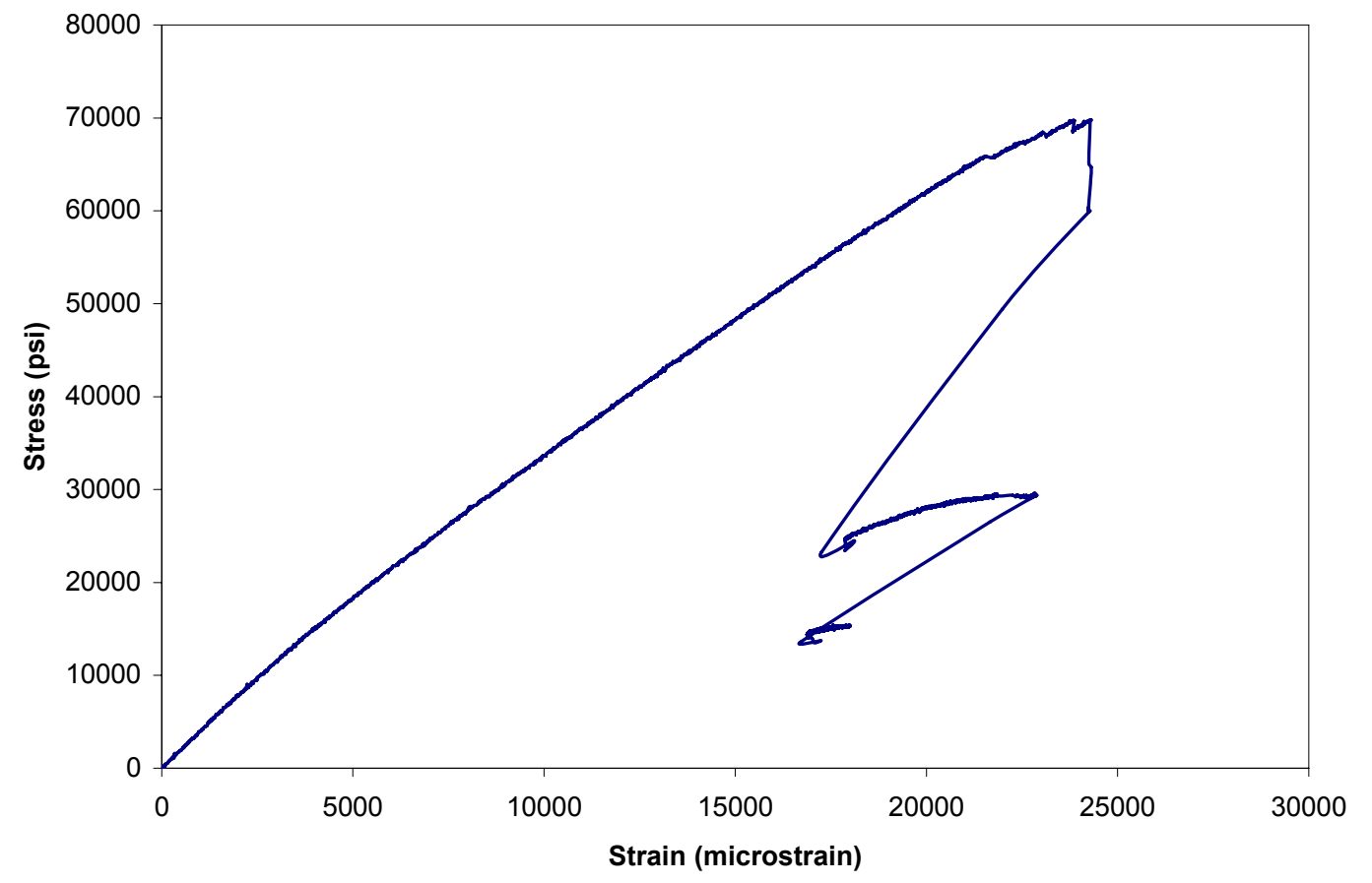

Figure 4.33 Typical Stress-Strain Curve for Quadri-directional Composites (Sample 69) 


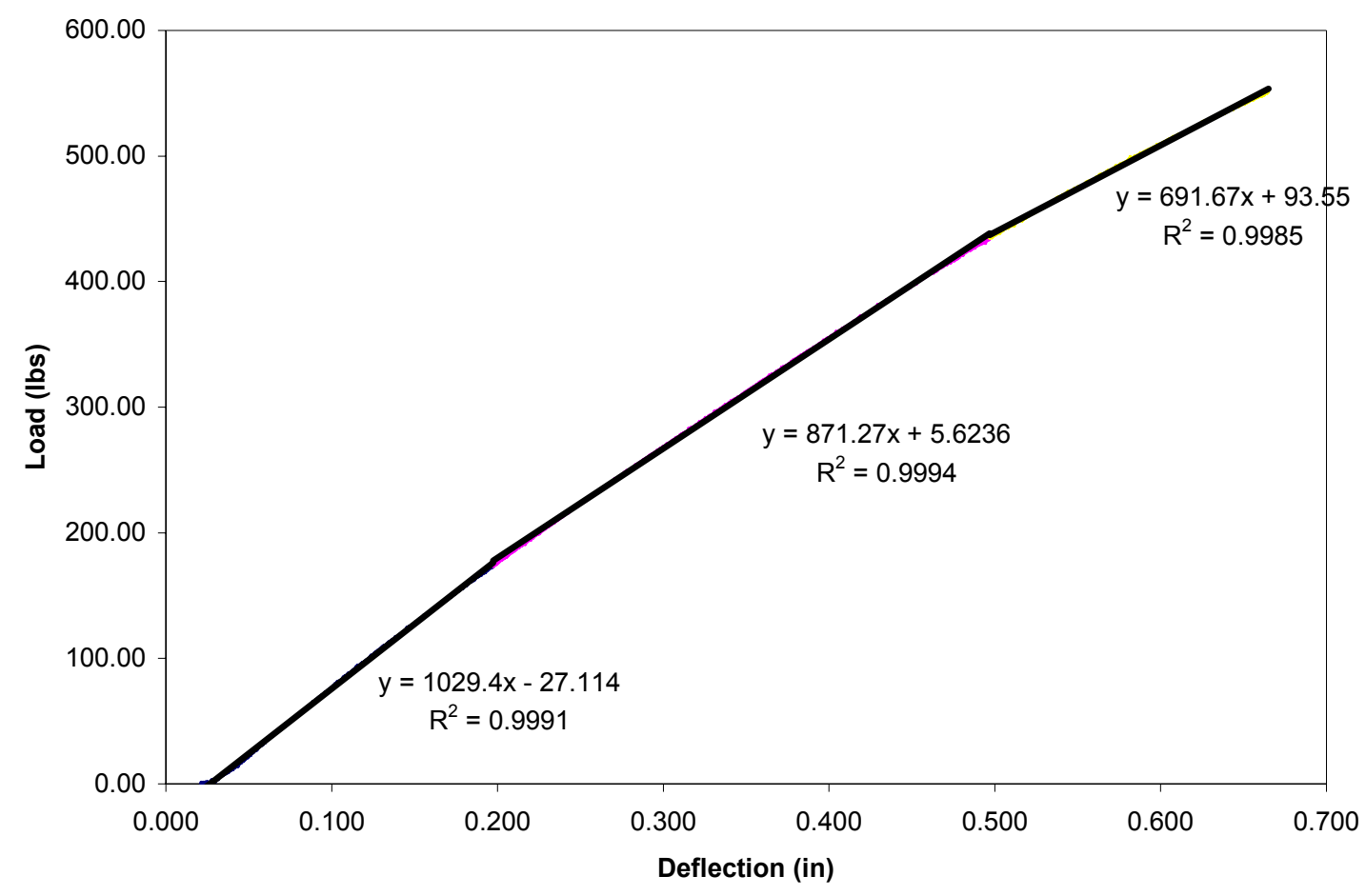

Figure 4.34 Typical Load-deflection Curve with Tri-linear Curves for Quadri-directional Composites (Sample 61)

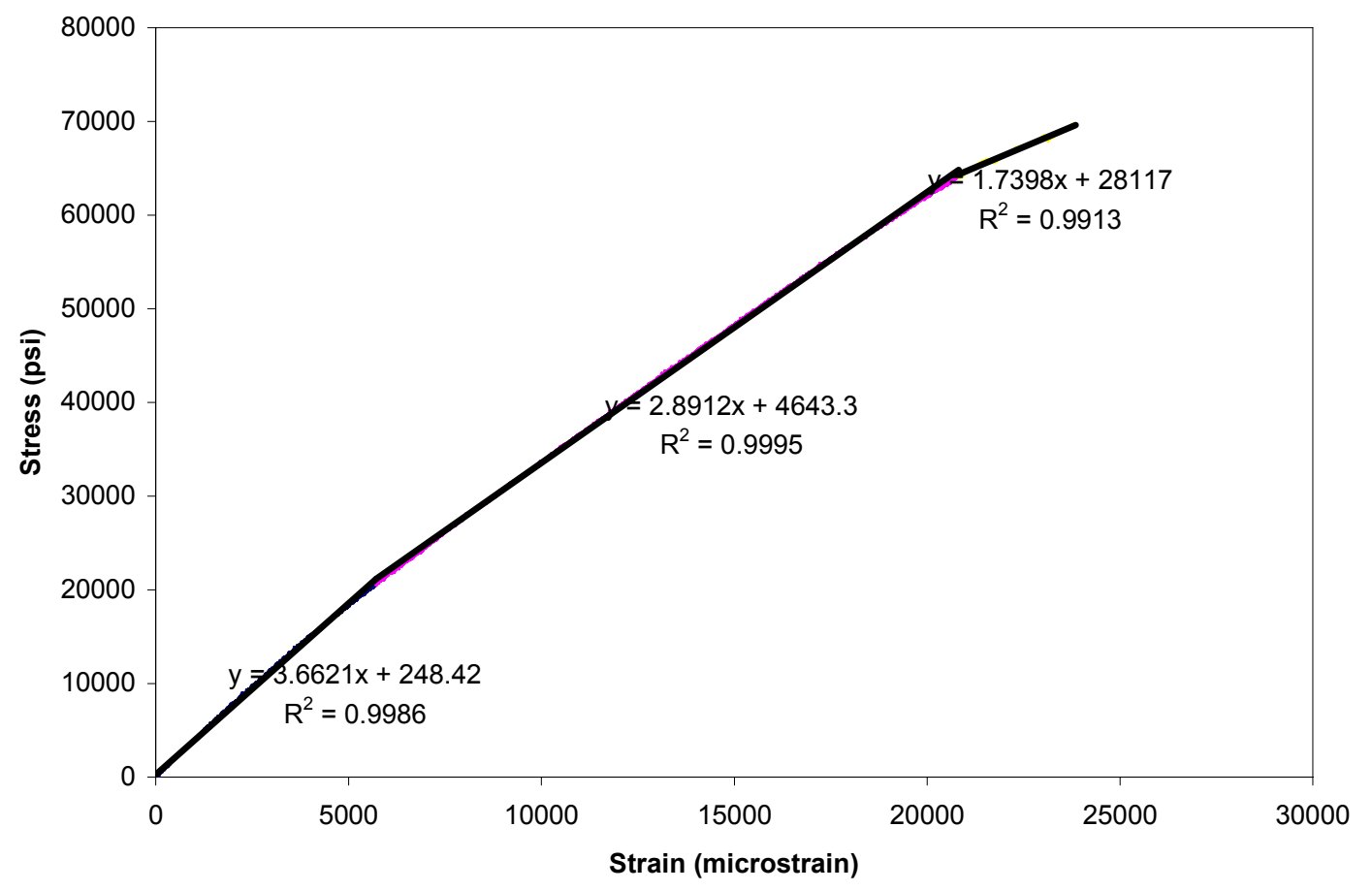

Figure 4.35 Typical Stress-Strain curve with Tri-linear Curves for Quadri-directional Composites (Sample 69) 
Table 4.9 Structural Properties of Quadri-directional Composites

\begin{tabular}{|c|c|c|c|c|c|c|c|c|c|c|c|c|c|c|c|c|}
\hline $\begin{array}{c}\text { Sample } \\
\text { ID }\end{array}$ & $\frac{\text { Lay-up }}{\text { (FA) }}$ & $\begin{array}{c}\text { Density } \\
\left(\mathrm{oz}^{2} \mathrm{yd}^{2}\right)\end{array}$ & $\begin{array}{l}\text { FVF } \\
(\%)\end{array}$ & $\frac{\text { FVF-X }}{(\%)}$ & $\begin{array}{c}\text { Max Load } \\
\text { (Ibs) }\end{array}$ & $\begin{array}{c}\text { Strain at } \\
\text { Max Load } \\
(\mu \varepsilon)\end{array}$ & $\begin{array}{c}\text { Stress at } \\
\text { Max Load } \\
\text { (ksi) }\end{array}$ & $\begin{array}{c}\text { Strain at } \\
\text { F.Slope } \\
(\mu \varepsilon)\end{array}$ & $\begin{array}{c}\text { Stress at } \\
\text { F.Slope } \\
\text { (ksi) }\end{array}$ & $\begin{array}{l}\text { Strain at } \\
\text { S. Slope } \\
\quad(\mu \varepsilon)\end{array}$ & $\begin{array}{c}\text { Stress at } \\
\text { S.Slope } \\
\text { (ksi) }\end{array}$ & $\begin{array}{c}E \alpha \\
\text { (msi) }\end{array}$ & $\begin{array}{c}E \beta \\
(m s i)\end{array}$ & $\begin{array}{c}\mathrm{E}_{\gamma} \\
(\mathrm{msi})\end{array}$ & $\mathrm{E} \alpha / \mathrm{E} \beta$ & $E \beta / E \gamma$ \\
\hline 61 & Quadriaxial & & & & 552 & 20817 & 73.73 & 6183 & 23.12 & 15552 & 58.06 & 4.17 & 3.53 & 2.80 & 1.18 & 1.26 \\
\hline 63 & 4 layers & & & & 548 & 21358 & 67.38 & 6213 & 21.65 & 16306 & 55.39 & 4.02 & 3.56 & 2.51 & 1.13 & 1.42 \\
\hline 65 & & & & & 511 & 19222 & 62.85 & 5768 & 21.57 & 15216 & 53.3 & 4.10 & 3.55 & 2.48 & 1.16 & 1.43 \\
\hline 66 & & & & & 536 & 20058 & 73.41 & 5673 & 23.88 & 15040 & 59.78 & 4.17 & 3.63 & 2.40 & 1.15 & 1.51 \\
\hline 69 & & & & & 514 & 23854 & 69.7 & 5712 & 20.6 & 20821 & 64 & 3.66 & 2.89 & 1.74 & 1.27 & 1.66 \\
\hline 610 & & 26 & & & 519 & 23085 & 67.9 & 5255 & 18.1 & 20594 & 61.1 & 3.54 & 2.77 & 2.63 & 1.28 & 1.05 \\
\hline 612 & & & 55 & 25 & 524 & 22157 & 68.2 & 4901 & 19.6 & 18061 & 60.9 & 4.05 & 3.18 & 1.85 & 1.27 & 1.72 \\
\hline & & & AVE & & 522.1 & 20991.4 & 67.8 & 5711.4 & 21.3 & 17020.0 & 57.9 & 4.0 & 3.3 & 2.4 & 1.2 & 1.4 \\
\hline & & & STD & & 25.0 & 2109.3 & 5.0 & 450.3 & 1.9 & 2511.3 & 4.4 & 0.2 & 0.3 & 0.4 & 0.1 & 0.2 \\
\hline
\end{tabular}

\section{Points to be noted:}

\section{Quadri-directional}

Fabric Construction: 0/90/45/-45/csm, csm/-45/45/90/0, csm/-45/45/90/0, csm/-45/45/90/0

FVF: $55 \%$

Average peak stress: $67.8 \mathrm{ksi}$

Average peak strain: $20991 \mu \varepsilon$

Average stiffness: $4.0 \mathrm{msi}$.

Ratio in change of first slope to second slope: 1.2; Ratio in change of second slope to third slope: 1.4 


\subsubsection{Summary}

The average maximum stress for quadri-directional composite is about $68 \mathrm{ksi}$ and the maximum strain is about 21000 microstrain. The stress is more or less same as that of uni-/bi -directional composites because the $90^{\circ}$ and $45^{\circ}$ fibers are not affected under bending loads as in tension loads. The change of first and second slope is at about $31 \%$ and $85 \%$ of maximum stress respectively. The ratio of change in first and second slope is 1.2 while that of second and third slope is 1.4 .

\subsubsection{Multi-directional Composites}

A typical load-deflection curve and or stress-strain curve for multidirectional composites with both polyurethane and vinylester resin system are shown in Figures 4.36 through 4.43. Details on structural properties of composites with polyurethane and vinyl ester resin systems are shown in Table 4.10 and 4.11 respectively.

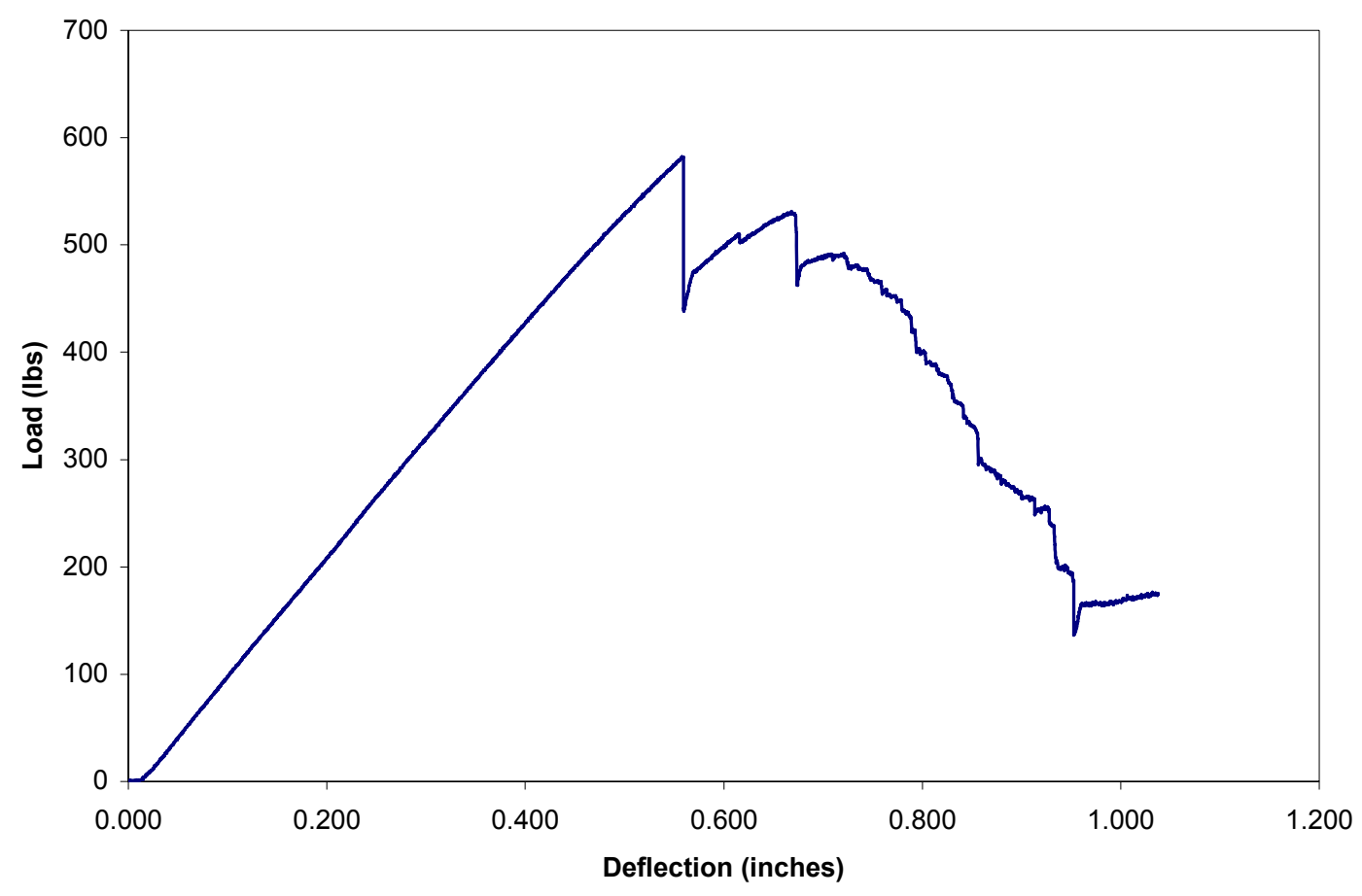

Figure 4.36 Typical Load-deflection Curve for Multidirectional Composite with Polyurethane resin (Sample 71) 


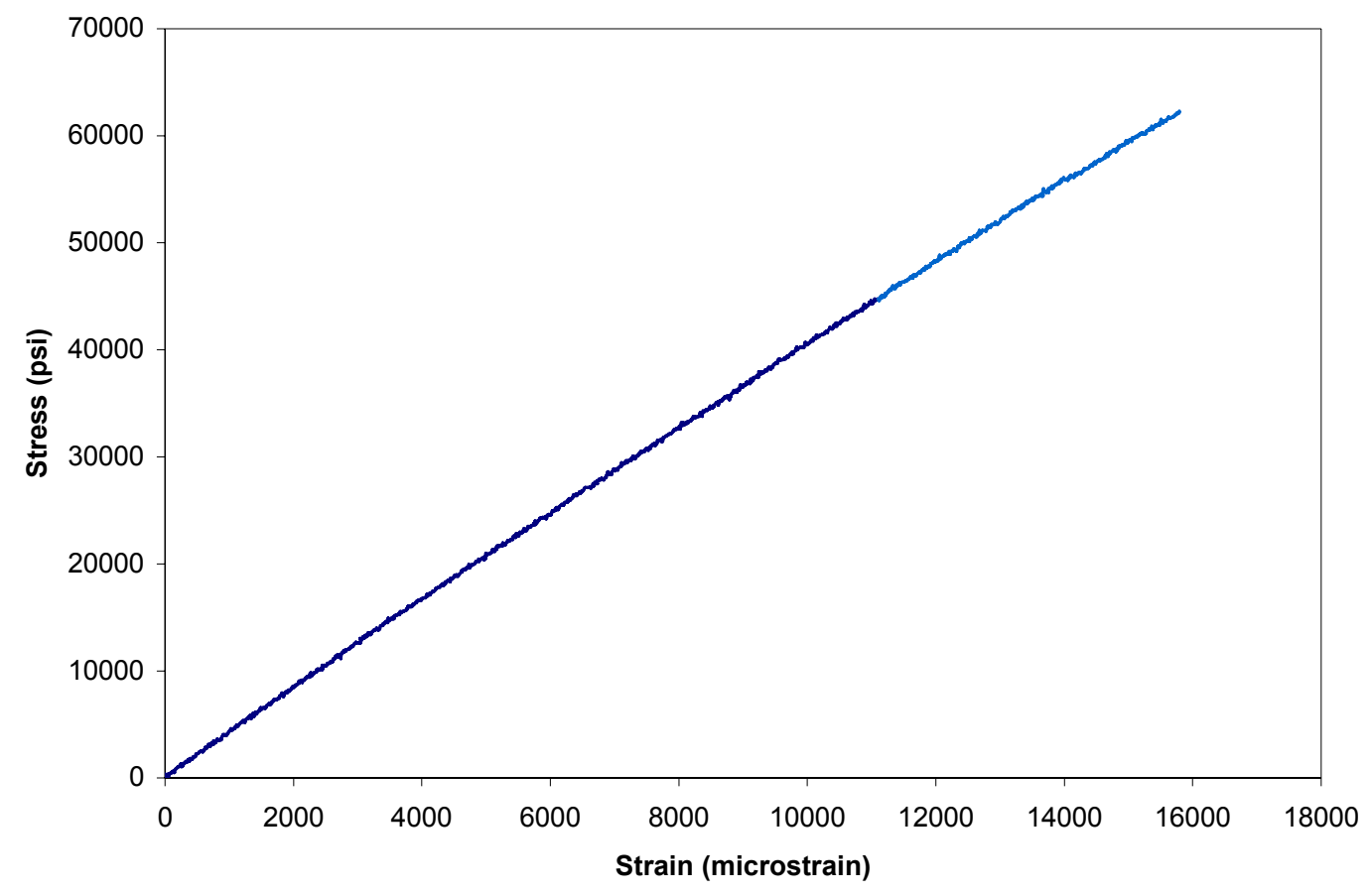

Figure 4.37 Typical Stress-Strain Curve for Multidirectional Composite with Polyurethane Resin (Sample 7H2)

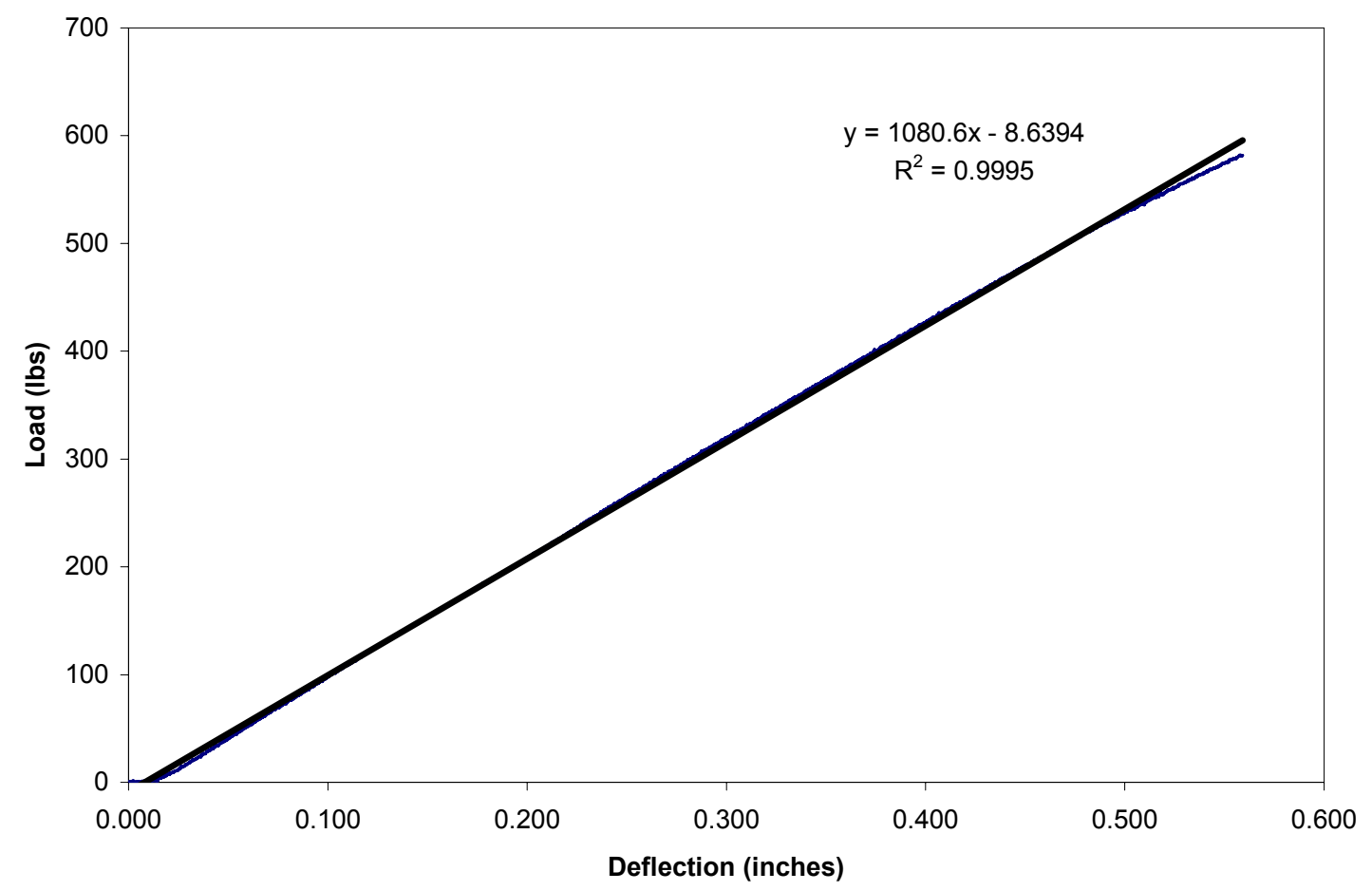

Figure 4.38 Load-deflection Curve with Linear Curve for Multidirectional Composite with Polyurethane Resin (Sample 71) 


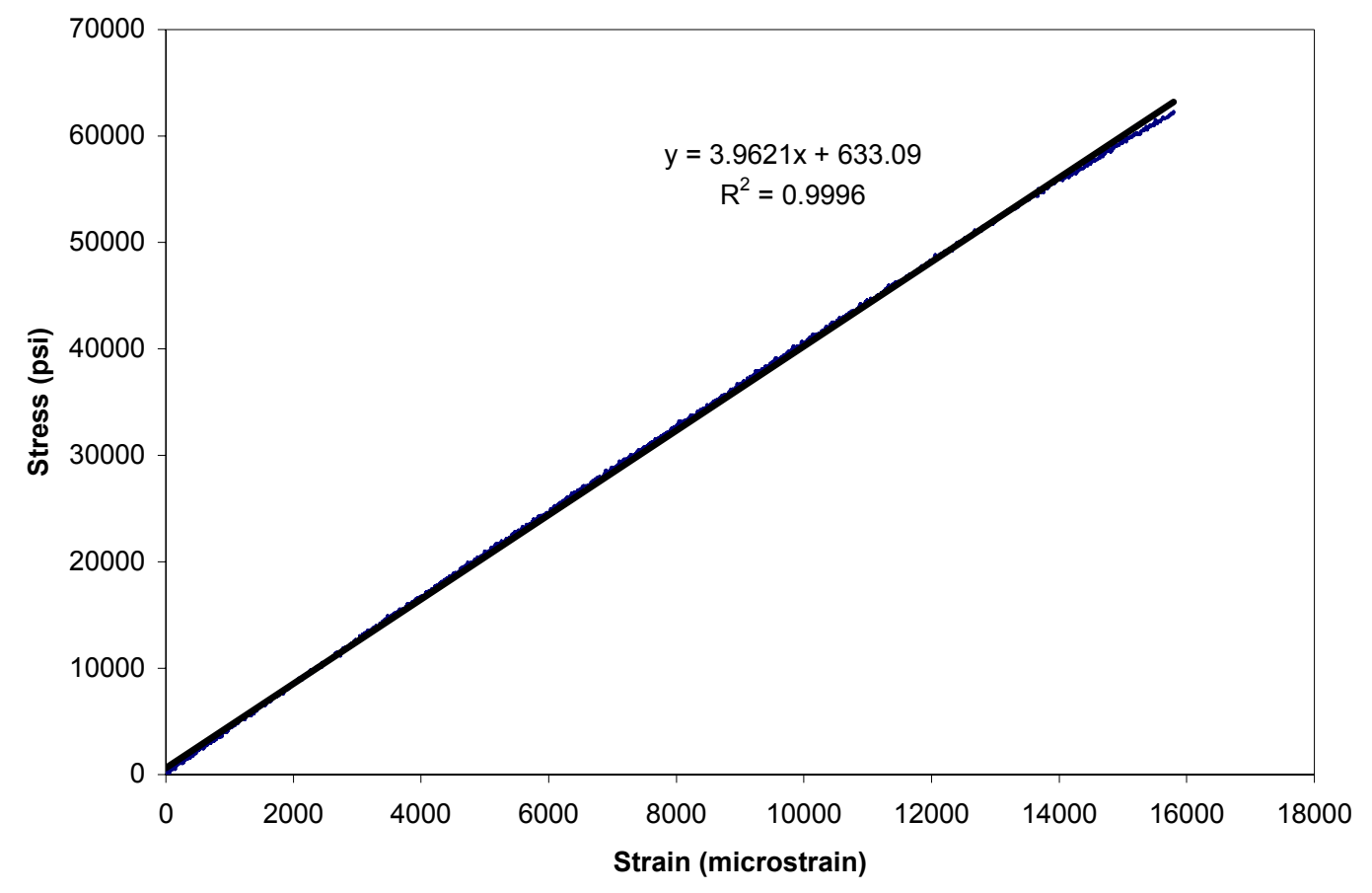

Figure 4.39 Stress-Strain Curve with Linear Curve for Multidirectional Composite with Polyurethane Resin (Sample 7H2)

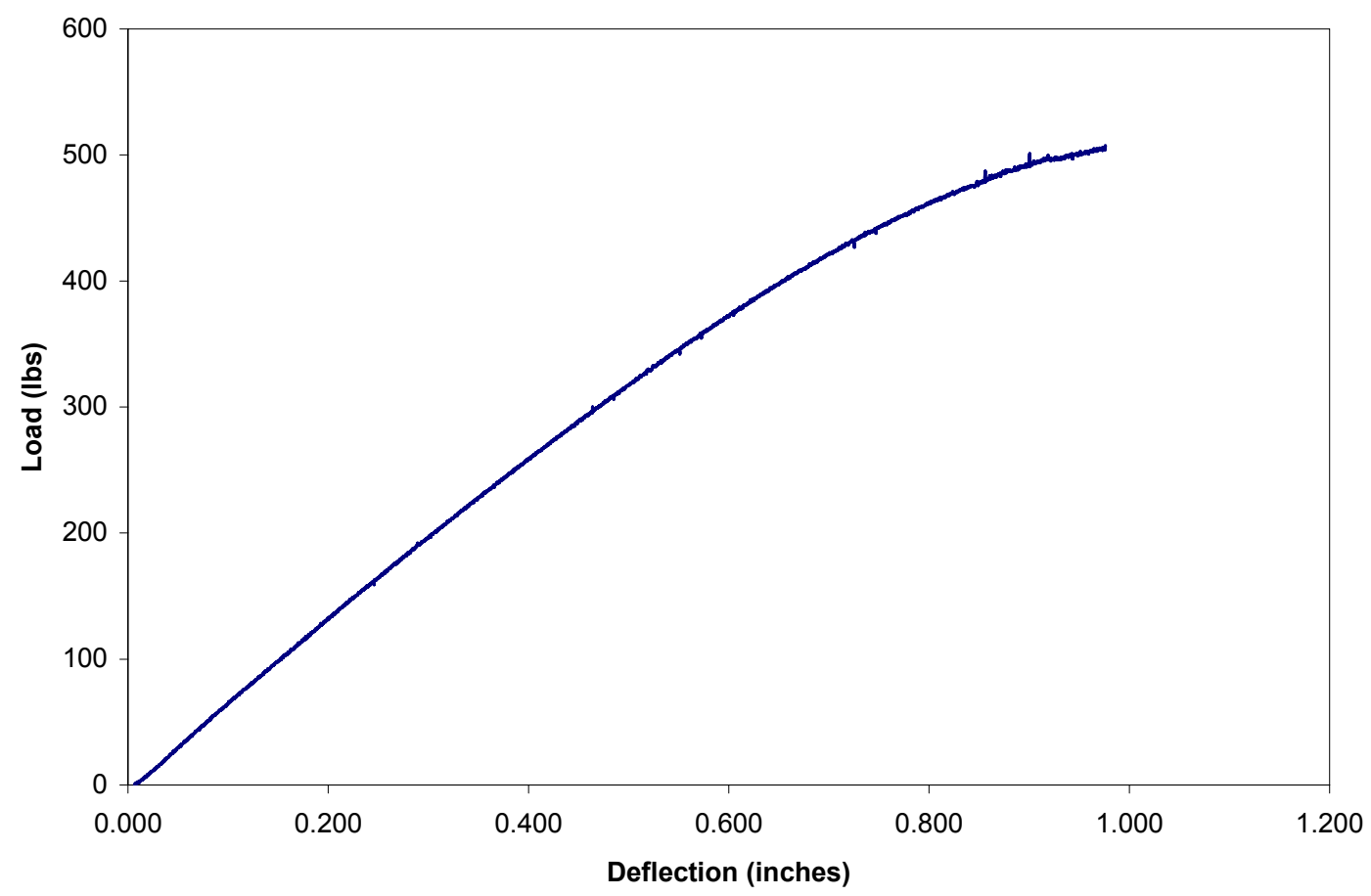

Figure 4.40 Typical Load-deflection Curve for Multidirectional Composite with Vinyl ester Resin (Sample 82) 


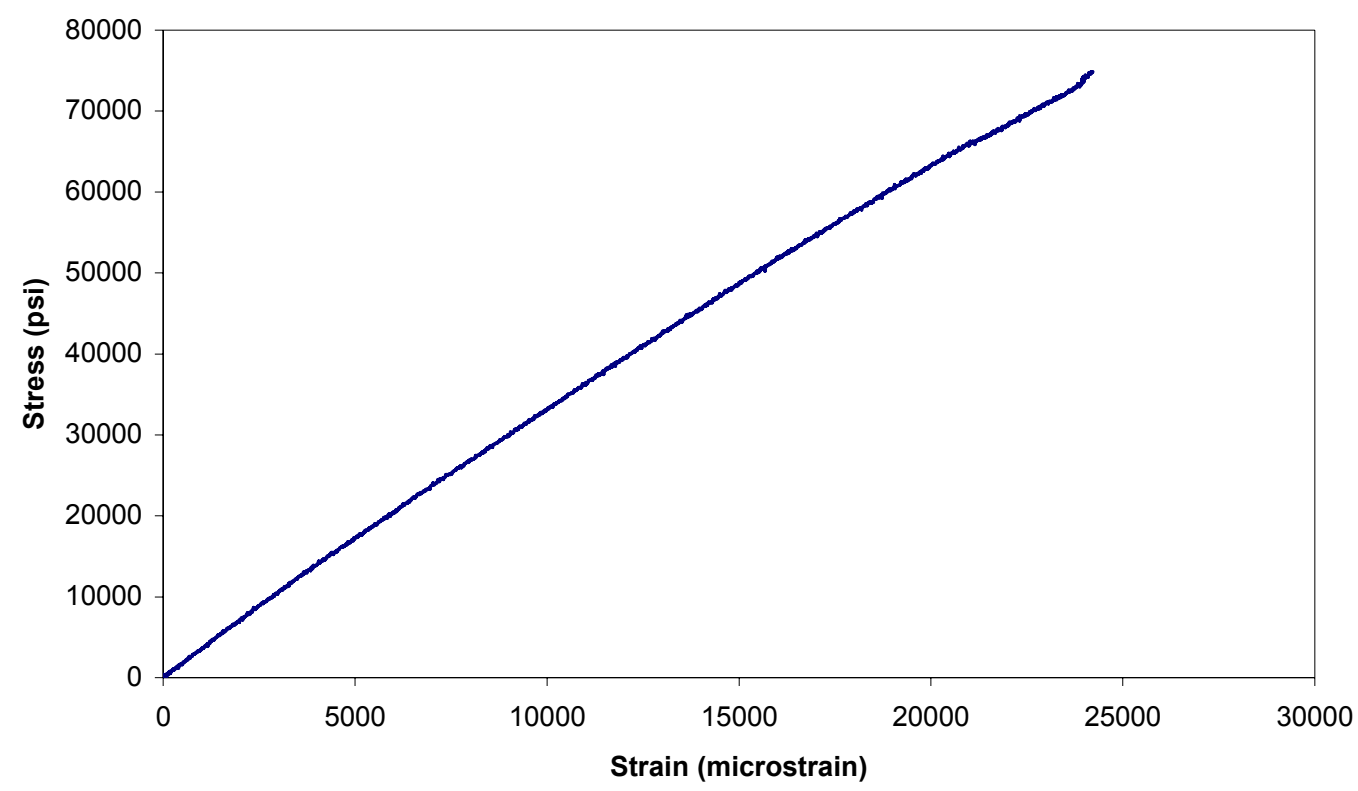

Figure 4.41 Typical Stress-Strain Curve for Multidirectional Composite with Vinyl ester Resin (Sample 812)

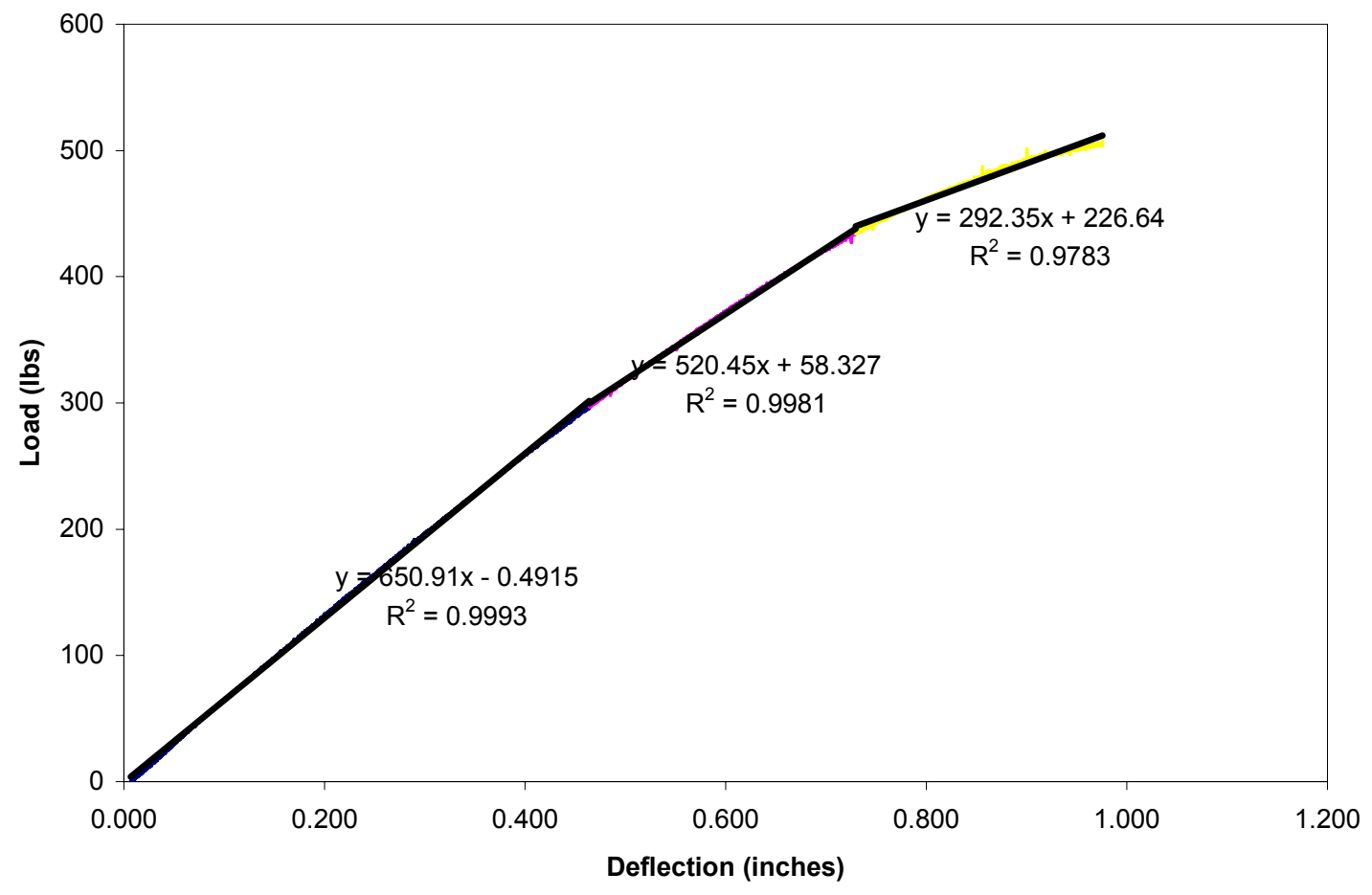

Figure 4.42 Load-deflection Curve with Tri-linear Curve for Multidirectional Composite with Vinyl ester resin (Sample 82) 


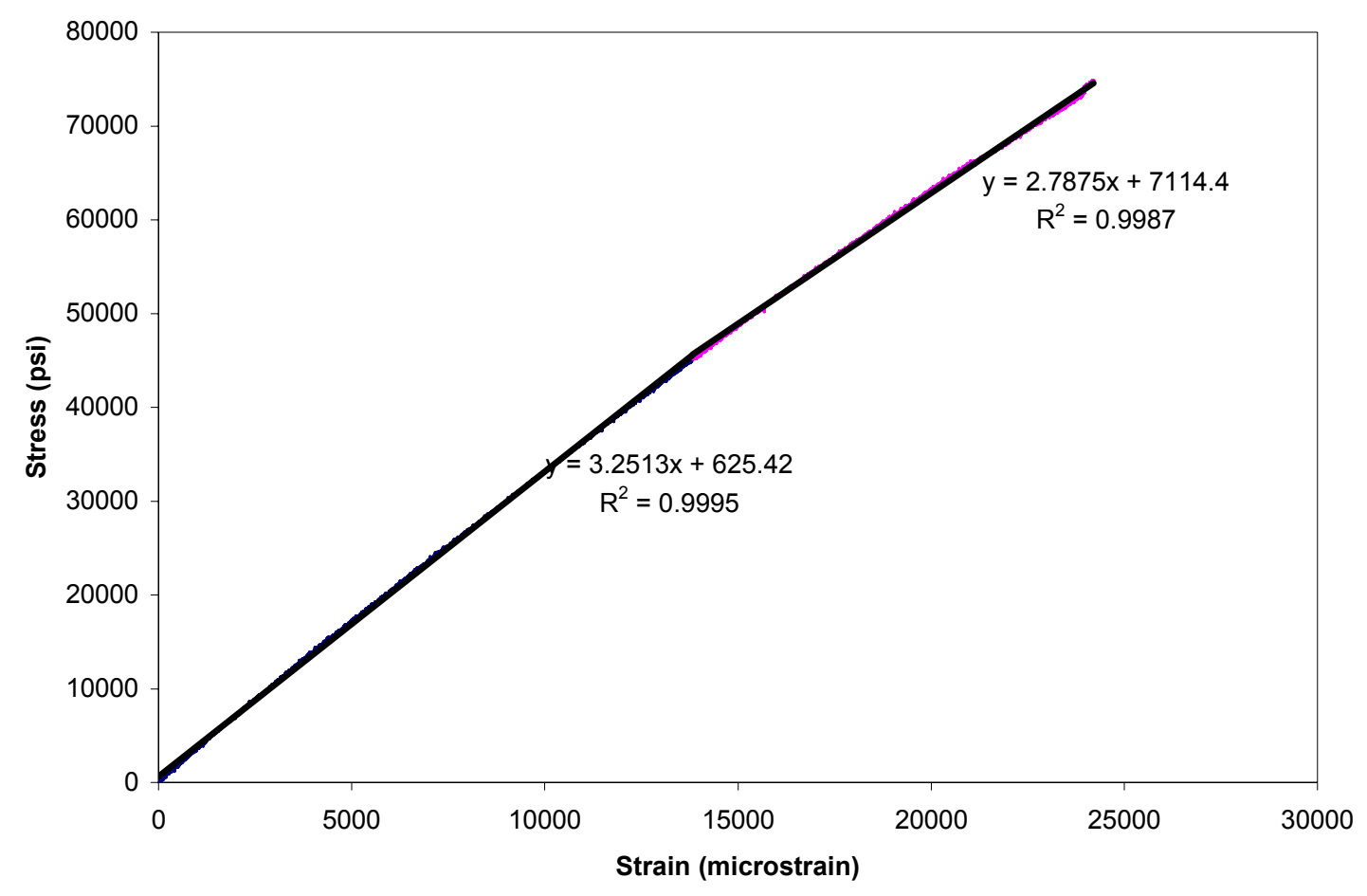

Figure 4.43 Stress-Strain Curve with Tri-linear Curve for Multidirectional Composite with Vinyl ester Resin (Sample 812)

Table 4.10 Structural Properties of Multi-directional Composite with Polyurethane Resin

\begin{tabular}{|c|c|c|c|c|c|c|c|c|}
\hline $\begin{array}{c}\text { Sample } \\
\text { ID }\end{array}$ & $\begin{array}{c}\text { Lay-up } \\
\text { (FA) }\end{array}$ & Density & $\begin{array}{l}\text { FVF } \\
(\%)\end{array}$ & \begin{tabular}{|c}
$\begin{array}{c}\text { FVF- } \\
X\end{array}$ \\
$(\%)$ \\
\end{tabular} & $\begin{array}{c}\text { Max Load } \\
\text { (bs) }\end{array}$ & $\begin{array}{c}\text { Strain at Max } \\
\text { Load }(\mu \varepsilon)\end{array}$ & $\begin{array}{c}\text { Stress at } \\
\text { Max } \\
\text { Load } \\
\text { (ksi) }\end{array}$ & $\begin{array}{c}E \alpha \\
\text { (msi) }\end{array}$ \\
\hline 71 & Polyurethane & & & & 582 & 18235 & 72.55 & 4.13 \\
\hline 72 & multi & & & & 569 & 17597 & 69.1 & 3.91 \\
\hline 74 & CSM, Rov,0/90 & & & & 557 & 16598 & 68.56 & 4.15 \\
\hline 75 & & & & & 506 & 14409 & 60.71 & 4.17 \\
\hline 76 & & & & & 486 & 14518 & 60.61 & 4.14 \\
\hline 712 & & & & & 466 & 17170 & 57.4 & 3.33 \\
\hline 713 & & & & & 475 & 16330 & 58.3 & 3.65 \\
\hline $7 \mathrm{H} 1$ & & & & & 499 & 16815 & 61.9 & 3.71 \\
\hline $7 \mathrm{H} 2$ & & & & & 494 & 15794 & 62.3 & 3.96 \\
\hline $7 \mathrm{H} 3$ & & & 53 & 43 & 479 & 18373 & 70.2 & 4.00 \\
\hline & & & AVE & & 511.3 & 16583.9 & 64.2 & 3.9 \\
\hline & & & STD & & 42.1 & 1375.9 & 5.4 & 0.3 \\
\hline
\end{tabular}


Table 4.11 Structural Properties of Multi-directional Composite with Vinyl ester Resin

\begin{tabular}{|c|c|c|c|c|c|c|c|c|c|c|c|c|c|c|c|c|}
\hline $\begin{array}{c}\text { Sample } \\
\text { ID }\end{array}$ & $\frac{\text { Lay-up }}{\text { (FA) }}$ & Density & $\begin{array}{l}\text { FVF } \\
(\%)\end{array}$ & \begin{tabular}{|c|}
$\begin{array}{c}\text { FVF- } \\
X\end{array}$ \\
$(\%)$ \\
\end{tabular} & $\begin{array}{c}\text { Max Load } \\
\text { (Ibs) }\end{array}$ & $\begin{array}{c}\text { Strain at Max } \\
\text { Load }(\mu \varepsilon)\end{array}$ & $\begin{array}{c}\text { Stress at } \\
\text { Max } \\
\text { Load } \\
\text { (ksi) }\end{array}$ & $\begin{array}{c}\text { Strain at } \\
\text { F.Slope } \\
(\mu \varepsilon)\end{array}$ & $\begin{array}{c}\text { Stress at } \\
\begin{array}{c}\text { F.Slope } \\
\text { (ksi) }\end{array}\end{array}$ & $\begin{array}{c}\text { Strain at } \\
\text { S. Slope } \\
(\mu \varepsilon)\end{array}$ & $\begin{array}{c}\text { Stress at } \\
\text { S.Slope } \\
\text { (ksi) }\end{array}$ & $\begin{array}{l}\mathrm{E} \alpha \\
\text { (msi) }\end{array}$ & $\begin{array}{c}\mathrm{E} \beta \\
(\mathrm{msi})\end{array}$ & $\begin{array}{c}\mathrm{E} \gamma \\
(\mathrm{msi})\end{array}$ & $E \alpha / E \beta$ & $E \beta / E \gamma$ \\
\hline 82 & Polyurethane & & & & 508 & 30550 & 70.5 & 14521 & 41.66 & 22846 & 60.26 & 2.84 & 2.27 & 1.28 & 1.25 & 1.78 \\
\hline 83 & multi & & & & 439 & 27383 & 61.76 & 12437 & 33.73 & 21804 & 53.91 & 2.79 & 2.12 & 1.32 & 1.32 & 1.61 \\
\hline 85 & & & & & 448 & 29322 & 75.74 & 12438 & 40.92 & 19724 & 60.39 & 2.81 & 2.21 & 1.34 & 1.27 & 1.66 \\
\hline 812 & & & & & 610 & 24198 & 74.8 & 13828 & 45.1 & & & 3.25 & 2.78 & & 1.17 & \\
\hline 813 & & & & & 630 & 24050 & 76.9 & 13384 & 45.7 & & & 3.42 & 2.94 & & 1.16 & \\
\hline & & & AVE & & 518.7 & 26960.7 & 70.8 & 13174.3 & 40.6 & 21284.5 & 57.7 & 3.0 & 2.4 & 1.4 & 1.2 & 1.6 \\
\hline & & & STD & & 82.4 & 2654.5 & 6.2 & 884.6 & 4.7 & 1343.4 & 3.2 & 0.3 & 0.3 & 0.2 & 0.1 & 0.2 \\
\hline
\end{tabular}

\section{Points to be noted:}

Multi-directional with polyurethane system

Fabric Construction: csm/0/90/rov/csm/rov/csm/rov/0/90/csm

FVF: $53 \%$

Average peak stress: $64.2 \mathrm{ksi}$

Average peak strain: $16583 \mu \varepsilon$

Average stiffness: 3.9 msi. 
Multi-directional with vinylester system

Fabric Construction: csm/rov/0/90/csm/rov/csm/rov/0/90/csm/rov/csm

FVF: $51 \%$

Average peak stress: $70.8 \mathrm{ksi}$

Average peak strain: $26960 \mu \varepsilon$

Average stiffness: $3.0 \mathrm{msi}$.

Ratio of change of first slope to second slope: 1.2

Ratio of change of second slope to third slope: 1.6

\subsubsection{Summary}

It is seen from Figures 4.38 and 4.39 that multi-directional composites with polyurethane has linear slope up to maximum stress while vinyl ester systems has tri-linear slope based on load-deflection curve (Figure 4.42) and bilinear slopes based on stress-strain curve (Figuer 4.43). The maximum stress for polyurethane resin system is $64 \mathrm{ksi}$ while that for vinyl ester resin system is 71 ksi. With regards to strain, the maximum strain of vinyl ester resin system is about $63 \%$ more than polyurethane because the vinyl ester resin used herein is a high elongation resin which is a hybrid of epoxy and urethane. The change of first and second slope is at about $57 \%$ and $81 \%$ of maximum stress respectively in vinylester resin system. The ratio of change of first and second slope is 1.2 while that of second and third slope is 1.6.These test date are described in greater depth in Chapter 5. 


\section{CHAPTER 5}

\section{DISCUSSION OF EXPERIMENTAL TEST RESULTS}

In this chapter, stress-strain behavior of composites (without and with normalization of stresses) under tension and bending loads. Load-deflection behavior of composites is provided in Section 5.1. Sections 5.2 and 5.3 describe effects of fiber architecture on ultimate strain and strength respectively. A glance on stiffness without and with normalization is discussed in Section 5.4. The effect of resin type in pultruded composites is presented in Section 5.5. Section 5.6 briefly talks on effect of loading on composites with different types of fiber architecture. Effect of process on structural properties of composites is provided in Section 5.7 and finally Section 5.8 discusses on failure modes.

\subsection{Stress-Strain Behavior}

The unidirectional composite system is highly orthotropic and introduction of cross-ply and angle ply fiber in a laminate changes the composite system to quasi isotropic. In this section the stress-strain behavior of pultruded composites with uni-, bi-, tri-, and quadri-directional fabrics under tension and bending loads are discussed in depth.

\subsubsection{Tension Response}

\subsubsection{Without Normalization of stress:}

Figure 5.1 shows stress-strain behavior of composites with uni-, bi-, tri- and quadri directional fabrics under tensile loading. The Figure 5.1 depicts that the intensity of nonlinearity in the stress-strain curve is more in tri- and quadri directional composites and less in uni and bi-directional composites. All the responses show linearity up to certain loading and then behave non-linearly up to maximum load. All uni-, bi- and quadri-directional composites have bilinear curves while those tri-directional ones have tri-linear curves. At the point of 
change in slope, micro cracking or micro delam initiates in the composites. It is observed that for composites with uni-, bi-, tri- with CSM, and quadri-directional fabrics, the change of slope takes place at about $33 \% \sim 40 \%$ of maximum load (Table 4.1 thru Table 4.4) but in tri directional fabric composites without CSM, the change in slope is at about $29 \%$ of maximum load (Table 4.3). As mentioned earlier this is attributed to presence of $\pm 45^{\circ}$ fibers, and without CSM, the micro cracks initiate earlier (Table 4.3) than in composites with CSM. In case of tridirectional composites (absence of $0^{0}$ ) change in slope at second bifurcation point is around $74 \%$ of maximum load in case where there is no CSM and about $69 \%$ in case of presence of CSM which indicates that cracking of fibers would have initiated. For composites with uni-, bi-, and quadri-directional fabrics, the ratio of change of slope between first and second is between $1.2 \sim 1.3$ while in case of tri-directional fabrics the ratio is about 1.8 2.0. 


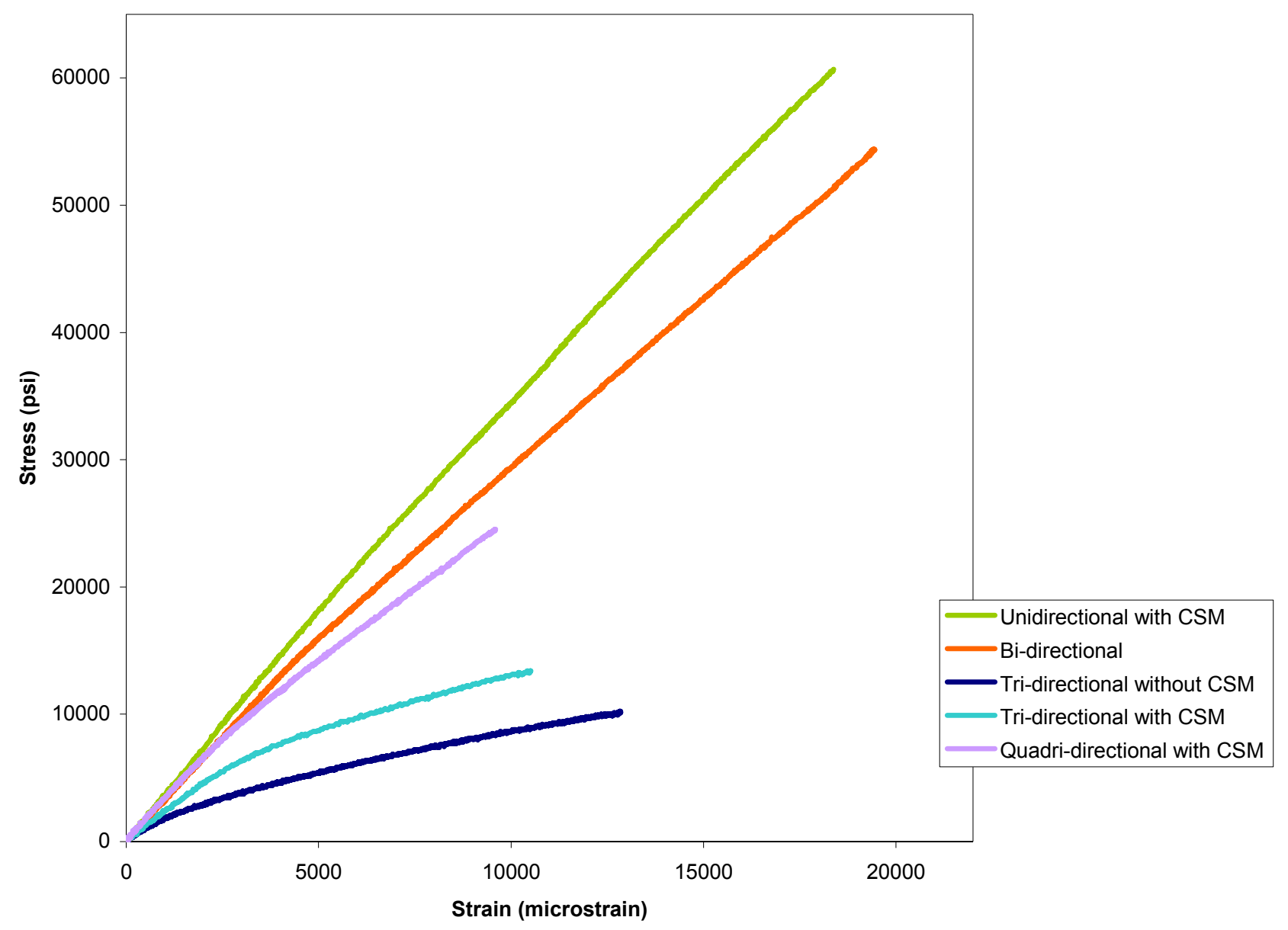

Figure 5.1 Typical Stress-Strain Curve of Composites with Various Fiber Architecture (tension)

\subsubsection{With Normalization of stress:}

Normalized stress with respect to effective FVF (\% of fibers in loading direction) for various fiber architecture is shown in Figure 5.2. From Figure 5.2 we can 


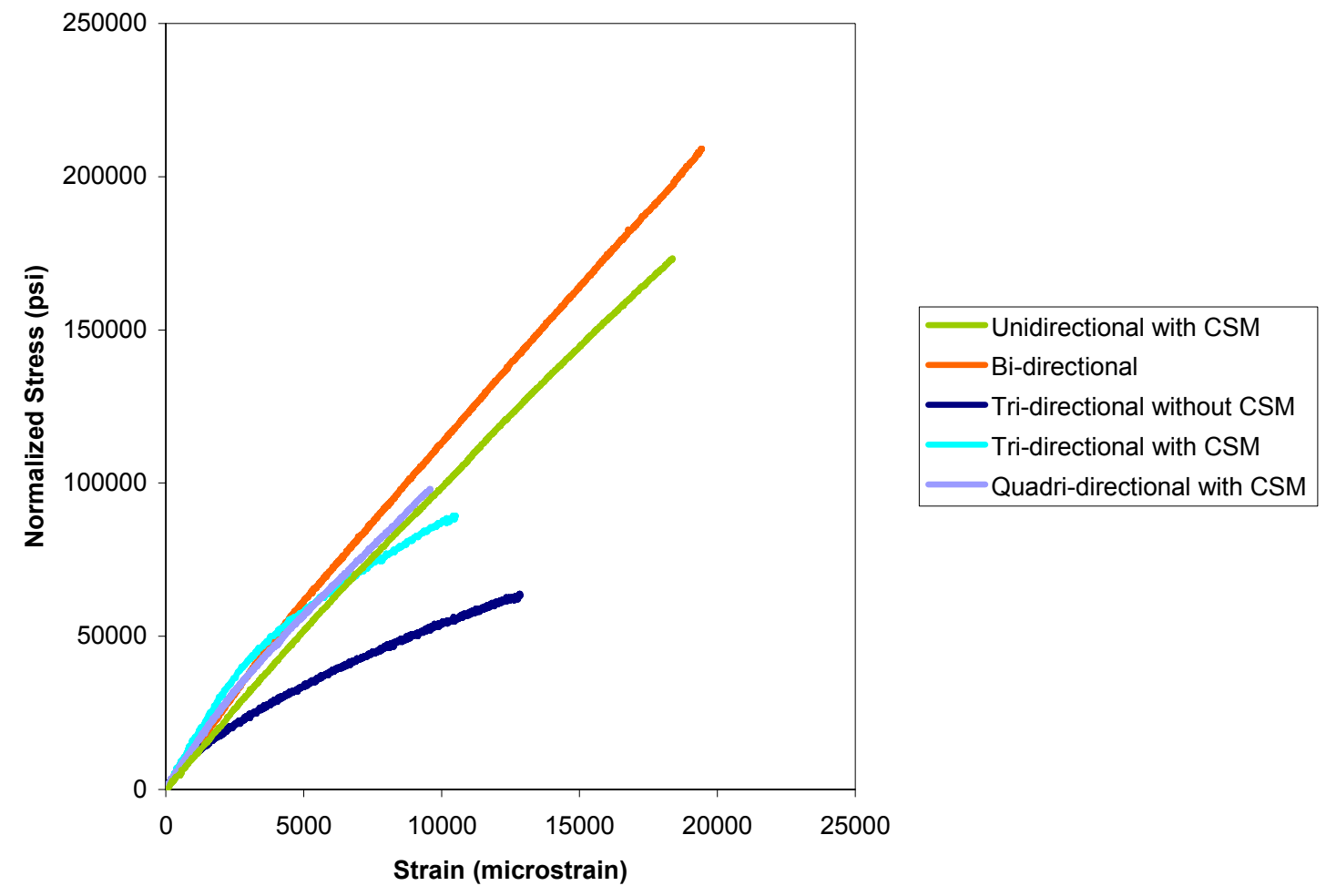

Figure 5.2 Typical Normalized Stress-Strain Curve of Composites with Various Fiber Architecture (tension)

observe that in tri-directional fabric composites, the intensity of non-linearity is more compared to uni-, bi-, and quadri-, which is attributed to absence of $0^{\circ}$ fibers in the load carrying direction, i.e., $0^{\circ}$ direction. The presence of CSM in tridirectional composites contributes to carrying more load than the ones without CSM. Details on maximum tensile strength based on normalized stress (Figure 5.2) for various fiber architecture shall be discussed more in details in Section 5.3.

\subsubsection{Bending Response}

\subsubsection{Stress-Strain Behavior}

Figure 5.3 shows the stress-strain behavior of composites with uni-, bi-, tri- and quadri-directional fabrics under bending. Figure 5.3 depicts that the intensity of 
nonlinearity in the stress-strain curve is more in tri-directional composites and less in uni- or bi-directional or even in quadri-directional composites. In bending the quadri-directional fabric behaves more of quasi-isotropic and the presence of $\pm 45^{\circ}$ does not affect as much as in tension. The tri-directional fabric is more nonlinear due to the absence of $0^{0}$ fibers or higher stress concentration effects. Like tension, all bending stress-strain curves show linearity up to certain percent of peak loading and then behave non-linearly up to peak load. It is observed that for composites with uni- directional fabrics, the change of first slope takes place at about $50 \%$ of maximum stress, in case of bi-directional the change of first slope is at $22 \%$, and for all other fabrics i.e, tri- and quadri-directional fabrics, the change of first slope is at about $31 \%-34 \%$. In unidirectional composites with CSM, at $50 \%$ of load, there might be delamination of mat. In case of bi-directional composites at $22 \%$ of load, failure in transverse direction is postulated. Ishai et.al., 1970 in his study found that there was abrupt decrease of slope in stressstrain curve for glass-epoxy composites, which the author associates with appearance of first crack in transverse layer. The second change of slope for uni- and quadri-directional fabrics occurs at about $80 \%$ of ultimate load, $65 \%$ for bi-directional and about $70 \%$ for tri-directional fabrics. For composites with uni-, bi-, and quadri-directional fabrics, the ratio of change of slope between first and second is 1.2 while in case of tri-directional fabrics the ratio is about 1.7. Ratios of changes in second and third slopes is about 1.4 for all composites. 


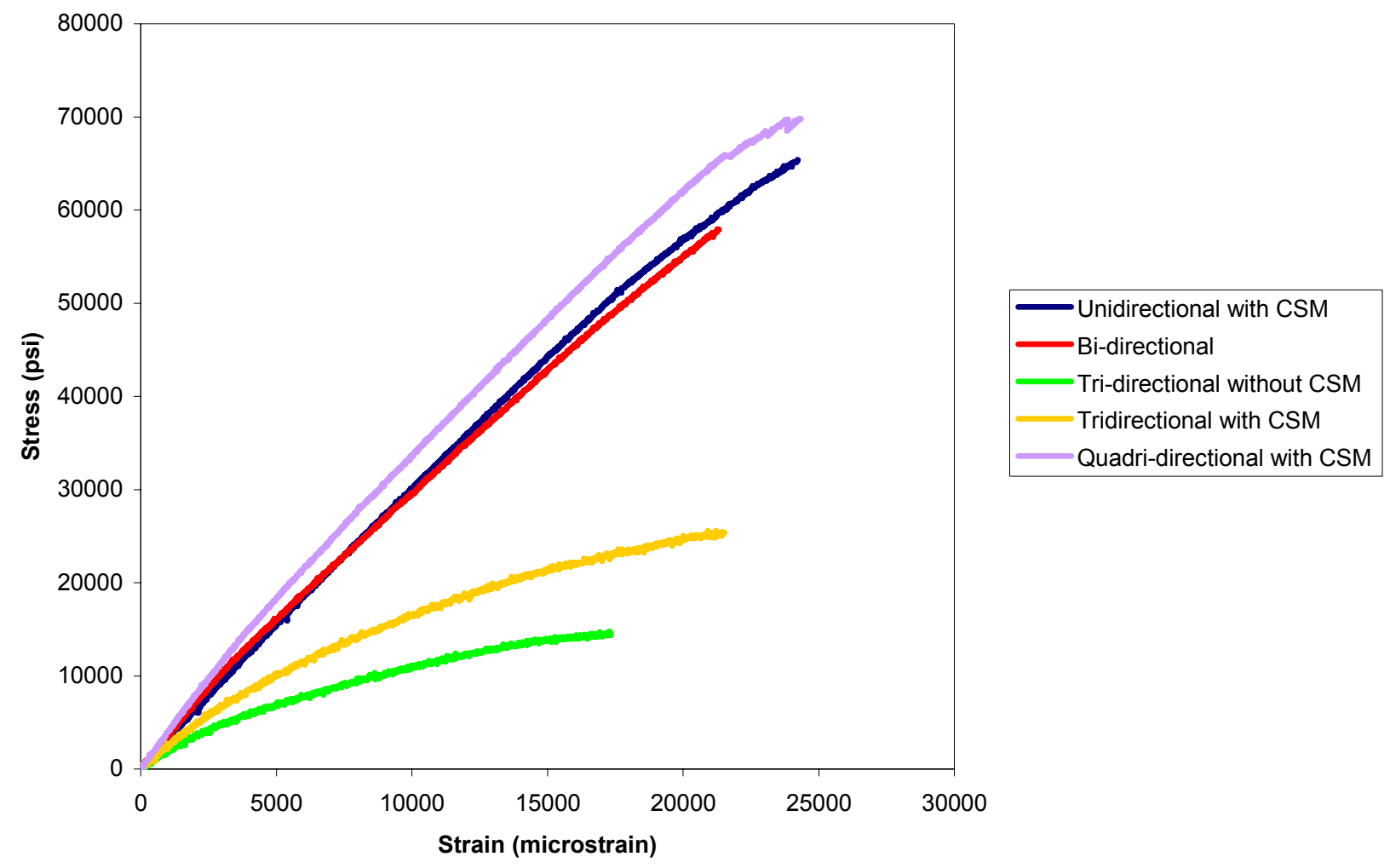

Figure 5.3 Stress-strain curve of composites with various fiber architecture (bending)

\subsubsection{With Normalization of stress:}

Normalized stress with respect to effective FVF (\% of fibers in loading direction) for various fiber architecture is shown in Figure 5.4. Neumeister et.al., 1996, has mentioned in his study that "A simple measure of how efficiently the fibers are used in each material, is the ultimate stress divided by the fiber volume fraction in the $0^{\circ}$ direction". From Figure 5.4 we can observe that the behavior of bi- and quadri-directional composites is of similar trend for effective FVF of about $25 \%$. The trend of tri-directional composites under bending is similar to Figure 5.3. Details on maximum bending strength based on normalized stress (Figure 5.4) for various fiber architecture shall be discussed in Section 5.3. 


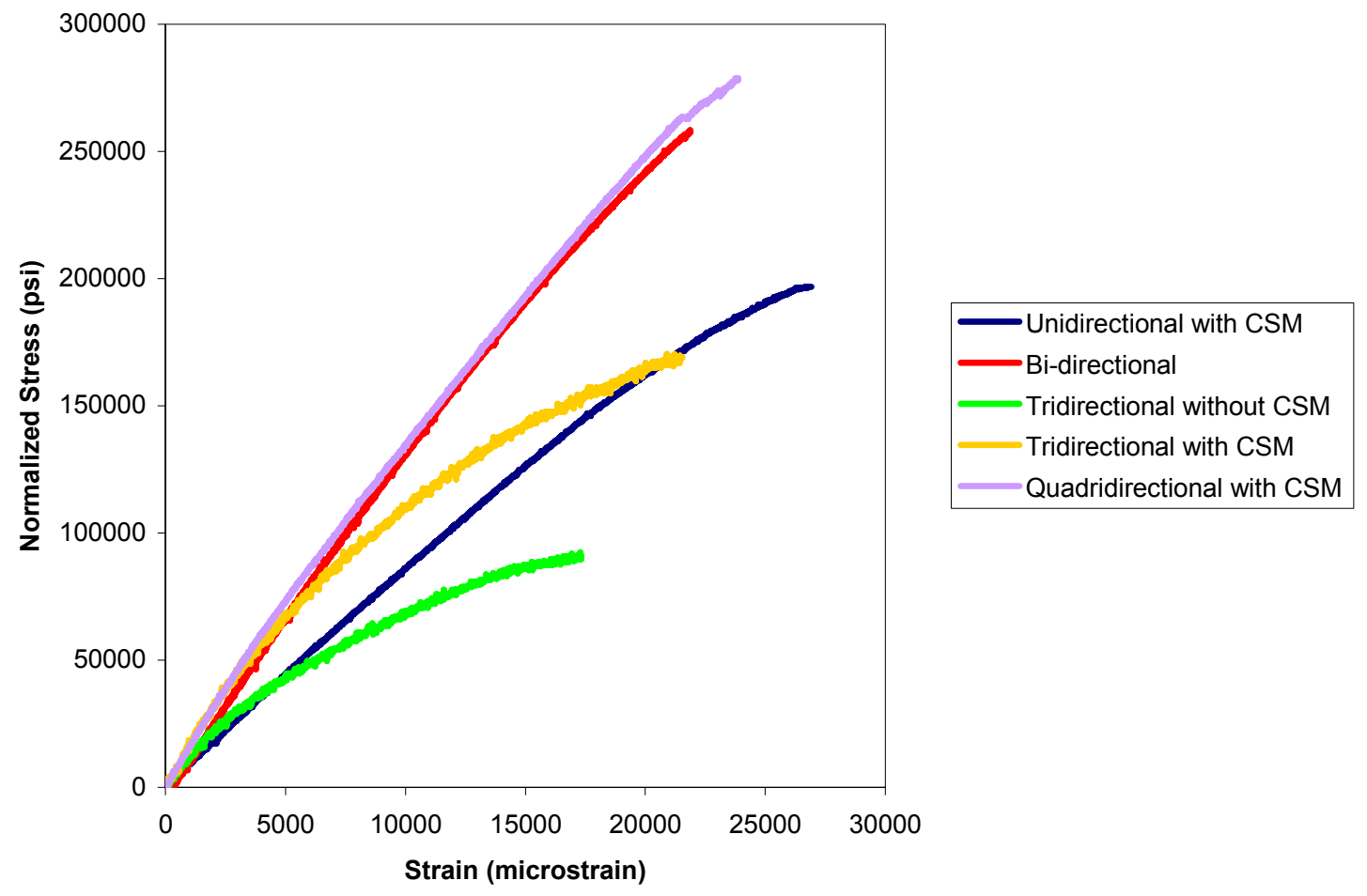

Figure 5.4 Typical Normalized Stress-Strain Curve of Composites with Various Fiber Architecture (bending)

\subsubsection{Load-Deflection Behavior}

Figure 5.5 shows load vs deflection response for composites with various fiber architecture under bending loads. All the curves show that the trend after the maximum load is somewhat similar, i.e, once the maximum load is achieved sudden drop in load is observed and fraction of load is picked up for additional strain. The overall response beyond the maximum load shows that composites have enough ductility beyond the maximum load. 


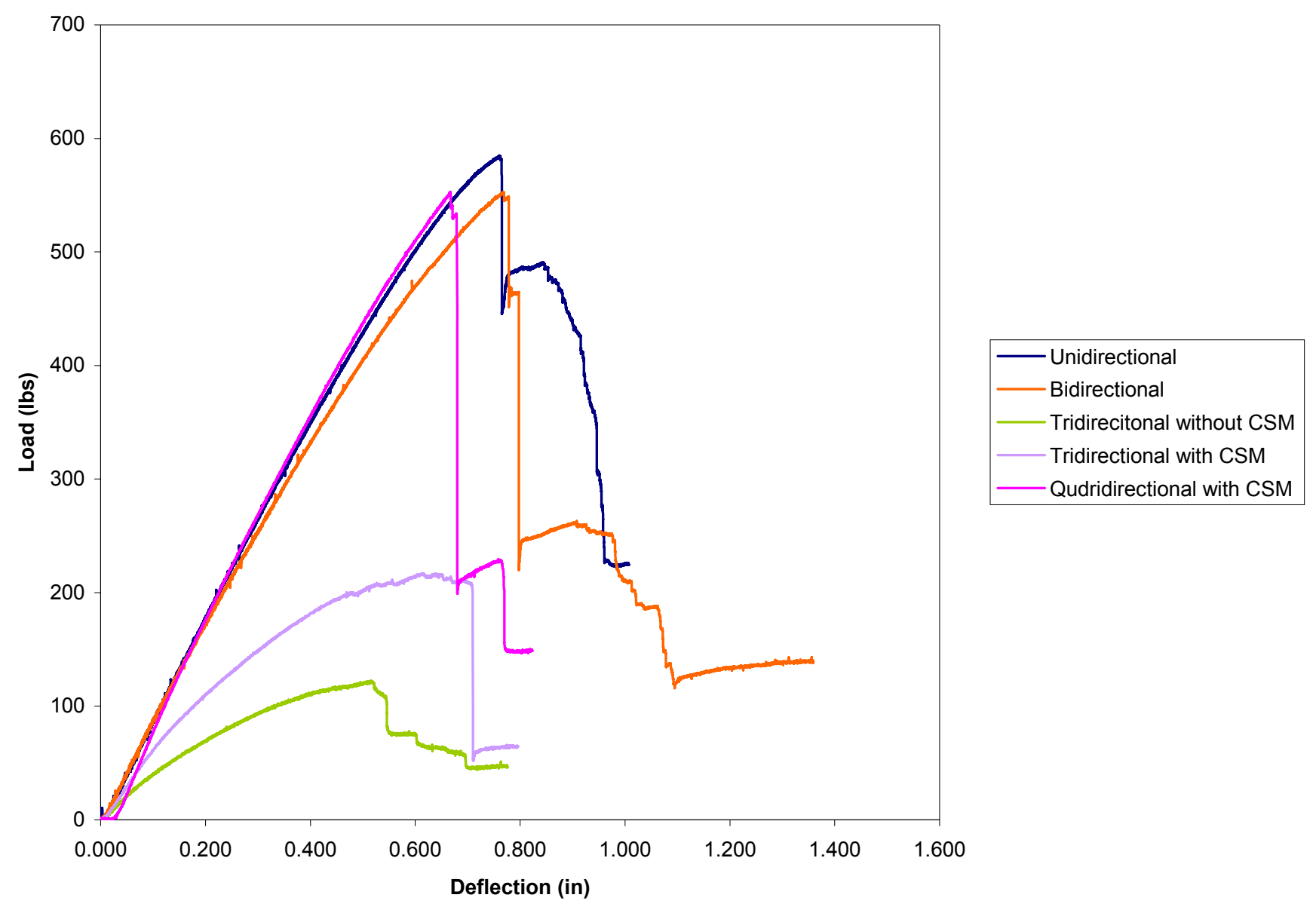

Figure 5.5 Typical Load-deflection Curve of Composites with Various Fiber Architecture (bending)

\subsection{Effect of Fiber Architecture on Ultimate Strain}

In this study, four types of fiber architecture i.e., uni-, bi-, tri- and quadridirectional pultruded composites having 45\% - 55\% FVF have been investigated. Fiber orientation is one of the most crucial variables, which determines the mechanical properties of composite (Kardos, 1985). Table 5.1 shows the average maximum strain of composites with uni-, bi-, tri- and quadri-directional fabrics under tensile and bending loads. We can observe that the maximum tensile strain ranged anywhere from 10,000 to 21000 microstrains while the bending strain ranges from 15,000 to 26,000 microstrains. A similar trend in ultimate strain was noted by Haj-Ali et.al., (2002) in a study conducted on 
pultruded FRP composites wherein the ultimate axial strain values were between 1.0 to $2.2 \%$ for fabric based pultruded coupons. Table 5.1 indicates that there is reduction in maximum strain with change in fiber orientations regardless of loading conditions. The reduction factor is attributed to cris-crossing fibers in a given laminate. For both tension and bending, the higher level of cris-crossing of fibers leads to greater reduction factor. In case of tension, reduction factor varies from 1.04 to 2.10 , while in case of bending the reduction factor varies from 1.11 to 1.60 with respect to unidirectional. The reduction factor under tensile loading is least in uni- and bi-directional and high in tri- and quadri-directional composites because the more cris-crossing of off-axis plies, results in higher stress concentration factor. Also, the off-axis ply gets disturbed due to cutting (which also prevails in $0 / 90$ fibers) and have edge effect due to which each lamina is not fully effective at the edge. In case of bending, the reduction factor is least in bidirectional and high in tri-directional composites. The qudri-direcitonal fabrics behave more like quasi-isotropic material especially in the presence of CSM.

Table 5.1 Ultimate strain of uni, bi, tri and quadri-directional composites

\begin{tabular}{|l|c|c|c|c|}
\hline \multirow{2}{*}{ Fiber Architecture } & \multicolumn{2}{|c|}{$\begin{array}{c}\text { Average ultimate strain } \\
(\mu \varepsilon)\end{array}$} & $\begin{array}{c}\text { Reduction factor in strain due } \\
\text { to various fiber } \\
\left(\mathbf{0}^{\mathbf{0}}, \mathbf{9 0}^{\circ}, \mathbf{\pm} \mathbf{4 5}^{\circ}\right)\end{array}$ \\
\hline & Tension & Bending & Tension & Bending \\
\hline Unidirectional & 21188 & 25296 & 1.00 & 1.00 \\
\hline Bi-directional & 20392 & 22842 & 1.04 & 1.11 \\
\hline Tri-directional & 11502 & 15846 & 1.84 & 1.60 \\
\hline Tri-directional with CSM & 11486 & 18647 & 1.84 & 1.36 \\
\hline Quadri-directional with CSM & 10075 & 20991 & 2.10 & 1.21 \\
\hline
\end{tabular}




\subsection{Effect of Fiber Architecture on Ultimate Strength}

\subsubsection{Without Normalization of Strength}

A slight deviation within $\pm 10^{\circ}$ of the unidirectional stress from major fiber direction results in pronounced strength drop (Azzi et.al., 1965; Ishai et al., 1968). The ultimate strength of uni-, bi-, tri- and quadri-directional composites under tensile and bending loads are shown in Table 5.2. In comparison with unidirectional composites under tensile loading, we can see that, there is about $10 \%$ decrease in maximum strength in bi-directional composites, $60 \%$ decrease in quadridirectional and about $80 \%$ decrease in tri-directional composites. The $10 \%$ decrease in ultimate strength in bi-directional composites compared to unidirectional composites simply reflects $10 \%$ decrease in total FVF between uni and bi-directional composites which means that the tensile strength is driven by FVF. In case of bi-and quadri -directional composites, though both have about $25 \%$ effective FVF in the loading direction of fibers, a significant amount of decrease in maximum strength is noted in quadri-directional composites, compared to bi-directional composites. This is because the off-axis plies have greater influence under tensile loading i.e, when composite with off-axis plies are stretched the overall fiber orientation is disturbed which further decreases the mechanical properties of the composites. This concepts correlates well with the study conducted by Leong et.al.(1999) on knitted glass fabrics, wherein he found that when knitted fabrics is stretched, the overall distribution and fiber orientations were changed, leading to significant changes on tension and compression properties.

The fibers/fabrics are not stretched in bending as much as they are in tension. Hence, no significant difference in ultimate strength between bi-, and quadridirectional composites is noted. The quadri-directional composites behave more like quasi-isotropic material and therefore the strength remains same as bidirectional composite since both have same effective fiber volume fraction in the loading direction ( $25 \%)$. We can also observe that the presence of CSM in 
tri-directional composites is favorable to ultimate strength in composites specifically under bending loads. Moreover the interfacial bonding between the fiber and resin controls bending strength of composites.

Table 5.2 Ultimate strength of uni, bi, tri and quadri-directional composites

\begin{tabular}{|l|c|c|c|c|}
\hline \multicolumn{1}{|c|}{ Fiber Architecture } & $\begin{array}{c}\text { FVF } \\
(\%)\end{array}$ & $\begin{array}{c}\text { FVF-X } \\
(\%)\end{array}$ & \multicolumn{2}{c|}{$\begin{array}{c}\text { Ave. Ultimate Stress } \\
\text { (ksi) }\end{array}$} \\
\hline & & & Tension & Bending \\
\hline Unidirectional & 45 & 35 & 64 & 70 \\
\hline Bi-directional & 52 & 26 & 57 & 68 \\
\hline Tri-directional & 55 & 16 & 10 & 15 \\
\hline Tri-directional with CSM & 51 & 15 & 14 & 26 \\
\hline Quadri-directional with CSM & 55 & 25 & 26 & 68 \\
\hline
\end{tabular}

\subsubsection{With Normalization of Strength}

The normalized maximum tensile and bending strength for various fiber architecture is shown in Table 5.3. The normalized strength for all fiber architecture shown in Table 5.3, should have remained constant (under both tensile and bending loads) if the longitudinal fibers were alone and effective in taking the load at failure (Numeister et.al., 1996); however in Table 5.3 the strength for various architecture are differing. The normalized maximum tensile strength of bi-directional composites is $20 \%$ higher than that in uni-directional composites, because $90^{\circ}$ fibers act as support points and help in $0^{\circ}$ fibers in taking more loads before failure. In quari-directional composites, the normalized maximum strength is about one half of bi-directional composites. Though quadri's have more supporting points in helping $0^{0}$ fibers to take more load, the $\pm 45^{\circ}$ fibers are not contributing as effectively as $90^{\circ}$. In case of tri-directional fabric composites, both the composites, with and without CSM, have effective FVF of $15 \%$ of the tri-directional composites with CSM being more than in composites without CSM. Here again, CSM contributes towards the strength. 
With regards to bending, we can observe that normalized maximum strength for bi- and quadri-directional composites are almost same (Refer Figure 5.4) because the effective FVF for both composite is about $25 \%$. As in tension, the bending strength of uni's is low compared to bi or quadri's because in bending CSM does not contributes towards strength as $90^{\circ}$ or $\pm 45^{\circ}$ fibers contributes. In case of tri-, the ones with CSM is nearly twice the bending strength without CSM.

Table 5.3 Normalized Maximum Strength

\begin{tabular}{|l|c|c|c|c|}
\hline \multicolumn{1}{|c|}{ Fiber Architecture } & $\begin{array}{c}\text { FVF } \\
(\%)\end{array}$ & $\begin{array}{c}\text { FVF-X } \\
(\%)\end{array}$ & \multicolumn{2}{c|}{ Nominal Maximum Stress } \\
& & & Tension & Bending \\
\hline Unidirectional & 45 & 35 & 183 & 200 \\
\hline Bi-directional & 52 & 26 & 219 & 261 \\
\hline Tri-directional & 55 & 16 & 63 & 94 \\
\hline Tri-directional with CSM & 51 & 15 & 93 & 173 \\
\hline Quadri-directional with CSM & 55 & 25 & 104 & 272 \\
\hline
\end{tabular}

\subsection{A Glance at Stiffness}

\subsubsection{Without Normalization of Stiffness}

The stiffness of pultruded glass composites having different fiber/fabric architectures have been evaluated based on stress-strain response under tension and bending. The experimental stiffness as are calculated from the tangents of stress-strain curves. E $\alpha$, and $E \beta$, correspond to the first tangent modulus and second tangent modulus of non-linear stress-strain curves. Theoretical modulus (EROM) is obtained using rule of mixtures considering the effective fiber volume fraction in the loading direction. From table 5.4, it is observed that tensile or bending modulus does not coincide with EROM. This may be attributed to manufacturing defects such as voids, improper we-out, 
micro cracks or fiber breakages existing in the composites even before they are tested. The EROM does not account for such preexisting defects.

Table 5.4 Stiffness of uni, bi, tri and quadri-directional composites

\begin{tabular}{|c|c|c|c|c|c|c|c|}
\hline \multirow[t]{3}{*}{ Fiber Architecture } & \multirow[t]{3}{*}{$\begin{array}{l}\text { FVF } \\
(\%)\end{array}$} & \multirow[t]{3}{*}{$\begin{array}{c}\text { FVF-X } \\
(\%)\end{array}$} & \multicolumn{2}{|c|}{$\begin{array}{c}\text { Average } \\
\text { Stiffness (msi) }\end{array}$} & \multicolumn{2}{|c|}{$\begin{array}{c}\text { Average Stiffness } \\
\text { (msi) }\end{array}$} & \multirow[b]{3}{*}{$\begin{array}{c}\text { EROM } \\
\text { (msi) }\end{array}$} \\
\hline & & & \multicolumn{2}{|c|}{ Tension } & \multicolumn{2}{|c|}{ Bending } & \\
\hline & & & $\begin{array}{c}\mathrm{E \alpha} \\
\text { (msi) }\end{array}$ & $\begin{array}{c}E \beta \\
(m s i)\end{array}$ & $\begin{array}{c}\mathrm{E \alpha} \\
(\mathrm{msi})\end{array}$ & $\begin{array}{c}\mathrm{E} \beta \\
(\mathrm{msi})\end{array}$ & \\
\hline Unidirectional 1 & 44 & 34 & 3.5 & 3.1 & 3.1 & 2.7 & 3.85 \\
\hline Bi-directional & 52 & 26 & 3.3 & 2.7 & 3.8 & 3.4 & 2.97 \\
\hline Tri-directional & 55 & 16 & 1.61 & 0.80 & 1.6 & 1.0 & 1.91 \\
\hline Tri-directional with CSM & 51 & 15 & 2.13 & 1.20 & 2.4 & 1.6 & 1.82 \\
\hline Quadri-directional with CSM & 55 & 25 & 3.15 & 2.39 & 4.0 & 3.3 & 2.85 \\
\hline
\end{tabular}

\subsubsection{With Normalization of Stiffness}

Table 5.5 shows normalized tensile and bending stiffness with respect to effective FVF in the loading directions. The first tangent tensile modulus ranges between 10 to $14 \mathrm{msi}$ and bending modulus ranges from 9 to $16 \mathrm{msi}$.

One must realize that the normalized stiffness cannot exceed the stiffness of glass fiber, which is around 10.4 msi. However, stiffness values exceeding 10.4 msi imply that fibers in directions other than the loading direction are contributing to the stiffness in the loading direction. 
Table 5.5 Normalized Tensile and Bending Stiffness

\begin{tabular}{|c|c|c|c|c|c|c|}
\hline \multirow[t]{3}{*}{ Fiber Architecture } & \multirow[t]{3}{*}{$\begin{array}{l}\text { FVF } \\
(\%)\end{array}$} & \multirow[t]{3}{*}{$\begin{array}{l}\text { FVF-X } \\
(\%)\end{array}$} & \multicolumn{2}{|c|}{$\begin{array}{c}\text { Average } \\
\text { Stiffness (msi) }\end{array}$} & \multicolumn{2}{|c|}{$\begin{array}{c}\text { Average Stiffness } \\
\text { (msi) }\end{array}$} \\
\hline & & & \multicolumn{2}{|c|}{ Tension } & \multicolumn{2}{|c|}{ Bending } \\
\hline & & & $\begin{array}{c}\text { Ea } \\
\text { (msi) }\end{array}$ & $\begin{array}{c}\mathrm{E} \beta \\
(\mathrm{msi})\end{array}$ & $\begin{array}{c}\mathrm{E \alpha} \\
(\mathrm{msi})\end{array}$ & $\begin{array}{c}\mathrm{E} \beta \\
(\mathrm{msi})\end{array}$ \\
\hline Unidirectional 1 & 44 & 34 & 10.3 & 9.1 & 9.1 & 7.9 \\
\hline Bi-directional & 52 & 26 & 12.7 & 10.4 & 14.6 & 13.1 \\
\hline Tri-directional & 55 & 16 & 10.1 & 5.0 & 10 & 6.25 \\
\hline Tri-directional with CSM & 51 & 15 & 14.2 & 8.0 & 16 & 10.6 \\
\hline Quadri-directional with CSM & 55 & 25 & 12.6 & 9.56 & 16 & 13.2 \\
\hline
\end{tabular}

\subsection{Effect of Resin Type in Pultruded Composites}

\subsubsection{Stress-Strain Behavior- Without Normalization of Stress}

As discussed in section 4.5, the mechanical properties of multidirectional composites having same thickness, FVF, fiber architecture with two different resin system namely polyurethane and vinyl ester has been evaluated. Figures 5.6 and 5.7 show stress-strain behavior of composites with polyurethane and vinylester under tension and bending, respectively. Figure 5.8 shows loaddeflection response of composites with different resins.

Figures 5.6 and 5.7 show that stress-strain behavior (under both tension and bending) for composites with polyurethane is linear while that for vinylester has exhibited bilinear slopes. This indicates that composites with polyurethane does not develop any microcracks until the load reaches its maximum, while in the vinylester resin system, the cracks initiates at about $40 \%$ to $50 \%$ of ultimate load. 


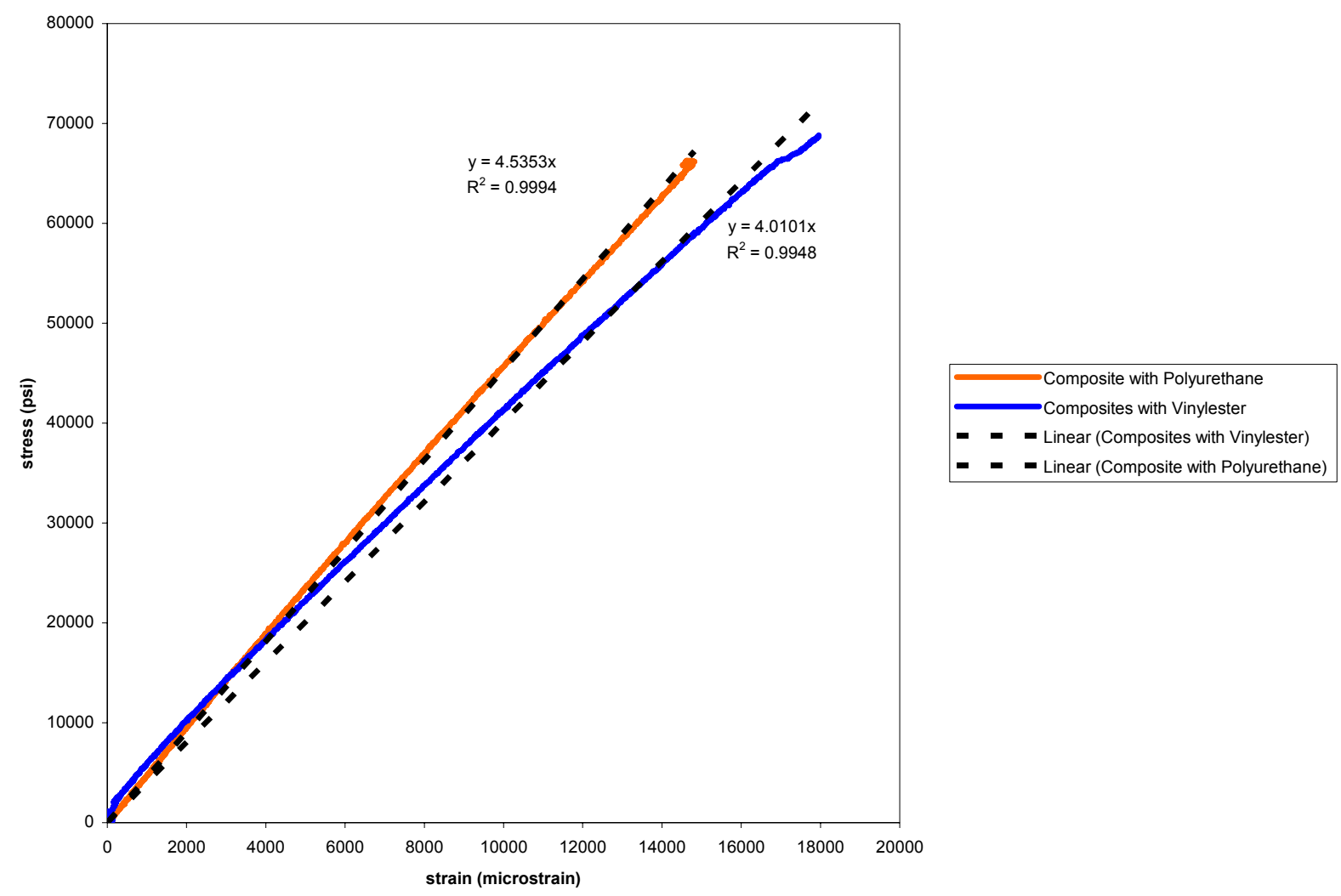

Figure 5.6 Stress-Strain Curve of Composites with Different Resin (tension)

Table 5.6 shows the structural response of composites with polyurethane and vinylester resin system.

Table 5.6 Structural properties of composites with polyurethane and vinyl ester resin system

\begin{tabular}{|l|c|c|}
\hline \multicolumn{1}{|c|}{ Structural Parameters } & \multicolumn{2}{|c|}{ Resin System } \\
\hline & Polyurethane & Vinylester \\
\hline Overall FVF $(\%)$ & 53 & 51 \\
\hline FVF- X (\%) & 43 & 38 \\
\hline Average Ultimate Tensile Strain ( $\mu \varepsilon)$ & 13438 & 18133 \\
\hline Average Ultimate Tensile Stress $(\mathrm{ksi})$ & 62 & 68 \\
\hline Average Tensile Stiffness (msi) & 4.59 & 4.09 \\
\hline Average Ultimate Bending Strain $(\mu \varepsilon)$ & 16583 & 26960 \\
\hline Average Ultimate Bending Stress $(\mathrm{ksi})$ & 64 & 70.8 \\
\hline Average Bending Stiffness (msi) & 3.9 & 3 \\
\hline
\end{tabular}




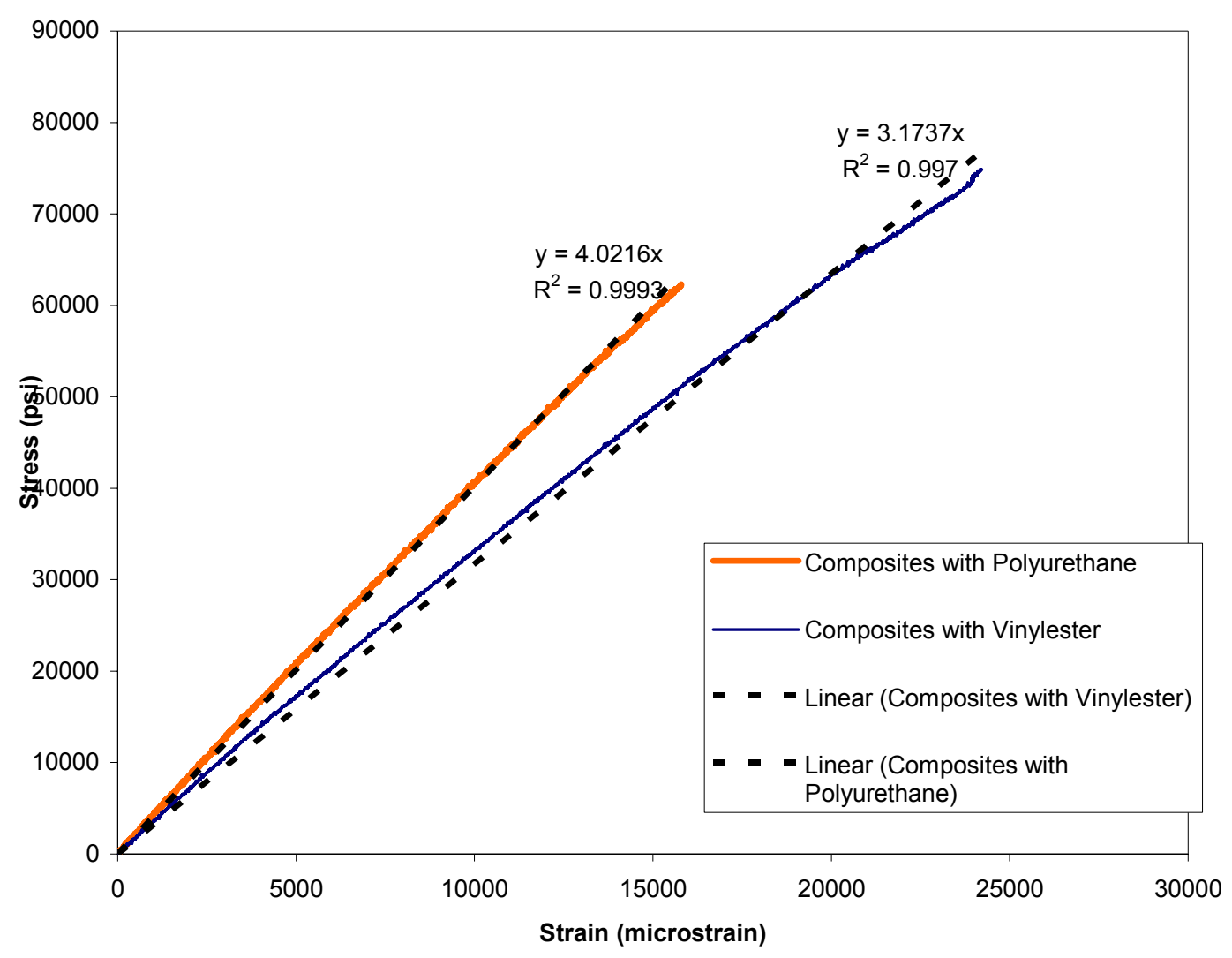

Figure 5.7 Stress-Strain Curve of Composites with Different Resin (bending)

It should be noted that the ultimate tensile strain of polyurethane composite is about $26 \%$ lesser than vinylester resin. In case of the bending strain, the polyurethane resin is about $38 \%$ lower than vinylester resin system. The difference in bending strain is attributed to inadequate binding capability of fibers and resin at the interfaces in urethane based composites. With respect to stress, both the tensile and bending stresses of the two resin systems are within $10 \%$ difference. As far as stiffness is concerned, the stiffness of composites with polyurethane is about $12 \%$ more than the vinyl ester in case of tension and $30 \%$ in bending. 


\subsubsection{Stress-Strain Behavior- With Normalization of Stress}

The normalized stress-strain behavior of two resin system under tension and bending is shown in Figures 5.8 and 5.9 respectively. Table 5.7 shows the normalized stress and stiffness for the two resin systems. In case of tension and bending, the normalized maximum stress for vinyl ester is about $25 \%$ more than that of polyurethane In case of stiffness, the normalized tensile stiffness for both resin is about $10 \mathrm{msi}$ and for bending the normalized bending stiffness is about 7 $\sim 9 \mathrm{msi}$.

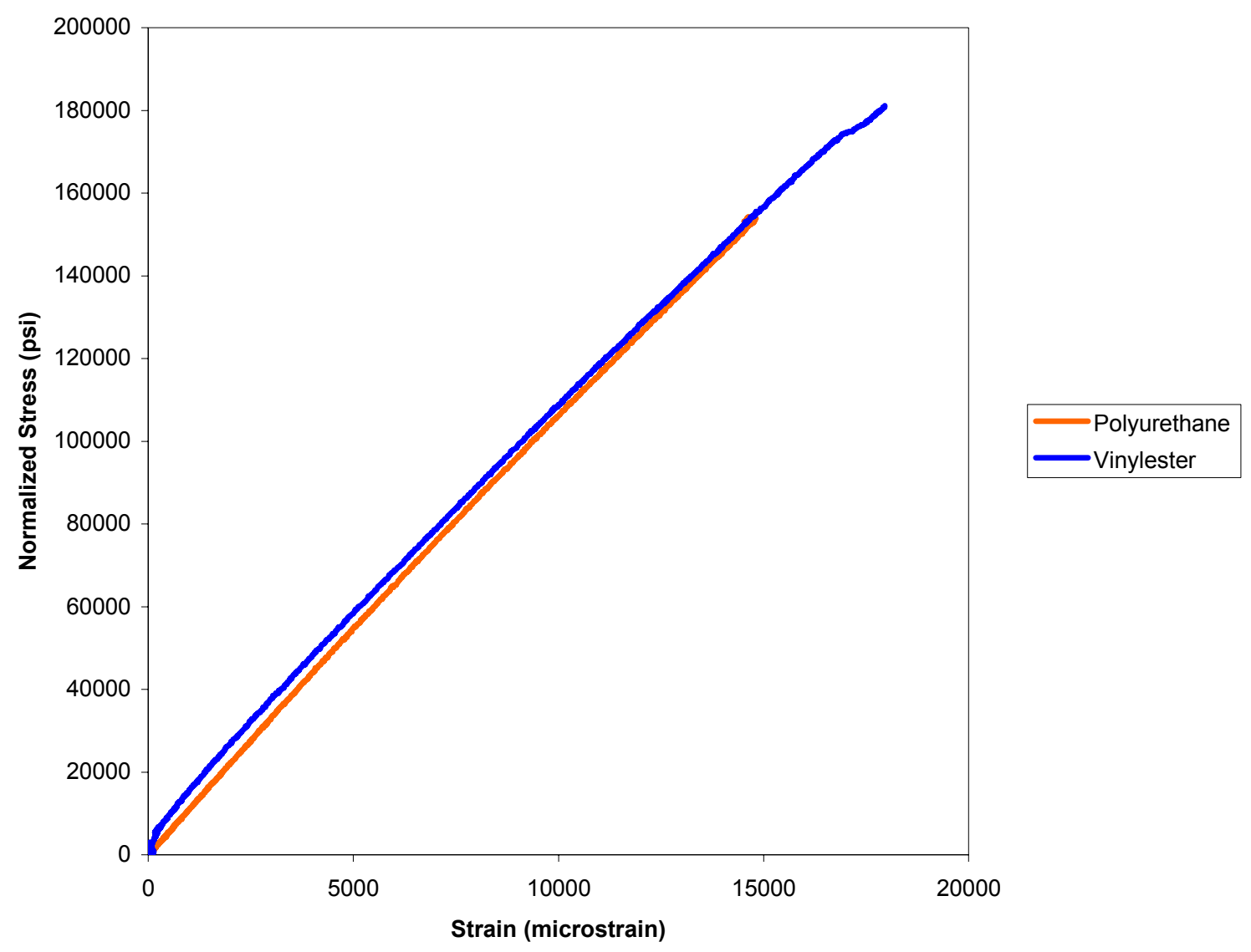

Figure 5.8 Typical Stress-Strain Curve of Composites with Different resin system (tension) 


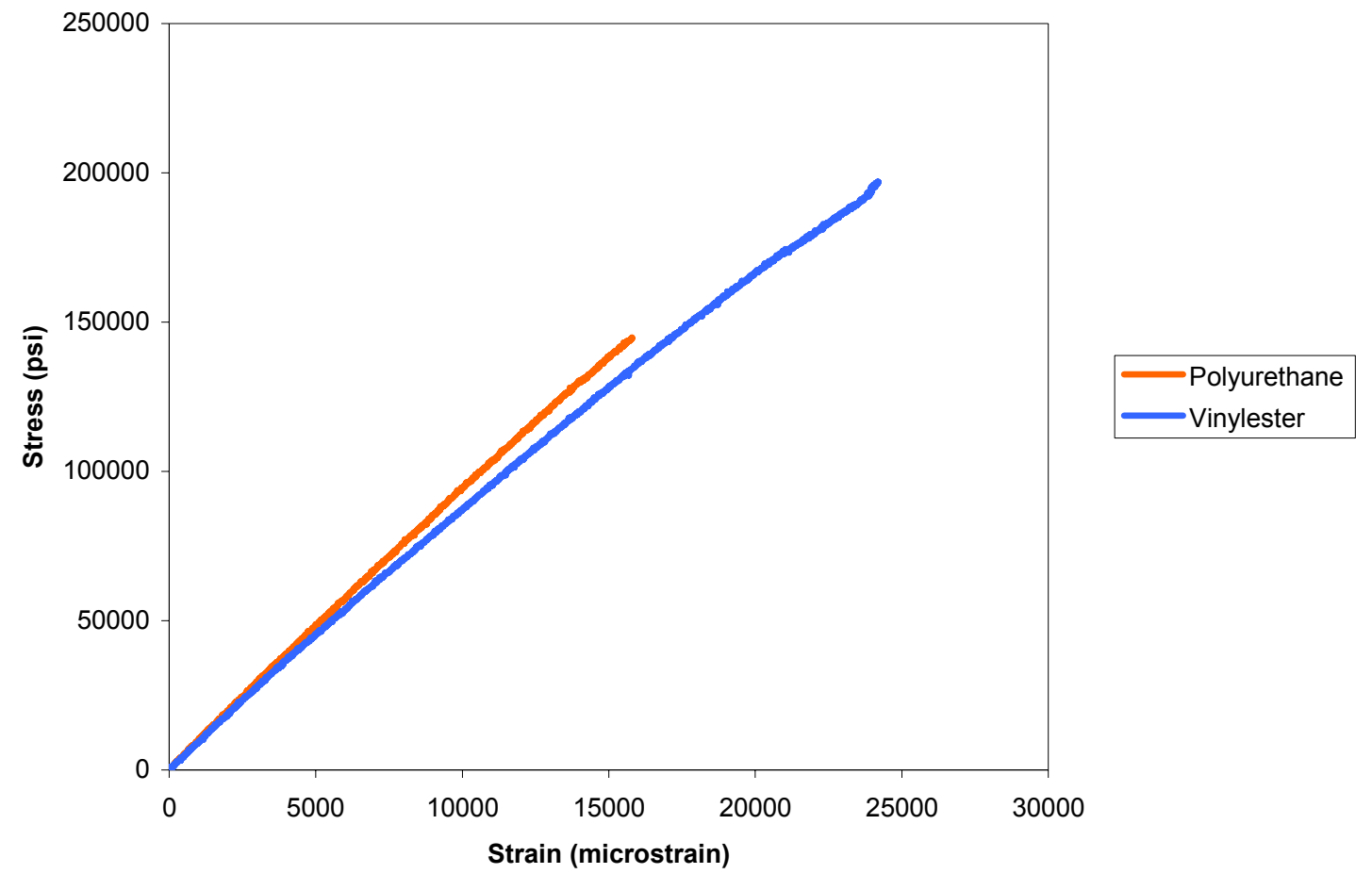

Figure 5.9 Typical Stress-Strain Curve of Composites with Different resin system (bending)

Table 5.7 Normalized Strength and Stiffness for Polyurethane and Vinylester

\begin{tabular}{|l|c|c|}
\hline \multicolumn{1}{|c|}{ Structural Parameters } & \multicolumn{2}{c|}{ Resin System } \\
\hline & Polyurethane & Vinylester \\
\hline Overall FVF (\%) & 53 & 51 \\
\hline FVF- X (\%) & 43 & 38 \\
\hline Normalized Ultimate Tensile Stress (ksi) & 144 & 179 \\
\hline Normalized Tensile Stiffness (msi) & 10.67 & 10.76 \\
\hline Normalized Ultimate Bending Stress (ksi) & 149 & 186 \\
\hline Normalized Bending Stiffness (msi) & 9.06 & 7.89 \\
\hline
\end{tabular}




\subsubsection{Load-Deflection Behavior}

Figure 5.10 indicates the load-deflection behavior for the two resin systems. It is obvious that vinylester has more ductility and toughness compared to polyurethane which indicates that vinylester resin is a high elongation resin.

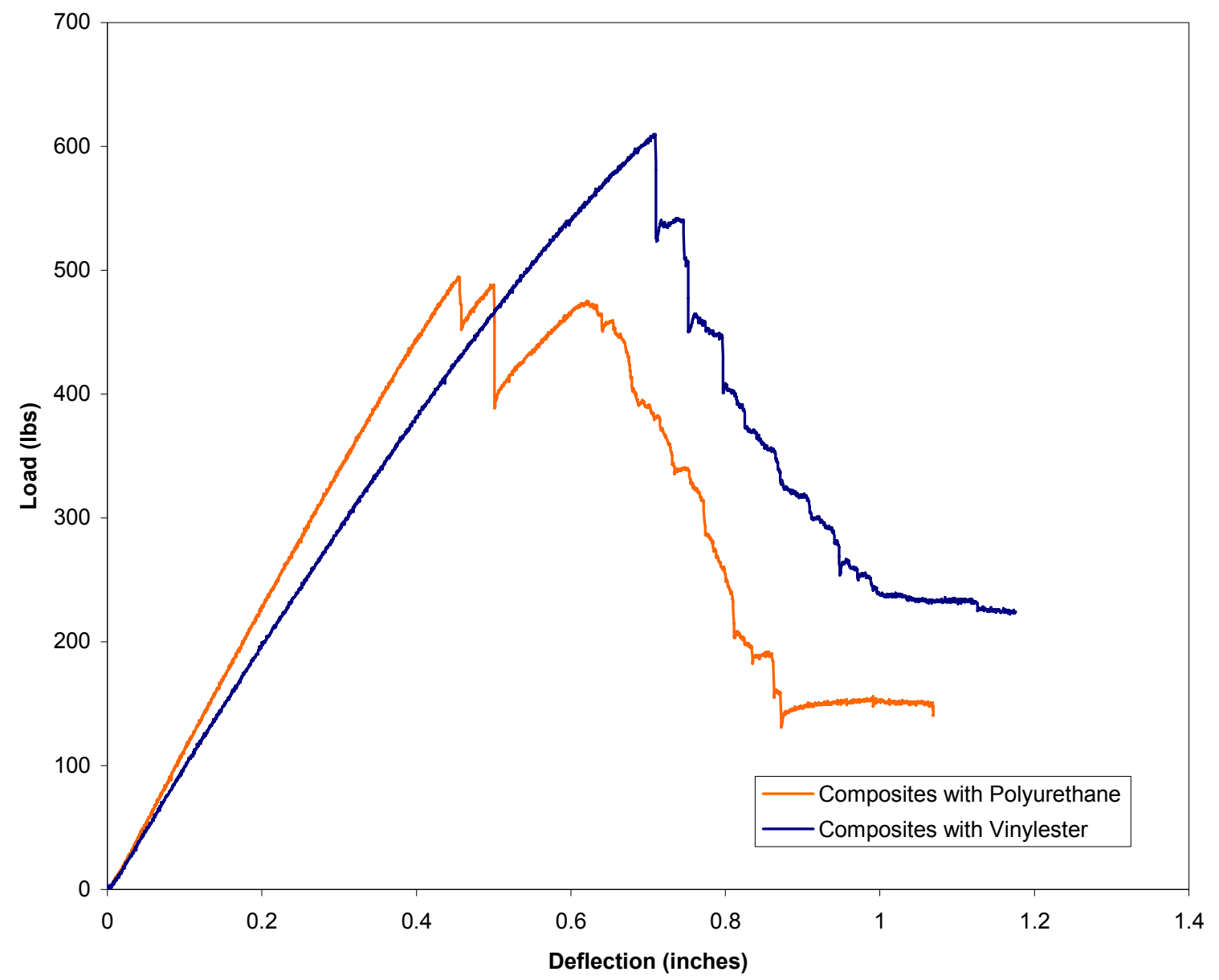

Figure 5.10 Load-deflection Curve of Composites with Different Resin System (bending) 


\subsection{Effect of Loading Conditions}

In general, the failure is mostly driven by the fiber orientations under tension. Especially the presence of $\pm 45^{\circ}$ fibers affects the overall structural performance of composite under tensile loading. This is attributed to the fact that, these fibers are pulled under tension during manufacturing and once they are further stretched under tensile loading, the laminate fails prematurely. Therefore the maximum strain of tri- or quadri-directional composites is less compared to unior bi-directional composites.

The bending failures are mostly driven by interfacial debond between fibers and resin system. Hayat et.al., 1998 noted in his study that fiber-matrix interface influences the mechanical and physical properties of composite materials under bending. In this study, the ultimate strength of composites varied depending upon the failure modes, which are different under tension compared to bending. Table 5.8 shows the ratio of bending strength to tensile strength varies anywhere from 1.09 to 2.62 .

Table 5.8 Ratio of Bending Strength to Tensile strength

\begin{tabular}{|l|c|c|c|}
\hline \multicolumn{1}{|c|}{ Fiber Architecture } & \multicolumn{2}{|c|}{ Average Ultimate Strength (ksi) } & Ben.Str./Ten.Str \\
\hline & Tension & Bending & \\
\hline Unidirectional & 64 & 70 & 1.09 \\
\hline Bi-directional & 57 & 68 & 1.19 \\
\hline Tri-directional & 10 & 15 & 1.50 \\
\hline Tri-directional with CSM & 14 & 26 & 1.86 \\
\hline Quadri-directional with CSM & 26 & 68 & 2.62 \\
\hline
\end{tabular}




\subsection{Effect of process conditions}

In this section, the effect of process conditions on structural performance of composites will be discussed. As mentioned in Chapter 2, composite plates of about $1 / 4$ " thick having same fiber architecture as pultruded plates were manufactured by compression molding process (Table 2.1 thru Table 2.3). The compression molded plates were tested under tension and bending similar to pultruded plates. Details of density, thickness, overall FVF, and FVF in the longitudinal direction are provided in Table 5.9. In pultrusion we can see that typically about $\sim 215 \mathrm{oz} / \mathrm{yd} 2$ of fabric produces a thickness of .25 " with an overall

FVF of about $50 \%$. In case of compression molding, the thickness varies for a given density of fabric. This might be because of human error involved during hand-lay up process. However, a FVF of maximum of $60 \%$ is achieved through compression molding process.

Table 5.9 Details on Physical Properties of Compression Molded vs Pultrusion Plates

\begin{tabular}{|l|c|c|c|c|c|c|c|c|}
\hline \multicolumn{1}{|c|}{ Fiber Architecture } & \multicolumn{2}{|c|}{ Density (oz/yd ${ }^{2}$ ) } & \multicolumn{2}{c|}{ Thickness (in) } & \multicolumn{2}{c|}{ FVF (\%) } & \multicolumn{2}{c|}{ FVF - X (\%) } \\
\hline & Pultrusion & $\begin{array}{c}\text { Comp. } \\
\text { Molding }\end{array}$ & Pultrusion & $\begin{array}{c}\text { Comp. } \\
\text { Molding }\end{array}$ & Pultrusion & $\begin{array}{c}\text { Comp. } \\
\text { Molding }\end{array}$ & $\begin{array}{c}\text { Comp. } \\
\text { Pultrusion } \\
\text { Molding }\end{array}$ \\
\hline Unidirectional & NA & 228 & 0.25 & 0.20 & 45 & $57-65$ & 35 & $57-65$ \\
\hline Bi-directional & 216 & $213-260$ & 0.25 & $0.22-0.28$ & 52 & $45-37$ & 26 & $22-18$ \\
\hline Tri-directional with CSM & 214 & 214 & 0.25 & $0.21-0.27$ & 51 & $59-44$ & 15 & $20-15$ \\
\hline Quadri-directional with CSM & $158^{*}$ & 245 & 0.25 & 0.23 & 55 & 55 & 25 & 28 \\
\hline
\end{tabular}

Note: * This was provided by manufacturer, however it is questionable.

Table 5.10 shows mechanical properties of compression molded plates under tension and bending loads. 
Table 5.10 Details on Mechanical Properties of Compression Molded Plates (Vadlamani, 2007)

\begin{tabular}{|l|c|c|c|c|c|c|}
\hline \multicolumn{1}{|c|}{ Fiber Architecture } & \multicolumn{3}{|c|}{ Tension } & \multicolumn{3}{c|}{ Bending } \\
\hline & $\begin{array}{c}\text { Ave.UIt. } \\
\text { Stress (ksi) }\end{array}$ & $\begin{array}{c}\text { Ave.Ult. } \\
\text { Strain }(\mu \varepsilon)\end{array}$ & $\begin{array}{c}\text { Stiffness } \\
(\mathbf{m s i})\end{array}$ & $\begin{array}{c}\text { Ave.Ult. } \\
\text { Stress } \\
(\mathbf{k s i})\end{array}$ & $\begin{array}{c}\text { Ave.UIt. } \\
\text { Strain }(\mu \varepsilon)\end{array}$ & $\begin{array}{c}\text { Stiffness } \\
(\mathbf{m s i})\end{array}$ \\
\hline Unidirectional & 100.7 & 16710 & 6.50 & 49.60 & 6562 & 7.63 \\
\hline Bi-directional & 56.3 & 22663 & 3.08 & 55.20 & 16941 & 3.48 \\
\hline Tri-directional with CSM & 22.3 & 19263 & 2.04 & 26.50 & 26134 & 1.54 \\
\hline Quadri-directional with CSM & 42.9 & 16850 & 3.06 & 57.00 & 17895 & 3.98 \\
\hline
\end{tabular}

Tension test results

Unidirectional:

- The average tensile stress for compression molded plates having unidirectional fibers is about $57 \%$ more than pultruded plates because the effective FVF in loading direction of compression molded plates is about $62 \%$ more than pultruded plates.

- The average tensile strain in compression molded plate is about $21 \%$ lesser than that of pultruded plates.

- The stiffness in compression-molded plates is about 2 times more than pultruded plates due to high FVF.

Bi-directional:

- The stresses are almost same for both compression molded and pultrusion plates.

- The maximum strain for compression (22663 $\mu \varepsilon$ ) and pultruded (20392 $\mu \varepsilon)$ plates are within $10 \%$ difference.

- The difference in stiffness is within $10 \%$ between two processes.

Tri-directional:

- Though the effective FVF for both plates is about $15-20 \%$, the average ultimate stress in compression molded plates is $59 \%$ more than pultruded plates. 
- The ultimate strain of compression molded plates is about $68 \%$ more than the pultruded plates because the presence of $\pm 45^{0}$ fibers was not affecting much in pultruded plates.

- There is no significant difference in stiffness between the two processes.

Quadri-directional:

- Like tri-directional plates, the average stress in quadri-directional plates for compression molded plates is about $65 \%$ more than the pultruded plates.

- The average tensile strain in compression molded plates is about $67 \%$ more than the pultruded plates because of the presence of $\pm 45^{\circ}$ fibers which were not affecting much in pultruded plates.

- There is no significant difference in stiffness between the two processes.

\section{Bending test results}

Bi-directional:

- The stresses in compression molded plates are around $55 \mathrm{ksi}$ for effective fiber volume fraction of $18 \%$ while the pultruded plates have about $68 \mathrm{ksi}$ with effective fiber volume fraction of $26 \%$. Such major stress difference is attributed to good bonding within laminae in compression molded plates.

- The average strain in compression molded plates is about 5900 microstrains less than pultruded plates which may be due to premature matrix failure in the compression face of the specimen.

Tri-directional:

- There is no difference in stress between compression molded and pultruded plates.

- The average ultimate strain in compression molded plates is about $40 \%$ more than the pultruded plates. This is attributed to potential void formation in pultruded plates where slight premature failure would have initiated and the voids were visually seen.

Quadri-directional:

- The average stress in a pultruded plate is about $20 \%$ more than the compression molded plates. 
- The strain in compression molded plate is about 18000 microstrain while that in a pultruded plate is about 21000 microstrain. 
Stress-Strain Behavior under Tension Loading

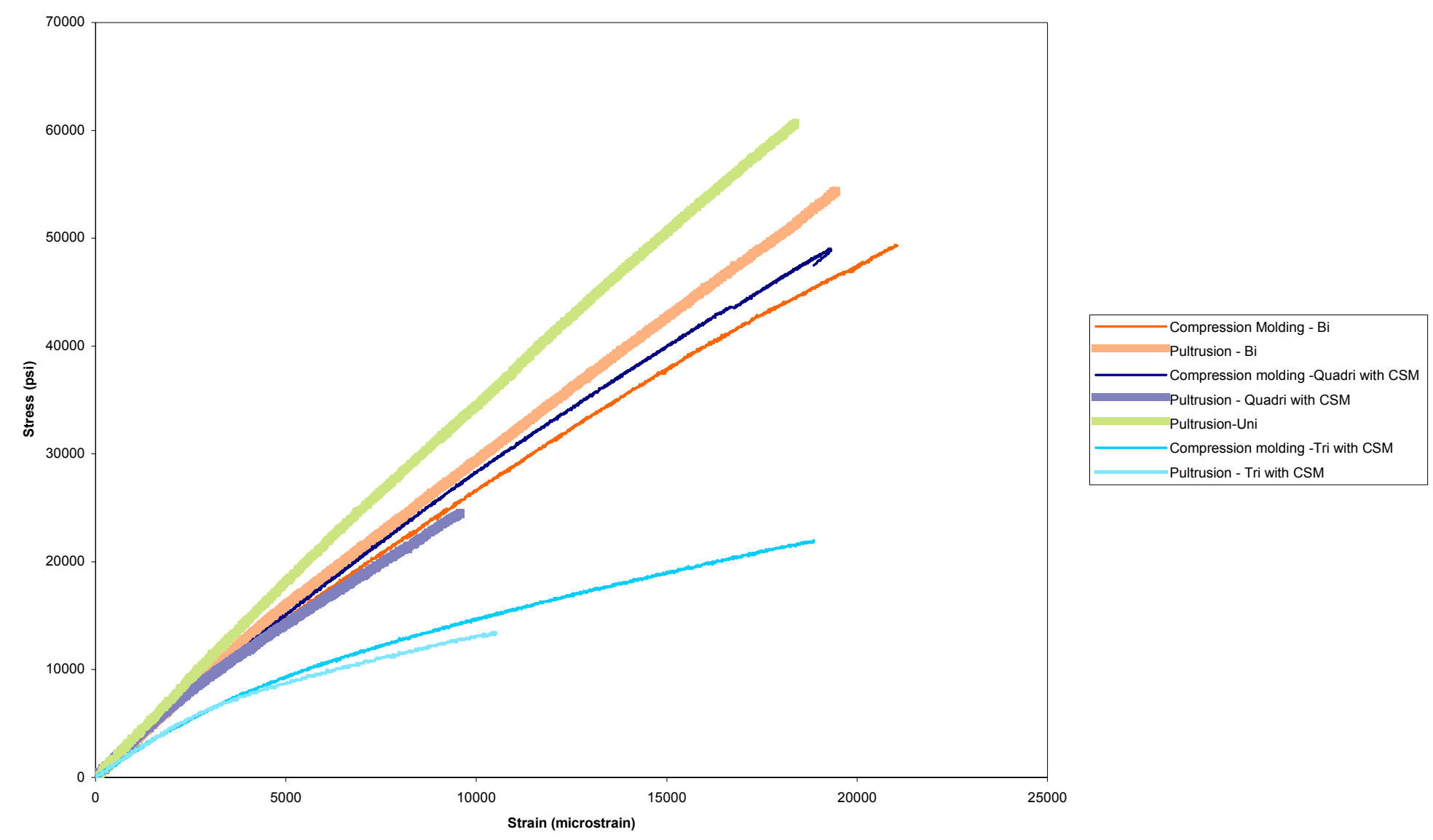

Figure 5.11 Stress-Strain Curve of Composites with Different Process under Tension 
Load-deflection Behavior under Bending Loading

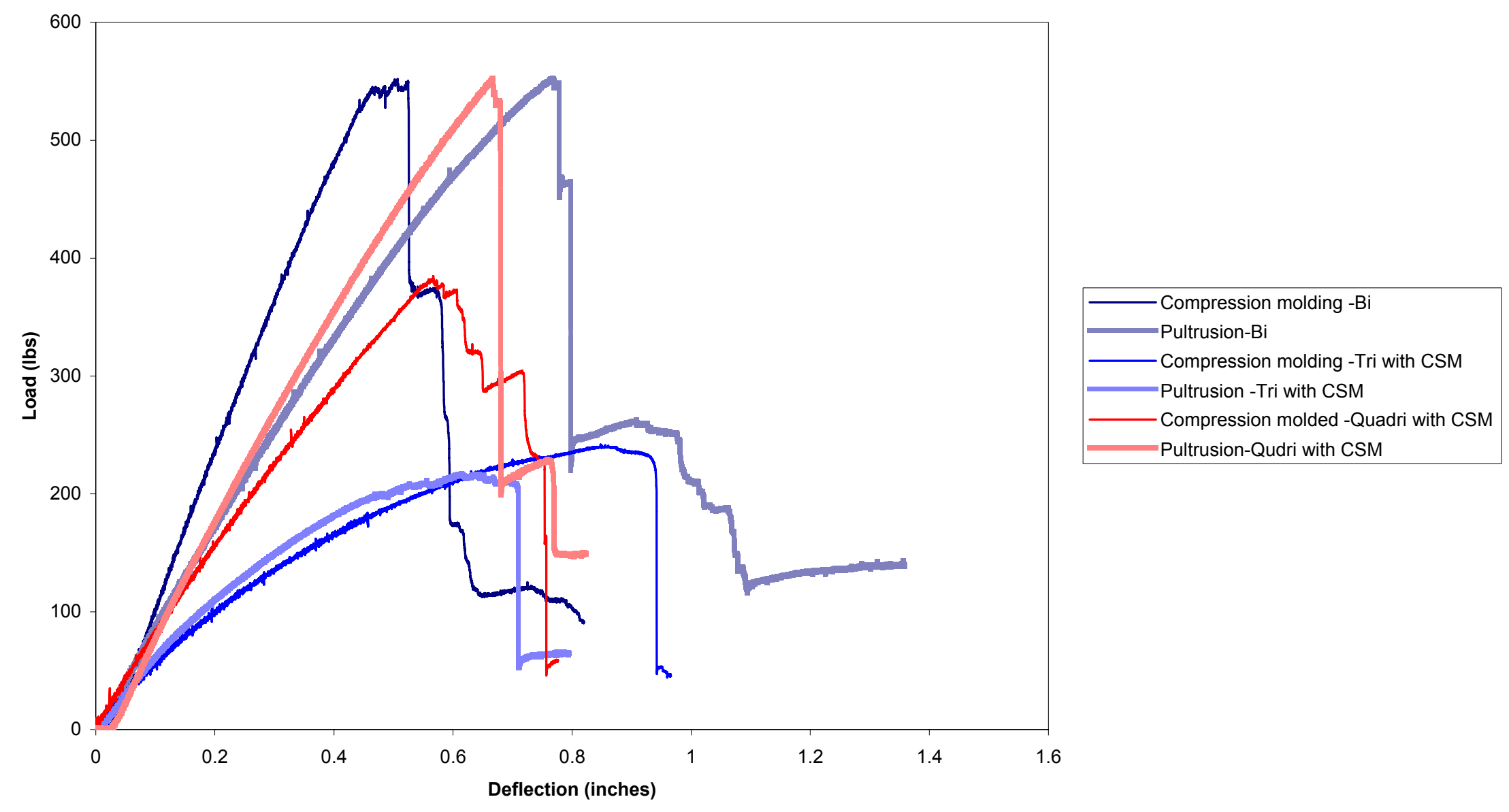

Figure 5.12 Load-deflection Curve of Composites with Different Process under Bending 
From Figure 5.11 we see that compression molded composites with tri- and quadri-directional composite have more ultimate strain compared (about $45 \%$ ) to pultruded plates. In bi-directional composites, no significant difference in ultimate strain is noted.

From Figure 5.12 we see that the ductility is more in bi-directional pultruded composites compared to compression molded composites. In case of composites with tri-directional and quadri-directional fabrics, the ductility behavior is more or less same for both pultruded and compression molded composites.

\subsection{Failure Modes}

Tension Coupons:

Unidirecitonal:

When unidirectional coupons were tested under tension loads, the specimens failed by longitudinal splitting of fibers, starting in grips and continued through the gage length as shown in Figure 5.13.
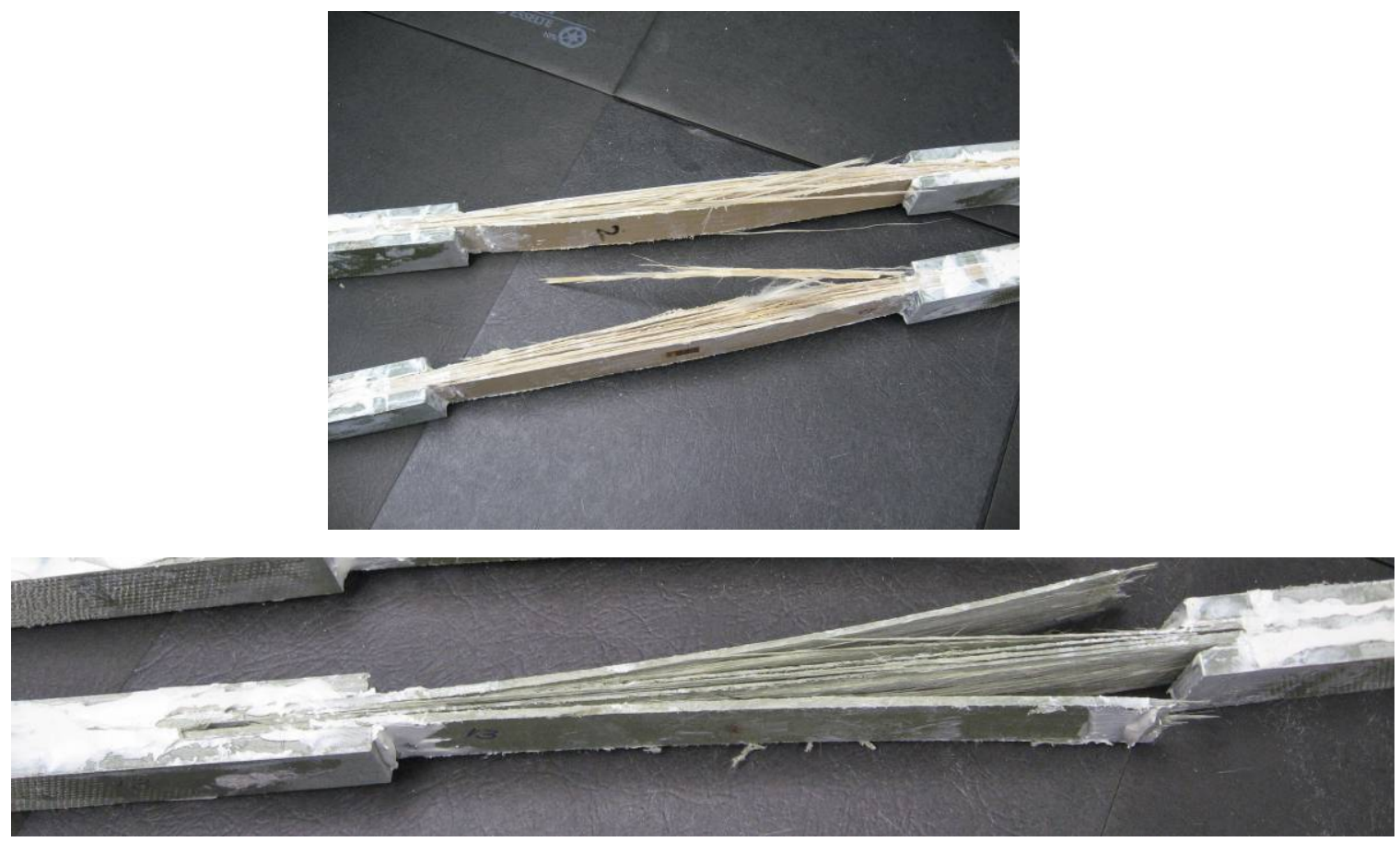

Figure 5.13 Failure Mode in Unidirectional Composites 
Bi-directional:

In bi-directional fabrics, following three types of failure modes have been identified (Figure 5.14):

1) Buckling of top laminae

2) Delamination, i.e. longitudinal splitting of fibers

3) Buckling of $0^{\circ}$ fibers at top

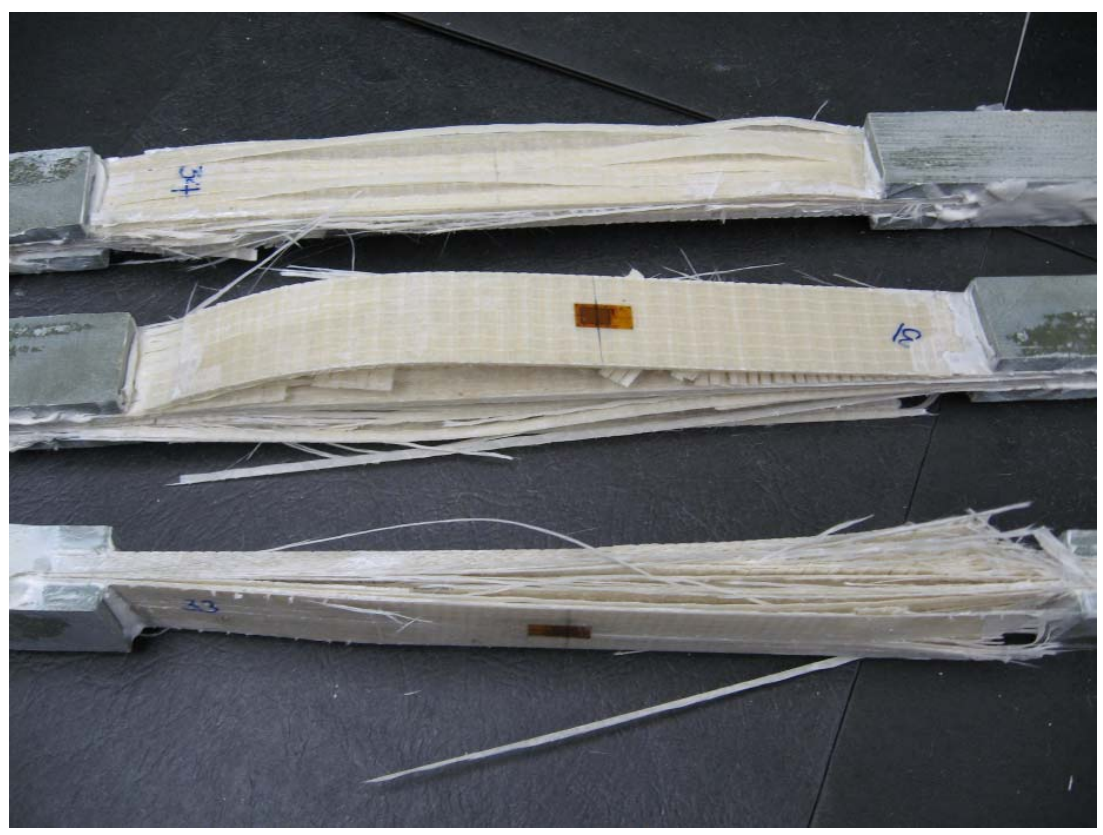

Figure 5.14 Failure Mode in Bidirectional Composites

Tri-directional:

The tri-directional composites both with and without CSM failed near the grips due to the absence of $0^{\circ}$ fibers in the loading direction (Figure 5.15).

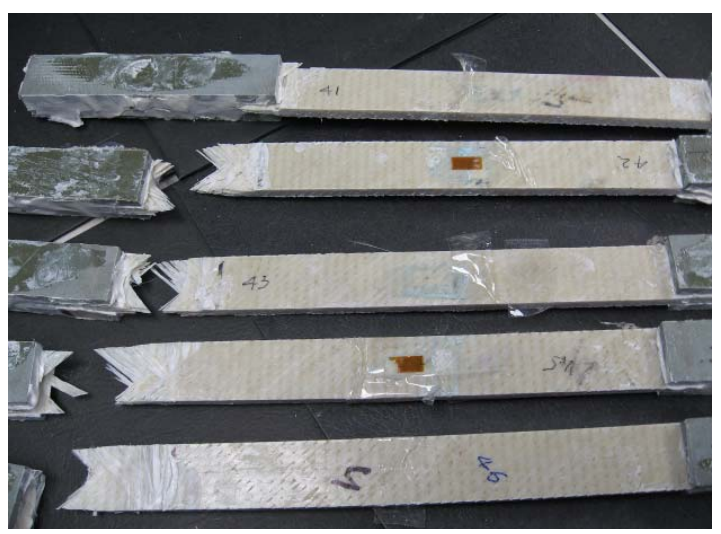

Figure 5.15 Failure Mode in Tridirectional Composites 
Quadri-directional:

Quadri-directional composites failed by longitudinal splitting of fibers, starting from grips through gage length (Figure 5.16).

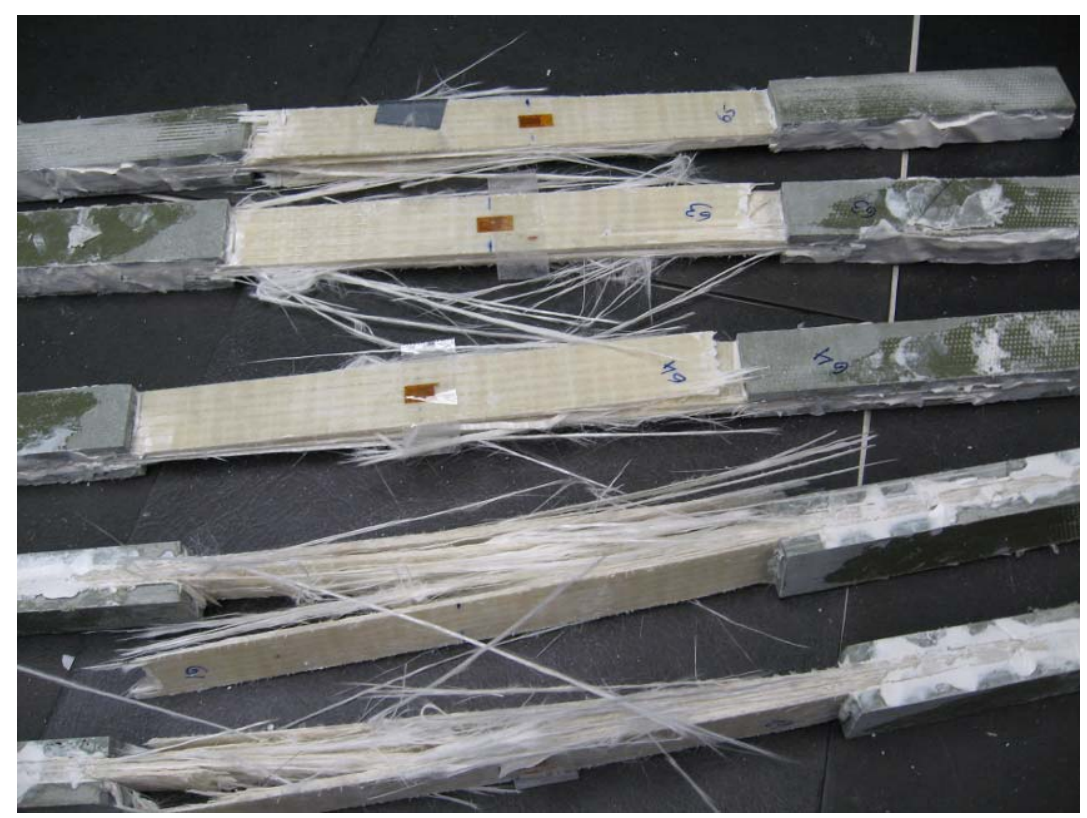

Figure 5.16 Failure Mode in Quadri-Directional Composites

Multidirectional:

In the multidirectional composites with polyurethane resin system, the tabs were bonded with epoxy based adhesive. Under tensile loading, in 3 out of 5 samples the tabs came out of the sample because the adhesive was not compatible with urethane samples. The two other samples failed by longitudinal splitting of fibers (Figure 5.17).

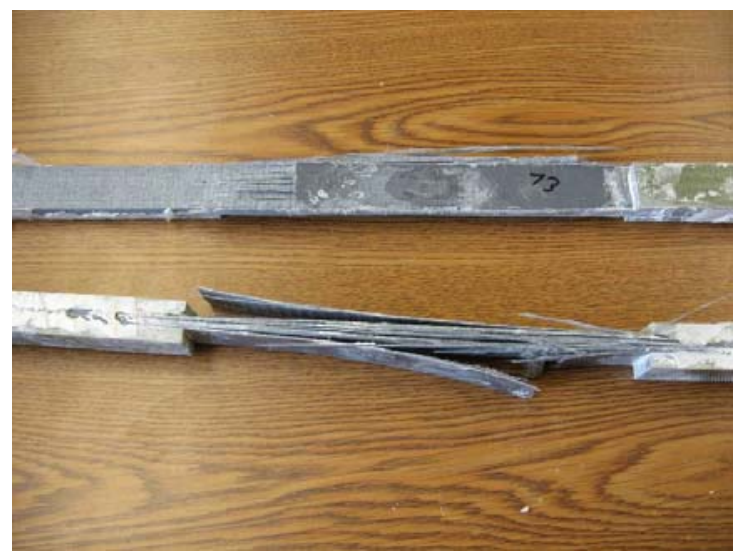

Figure 5.17 Failure Mode in Polyurethane Composites 
In case of composites with vinylester resin system, the failure mode was similar to uni and bi-directional plates ie. by longitudinal splitting of fibers (Figure 5.18).

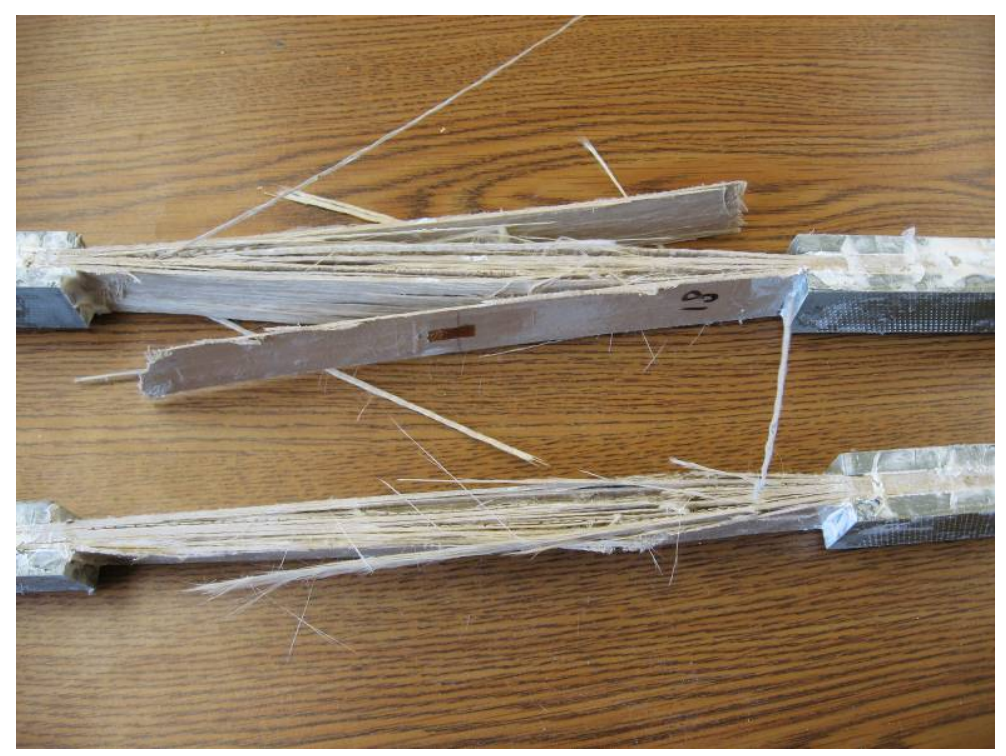

Figure 5.18 Failure Mode in Vinylester Composites

Bending Coupons:

Unidirectional:

The unidirectional coupons subjected to bending loads failed by fiber delamination at the bottom i.e, tension failure (Figure 5.19).

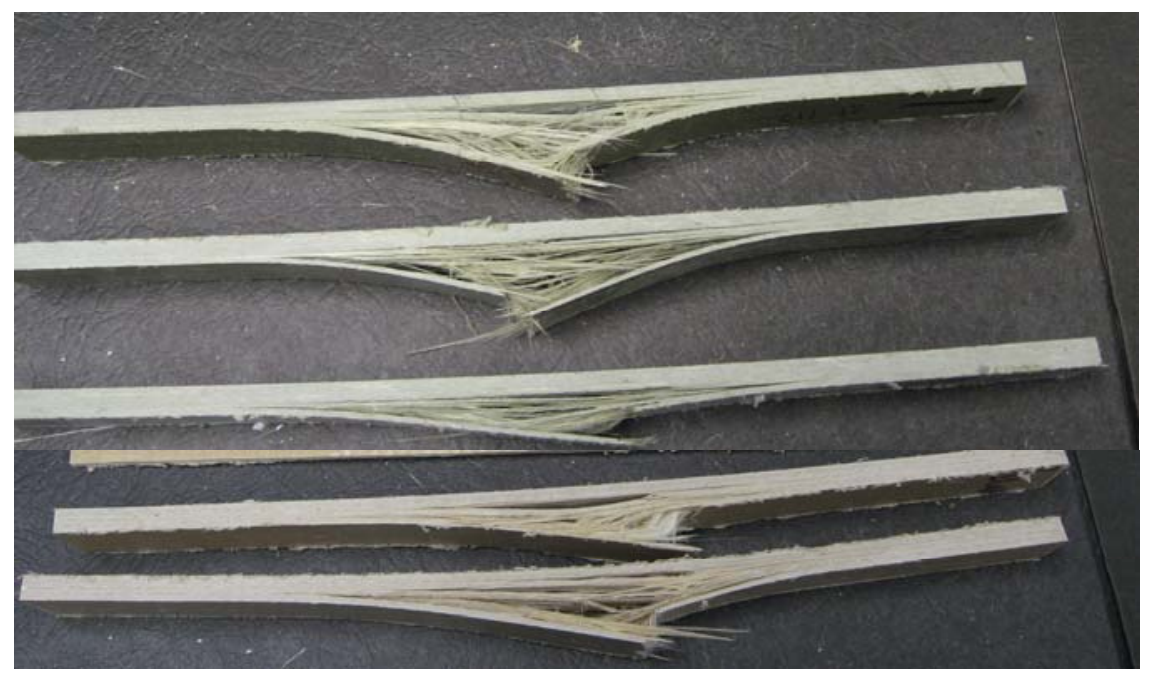

Figure 5.19 Failure Mode in Uni-directional Composites 
Bi-directional:

The failure modes in bi-directional composite (Figure 5.20) were of three types:

1) top layer buckled leading to pull out of $0^{\circ}$ fiber at bottom.

2) pull of $0^{\circ}$ fiber on top leading to tension failure.

3) compression failure leading to delamination of bottom layer.

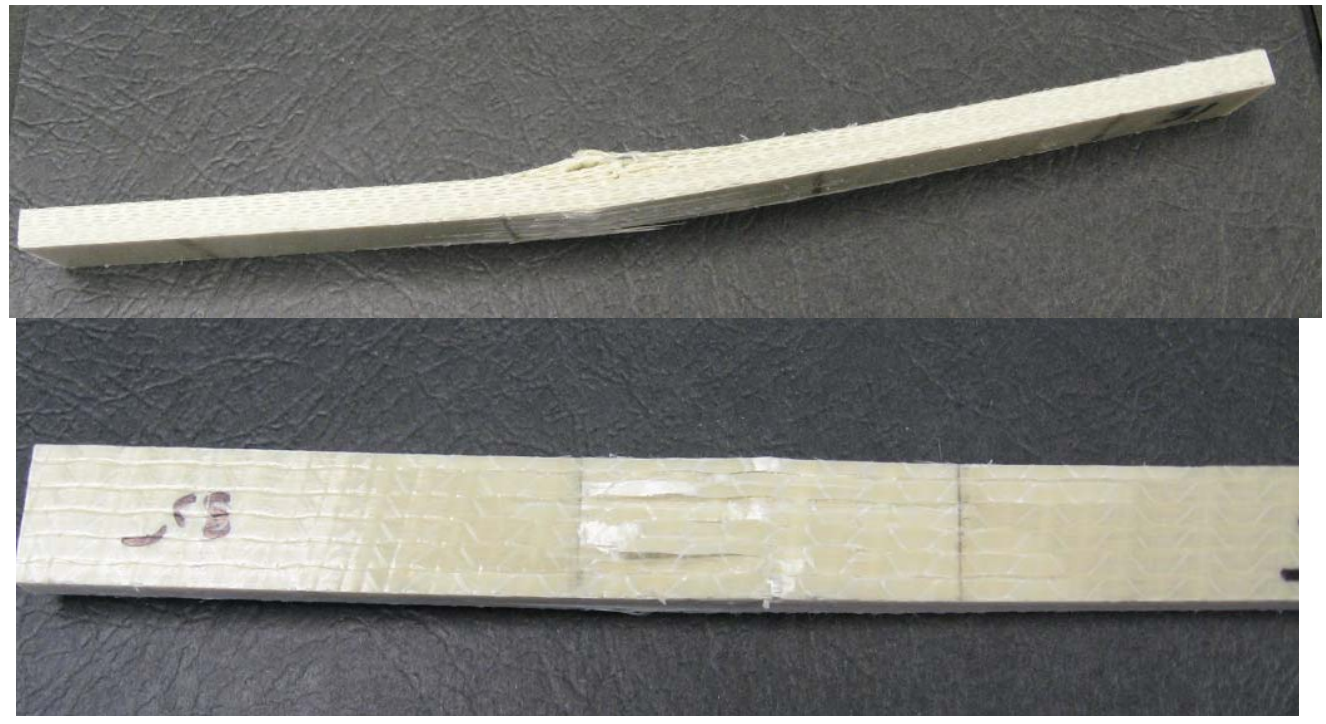

Tri-directional:

Figure 5.20 Failure Mode in Bi-directional Composites

In tri-directional composites with CSM and without CSM, coupons failed at bottom by shearing at $45^{\circ}$ as shown in Figure 5.21 .

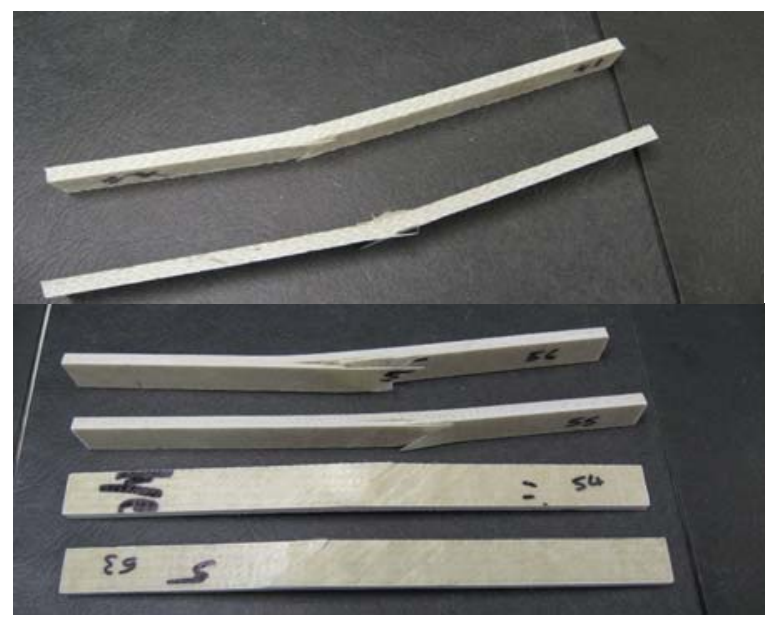

Figure 5.21 Failure Mode in Tri-directional Composites 
Quadri-directional:

In quadri-directional composites, $0^{\circ}$ fibers pulled at top leading to pulling of fibers at bottom (Figure 5.22).

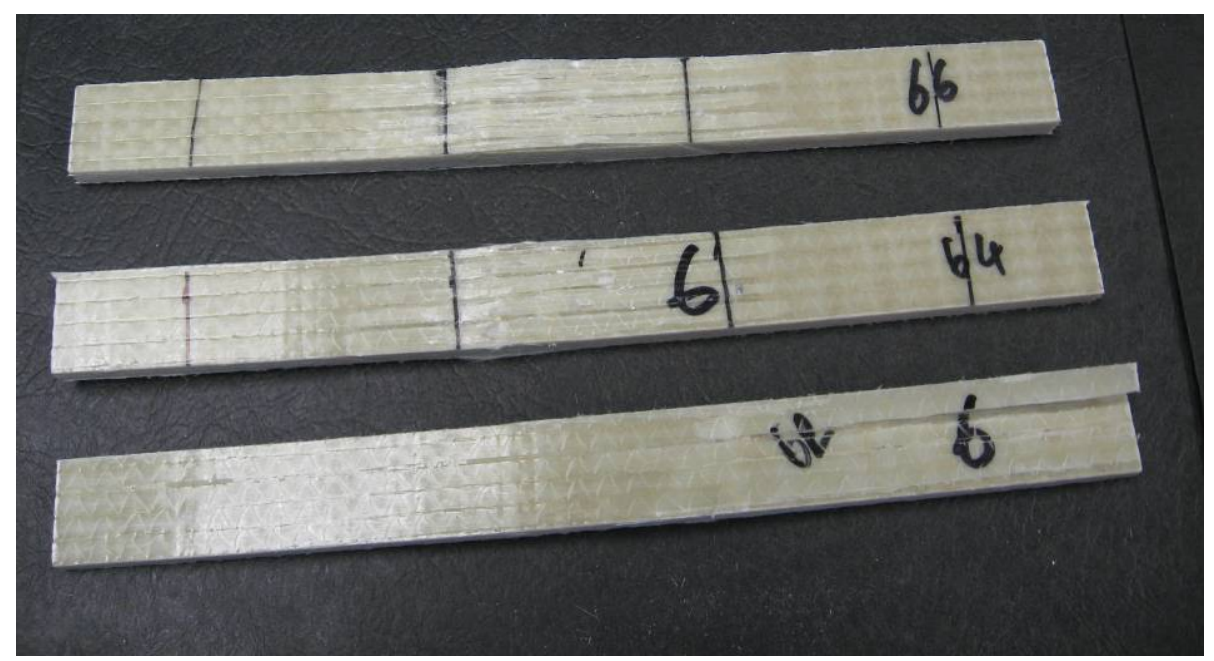

Figure 5.22 Failure Mode in Quadri-directional Composites

Multidirectional composites:

Multidirectional composites with polyurethane resins under bending loads failed either by compression failure at top leading to tension failure at bottom or failed under tension failure at bottom i.e., delamination of fibers at bottom as shown in Figure 5.23.

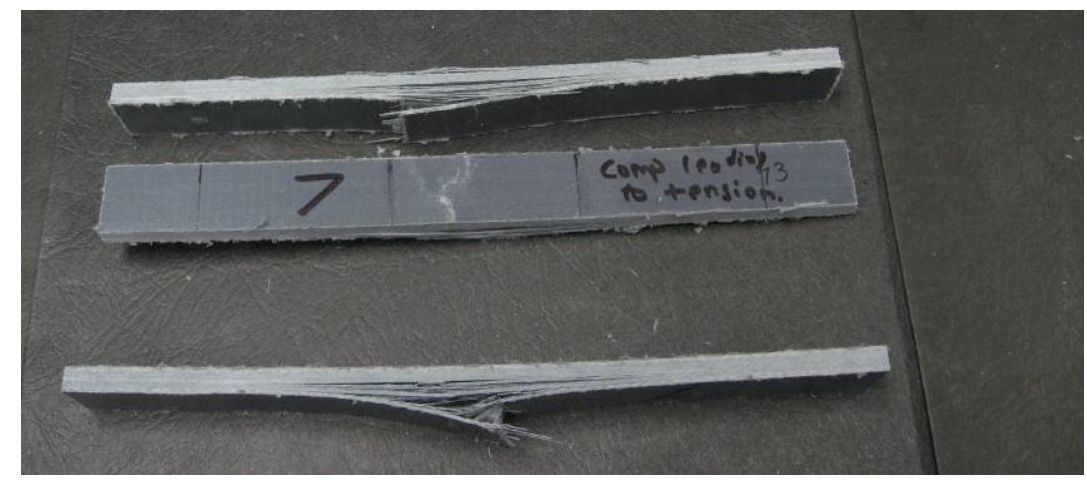

Figure 5.23 Failure Mode in Multi-directional Composite with Polyurethane Resin System 
In case of multidirectional composites with vinylester resin system, all the coupons had tension failure (Figure 5.24).

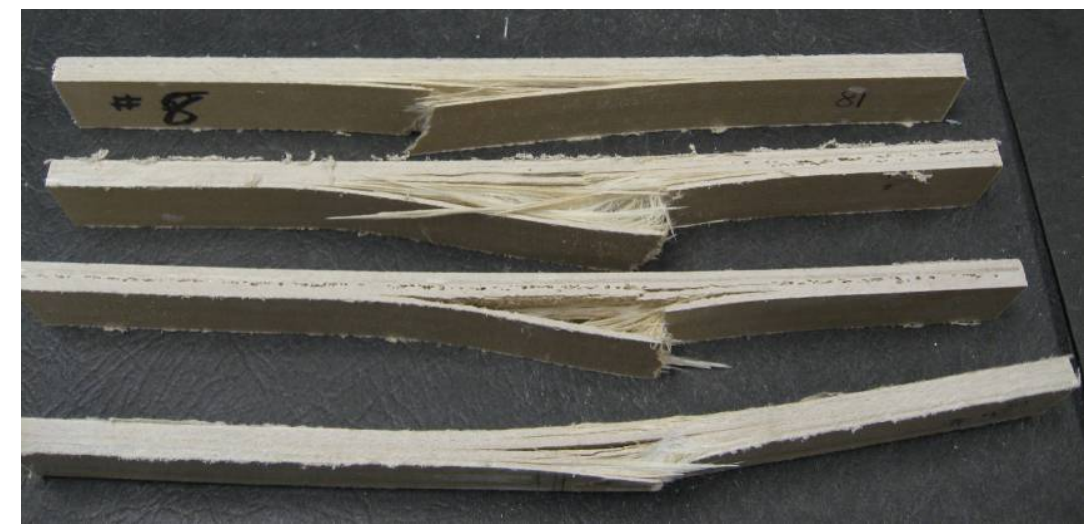

Figure 5.24 Failure Mode in Multi-directional Composite with Vinylester Resin System 


\section{CHAPTER 6}

\section{STRAIN ENERGY DENSITY}

\subsection{Introduction}

Stress-strain response in terms of area under the response curve is one of the important measures of strain energy. From previous sections we find that stress-

strain curve for both pultruded and compression molded plates, is non-linear up to peak stress. This non-linearity indicates initiation of damages in composites under given loading conditions. In this section, strain energy density based on area under stress-strain curve for pultruded and compression molded composites is evaluated under tension and bending loads.

\subsection{Strain energy density}

The strain energy density (up-to ultimate load) based on stress-strain response has been evaluated for pultruded and compression molded plates. The strain energy density values without normalization are shown in Tables 6.1 through 6.4. From Tables 6.1 through 6.4 it is observed that strain energy density for composites is constant within a given architecture and process. 
Table 6.1 Tension Test Results for Pultruded Specimens

\begin{tabular}{|c|c|c|c|c|c|c|c|c|c|c|c|c|}
\hline $\begin{array}{c}\text { Sample } \\
\text { ID }\end{array}$ & Fiber Lay-up & $\begin{array}{l}\mathrm{L} \\
\text { (in) }\end{array}$ & $\begin{array}{l}\text { W } \\
\text { (in) }\end{array}$ & $\begin{array}{c}\mathrm{T} \\
\text { (in) }\end{array}$ & $\begin{array}{c}\mathrm{A} \\
\left(\mathrm{in}^{2}\right)\end{array}$ & $\begin{array}{l}\mathrm{AL} \\
\left(\mathrm{in}^{3}\right)\end{array}$ & $\begin{array}{l}\text { FVF } \\
(\%) \\
\end{array}$ & $\begin{array}{c}\text { FVF-X } \\
(\%)\end{array}$ & $\begin{array}{c}\text { Max } \\
\text { Load } \\
\text { (kips) }\end{array}$ & $\begin{array}{c}\text { Strain at } \\
\text { peak load } \\
(\mu \varepsilon)\end{array}$ & $\begin{array}{c}\text { Stress at } \\
\text { peak load } \\
(k s i)\end{array}$ & $\begin{array}{c}\text { U @ ulitmate } \\
\text { load (psi) }\end{array}$ \\
\hline 11 & Uni-directional & 8 & 1.017 & 0.258 & 0.262 & 2.098 & 44 & 34 & 16 & 19730 & 60 & $6.24 \mathrm{E}+08$ \\
\hline 12 & with CSM & 8 & 1.014 & 0.263 & 0.267 & 2.134 & 44 & 34 & 16 & 17107 & 58 & $4.91 \mathrm{E}+08$ \\
\hline \multirow[t]{2}{*}{14} & & 8 & 1.011 & 0.254 & 0.257 & 2.056 & 44 & 34 & 16 & 18382 & 61 & $5.80 \mathrm{E}+08$ \\
\hline & & AVE & 1.014 & 0.258 & 0.262 & 2.096 & 44 & 34 & 16 & 18406 & 59 & $5.65 \mathrm{E}+08$ \\
\hline 23 & Uni-directional & 8 & 1.021 & 0.257 & 0.262 & 2.096 & 45 & 35 & 17 & 21877 & 64 & $7.39 \mathrm{E}+08$ \\
\hline 24 & with CSM & 8 & 1.022 & 0.250 & 0.255 & 2.039 & 45 & 35 & 17 & 20665 & 65 & $7.04 \mathrm{E}+08$ \\
\hline \multirow[t]{2}{*}{25} & & 8 & 1.003 & 0.245 & 0.245 & 1.962 & 45 & 35 & 15 & 21022 & 62 & $6.80 E+08$ \\
\hline & & AVE & 1.015 & 0.250 & 0.254 & 2.032 & 45 & 35 & 16 & 21188 & 64 & $7.08 E+08$ \\
\hline 33 & Bi-directional & 8 & 1.019 & 0.246 & 0.251 & 2.005 & 52 & 26 & 13 & 19421 & 54 & $5.48 \mathrm{E}+08$ \\
\hline 34 & $0 / 90$ & 8 & 1.007 & 0.252 & 0.253 & 2.026 & 52 & 26 & 14 & 21471 & 55 & $6.60 \mathrm{E}+08$ \\
\hline 35 & & 8 & 1.010 & 0.247 & 0.250 & 1.998 & 52 & 26 & 15 & 18700 & 61 & 5.87E+08 \\
\hline \multirow[t]{2}{*}{38} & & 8 & 1.009 & 0.245 & 0.247 & 1.977 & 52 & 26 & 14 & 21977 & 58 & 7.16E+08 \\
\hline & & AVE & 1.011 & 0.247 & 0.250 & 2.001 & 52 & 26 & 14 & 20392 & 57 & $6.28 \mathrm{E}+08$ \\
\hline 41 & Triaxial & 8 & 1.027 & 0.250 & 0.257 & 2.057 & 55 & 16 & 3 & 12394 & 10 & 7.47E+07 \\
\hline 43 & $45 / 90 /-45$ & 8 & 1.013 & 0.251 & 0.254 & 2.032 & 55 & 16 & 2 & 12622 & 9 & $6.85 \mathrm{E}+07$ \\
\hline 44 & without CSM & 8 & 1.010 & 0.249 & 0.252 & 2.012 & 55 & 16 & 2 & 11641 & 10 & $6.76 \mathrm{E}+07$ \\
\hline 45 & & 8 & 1.012 & 0.253 & 0.256 & 2.051 & 55 & 16 & 3 & 12862 & 10 & $7.83 \mathrm{E}+07$ \\
\hline \multirow[t]{2}{*}{46} & & 8 & 1.016 & 0.247 & 0.251 & 2.010 & 55 & 16 & 2 & 10004 & 9 & $5.69 E+07$ \\
\hline & & AVE & 1.016 & 0.250 & 0.254 & 2.032 & 55 & 16 & 2 & 11905 & 10 & $6.92 \mathrm{E}+07$ \\
\hline 51 & Triaxial & 8 & 1.019 & 0.252 & 0.257 & 2.054 & 51 & 15 & 4 & 11535 & 14 & $9.72 \mathrm{E}+07$ \\
\hline 54 & $45 / 90 /-45$ & 8 & 1.012 & 0.250 & 0.253 & 2.027 & 51 & 15 & 4 & 12977 & 15 & $1.16 \mathrm{E}+08$ \\
\hline 56 & with CSM & 8 & 1.010 & 0.255 & 0.257 & 2.055 & 51 & 15 & 4 & 11233 & 14 & $9.46 \mathrm{E}+07$ \\
\hline 57 & & 8 & 1.008 & 0.246 & 0.248 & 1.981 & 51 & 15 & 3 & 10516 & 13 & $8.72 \mathrm{E}+07$ \\
\hline \multirow[t]{2}{*}{510} & & 8 & 1.008 & 0.243 & 0.245 & 1.962 & 51 & 15 & 4 & 11172 & 15 & $1.02 \mathrm{E}+08$ \\
\hline & & AVE & 1.011 & 0.249 & 0.252 & 2.016 & 51 & 15 & 4 & 11487 & 14 & 9.94E+07 \\
\hline 61 & Quadriaxial & 8 & 1.021 & 0.248 & 0.253 & 2.021 & 55 & 25 & 6 & 9595 & 25 & $1.28 \mathrm{E}+08$ \\
\hline 62 & $0 / 90 / 45 /-45)$ & 8 & 1.006 & 0.246 & 0.247 & 1.978 & 55 & 25 & 6 & 9341 & 26 & $1.31 \mathrm{E}+08$ \\
\hline 64 & with CSM & 8 & 1.017 & 0.249 & 0.253 & 2.021 & 55 & 25 & 7 & 10931 & 27 & $1.61 \mathrm{E}+08$ \\
\hline \multirow[t]{2}{*}{65} & & 8 & 1.008 & 0.249 & 0.251 & 2.006 & 55 & 25 & 7 & 10436 & 27 & 1.47E+08 \\
\hline & & AVE & 1.013 & 0.248 & 0.251 & 2.007 & 55 & 25 & 7 & 10076 & 26 & 1.41E+08 \\
\hline
\end{tabular}


Table 6.2 Bending Test Results for Pultruded Specimens

\begin{tabular}{|c|c|c|c|c|c|c|c|c|c|c|c|c|}
\hline$\underset{\text { ID }}{\text { Sample }}$ & $\begin{array}{c}\text { Other } \\
\text { parmerters }\end{array}$ & $\begin{array}{l}\mathrm{L} \\
\text { (in) }\end{array}$ & $\begin{array}{l}W \\
\text { (in) }\end{array}$ & $\begin{array}{c}T \\
\text { (in) }\end{array}$ & $\underset{\left(i^{2}\right)}{A}$ & $\begin{array}{l}\mathrm{AL} \\
\left(\mathrm{in}^{3}\right)\end{array}$ & $\begin{array}{l}\text { FVF } \\
\text { (\%) }\end{array}$ & FVF-X (\%) & $\begin{array}{c}\text { Max Load } \\
\text { (kips) }\end{array}$ & $\begin{array}{c}\text { Strain at } \\
\text { peak load } \\
(\mu \varepsilon)\end{array}$ & $\begin{array}{c}\text { Stress at } \\
\text { peak } \\
\text { load (ksi) }\end{array}$ & $\begin{array}{c}\text { U @ ultimate } \\
\text { load } \\
\text { (psi) }\end{array}$ \\
\hline 19 & Uni-directional & 6 & 0.778 & 0.258 & 0.201 & 1.204 & 44 & 34 & 587 & 25416 & 68 & $9.00 \mathrm{E}+08$ \\
\hline 110 & with CSM & 6 & 0.782 & 0.259 & 0.202 & 1.214 & 44 & 34 & 612 & 29435 & 70 & 1.17E+09 \\
\hline 111 & & 6 & 0.771 & 0.255 & 0.196 & 1.178 & 44 & 34 & 572 & 26924 & 69 & $1.03 E+09$ \\
\hline \multirow[t]{2}{*}{112} & & 6 & 0.766 & 0.255 & 0.195 & 1.172 & 44 & 34 & 608 & 27892 & 73 & $1.14 \mathrm{E}+09$ \\
\hline & & AVE & 0.774 & 0.257 & 0.199 & 1.192 & 44 & 34 & 595 & 27417 & 70 & $1.06 \mathrm{E}+09$ \\
\hline 28 & Uni-directional & 6 & 0.772 & 0.242 & 0.187 & 1.121 & 45 & 35 & 491 & 29248 & 65 & $1.07 \mathrm{E}+09$ \\
\hline 29 & with CSM & 6 & 0.773 & 0.245 & 0.189 & 1.134 & 45 & 35 & 525 & 28897 & 68 & $1.08 \mathrm{E}+09$ \\
\hline 210 & & 6 & 0.759 & 0.247 & 0.187 & 1.125 & 45 & 35 & 481 & 22449 & 62 & $7.45 \mathrm{E}+08$ \\
\hline \multirow[t]{2}{*}{212} & & 6 & 0.779 & 0.243 & 0.189 & 1.134 & 45 & 35 & 505 & 30264 & 66 & $1.09 E+09$ \\
\hline & & AVE & 0.771 & 0.244 & 0.188 & 1.129 & 45 & 35 & 501 & 27715 & 65 & $9.98 \mathrm{E}+08$ \\
\hline 32 & Bi-directional & 6 & 0.781 & 0.245 & 0.192 & 1.151 & 52 & 26 & 553 & 22137 & 67 & $8.01 \mathrm{E}+08$ \\
\hline 33 & $0 / 90$ & 6 & 0.782 & 0.245 & 0.192 & 1.150 & 52 & 26 & 546 & 21947 & 67 & $7.89 E+08$ \\
\hline 34 & & 6 & 0.768 & 0.245 & 0.188 & 1.128 & 52 & 26 & 553 & 25034 & 69 & $9.54 \mathrm{E}+08$ \\
\hline 35 & & 6 & 0.778 & 0.245 & 0.190 & 1.143 & 52 & 26 & 556 & 21669 & 74 & $8.75 E+08$ \\
\hline 36 & & 6 & 0.781 & 0.245 & 0.191 & 1.148 & 52 & 26 & 604 & 25522 & 74 & $1.05 E+09$ \\
\hline \multirow[t]{2}{*}{37} & & 6 & 0.772 & 0.246 & 0.190 & 1.142 & 52 & 26 & 547 & 22270 & 68 & $8.14 \mathrm{E}+08$ \\
\hline & & AVE & 0.777 & 0.245 & 0.191 & 1.144 & 52 & 26 & 560 & 23097 & 70 & $8.80 E+08$ \\
\hline 48 & Triaxial & 6 & 0.758 & 0.244 & 0.185 & 1.111 & 55 & 16 & 115 & 19417 & 15 & $1.88 \mathrm{E}+08$ \\
\hline 411 & $45 / 90 /-45$ & 6 & 0.759 & 0.245 & 0.186 & 1.114 & 55 & 16 & 107 & 15544 & 14 & $1.30 \mathrm{E}+08$ \\
\hline 412 & & 6 & 0.749 & 0.245 & 0.184 & 1.102 & 55 & 16 & 109 & 18888 & 15 & $1.79 \mathrm{E}+08$ \\
\hline \multirow[t]{2}{*}{413} & & 6 & 0.769 & 0.247 & 0.190 & 1.140 & 55 & 16 & 115 & 17287 & 15 & $1.60 \mathrm{E}+08$ \\
\hline & & AVE & 0.759 & 0.245 & 0.186 & 1.117 & 55 & 16 & 112 & 17784 & 15 & 1.64E+08 \\
\hline 58 & Triaxial & 6 & 0.777 & 0.242 & 0.188 & 1.126 & 51 & 15 & 198 & 21630 & 26 & $3.57 E+08$ \\
\hline 59 & $45 / 90 /-45$ & 6 & 0.785 & 0.245 & 0.192 & 1.154 & 51 & 15 & 195 & 17268 & 25 & $2.57 \mathrm{E}+08$ \\
\hline 510 & with CSM & 6 & 0.769 & 0.245 & 0.188 & 1.130 & 51 & 15 & 194 & 19112 & 25 & $3.03 E+08$ \\
\hline 511 & & 6 & 0.777 & 0.242 & 0.188 & 1.128 & 51 & 15 & 189 & 16639 & 25 & $2.43 \mathrm{E}+08$ \\
\hline 512 & & 6 & 0.777 & 0.244 & 0.190 & 1.137 & 51 & 15 & 196 & 21504 & 26 & $3.43 E+08$ \\
\hline \multirow[t]{2}{*}{513} & & 6 & 0.774 & 0.249 & 0.193 & 1.156 & 51 & 15 & 191 & 21109 & 24 & $3.23 E+08$ \\
\hline & & AVE & 0.776 & 0.244 & 0.190 & 1.139 & 51 & 15 & 194 & 19544 & 25 & $3.04 \mathrm{E}+08$ \\
\hline 69 & Quadriaxial & 6 & 0.747 & 0.244 & 0.182 & 1.094 & 55 & 25 & 514 & 23854 & 70 & $9.14 \mathrm{E}+08$ \\
\hline 610 & $0 / 90 / 45 /-45)$ & 6 & 0.766 & 0.244 & 0.187 & 1.121 & 55 & 25 & 519 & 23085 & 68 & $8.21 \mathrm{E}+08$ \\
\hline \multirow[t]{2}{*}{612} & with CSM & 6 & 0.773 & 0.245 & 0.189 & 1.133 & 55 & 25 & 524 & 22157 & 68 & $8.56 \mathrm{E}+08$ \\
\hline & & AVE & 0.762 & 0.244 & 0.186 & 1.116 & 55 & 25 & 519 & 23032 & 69 & $8.64 E+08$ \\
\hline
\end{tabular}


Table 6.3 Tension Test Results for Compression Molded Specimens

\begin{tabular}{|c|c|c|c|c|c|c|c|c|c|c|c|c|}
\hline $\begin{array}{c}\text { Sample } \\
\text { ID }\end{array}$ & Fiber Lay-Up & $\begin{array}{l}\mathrm{L} \\
\text { (in) }\end{array}$ & $\begin{array}{l}W \\
\text { (in) }\end{array}$ & $\begin{array}{c}\mathrm{T} \\
\text { (in) }\end{array}$ & $\begin{array}{c}\text { A } \\
\left(\text { in }^{2}\right)\end{array}$ & $\begin{array}{c}A L \\
\left(\mathrm{in}^{3}\right)\end{array}$ & $\begin{array}{l}\text { FVF } \\
(\%)\end{array}$ & $\begin{array}{c}\text { FVF-X } \\
(\%)\end{array}$ & $\begin{array}{l}\text { Max } \\
\text { Load } \\
\text { (Ibs) }\end{array}$ & $\begin{array}{c}\text { Strain at } \\
\text { peak } \\
\text { load }(\mu \varepsilon)\end{array}$ & $\begin{array}{c}\text { Stress at } \\
\text { peak load } \\
(\mathrm{ksi})\end{array}$ & $\begin{array}{c}\text { U @ ultimate } \\
\text { load (psi) }\end{array}$ \\
\hline TUL3Q & Unidirectional & 5.30 & 1.03 & 0.20 & 0.21 & 1.09 & 58 & 58 & 20647 & 18086 & 98 & $9.78 \mathrm{E}+08$ \\
\hline TUL4Q & 19 layers & 5.30 & 1.03 & 0.19 & 0.20 & 1.04 & 58 & 58 & 20293 & 15385 & 104 & $7.54 \mathrm{E}+08$ \\
\hline TUL5Q & & 5.30 & 1.03 & 0.20 & 0.21 & 1.09 & 58 & 58 & 21910 & 16991 & 105 & $8.60 \mathrm{E}+08$ \\
\hline TUL7Q & & 5.30 & 1.02 & 0.20 & 0.20 & 1.08 & 58 & 58 & 20816 & 15438 & 103 & $7.78 \mathrm{E}+08$ \\
\hline \multirow[t]{2}{*}{ TUL8Q } & & 5.30 & 1.03 & 0.20 & 0.21 & 1.09 & 58 & 58 & 19800 & 17653 & 94 & $9.89 \mathrm{E}+08$ \\
\hline & AVE & 5.300 & 1.028 & 0.198 & 0.204 & 1.079 & 58 & 58 & 20693 & 16710 & 101 & $8.72 E+08$ \\
\hline TBL2Q & $0 / 90$ & 6.00 & 1.01 & 0.22 & 0.22 & 1.33 & 45 & 22 & 11332 & 20502 & 52 & $5.74 \mathrm{E}+08$ \\
\hline TBL3Q & 18 Layers & 6.00 & 1.00 & 0.22 & 0.22 & 1.32 & 45 & 22 & 13164 & 23378 & 60 & $7.60 \mathrm{E}+08$ \\
\hline TBL4Q & & 6.00 & 1.01 & 0.22 & 0.22 & 1.33 & 45 & 22 & 11286 & 22153 & 51 & $6.24 \mathrm{E}+08$ \\
\hline TBL5Q & & 6.00 & 1.01 & 0.22 & 0.22 & 1.33 & 45 & 22 & 12918 & 25030 & 58 & $8.22 \mathrm{E}+08$ \\
\hline \multirow[t]{2}{*}{ TBL7Q } & & 6.00 & 1.00 & 0.22 & 0.22 & 1.32 & 45 & 22 & 13241 & 22254 & 60 & $6.86 \mathrm{E}+08$ \\
\hline & AVE & 6.000 & 1.006 & 0.220 & 0.221 & 1.328 & 45 & 22 & 12388 & 22664 & 56 & $6.93 E+08$ \\
\hline TTT2Q & 45/90/-45/CSM & 7.80 & 1.02 & 0.22 & 0.22 & 1.75 & 59 & 20 & 4881 & 18860 & 22 & $2.50 \mathrm{E}+08$ \\
\hline TTT4Q & 6 layers & 7.80 & 1.02 & 0.22 & 0.22 & 1.75 & 59 & 20 & 4788 & 19544 & 22 & $2.62 E+08$ \\
\hline TTT5Q & & 7.80 & 1.03 & 0.20 & 0.21 & 1.61 & 59 & 20 & 5081 & 20633 & 25 & $3.04 \mathrm{E}+08$ \\
\hline TTT6Q & & 7.80 & 1.04 & 0.21 & 0.22 & 1.70 & 59 & 20 & 4942 & 19671 & 22 & $2.60 \mathrm{E}+08$ \\
\hline TTT7Q & & 7.80 & 1.02 & 0.22 & 0.22 & 1.75 & 59 & 20 & 4557 & 17572 & 21 & $2.18 \mathrm{E}+08$ \\
\hline \multirow[t]{2}{*}{ TTT8Q } & & 7.80 & 1.03 & 0.22 & 0.23 & 1.77 & 59 & 20 & 5019 & 19302 & 22 & $2.53 \mathrm{E}+08$ \\
\hline & AVE & 7.800 & 1.027 & 0.215 & 0.221 & 1.721 & 59 & 20 & 4878 & 19264 & 22 & $2.58 \mathrm{E}+08$ \\
\hline TQL2Q & 0/90/+45/-45/CSM & 7.40 & 1.02 & 0.23 & 0.23 & 1.74 & 55 & 28 & 11594 & 19308 & 49 & $5.11 \mathrm{E}+08$ \\
\hline TQL4Q & 4 layers & 7.40 & 1.02 & 0.23 & 0.23 & 1.74 & 55 & 28 & 10408 & 17715 & 45 & $4.15 \mathrm{E}+08$ \\
\hline TQL5Q & & 7.40 & 1.02 & 0.23 & 0.23 & 1.74 & 55 & 28 & 9808 & 15968 & 41 & $3.51 \mathrm{E}+08$ \\
\hline TQL6Q & & 7.40 & 1.02 & 0.23 & 0.23 & 1.74 & 55 & 28 & 9284 & 14718 & 39 & $2.98 \mathrm{E}+08$ \\
\hline TQL7Q & & 7.40 & 1.02 & 0.23 & 0.23 & 1.74 & 55 & 28 & 9531 & 15257 & 41 & $3.36 \mathrm{E}+08$ \\
\hline \multirow[t]{2}{*}{ TQL8Q } & & 7.40 & 1.03 & 0.24 & 0.25 & 1.83 & 55 & 28 & 10455 & 18136 & 43 & $4.24 \mathrm{E}+08$ \\
\hline & AVE & 7.40 & 1.02 & 0.23 & 0.24 & 1.75 & 55 & 28 & 10180 & 16850 & 43 & $3.89 \mathrm{E}+08$ \\
\hline QWOCL1 & $1 \quad 0 / 90 /+45 /-45 /$ & 6 & 1.010 & 0.180 & 0.18 & 1.09 & 44 & 22 & 5396 & 14027 & 30 & $2.35 \mathrm{E}+08$ \\
\hline QWOCL2 & 4 layers & 6 & 1.000 & 0.170 & 0.17 & 1.02 & 44 & 22 & 5219 & 11977 & 31 & $2.00 \mathrm{E}+08$ \\
\hline \multirow[t]{2}{*}{ QWOCL3 } & & 6 & 1.010 & 0.170 & 0.17 & 1.03 & 44 & 22 & 5615 & 13959 & 32 & $2.45 \mathrm{E}+08$ \\
\hline & & 6.000 & 1.007 & 0.173 & 0.175 & 1.047 & 44 & 22 & 5410 & 13321 & 31 & $2.27 E+08$ \\
\hline
\end{tabular}


Table 6.4 Bending Test Results for Compression Molded Specimens

\begin{tabular}{|c|c|c|c|c|c|c|c|c|c|c|c|c|}
\hline $\begin{array}{c}\text { Sample } \\
\text { ID }\end{array}$ & Fiber Lay-up & $\begin{array}{l}\mathrm{L} \\
\text { (in) }\end{array}$ & $\begin{array}{l}\text { W } \\
\text { (in) }\end{array}$ & $\begin{array}{c}\mathrm{T} \\
\text { (in) }\end{array}$ & $\begin{array}{c}A \\
\left(i n^{2}\right)\end{array}$ & $\begin{array}{c}A L \\
\left(i^{3}\right)\end{array}$ & $\begin{array}{l}\text { FVF } \\
(\%)\end{array}$ & $\begin{array}{c}\text { FVF-X } \\
(\%)\end{array}$ & $\begin{array}{c}\text { Max Load } \\
\text { (Ibs) }\end{array}$ & $\begin{array}{c}\text { Strain } \\
\text { at peak } \\
\text { load } \\
(\mu \varepsilon)\end{array}$ & $\begin{array}{c}\text { Stress at } \\
\text { peak load } \\
\text { (ksi) }\end{array}$ & $\begin{array}{c}\text { U @ ultimate } \\
\text { load (psi) }\end{array}$ \\
\hline BUQL2 & Unidirectional & 6.00 & 0.76 & 0.20 & 0.15 & 0.91 & 65 & 65 & 259 & 7312 & 52 & $1.94 \mathrm{E}+08$ \\
\hline BUQL3 & 19 layers & 6.00 & 0.77 & 0.20 & 0.15 & 0.91 & 65 & 65 & 226 & 6004 & 45 & 1.37E+08 \\
\hline \multirow[t]{2}{*}{ BUQL4 } & & 6.00 & 0.77 & 0.20 & 0.15 & 0.91 & 65 & 65 & 235 & 6373 & 47 & $1.51 \mathrm{E}+08$ \\
\hline & AVE & 6.00 & 0.77 & 0.20 & 0.15 & 0.91 & 65 & 65 & 250 & 6563 & 50 & $1.61 E+08$ \\
\hline BBL2Q & Bidirectional $(0 / 90)$ & 6.00 & 0.77 & 0.28 & 0.21 & 1.28 & 37 & 18 & 427 & 16841 & 43 & $3.85 E+08$ \\
\hline \multirow[t]{2}{*}{ BBL4Q } & 22 layers & 6.00 & 0.67 & 0.26 & 0.17 & 1.05 & 37 & 18 & 508 & 17041 & 67 & $5.94 \mathrm{E}+08$ \\
\hline & AVE & 6.00 & 0.72 & 0.27 & 0.19 & 1.17 & 37 & 18 & 468 & 16941 & 55 & $4.89 E+08$ \\
\hline BTT2Q & 45/90/-45/CSM & 6.00 & 0.75 & 0.30 & 0.23 & 1.36 & 44 & 15 & 298 & 26587 & 26 & $4.23 E+08$ \\
\hline BTT3Q & 4 layers & 6.00 & 0.72 & 0.26 & 0.19 & 1.12 & 44 & 15 & 210 & 25594 & 26 & $3.49 \mathrm{E}+08$ \\
\hline \multirow[t]{2}{*}{ BTT4Q } & & 6.00 & 0.75 & 0.27 & 0.20 & 1.21 & 44 & 15 & 248 & 26222 & 27 & $4.30 \mathrm{E}+08$ \\
\hline & AVE & 6.00 & 0.74 & 0.28 & 0.21 & 1.23 & 44 & 15 & 252 & 26134 & 27 & $4.01 E+08$ \\
\hline BQL1Q & 0/90/+45/-45/CSM & 6.00 & 0.77 & 0.22 & 0.17 & 1.01 & 56 & 29 & 335 & 16223 & 54 & $4.62 E+08$ \\
\hline BQL2Q & 4 layers & 6.00 & 0.77 & 0.22 & 0.17 & 1.03 & 56 & 29 & 364 & 18545 & 56 & $5.62 E+08$ \\
\hline \multirow[t]{2}{*}{ BQL3Q } & & 6.00 & 0.76 & 0.22 & 0.17 & 1.01 & 56 & 29 & 378 & 18920 & 61 & $6.11 \mathrm{E}+08$ \\
\hline & AVE & 6.00 & 0.77 & 0.22 & 0.17 & 1.02 & 56 & 29 & 359 & 17896 & 57 & $5.45 E+08$ \\
\hline QWOCL1 & $0 / 90 /+45 /-45 /$ & 6.00 & 0.75 & 0.18 & 0.13 & 0.808 & 44 & 22 & 159 & 15414 & 41 & $3.46 \mathrm{E}+08$ \\
\hline QWOCL2 & 4 layers & 6.00 & 0.75 & 0.17 & 0.13 & 0.781 & 44 & 22 & 163 & 15649 & 43 & $3.65 E+08$ \\
\hline \multirow[t]{2}{*}{ QWOCL3 } & & 6.00 & 0.75 & 0.17 & 0.13 & 0.768 & 44 & 22 & 159 & 14702 & 42 & $3.36 \mathrm{E}+08$ \\
\hline & AVE & 6.000 & 0.750 & 0.175 & 0.131 & 0.786 & 44 & 22 & 160 & 15255 & 42 & $3.49 E+08$ \\
\hline
\end{tabular}


Table 6.5 gives a brief comparison of strain energy density for specimens made of compression molding and pultrusion process, and subjected to tension and bending loads without normalization of stresses.

Table 6.5 Comparison of Strain Energy Density for Compression Molding and Pultrusion

\begin{tabular}{|c|c|c|c|c|c|c|c|}
\hline \multirow[t]{3}{*}{ Fiber Architecture } & \multicolumn{3}{|c|}{ Compression Molding } & \multicolumn{3}{|c|}{ Pultrusion } & \\
\hline & \multicolumn{3}{|c|}{ Tension } & \multicolumn{3}{|c|}{ Tension } & \\
\hline & $\begin{array}{c}\text { Stress } \\
\text { (ksi) }\end{array}$ & $\begin{array}{c}\text { Strain } \\
(\mu \varepsilon)\end{array}$ & $\begin{array}{c}\text { Uc } \\
\text { (psi) }\end{array}$ & $\begin{array}{c}\text { Stress } \\
\text { (ksi) }\end{array}$ & $\begin{array}{c}\text { Strain } \\
(\mu \varepsilon)\end{array}$ & $\begin{array}{l}\text { Up } \\
\text { (psi) }\end{array}$ & $\mathrm{Uc} / \mathrm{Up}$ \\
\hline Uni & 101 & 16710 & $8.72 \mathrm{E}+08$ & 64 & 21188 & $7.08 \mathrm{E}+08$ & 1.23 \\
\hline $\mathrm{Bi}$ & 56 & 22664 & $6.93 E+08$ & 57 & 20392 & $6.25 \mathrm{E}+08$ & 1.11 \\
\hline Tri without CSM & & & & 10 & 11905 & $6.92 E+07$ & \\
\hline Tri with CSM & 22 & 19264 & $2.58 \mathrm{E}+08$ & 14 & 11487 & $9.94 \mathrm{E}+07$ & 2.60 \\
\hline Quadri with CSM & 43 & 16850 & $3.89 E+08$ & 26 & 10076 & $1.41 \mathrm{E}+08$ & 2.76 \\
\hline Quadri without CSM & 31 & 13321 & 2.27E+08 & & & & \\
\hline
\end{tabular}

\begin{tabular}{|c|c|c|c|c|c|c|c|}
\hline \multirow[t]{3}{*}{ Fiber Architecture } & \multicolumn{3}{|c|}{ Compression Molding } & \multicolumn{3}{|c|}{ Pultrusion } & \\
\hline & \multicolumn{3}{|c|}{ Bending } & \multicolumn{3}{|c|}{ Bending } & \\
\hline & $\begin{array}{c}\text { Stress } \\
\text { (ksi) }\end{array}$ & $\begin{array}{c}\text { Strain } \\
(\mu \varepsilon)\end{array}$ & $\begin{array}{c}\text { Uc } \\
\text { (psi) }\end{array}$ & $\begin{array}{c}\text { Stress } \\
\text { (ksi) }\end{array}$ & $\begin{array}{c}\text { Strain } \\
(\mu \varepsilon)\end{array}$ & $\begin{array}{l}\text { Up } \\
\text { (psi) }\end{array}$ & Uc/Up \\
\hline Uni & 50 & 6563 & $1.61 \mathrm{E}+08^{*}$ & 65 & 27715 & $9.98 \mathrm{E}+08$ & 0.16 \\
\hline $\mathbf{B i}$ & 55 & 16941 & $4.89 \mathrm{E}+08$ & 70 & 23097 & $8.80 \mathrm{E}+08$ & 0.56 \\
\hline Tri without CSM & & & & 15 & 17784 & $1.64 \mathrm{E}+08$ & \\
\hline Tri with CSM & 27 & 26134 & $4.01 \mathrm{E}+08$ & 25 & 19544 & $3.04 \mathrm{E}+08$ & 1.32 \\
\hline Quadri with CSM & 57 & 17896 & $5.45 \mathrm{E}+08$ & 69 & 23032 & $8.64 \mathrm{E}+08$ & 0.63 \\
\hline Quadri without CSM & 42 & 15255 & $3.49 \mathrm{E}+08$ & & & & \\
\hline
\end{tabular}


The following conclusions can be drawn on the strain energy density based on the process and loading conditions:

\section{Pultrusion:}

Tension:

- As the ultimate strain decreases, strain energy density decreases.

- There is no significant difference in strain energy density for composites with uni- or bi-directional composites.

- The presence of $\pm 45^{\circ}$ fibers reduces strain energy density ( $80 \%$ in quadri's compared to uni-directional composites), because the fibers are pulled under tension during pultrusion process and when they are further stretched in longititudinal direction, the composites fail prematurely thereby decreasing strain energy density.

- The presence of CSM increases the strain energy density values by about $45 \%$, which is attributed to the fact that pultruded composites with CSM can take a maximum load up to 2 times more than the composites without CSM.

\section{Bending:}

- As the ultimate stress decreases, strain energy density decreases.

- There is no significant difference in strain energy density for composite with uni-, bi-, and quadric- directional composites.

- As in tension, the presence of CSM increases the strain energy density by about twice the stress without CSM.

\section{Compression Molding:}

Tension:

- The strain energy density is almost same for bi-directional composites as in pultrusion because both have almost same effective FVF, ultimate stress and strain. 
- The presence of $\pm 45^{\circ}$ fibers in tri-directional or quadri-directional composites does reduce $(\sim 55 \%)$ the strain energy density as in pultrusion but not as much as in pultruded specimens.

- The presence of CSM increases the strain energy density values by about $70 \%$, which is attributed to the fact that compression molded composites with CSM can take maximum load by about twice the composites without CSM.

- Overall strain energy density in compression molded specimens was more than in pultruded specimens.

Bending:

- The presence of CSM increased the strain energy density by about $55 \%$.

- The strain energy density in compression molded specimens is less than pultruded specimens.

It should be noted that from Table 6.5, that strain energy density for compression molded plates are always higher than pultruded plates (ignoring tri-directional plates) while in bending, it is vice versa. In case of tension, the failure modes for both compression molded specimens and pultruded specimens are same. But in bending since the ultimate strain for compression molded specimens is lower than pultruded specimens, the strain energy density is low. This is attributed to failure modes in compression molded specimens. The failure mostly initiates on compression side (Vadlamani, 2007) leading to tension failure. In a study conducted on compressive behavior of compression molded glass-epoxy composites, Kishore et.al, 2001, observed that during failure fibers, were not clean and bear, and resin smearing was seen.

Strain Energy Density Based on Normalization of Stresses:

Table 6.6 gives a brief comparison of normalized strain energy density for compression molding and pultrusion, under tension and bending loads. 
Table 6.6 Normalized Strain Energy Density

\begin{tabular}{|c|c|c|c|c|c|c|}
\hline \multirow[t]{3}{*}{ Fiber Architecture } & \multicolumn{3}{|c|}{ Compression Molding } & \multicolumn{3}{|c|}{ Pultrusion } \\
\hline & \multicolumn{3}{|c|}{ Tension } & \multicolumn{3}{|c|}{ Tension } \\
\hline & \begin{tabular}{|c|}
$\begin{array}{c}\text { Overall } \\
\text { FVF }\end{array}$ \\
\end{tabular} & FVF-X & $\mathrm{U}_{\mathrm{NC}}(\mathrm{psi})$ & Overall FVF & FVF-X & $\mathrm{U}_{\mathrm{NP}}(\mathrm{psi})$ \\
\hline Unidirectional & 58 & 58 & $1.50 \mathrm{E}+09$ & 45 & 35 & $5.78 \mathrm{E}+09$ \\
\hline Bi-directional & 45 & 22 & $3.15 \mathrm{E}+09$ & 52 & 26 & $9.29 \mathrm{E}+09$ \\
\hline Quadri-directional with CSM & 54 & 28 & $4.96 \mathrm{E}+09$ & 55 & 25 & $2.26 \mathrm{E}+09$ \\
\hline Quadri-directional without CSM & 44 & 22 & 4.69E+09 & & & \\
\hline \multirow[t]{3}{*}{ Fiber Architecture } & \multicolumn{3}{|c|}{ Compression Molding } & \multicolumn{3}{|c|}{ Pultrusion } \\
\hline & \multicolumn{3}{|c|}{ Bending } & \multicolumn{3}{|c|}{ Bending } \\
\hline & Overall FVF & FVF-X & $\mathrm{U}_{\mathrm{NC}}(p s i)$ & Overall FVF & FVF-X & $\mathrm{U}_{\mathrm{NP}}(\mathrm{psi})$ \\
\hline Unidirectional & 65 & 65 & 2.47E+08* & 45 & 35 & $2.85 \mathrm{E}+09$ \\
\hline Bi-directional & 37 & 18 & 2.72E+09 & 52 & 26 & $3.39 E+09$ \\
\hline Quadri-directional with CSM & 56 & 29 & $1.88 \mathrm{E}+09$ & 55 & 25 & $3.45 E+09$ \\
\hline Quadri-directional without CSM & 44 & 22 & $1.59 E+09$ & & & \\
\hline
\end{tabular}

* Data Error

\section{Tension}

- The normalized strain energy density is least for uni- and high for quadri-directional composites in case of compression molded composites.

- In pultrusion, the quadri-directional composites have least strain energy density because the presence of off-axis plies reduces the capability of straining which in turn reduces the strain energy density.

\section{Bending}

- For compression molded composites, the normalized strain energy density decreases in quadri- compared to bi-directional composites which may be attributed interface bonding failure.

- In pultrusion, the strain energy density is within $20 \%$ difference regardless of fiber/fabric architecture. 


\section{CHAPTER 7}

\section{CONCLUSIONS}

In this study, pultruded Glass Fiber Reinforced Polymers (GFRP) with different types of fiber architecture (uni-, bi-, tri with and without CSM- and quadridirectional fabrics) and different resin system (polyurethane and vinyl ester) were tested under tension and bending to evaluate the stress, strain, stiffness and strain energy density. The properties of pultruded composites were then compared with compression molded composites having same fiber architecture. The following conclusions are drawn from the study:

\subsection{Conclusions}

\section{Stress-Strain Behavior}

- Under tension, bi-linear stress-strain response (up to maximum stress) was observed for GFRP composites with uni-, bi- and quadri- directional fabrics and a tri-linear response was observed for composites with tri-directional fabrics.

- In case of bending, tri-linear stress-strain response (up to maximum stress) was observed in uni- and quadric- directional composites, while bi- and tridirectional fabric, had four linear slopes up to maximum stress. The fourth linear slope was at $90 \%$ of maximum stress which can be neglected.

- For all composite materials with different fiber architectures the first change of slope is between $29 \%-40 \%$ of maximum stress and second change of slope in tri- is between $69 \%-74 \%$ of maximum stress under tension.

- In case of bending, the first change of slope for uni- is $50 \%$, bi- $22 \%$ and triand quadri- are in the range of $31-34 \%$ of maximum stress. The second change of slope for all (uni-, bi-, tri- and quadric-) fiber architecture is between $65 \%-80 \%$ of maximum stress. The third change of slope for bi- and tri- is about $90 \%$ of maximum stress that can be neglected. 
- For composite with uni-, bi-, and quadri, the ratio of change of first and second slope is between $1.2-1.3$ for both tension and bending.

- In case of tri- the ratio of change of first and second slope is between 1.7 2.0 for both, tension and bending.

- The ratio of change of second and third slope for all composites is about 1.4.

\section{Properties:}

- The maximum tensile strain is about 20000 microstrain for uni- and bi- and 10,000 microstrain for tri and quadri's. The maximum bending strain ranges from 20,000 to 26,000 microstrain for uni-, bi-, and quadri's and 15000 microstrain for tri-directional composites.

- In comparison with uni-, under tensile loading, there is about $10 \%$ decrease in maximum strength in bi-, $60 \%$ decrease in quadri- and about $80 \%$ decrease in tri-directional composites.

- The maximum bending strength for bi and quadri with $25 \%$ effective FVF is constant.

- Normalized tensile strength for bi- is higher compared to unidirectional composites because $90^{\circ}$ fibers support $0^{\circ}$ fibers in taking more loads.

- Normalized bending strength for bi- and quadri- are same for effective FVF of $25 \%$.

- Tension and bending stiffness did not match EROM which is attributed to effect of pre-existing manufacturing defects.

- For all composites with different fiber architecture, the normalized tensile modulus ranges between $10 \mathrm{msi}$ to $14 \mathrm{msi}$ and bending modulus ranges from 9 to $16 \mathrm{msi}$.

\section{Effect of Resin Type:}

- The stress-strain response of composite with polyurethane is linear up to maximum stress which indicates that there is no micro crack, while for that for vinyl ester the stress-strain response is bilinear. 
- The maximum tensile strain of polyurethane composite is $26 \%$ lesser than vinyl ester resin while that of bending strain is $38 \%$ less which is attributed to binding capability of fiber and resin.

- The tensile and bending stiffness of composites with polyurethane resin is about $12 \%$ and $30 \%$ respectively more than the vinyl ester composites.

- The normalized maximum stress for (both tension and bending) vinyl ester is about $25 \%$ more than polyurethane for both tension and bending.

- The normalized tensile stiffness for both resin is about $10 \mathrm{msi}$ and bending stiffness is about 7-9 msi.

- The vinyl ester resin has more ductility and toughness compared to polyurethane resin system.

\section{Effect of Loading Conditions:}

- The ratio of bending strength to tensile strength for uni- to quadri- varies from 1.09 to 2.62 .

\section{Effect of Process Conditions:}

\section{Unidirectional:}

- The average tensile stress for compression molded plates having unidirectional fibers is about $57 \%$ more than pultruded plates because the FVF in loading direction of compression molded plates is about $62 \%$ more than pultruded plates.

- The average tensile strain in compression molded plate is about $21 \%$ lesser than that of pultruded plates.

- The tensile and bending stiffness in compression-molded plates is about 2 times more than pultruded plates due to high FVF.

\section{Bi-directional:}

- The tensile stresses are almost same for both compression molded and pultrusion plates. In case of bending the stresses in compression molded plates are around $55 \mathrm{ksi}$ for effective fiber volume fraction of $18 \%$ while the pultruded plates have about $68 \mathrm{ksi}$ with effective fiber volume fraction of $26 \%$. 
Such major stress difference is attributed to good bonding within laminae in compression molded plates.

- The maximum tensile strain for compression (22663 $\mu$ ) and pultruded (20392 $\mu \varepsilon)$ plates are within $10 \%$ difference. The average bending strain is about 5900 microstrain less than pultruded plates which may be due to premature matrix failure in the compression face of the specimen.

- The difference in stiffness (for both tension and bending) is within $10 \%$ between two processes.

Tri-directional:

- Though the effective FVF for both plates is about $15-20 \%$, the average tensile ultimate stress in compression molded plates is $59 \%$ more than pultruded plates. There is no difference in bending stress between compression molded and pultruded plates.

- The ultimate tensile strain of compression molded plates is about $68 \%$ more than the pultruded plates because the presence of $\pm 45^{\circ}$ fibers was not affecting much in pultruded plates. The average bending ultimate strain in compression molded plates is about $40 \%$ more than the pultruded plates. This is attributed due to presence of voids in pultruded plates where failure would have initiated, because the voids were visually seen.

Quadri-directional:

- The average tensile stress in quadri-directional plates for compression molded plates is about $65 \%$ more than the pultruded plates. In case of bending, the average stress in a pultruded plate is about $20 \%$ more than the compression molded plates.

- The average tensile strain in compression molded plates is about $67 \%$ more than the pultruded plates because of the presence of $\pm 45^{\circ}$ fibers which were not affecting much in pultruded plates. The bending strain in compression molded plate is about 18000 microstrain while that in a pultruded plate is about 21000 microstrain.

- There is no significant difference in stiffness (for both tension and bending) between the two processes. 
Strain Energy Density:

- In case of pultrusion, there is no significant difference in strain energy density for composites with uni or bi-directional composites under tensile loading. There is about $80 \%$ decrease in strain energy density in quadri- directional composite, when compared to uni- because when off-axis plies in quadri are pulled in tension, the composites fail prematurely thereby decreasing strain energy density. In case of bending, there is no significant difference in strain energy density for composite with uni, bi, and quadri directional composites.

- In case of compression molding, the strain energy density under tensile loading is almost same for bi-directional composites as in pultrusion because both have almost same effective FVF, ultimate stress and strain. In case of quadri-directional composites, the presence of $\pm 45^{\circ}$ fibers does reduce $(\sim 55 \%)$ the strain energy density as in pultrusion but not as much as in pultruded specimens. Overall the strain energy density in compression molded specimens is more than pultruded specimens under tensile loading, and less under bending loads.

- Under tensile loading, the normalized strain energy density is the smallest value for uni- and high for quadri-directional composites in case of compression molded composites while in

pultrusion, the quadri-directional composites have least strain energy density because the presence of off-axis plies reduces the capability of straining which in turn reduces the strain energy density.

- Under bending loads, for compression molded composites, the normalized strain energy density decreases in quadri- compared to bi-directional composites which may be attributed interface bonding failure. In pultrusion, the strain energy density is within $20 \%$ difference regardless of fiber/fabric architecture. 


\subsection{Recommendations}

- Structural behavior of polyurethane and vinyl ester resin system need to be further investigated.

- Strain energy density for pultruded composites under tension, especially with off-axis plies need to be further evaluated.

- Since the strain energy density is found to be nearly constant for pultruded composites with uni-, bi, and quadri-directional composites, under bending, specimens with different effective FVF can be performed to check the validity of constant.

- Strain energy density for resin system other than vinyl ester system has to be evaluated. 


\section{REFERENCES}

1. Kaddour A.S., Hinton M.J., Soden P.D., Failure Criteria in FRP composites: The World Wide Failure Exercise, ELSEVIER, 2004.

2. Huang H., Springer G.S., and Christensen R.M., "Predicting Failure in Composite Laminates Using Dissipated Energy", Journal of Composite Materials, Vol. 37, No. 23/2003.

3. M. Daniel and O. Ishai, Engineering Mechanics of Composite Materials, Second Edition, Oxford University Press, 2005.

4. Vadlamani D., "Strain Energy Density based Failure Criterion for GFRP Coupons under Tension and Bending, Master's Thesis, West Virginia University, Morgantown, WV, 2007.

5. www.netcomposites.com

6. Barbero E.J., "Introduction to Composite Material Design, Taylor \& Francis, Philadelphia, 1998.

7. Ishai O., Lavengood R.E., "The Mechanical Performance of Bidirectional Fiber-Glass Polymeric Composites", Israel Journal of Technology, Vol. 8, No. 1-2., pp. 101-109, 1970.

8. Kardos J.L., "Critical issues in achieving desirable mechanical properties for short fiber composites, Pure \& Appl, Chem, Vol.57, No.11, pp 16511657, 1985.

9. Haj-Ali R., Kilic H., "Nonlinear Behavior of Pultruded FRP Composites," Composites: Part B 33, 2002.

10. Azzi, V.D. and Tsai S.W., "Anisotropic Strength of Composites", Experimental Mechanics, 5, 283-288, 1965.

11. Ishai, O., R.M. Anderson and R.E. Lavengood, "Failure Time Characteristics of Continuous Unidirectional Galss-Epoxy Composite in Flexure, Interim Report of Monsanto/Washington University Association, AD 827-065, 1968. 
12. Leong K.H., Herszberg M.N., "The Effects of Deforming Knitted Glass Fabrics on the basic Composites Mechanical Properties", Journal of Materials Science 34, 1999.

13. Neumeister J, Jansson S., and Leckie F., "The Effect of Fiber Architecture on The Mechanical Properties of Carbon/Carbon Fiber Composites", Mechanical Properties of Composites, Acta Mater. Vol 44, No. 2. pp. 573585. 1996.

14. Hayat, M.A. and Suliman, M.A., "Mechanical Structural Properties of Glass Reinforced Phenolic Laminates, Polymer Testing, 17: 79-97, 1998.

15. Kishore., Maiti A., "Compressive Behavior and Fracture Features of Rubber Bearing Glass-Epoxy Composites Exposed to Aqueous Media, "Journal of Reinforced Plastics and Composites, Vol. 20.No. 17/2001. 